\title{
Activació d'hidrocarburs i òxids de carboni mitjançant fotocatàlisi
}

\author{
Francesc Sastre i Calabuig
}

Director:

Hermenegildo García Gómez
Tesi Doctoral

2013 



\section{UNIVERSITAT POLITÈCNICA DE VALÈNCIA}

INSTITUT UNIVERSITARI MIXT DE TECNOLOGIA QUÍMICA (UPV-CSIC)

\section{Activació d'hidrocarburs i òxids de carboni mitjançant fotocatàlisi}

Tesi Doctoral

Presentada per:

Francesc Sastre i Calabuig

Dirigida per:

Hermenegildo García Gómez

València, 2013 

A Borja Pardo, sempre estaràs amb nosaltres. 


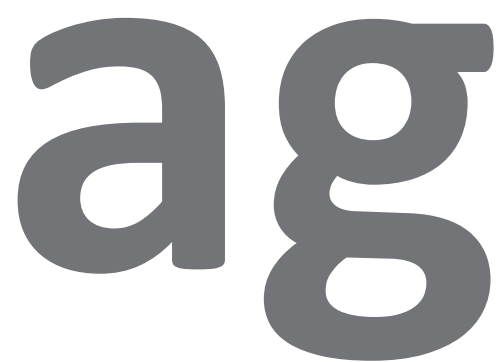

agraïments

En primer lloc vull agrair al meu director de Tesi, Hermenegildo García, per donar-me l'oportunitat de fer-la amb ell, escoltar-me cada dia i per la seua comprensió i suport al Ilarg d'aquests anys. Al professor Avelino Corma i a tota la gent d'administració de l'ITQ.

Vull agrair a tota la gent de I'ITQ que ha fet possible que dia a dia poguera solucionar els problemes que anaven sorgint. A Ximo, per ajudar-me en l'anàlisi dels gassos i en tot allò que li he demanat, al professor Vicente Fornés, Jesús, Alejandro, José Gaona, Nacho, Paquito, Javier Zamarripa i a Javier Pérez. A Vicent, pels moments de xerradeta en la porteria i informarme de tot el que passava al món. 
Gràcies, també, a tots els meus companys de l'ITQ i del grup d'Herme, amb què hem estat compartint tot aquest temps: Pedro Atienzar, Marcos, Marco, Amparo Forneli, Esther, Mikel, Mireia, Belén, Stefan, Herme junior, Pablo Ramos, Xisco, Carmen Clemente, Victoria, Yanick, Cristina, Cristina "murciana", Elena i Juan. A Marica.

Com no, al grup d'esmorzar per compartir tants moments: Abdessamad el moret, Ana Primo, Maria i Pepo. Al grup dels dinars, que ja s'ha convertit en una molt bona costum, Guillermo, Paula, Judit, Nacho, Faber, Edurne, Alberto, Maike.

Als meus companys de màster, Olalla, Nacho, Andrés, Teresa i Diego, pels treballs fets, les hores de classe i les vesprades de tapes.

A La Rotovense Musical o, més ben dit, a la gent que la forma, per passar tantes nits d'assaigs, eixides a tocar, fer fotocòpies i tantes altres tasques; a pesar de que reneguem, ens ho passem d’allò més bé, especialment a a Arnau, Javi Bataller, Salva, Ramonet, Josep, Anna percu i Jose. A Carlos i Mari, per la seua amistat i el seu suport en tot moment. Ànims que prompte tindrem un local. Als amics de l'Olleria, especialment a Fèlix i Fani, Alicia i Patricia.

A Àngeles i a Paco, perquè ja em sent com un fill més d'ells.

Als companys de carrera; després d'una etapa que varem viure junts, continuem en contacte. Ells són: Aurora, Ferran, Claudia, M. José, Esther, Isabel, Saül, Julian i Raquel.

A Jordi Puig, per ensenyar-me tantes coses i ajudar-me sempre; continua així i no canvies mai, qued’ací no res ja ets alcalde.

Als meus amics de sempre per créixer junts i anar fent-nos persona a poc a poc: Jordi, Marilau, Amanda, Estefania, Marifermi, Marc, Rafa i Anna, Joan, Edu, Fortaña, Carla, Lluis Canet, Joana, Paco Xicotet, Rafa, Javieret, 
Anna Igualde i Joan; a Estrella de Terol, i a Borja que sempre estarà al nostre cor. Com no, menció especial per a Jaume, perquè no mereix menys amb tot el que hem viscut.

Als amics que dia rere dia vaig incorporant a la meua vida, Cristian Jorques i Alex Sa Nostra.

A la meua família per donar-me el seu suport dia rere dia, i a tota la "retaila" de cosins i oncles Calabuig's, als cosins de Bilbao. Especialment, als meus pares Paco i Marieli, per comprendre'm, recolzar-me i ser tan "renegons". A la meua germana Elisa, com a bons germans ens barallem dia rere dia, i des de que se n'anà a l'illa la trobe molt a faltar.

A les meues àvies Elisa i Amparo, ja que sense elles no hagués menjat ni la meitat de bé a València, i als meus avis que a pesar que ja no són ací, em van ensenyar moltes coses. 



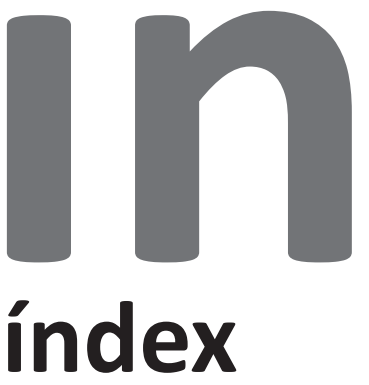

C1. Introducció

17

1.1. Reaccions fotoquímiques

19

1.2. Regim UV Ilunyà

21

1.3. Activació del metà

29

1.4. Combustibles solars a partir del $\mathrm{CO}_{2}$

37

1.5. Referències

43 


\section{C3. Transformació selectiva de metà a compostos oxigenats d'un carboni}

3.2. Resultats i discussió

3.2.1. Reaccions fotoquímiques implicades

3.2.2. Influència de la presència d'oxigen

3.2.3. Consum d'energia en la conversió de $\mathrm{CH}_{4}$ per fotòlisi amb llum UV Ilunyana

3.2.4. Naturalesa del sòlid inorgànic

3.2.5. Cicle en dues etapes

3.2.6. Mecanisme de reacció

3.2.7. Consum d'energia

3.3. Conclusions

3.4. Referències 
C4 Activació fotocatalítica de l'età sobre superfícies de sílice 99 mitjançant llum ultraviolada en la zona profunda

$\begin{array}{ll}\text { 4.1. Introducció } & 101\end{array}$

4.2. Resultats i discussió 105

$\begin{array}{ll}\text { 4.3. Conclusions } & 119\end{array}$

$\begin{array}{ll}\text { 4.4. Referències } & 121\end{array}$

C5. Activació del benzè per irradiació amb llum UV Ilunyana en superfícies de zeolites ZSM-5. 


\section{C6. Reducció fotocatalítica del $\mathrm{CO}_{2}$ a metà per irradiació amb llum UV 141 llunyana}

6.1. Introducció

6.2. Resultats i discussió

6.2.1 Reducció del $\mathrm{CO}_{2}$ amb $\mathrm{H}_{2}$ promoguda per fotòlisi a $185 \mathrm{~nm}$

6.2.2 Reducció fotoquímica del $\mathrm{CO}_{2}$ amb $\mathrm{H}_{2} \mathrm{O}$ promoguda per llum de $185 \mathrm{~nm}$

6.2.3 Influència en la presència d'un sòlid bàsic.

5.3. Conclusions

159

5.4. Referències 


\section{C7. Generació d' $\mathrm{H}_{2} \circ \mathrm{CH}_{4}$ a partir de $\mathrm{CO}_{2}$ per reducció en dues etapes 165}

7.2.1 Irradiació directa en fase gas amb llum de longitud d'ona de $185 \mathrm{~nm}$ del $\mathrm{CO}_{2}$ en absència de sòlids.

7.2.2 Reacció fotocatalítica del CO amb compostos contenint $\mathrm{H}_{2}$

7.3. Conclusions

7.4. Referències 
8.1. Reactius utilitzats i síntesi de 201 materials

\author{
8.1.1. Gasos \\ 8.1.2. Materials
}

8.2. Tècniques experimentals de caracterització físico-química 207

8.3. Assaigs fotocatalítics 211

8.3.1. Sistema de reacció

8.3.2. Assaig fotocatalític

8.3.3. Càlculs i paràmetres desriptors de les

reaccions

8.4. Referències

225

C9. Conclusions

227

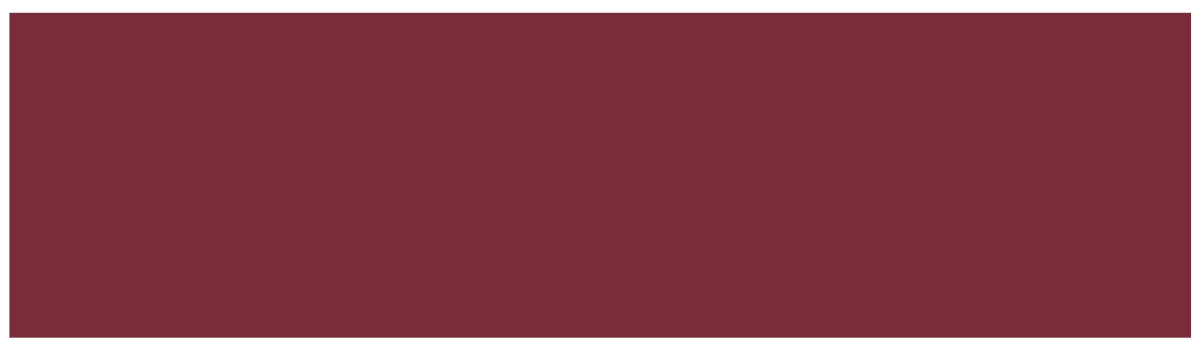




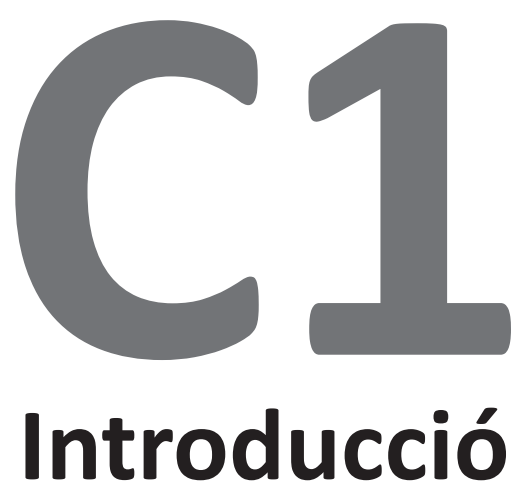





\section{Reaccions}

La radiació electromagnètica pot interaccionar amb la matèria de diverses maneres depenent-ne de la longitud d'ona. En particular, la radiació UV-visible, considerada com aquelles irradiacions on la longitud d'ona està compresa entre 200 i 800 nm, en ser absorbida, dóna lloc a transicions dels electrons de la capa de valència entre els orbitals frontera HOMO-LUMO. Aquestes transicions electròniques són les responsables del fenomen de color, així com de les bandes d'absorció de l'espectroscòpia òptica.

Després de l'absorció del quàntum de llum de la zona UV visible, els electrons de l'orbital ocupat de major energia (HOMO) pateixen una excitació a nivells electrònics desocupats. Aquests estats electrònics excitats tenen un temps de vida molt curt i poden patir desexcitació a l'estat electrònic excitat de menor energia fonamental, bé mitjançant una conversió interna no radioactiva consistent en vibracions d'enllaç i canvis conformacionals o bé mitjançant una desactivació radioactiva, fenomen que es coneix com fluorescència. Generalment la conversió interna no radioactiva predomina en totes les transicions electròniques des dels estats excitats superiors cap al LUMO, però el decaïment del LUMO al HOMO pot tenir lloc per a determinades molècules, gairebé exclusivament mitjançant un mecanisme de desactivació per fluorescència principalment per a aquelles que són rígides. 
Alternativament, l'estat excitat singlet corresponent a un electró desaparellat en el LUMO pot patir un fenomen conegut com encreuament intersistema donant Iloc a l'estat corresponent triplet, on els espins dels electrons desaparellats són paral·lels i que és generalment de menor energia que el singlet. Aquest primer estat excitat triplet posseeix un temps de vida significativament més llarg que el singlet, ja que la desactivació del triplet requereix d'un altre encreuament intersistema cap a l'estat fonamental que està prohibit pel principi de conservació de l'espín. ${ }^{[1]}$ Així mentre típicament el primer estat excitat singlet té un temps de vida de l'ordre de nanosegons, els primers estats excitats triplet posseeixen temps de vida en el rang de microsegons. L'Esquema 1.1, conegut com diagrama de Jablonski, representa algun dels possibles passos elementals que poden tenir lloc després de l'absorció d'un fotó de la zona UV visible.

ESTATS

SINGLET

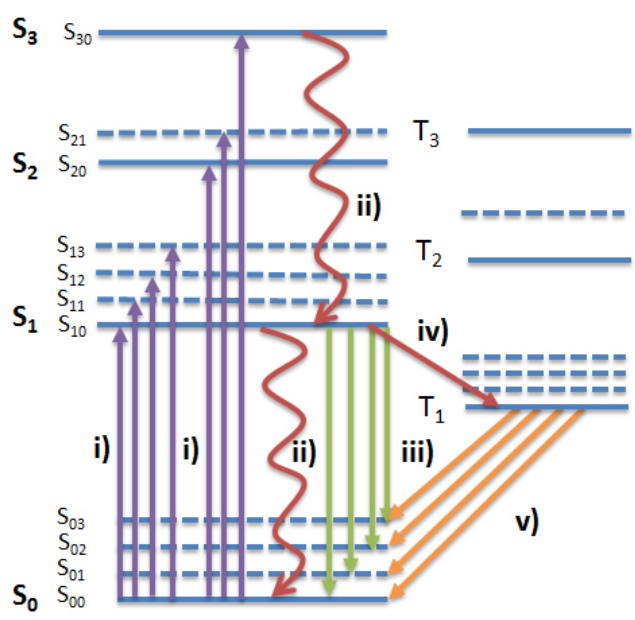

Esquema 1.1. Diagrama Jablonski, on es resumeixen els fenòmens que poden tenir lloc després de l'absorció d'un fotó a la zona UV-visible (i) tals com conversió interna (ii), fluorescència (iii), encreuament inter sistemes (iv) i fosforescència (v).

Tant a partir del primer estat electrònic excitat singlet com del triplet solen tenir lloc ruptures d'enllaç, transposicions o reacció amb altres molècules. Aquests processos constitueixen l'objecte d'estudi de la fotoquímica. 
Generalment la zona de I'UV es considera que correspon a les radiacions entre longituds d'ona de 200 a $400 \mathrm{~nm}$. El motiu pel qual no es consideren longituds d'ona per sota de $200 \mathrm{~nm}$ és que aquestes radiacions són absorbides per materials que són transparents a la radiació visible $i$ que són habitualment emprats en mesures òptiques com són silicats vitris i quars. No obstant això, en els anys 60 , va haver un interés per estudiar els processos promoguts per irradiació amb longituds d'ona menor que 200 $\mathrm{nm}$. Per a l'estudi d'aquest tipus de fotoreaccions cal emprar finestres amb materials transparents diferents a les habituals per processos convencionals a la zona de I'UV-visible. En particular, són comunes les cel-les d'halurs de metalls alcalins i alcalinoterris, on el $\mathrm{CaF}_{2}$ és un material comú, també per a determinat rangs de longituds d'ones propers als 200 nm (160-200 nm) es pot emprar quars sintètic d'alta puresa (suprasil ${ }^{\circledR}$ ) que presenta un elevat grau de transmissió fins als $160 \mathrm{~nm}$.

Ja que l'energia dels fotons resulta ser inversament proporcional a la longitud d'ona d'acord amb l'equació fonamental 1.1, resulta que els fotons amb longitud d'ona inferior a $200 \mathrm{~nm}$ són els que tenen més energia. Així, una mol de fotons de 185 o $165 \mathrm{~nm}$ posseeix una energia de $140.7 \mathrm{i}$ $157.8 \mathrm{kcal} / \mathrm{mol}$ respectivament. Aquests valors d'energia són comparables o superiors als que es requereixen per a la ruptura dels enllaços químics. 
L'energia de l'enllaç $\mathrm{OH}$ a l'aigua és de $110 \mathrm{kcal} / \mathrm{mol}$ i l'energia de l'enllaç $\mathrm{CO}$ en el $\mathrm{CO}_{2}$ és de $129 \mathrm{kcal} / \mathrm{mol}$. Per tant, l'absorció d'un fotó d'aquestes longituds d'ona podria provocar la ruptura d'aquests enllaços tal com ha estat descrit en determinats casos. ${ }^{[2-4]}$

\section{$E=h \cdot v=h \cdot c / \lambda \quad E q 1.1$}

Per tal de diferenciar les radiacions UV que són transmeses per materials convencionals (superiors a $200 \mathrm{~nm}$ ) d'aquelles altres longituds d'ona que requereixen materials òptics no habituals (longituds d'ona inferiors a $200 \mathrm{~nm}$ ), és habitual emprar els termes de regió UV propera i regió UV llunyana depenent de si la longitud d'ona és superior o inferior a $200 \mathrm{~nm}$, respectivament.

Entre les reaccions que han estat estudiades emprant fotons de la zona de I'UV Ilunyana, convé esmentar per la rellevància que du aparellada en aquesta tesi doctoral el trencament directe de $\mathrm{I}^{\prime} \mathrm{H}_{2} \mathrm{O},^{[5-8]}$ procés que s'inicia en trencar homolíticament l'enllaç $\mathrm{OH}$ de l'aigua generant un àtom d'hidrogen $\mathrm{i}$ un radical hidroxil (equació 1.2). Subseqüentement, l'àtom d'hidrogen podria donar lloc a la formació d' $\mathrm{H}_{2}$ molecular per acoblament de dos d'aquests àtoms (equació 1.3), mentre que els radicals hidroxil podrien formar en primer lloc peròxid d'hidrogen en fase gas amb la formació del primer enllaç O-O (equació 1.4), i posteriorment la descomposició del $\mathrm{H}_{2} \mathrm{O}_{2}$ amb la formació d’O $\mathrm{O}_{2}$ molecular (equació 1.5).

$$
\begin{array}{lll}
\mathrm{H}^{+}+\mathrm{H}^{\cdot} \longrightarrow & \mathrm{H}^{\cdot}+\mathrm{OH}^{\cdot} & \mathrm{Eq} 1.2 \\
\mathrm{OH}^{*}+\mathrm{OH}^{\cdot} \longrightarrow & \mathrm{H}_{2} & \mathrm{Eq} 1.3 \\
\longrightarrow & \mathrm{H}_{2} \mathrm{O}_{2} & \mathrm{Eq} 1.4
\end{array}
$$

$$
\mathrm{H}_{2} \mathrm{O}_{2} \longrightarrow \mathrm{O}_{2}+\mathrm{H}_{2} \quad \text { Eq } 1.5
$$


Els estudis pioners en aquest camp han determinat que el rendiment quàntic per a la primera etapa de la fotòlisi de l' $\mathrm{H}_{2} \mathrm{O}$ amb llum UV Ilunyana (equació 1.2) transcorre amb rendiments quàntics propers a la unitat. ${ }^{[5]}$ Aquest fet, juntament amb l'elevada absortivitat molar de l'aigua a longituds d'ona inferiors als $200 \mathrm{~nm}$, determina que, mentre l'aigua és fotoquímicament estable en ser irradiada amb radiació de longituds d'ona a la regió UV propera a la visible, aquesta pateix una transformació amb una eficiència alta quan s'irradia amb longitud d'ona a la zona d'UV Ilunyana.

Convé indicar que la majoria d'estudis que descriuen processos fotoquímics emprant radiacions de la zona UV llunyana es refereixen a reaccions que tenen lloc en fase gas, ${ }^{\left[{ }^{[9]}\right.}$ i en molts casos aquests processos $\mathrm{s}$ 'han relacionat amb reaccions fotoquímiques que tenen lloc a l'estratosfera terrestre o que puguen estar implicats en l'origen de la formació de les primeres molècules orgàniques en etapes primigènies de la cosmogènesi terrestre. ${ }^{[3]}$

Son d'especial interès els estudis que han demostrat que la fotòlisi del $\mathrm{CO}_{2}$ amb llum UV Ilunyana a 123.6 i 160 nm dóna lloc a la formació de $\mathrm{CO}, \mathrm{O}_{2} \mathrm{i}$ $\mathrm{O}_{3}$ (Equacions 1.6-1.8). La formació d'aquests productes sembla estar d'acord amb l'existència d'un mecanisme de fotodissociació amb un rendiment quàntic que arriba al seu màxim a $147 \mathrm{~nm}$ i que, per això, ha estat atribuït a molècules de $\mathrm{CO}_{2}$ en estat excitat.

Aquests estudis han determinat que les proporcións entre $\mathrm{O}_{3} \mathrm{i}_{2}$ molecular que es pot aconseguir irradiant $\mathrm{CO}_{2}$ per produir-ne la fotodissociació són comparables a les que s'obtenen quan s'irradia $\mathrm{O}_{2}$ pur, un fet que s'ha interpretat com a indicatiu de l'assoliment d'equilibris entre la formació d'O $\mathrm{O}_{3}$ i la seua fotòlisi.

L'addició de vapor d' $\mathrm{H}_{2} \mathrm{O}$, fins i tot en quantitats de traces, origina la formació de $\mathrm{CO}_{2}$. Determinant que a pressions baixes la presència d'humitat origina la formació de $\mathrm{CO}_{2}$ fins i tot quan es troba $\mathrm{CO}$ present en el medi. 
D'altra banda, relacionat amb l'origen de la formació de biomolècules senzilles, s'ha descrit que la fotòlisi d'una barreja de $\mathrm{CO}$ i $\mathrm{H}_{2} \mathrm{O}$ en fase gas a $185 \mathrm{~nm}$ dóna lloc a la formació d'alcohols, aldehids i àcids orgànics amb un rendiment global per a tots els productes que ha estat estimat en $3.3 \%$. S'ha calculat que aquest elevat rendiment quàntic podria haver contribuït a la formació de $10^{11}$ molècules orgàniques per $\mathrm{cm}^{2}$ i per segon en l'atmosfera de la terra primitiva. ${ }^{[3]}$ Aquests estudis proporcionen l'evidència que indiquen que les molècules $\mathrm{d}^{\prime} \mathrm{H}_{2} \mathrm{O}$ pateixen una fotòlisi preferent en aquestes condicions $\mathrm{i}$ que resulta en la formació d'àtoms d'hidrogen que són capaços de reduir el CO a una varietat de compostos d'un i dos àtoms de C. ${ }^{[10]}$ Alhora el mateix estudi ha demostrat que aquestes molècules orgàniques en fase vapor pateixen descomposició per la mateixa longitud d'ona, llevat que hi haja una elevada concentració de vapor d' $\mathrm{H}_{2} \mathrm{O}$ i que aquests compostos oxigenats h'estiguen protegits davant la descomposició per una concentració elevada d'aquest vapor $\mathrm{d}^{\prime} \mathrm{H}_{2} \mathrm{O}$. Les equacions 1.9 i 1.10 resumeixen les reaccions descrites per a la formació de compostos oxigenats a partir de la fotòlisi de vapor d' $\mathrm{H}_{2} \mathrm{O}$ i CO així com les reaccions secundàries que poden tenir lloc.
$\mathrm{CO}_{2}$

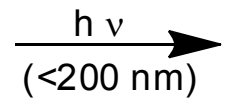
$\mathrm{CO}+\mathrm{O}$
Eq 1.6
$\mathrm{O}+\mathrm{O}_{2}$

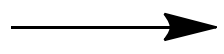
$\mathrm{O}_{3}$
Eq 1.7
$\mathrm{O}+\mathrm{O}_{3}$
$2 \mathrm{O}_{2}$
Eq 1.8

Aquest efecte de filtre de radiacions UV de la zona llunyana té també lloc d'una forma natural per l'atmosfera terrestre. Així, mentre que les radiacions solars contenen longituds d'ona en un ampli rang de l'espectre electromagnètic, incloent longituds d'ona de la zona UV Ilunyà, quan aquestes radiacions tan energètiques travessen l'atmosfera terrestre, pateixen un procés d'absorció selectiva i són filtrades de manera que a la superfície terrestre només arriben fotons de la zona UV propera pròximes a longituds d'ona visibles. D'aquestes radiacions UV properes, les quals constitueixen al 
voltant d'un $4 \%$ de l'energia solar total que arriba a la superfície terrestre, les més importants són els raigs UVA, que van des de 360-380 nm i que són responsables de processos de pigmentació de la pell. ${ }^{[1-13]}$ Específicament la radiació UV Ilunyana s'elimina completament i en aquest fenomen de filtració de radiacions juga un paper especial la capa d'ozó, que garanteix que les radiacions a nivell de superfície terrestre no produeixen danys al DNA ni en altres biomolècules responsables de la vida.

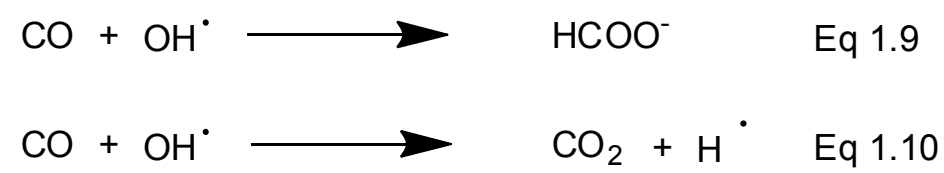

A més de reaccions en fase gas, i més directament relacionats amb la present tesi doctoral, s'han descrit en la literatura estudis sobre processos que ocorren en les superfícies de materials orgànics $i$ inorgàniques quan són sotmesos a radiació amb llum UV a la zona llunyana. Així, irradiacions en un llit fluïditzat de partícules de poliestiré origina que la superfície d'aquest polímer pateix un procés de degradació en absència d'oxigen, i de degradació i oxidació si aquest gas es troba present en el medi. El fet que la radiació UV Ilunyana posseeix tanta energia i siga absorbida fins i tot per materials transparents en altres zones espectrals determina que la penetració en un medi líquid o sòlid d'aquest tipus de radiacions siga molt baixa. Així, per exemple, s'ha determinat que radiació de $185 \mathrm{~nm}$ emesa per un llum de $\mathrm{Hg}$ de baixa pressió de $8 \mathrm{~W}$ de potència és capaç de penetrar i difondre en $\mathrm{H}_{2} \mathrm{O}$ pura tan sols uns mil-límetres ja que tots els fotons provinents del tub fluorescent són absorbits més enllà d'aquesta zona. Aquesta baixa penetració de la radiació UV Ilunyana i el fet que sigua tan fàcilment absorbida és especialment rellevant, quan els mitjans que volen irradiar no són fases gasoses sinó que es tracta de fases condensades, líquides o sòlides. En particular, la irradiació de fases sòlides només pot tenir lloc en una part molt superficial del material ja que s'estima que la penetració d'aquestes longituds d'ona tan energètiques no pot tenir lloc més enllà d'unes poques micres. Per aquest motiu, la irradiació 
amb UV Ilunyà de materials sòlids ha atret escàs interès tot i que, per altra banda, podria tenir aplicació en la modificació de superfícies de polímers i d'altres materials orgànics o inorgànics. ${ }^{[14-16]}$ Així, seria possible considerar que la irradiació de materials hidrofòbics amb llum UV llunyana en presència d'O $\mathrm{O}_{2}$ i humitat podria donar lloc a la transformació d'aquests materials de hidrofòbics en hidrofílics, si s'aconsegueix implantar a la superfície suficients grups hidroxil mitjançant funcionalització promoguda per fotodissociació d'enllaços covalents i acoblament de radicals amb grups hidroxil.

En aquest context cal destacar que no s'ha descrit fins a la present tesi, la irradiació de materials aluminosilicats amb llum UV de la zona llunyana. Els aluminosilicats en la superfície tenen grups silanols ( $(\equiv \mathrm{Si}-\mathrm{OH})$ que són anàlegs a molècules d' $\mathrm{H}_{2} \mathrm{O}$ i que, per tant, també podrien patir reaccions de fotodissociació i trencaments d'enllaç. De fet, part de la present tesi doctoral es basarà en l'activació d'aquest tipus de superfícies amb llum UV d'acord amb l'equació 1.11 que proposa el trencament homolític de l'enllaç $\mathrm{OH}$ d'un grup silanol superficial amb la formació d'un àtom d'hidrogen i radicals sililoxil. Aquest procés serà d'especial importància per a promoure reaccions radicalàries de metà i altres hidrocarburs (età) alifàtics i aromàtics (benzè) adsorbits en les superfícies externes o confinats a l'interior de microporus (confinament en una cavitat de reacció).

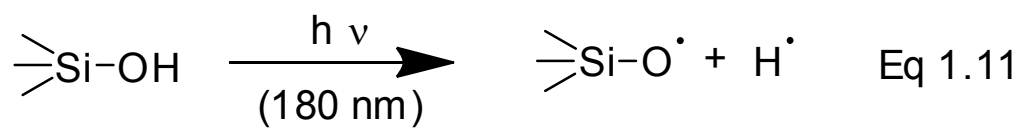

El nostre grup té experiència en la preparació i caracterització de gran nombre de materials silicis on, variant la mida de partícula, podem controlar l'àrea superficial externa, la qual augmenta per partícules de grandària nanomètrica. A més en els silicats és possible crear porus de mides subnanométriques (zeolites) ${ }^{[17-20]}$ o de mides superiors a $1 \mathrm{~nm}$ (sílices mesoporoses nanoestructurades) ${ }^{[21,22]}$ que es caracteritzen per una elevada 26 àrea superficial. Aquests materials micro i mesoporosos tenen una alta 
capacitat d'absorció de gasos, i de fet, la majoria de les aplicacions d'aquests materials està relacionades amb aquesta propietat (procés de separació dels components de l'aire) ${ }^{[23,24]}$ o amb l'aplicació de l'adsorció en processos catalítics. ${ }^{[25-28]}$ D'acord amb la hipòtesi de partida, aquests materials podrien servir per a processos d'activació d'hidrocarburs si són irradiats eficientment amb llum a la zona UV Ilunyana. 



\section{Activació del metà}

En aquest context, el desenvolupament de reaccions selectives d'activació del $\mathrm{CH}_{4}$ constitueix encara avui dia un dels reptes de la química i que, a més de la seua vessant fonamental i de ciència bàsica, té un component aplicat de gran valor econòmic. El metà és el compost orgànic menys reactiu, la qual cosa és la causa de la fortalesa dels enllaços C-H i motiu pel qual la majoria de reaccions que tenen aquest compost com a substrat (excepte la combustió i la cloració) siguen endotèrmiques i requerisquen d'una aportació d'energia adequada per tal de desplaçar l'equilibri de la reacció. Entre els diversos processos que estan sent assajats per a l'activació del $\mathrm{CH}_{4}$ destaquen el seu acoblament oxidatiu per donar lloc a etilé i $\mathrm{H}_{2} \mathrm{O}$ en presència d' $\mathrm{O}_{2^{\prime}}$, l'aromatització per donar lloc a benzè i $\mathrm{H}_{2}$, que ha de ser separat per desplaçar l'equilibri i l'oxidació selectiva a metanol o altres productes oxigenats d'un carboni. Les equacions 1.12 a 1.15 resumeixen aquests processos que estan essent investigats en el context de l'activació del metà. S'han descrit reaccions com les de Periana, en fase homogènia, on el metà reacciona amb àcid sulfúric concentrat en presència d'un complex de Pt per donar lloc a sulfat de metil (Equació 1.15).[29, 30] Tot i que aquesta reacció certament és notable, el fet que requerisca àcid sulfúric pur a més de Pt la fa de difícil implantació industrial. 


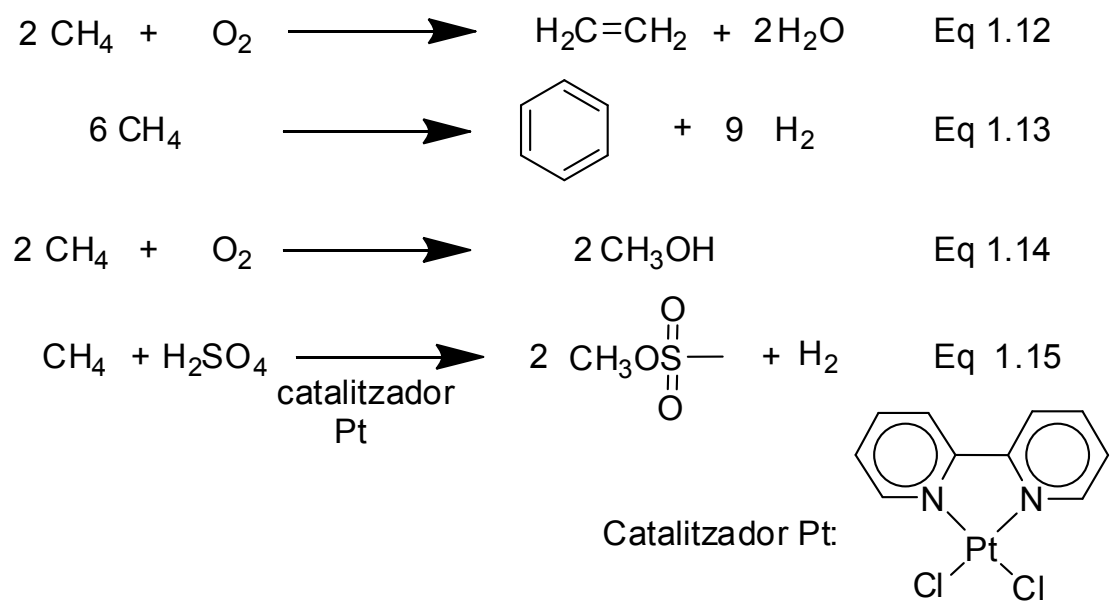

En aquest context, una reacció d'activació del metà que és simple i que és coneguda des de fa molts anys és la reacció del metà amb radical hidroxil per a donar lloc inicialment a un radical metil el qual mitjançant, reaccions d'acoblament, origina metanol i etanol. Les equacions 1.16 a 1.21 resumeixen aquests processos. La generació de radicals hidroxil pot ser duta a terme convenientment en un gran nombre de processos entre els quals destaquem per la seua simplicitat les reaccions de tipus Fenton en què el $\mathrm{H}_{2} \mathrm{O}_{2}$ pateix reacció per un metall reductor generalment $\mathrm{Fe}^{2+}$ a pH àcid, per generar un ió hidròxid i radical hidroxil (Equació 1.22). ${ }^{[31]}$ El problema d'aquestes reaccions radicalàries és la falta de selectivitat, ja que els productes primaris reaccionen molt més ràpidament que el metà i van evolucionant amb el transcurs de la reacció cap a altres productes amb major estat d'oxidació (aldehids, cetones i àcids) o/i amb major nombres de carbonis. Fins al moment, no s'ha aconseguit augmentar la selectivitat d'aquest procés d'oxidació que generalment es porta a terme en fase gas, de manera que l'interés de la reacció és molt limitat. En la present tesi doctoral es pretén controlar la selectivitat de l'oxidació del metà duent a terme aquest procés en un espai confinat que limite la quantitat de $\mathrm{CH}_{4}$ i de radical hidroxil que es troba present en la reacció i que puga presentar l'adsorció selectiva d'uns productes davant d'altres. 
Com hem comentat amb anterioritat, els processos de transformació selectiva del metà tenen una gran transcendència a nivell industrial. ${ }^{[32-37]}$ La importància deriva que el metà és el principal component en els jaciments de gas natural i reserves d'altres combustibles fòssil| ${ }^{[38-40]}$. Existeixen jaciments de gas natural on el $\mathrm{CH}_{4}$ està present en proporcions superiors a $90 \%$. No obstant això, molts d'aquests jaciments de gas natural es troben en àrees geogràfiques remotes allunyades dels llocs de consum d'Amèrica del Nord, Europa o Orient Llunyà, i n'és necessari el transport des dels camps d'extracció de gas natural cap als països industrialitzats. A causa del baix punt d'ebullició del gas natural (-196 ${ }^{\circ} \mathrm{C}$ a pressió atmosfèrica), el transport del $\mathrm{CH}_{4}$ es porta a terme en moltes ocasions en fase gas a temperatures baixes i pressions elevades, en mitjans de transport especials que per una banda encareixen considerablement aquesta matèria primera i, per un altre, origina problemes de seguretat. Seria d'un enorme interés i un alt impacte econòmic desenvolupar processos simples de funcionalització del $\mathrm{CH}_{4}$ que convertiren a aquest compost en un derivat líquid o que pogueren liquar-lo en condicions el més moderades possibles.

$$
\begin{aligned}
& \mathrm{OH}^{\circ}+\mathrm{CH}_{4} \longrightarrow \mathrm{H}_{2} \mathrm{O}+\mathrm{CH}_{3}{ }^{\circ} \text { Eq } 1.16 \\
& \mathrm{CH}_{3}^{\circ}+\mathrm{CH}_{3}^{\cdot} \longrightarrow \mathrm{CH}_{3} \mathrm{CH}_{3} \longrightarrow \mathrm{Eq} 1.17 \\
& \mathrm{OH}^{\circ}+\mathrm{CH}_{3} \mathrm{CH}_{3} \longrightarrow \mathrm{H}_{2} \mathrm{O}+\mathrm{CH}_{3} \mathrm{CH}_{3} \quad \mathrm{Eq} 1.18 \\
& \mathrm{CH}_{3}^{\circ}+\mathrm{CH}_{3} \mathrm{CH}_{3}^{\cdot} \longrightarrow \mathrm{CH}_{3} \mathrm{CH}_{2} \mathrm{CH}_{3} \longrightarrow \text { Eq } 1.19 \\
& \mathrm{CH}_{3}^{\circ}+\mathrm{O}_{2} \longrightarrow \mathrm{CH}_{3} \mathrm{O}-\mathrm{O}^{\circ} \mathrm{Eq} 1.20 \\
& \mathrm{CH}_{3} \mathrm{O}-\mathrm{O}^{\circ}+\mathrm{CH}_{3} \longrightarrow \mathrm{CH}_{3} \mathrm{O}-\mathrm{OH}+\mathrm{CH}_{3}^{\cdot} \text { Eq } 1.21 \\
& \mathrm{Fe}^{2+}+\mathrm{H}_{2} \mathrm{O}_{2} \longrightarrow \mathrm{Fe}^{3+}+\mathrm{OH}^{-}+\mathrm{OH}^{\cdot} \quad \mathrm{Eq} 1.22
\end{aligned}
$$


El principal procés de transformació del $\mathrm{CH}_{4}$ a nivell industrial és el reformat $a m b$ vapor. ${ }^{[41,37]}$ En aquest procés el metà és oxidat mitjançant vapor d' $\mathrm{H}_{2} \mathrm{O}$ a temperatures elevades al voltant de $800{ }^{\circ} \mathrm{C}$ per donar lloc a una barreja de $\mathrm{CO}$ i $\mathrm{H}_{2}$ (anomenada gas de síntesi o també gas per metanol). ${ }^{[42-44]}$ El valor d'aquesta barreja de gasos augmenta amb el seu contingut en $\mathrm{H}_{2} \cdot{ }^{[40,45-47]}$ En principi, el reformat al vapor del $\mathrm{CH}_{4}$ és el procés industrial que proporciona un major contingut en $\mathrm{H}_{2}$, el qual pot arribar a ser fins de tres equivalents pel que fa al $\mathrm{CO}$. El principal inconvenient d'aquest procés, que es porta a terme en grans quantitats, és que requereix de plantes de transformació complexes que suposen una inversió en capital de bilions de dòlars. ${ }^{[48-50]}$ El reformat de vapor no és, per tant, un procés adequat per ser implementat en els jaciments de gas natural ja que les instal-lacions requerides per a aquests processos són summament costoses i l'operació del procés requereix un control estricte de les condicions. Generalment el $\mathrm{CO} \mathrm{i}_{2}$ produït al reformat de vapor del $\mathrm{CH}_{4}$ és consumit en la mateixa instal·lació a causa de la dificultat i cost del transport d'aquests gasos. Els principals usos del $\mathrm{CO}$ (juntament amb una proporció adequada d' $\mathrm{H}_{2}$ ) són la formació de metanol i la formació d'hidrocarburs mitjançant el denominat procés Fischer Tropsch. En aquest procés, els hidrocarburs formats són predominantment lineals i el seu ús com a benzines requereix d'etapes prèvies d'isomerització. ${ }^{[51-53]}$ No obstant això, els alcans lineals de longitud al voltant de 16 àtoms de carboni són els més adequats per a motors dièsel i són els components desitjats en la fracció de gasoil d’automoció. També el CO és emprat per carbonilacions com per exemple l'obtenció d'àcid acètic metanol o la formilació del propè a n-butanal i isobutiraldehid (Equacions 1.23 a 1.25). ${ }^{[54-56]}$ Addicionalment el CO pot patir un procés d'oxidació addicional amb vapor d' $\mathrm{H}_{2} \mathrm{O}$ per donar $\mathrm{CO}_{2}$ i una quantitat addicional de $\mathrm{H}_{2}$.
$\mathrm{CO}+2 \mathrm{H}_{2}$
$\mathrm{CH}_{3} \mathrm{OH}$
Eq 1.23
co +
$\mathrm{H}_{2}$
$\mathrm{C}_{\mathrm{n}} \mathrm{H}_{2 \mathrm{n}+2}+2 \mathrm{H}_{2}$
Eq 1.24

32

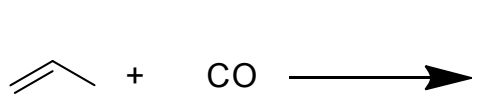<smiles>CCCC=O</smiles>

Eq 1.25

Esquema 1.2. Processos a partir del $\mathrm{CO}$ 
Pel que fa l' $\mathrm{H}_{2}$, aquest presenta aplicació en processos d'hidrocraqueig, fixació de nitrogen per donar amoníac $i$ en processos d'hidrogenació (equacions 1.26 i 1.27). També es consumeix en quantitats significatives $d^{\prime} \mathrm{H}_{2}$ en la formació de metanol a partir de gas de síntesi i hidroformilacions. En un futur $\mathrm{I}^{\prime} \mathrm{H}_{2}$, segurament provinent de fonts renovables com ara $\mathrm{H}_{2} \mathrm{O}$ o biomassa, podrà jugar un paper com a combustible per a transport, probablement acoblat amb piles de combustible.

Els processos industrials que s'acaben de comentar són endotèrmics $i$ requereixen un elevat consum d'energia que s'obté mitjançant la combustió parcial de metà o altres hidrocarburs. ${ }^{[57-59]}$ L'operació de la planta exigeix un control acurat de les velocitats de reacció, de la composició dels gasos i de l'activitat dels catalitzadors.

Hidrocraqueig

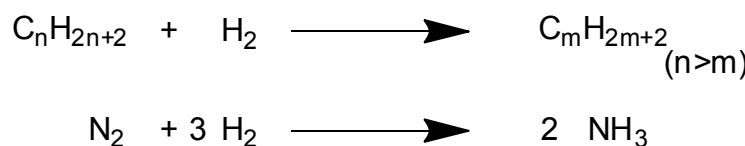

Eq 1.26

Procés Haber

$\mathrm{N}_{2}+3 \mathrm{H}_{2}$

$2 \mathrm{NH}_{3}$

Eq 1.27

A la vista de tot el que hem comentat anteriorment, no és fàcil implementar processos complexos de reformat amb vapor, que es duen a terme en grans instal.lacions en els llocs en què es troben els jaciments, que típicament són àrees remotes i es troben dispersos sobre una gran superfície. Per això seria convenient desenvolupar un altre tipus de funcionalització que permeteria la transformació del $\mathrm{CH}_{4}$ sense una elevada inversió en instal-lacions i que en una sola etapa convertira aquest hidrocarbur saturat en metanol o en un altre derivat que bé sigui líquid a temperatura ambient o puga ser liquat fàcilment.

Entre les diverses alternatives, s'han explorat tres possibilitats com són la dimerització oxidativa del metà a etilé, l'oligomerització al benzé i hidrocarburs aromàtics, i la transformació directa del metà a metanol. En el primer cas (equació 1.12), la formació d' $\mathrm{H}_{2} \mathrm{O}$ per combustió parcial del $\mathrm{CH}_{4}$ és la força termodinàmica que permet la formació d'etilé possiblement per acoblament de dos carbens. ${ }^{[60]}$ Aquest procés, però, és més adequat en la 
indústria petroquímica pels amplis usos del etilè com a precursor de polímers i d'altres substrats que com a combustible. A més l'etilè és un compost orgànic gasós que també requereix baixes temperatures per arribar a la fase líquida. L'aromatització del $\mathrm{CH}_{4}$ (equació 1.13) presenta com a avantatge la formació en el procés d'una gran quantitat $d^{\prime} \mathrm{H}_{2}$ que posseeix un gran interès en la indústria química. No obstant això, per tractar-se d'un equilibri desfavorable, la formació de benzé fa necessari l'ús de reactors de membrana selectius que permeten la permeació exclusiva d' $\mathrm{H}_{2}$ sense permetre la difusió de $\mathrm{CH}_{4}{ }^{[61,62]}$ Per això, l'aromatització del metà fa necessari, juntament amb el desenvolupament de catalitzadors eficients que no pateixen desactivació, el disseny de reactors que separen $\mathrm{I}^{\prime} \mathrm{H}_{2}$ que es vaja formant del medi de reacció. Finalment la transformació directa del $\mathrm{CH}_{4}$ en metanol (equació 1.14) presenta com a avantatge que el producte final és un compost líquid a pressió i temperatura ambients a més de posseir una elevada densitat d'energia per unitat de massa i volum, un fet que en fa adequat el metanol per a l'ús com a combustible. A més el metanol pot emprar-se com a alimentació en piles de combustibles de manera alternativa a I' $\mathrm{H}_{2}$ gas, pel que el seu ús podria representar una transició adequada a la tecnologia de $\mathrm{I}^{\prime} \mathrm{H}_{2}$ ja que faria possible l'ús de motors elèctrics basats en piles de combustibles. Aquestes piles de combustible basades inicialment en metanol posteriorment podrien ser alimentades arribat el cas amb $\mathrm{H}_{2}$ en lloc de amb metanol. ${ }^{[63,64]}$ En vista de l'interès de la conversió directa del $\mathrm{CH}_{4}$ en $\mathrm{CH}_{3} \mathrm{OH}$ al Capítol 3 descriurem l'ús de radiació UV llunyana en combinació amb un sòlid que provinga al sistema de grups hidroxils superficials, per a l'activació selectiva del $\mathrm{CH}_{4}$ a compostos oxigenats d'un àtom de $\mathrm{C}$. La possibilitat d'aplicar aquest mètode de funcionalització a altres hidrocarburs es demostrarà al Capítol 4, en dur a terme la reacció de funcionalització de l'età per fotòlisi amb llum UV de la zona llunyana de superfícies d'aluminosilicats. D’altra banda l'activació directa del benzé via radicalària seguint un esquema anàleg a l'emprat per a l'activació del $\mathrm{CH}_{4}$ es demostrarà al Capítol 5 duent a terme la transformació del benzé en fenol $\mathrm{i}$ anilina en fer reaccionar el compost aromàtic amb aigua $\mathrm{o}$ amoníac en un procés promogut per la fotòlisi de sòlids amb Ilum UV Ilunyana. 
L'esquema 1.4 resumeix els processos de funcionalització d'hidrocarburs que seran objecte d'estudi en aquesta tesi doctoral.

A més de la funcionalització del $\mathrm{CH}_{4}$, un altre dels reptes de gran $\mathrm{CH}_{4}+\mathrm{H}_{2} \mathrm{O} \underset{(<200 \mathrm{~nm})}{\stackrel{\mathrm{h} v / \text { sòlid }}{\longrightarrow}} \quad \mathrm{CH}_{3} \mathrm{OH} \quad$ Capítol 3 $\mathrm{CH}_{3} \mathrm{CH}_{3}+\mathrm{H}_{2} \mathrm{O} \underset{(<200 \mathrm{~nm})}{\stackrel{\text { h v/sòlid }}{\longrightarrow}} \quad \mathrm{CH}_{3} \mathrm{CH}_{2} \mathrm{OH} \quad$ Capítol 4<smiles>Cc1ccccc1</smiles>

Esquema 1.3. Processos de funcionalització d'hidrocarburs. 



\section{Combustibles \\ solars a partir $\operatorname{del~} \mathrm{CO}_{2}$}

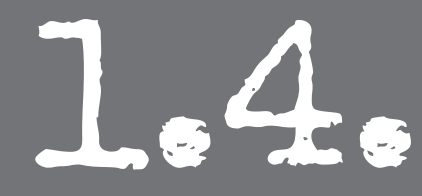

importància en la química actual relacionat també amb la sostenibilitat i fonts d'energia renovables és l'obtenció de Combustibles Solars per reducció del $\mathrm{CO}_{2}{ }^{.65-68]}$ De manera anàloga a com s'acaba de comentar per altres processos basats en $\mathrm{CH}_{4}$, la majoria de reaccions de reducció del $\mathrm{CO}_{2}$ són endergòniques i requereixen l'aportació d'energia per poder dur-les a terme. ${ }^{[69-71]}$ Per tal de desenvolupar processos sostenibles, la font d'energia primària ha de ser una font renovable. D'entre elles la llum solar constitueix en principi una font d'energia primària adequada i el concepte de combustibles solars consisteix a obtenir compostos químics que puguen ser emprats com a combustibles a partir de la llum del Sol.

En aquest context una possibilitat consisteix a transformar el $\mathrm{CO}_{2}$ en metanol, compostos oxigenats un carboni i, fins i tot, en $\mathrm{CO}$ i $\mathrm{CH}_{4}$. Moltes de les estratègies que han estat objecte d'estudi es basen en l'ús de fotocatalitzadors, com per exemple el $\mathrm{TiO}_{2}$, que absorbeixen directament la radiació solar i la transformen, mitjançant un procés de separació de càrregues en energia química, que permet la reducció (electrons a la banda de conducció) i l'oxidació (buits positius en la banda de valència) en una mateixa partícula de fotocatalitzador. ${ }^{[72,67]}$

El principal problema de la fotocatàlisi consisteix en la baixa eficiència 
de les reaccions fotocatalítiques a causa de processos de recombinació de càrrega i a la baixa o nul.la resposta del fotocatalitzador a longituds d'ona de la zona del visible. Per això, juntament amb estudis emprant diferents fotocatalitzadors, s'han explorat igualment altres alternatives on l'energia solar és transformada de manera més eficient en energia elèctrica i posteriorment es fa servir aquesta energia elèctrica per promoure l'electrocatàlisi del $\mathrm{CO}_{2}$. L'avantatge d'aquest procediment indirecte consisteix en què la llum solar es pot convertir en energia elèctrica mitjançant l'ús de cel·les fotovoltaiques amb una eficiència que pot arribar al $40 \%{ }^{[73]} \mathrm{i}$, posteriorment, l'ús de l'energia elèctrica en la reducció electroquímica del $\mathrm{CO}_{2}$ podria dur a terme igualment amb una alta eficiència. ${ }^{[74]}$ En contrast, el procés fotocatalític directe no es pot dur a terme actualment ni tan sols amb una eficiència propera a l'1\%. A més, el procés electroquímic, emprant elèctrodes de coure, es pot dur a terme amb una alta eficiència i selectivitat cap al metanol mentre que molts dels processos fotocatalítics es caracteritzen per una selectivitat molt baixa. ${ }^{[70,75]}$

En aquest context, els capítols 6 i 7 d'aquesta tesi doctoral van encaminats a la transformació del $\mathrm{CO}_{2}$ mitjançant l'ús de llum UV Ilunyana (Capítol 6) o una combinació de llum UV llunyana i llum solar (Capítol 7). La radiació solar que arriba a la superfície terrestre no posseeix radiació de longituds d'ona en aquesta zona de l'UV Ilunyana que, no obstant això, sí que es troba present en la radiació solar interestel·lar o a l'estratosfera terrestre. Per això, la nostra estratègia per a la fotoreducció del $\mathrm{CO}_{2}$, basada en l'ocupació de radiació de longituds d'ona inferior a $200 \mathrm{~nm}$, no pot emprar-se amb llum solar a la superfície terrestre i s'ha de basar en un procés en dues etapes en què l'energia solar és convertida primer en energia elèctrica i posteriorment aquesta energia elèctrica pot ser utilitzada per alimentar llums que emeten en la longitud d'ona requerida. No obstant això, igual que en les estratègies basades en la reducció electroquímica, la nostra estratègia per produir combustibles solars a partir de $\mathrm{CO}_{2}$ tindrien l'avantatge que les dues etapes, és a dir, la conversió de llum solar en energia elèctrica i ocupació d’aquesta 
energia elèctrica per a l'activació del $\mathrm{CO}_{2}$ posseirien en el seu conjunt una eficiència molt superior a la que s'aconsegueix actualment amb la fotocatàlisi directa amb llum solar.

En particular, existeixen certs precedents en la literatura que han demostrat que la fotòlisi directa de $\mathrm{CO}_{2}$ amb llum UV Ilunyana pot produir trencament homolític de l'enllaç $\mathrm{CO}$ formant $\mathrm{CO}$, un àtom d'oxigen (equació 1.28). ${ }^{[2-4]}$ La nostra hipòtesi de partida és aplicar aquest coneixement per desenvolupar processos més eficients on la combinació amb la fotòlisi del $\mathrm{CO}_{2}$ poguera donar lloc a $\mathrm{CH}_{4} \mathrm{O}$ a altres compostos d'interés com a combustibles solars.

A més, com en el cas que s'ha comentat anteriorment sobre l'activació

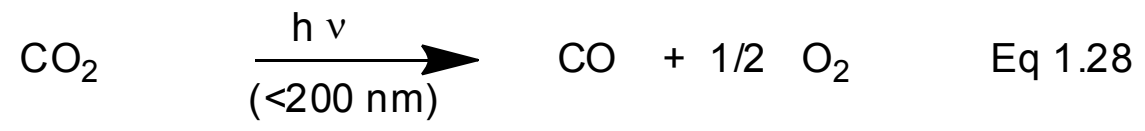

de superfícies posseint grups hidroxil mitjançant llum UV de la zona llunyana, podria ser que la irradiació de $\mathrm{CO}_{2}$ o barreges de $\mathrm{CO}_{2} \mathrm{i}_{2} \mathrm{O}$ sobre superfícies produiren processos de transformació de $\mathrm{CO}_{2}$ més eficients que els que $s^{\prime}$ han descrit en fase gas per al $\mathrm{CO}_{2}$ pur. Aquesta major eficiència podria derivar d'una banda de la major absorció de fotons que poden presentar els medis sòlids opacs respecte amb els compostos gasosos i per una altra de la preactivació del $\mathrm{CO}_{2}$ que s'origina quan aquest s'adsorbeix sobre superfícies sòlides. De fet se sap que el $\mathrm{CO}_{2}$ s'adsorbeix fortament sobre superfícies de sòlids bàsics formant espècies de naturalesa similar als carbonats, on grups nucleofílics superficials interaccionen amb el carboni del $\mathrm{CO}_{2}$ al mateix temps que centres electrofílics poden interaccionar amb els oxígens del $\mathrm{CO}_{2}$ mitjançant ponts d'hidrògens. Aquesta activació àcid-base és d'aplicació general per a l'adsorció de $\mathrm{CO}_{2}$ i condueix a una deformació de la molècula lineal del $\mathrm{CO}_{2}$ en major o menor mesura depenent de la intensitat de la interacció. L'Esquema 1.4 resumeix el tipus de centres que ha de posseir una superfície per absorbir intensament $\mathrm{CO}_{2}$. $\mathrm{Si}$ al mateix temps l'absorció 
de $\mathrm{CO}_{2}$ es combina amb l'activació fotoquímica consistent en ruptura de l'enllaç $\mathrm{CO}$ del $\mathrm{CO}_{2}$ o transferència electrònica acoblada amb transferència protònica sincronitzada, seria possible aconseguir d'una manera eficient la transformació del $\mathrm{CO}_{2}$ respecte de processos anàlegs en absència de sòlids.

Esquema 1.4. Activació del $\mathrm{CO}_{2}$ per adsorció en superfícies sòlides que contenen centres d'adsorció.

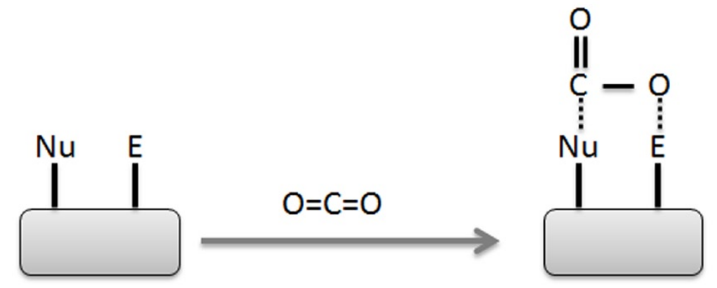

Nu: centres nucleofílics

E: centres electrofílics

D'altra banda, a més de la transformació del $\mathrm{CO}_{2}$ amb aigua en un procés que és altament endergònic i recorda la fotosíntesi natural pel tipus de substrats implicats i per l'activació fotoquímica, ${ }^{[76-79]}$ seria possible imaginar de forma alternativa un procés en dues etapes en què en la primera es generera $\mathrm{CO}$ per trencament de l'enllaç $\mathrm{CO}$ i en la segona el CO patira una transformació posterior. L'avantatge d'aquest procés en dues etapes deriva de la possibilitat de portar-les a terme en condicions d'irradiació diferents. Per fer aquesta transformació les condicions ideals podrien ser:

-Etapa 1: Trencament del $\mathrm{CO}_{2}$ per donar $\mathrm{CO}+\mathrm{O}_{2}$. Condicions: absència d'humitat i irradiació amb longituds d'ona inferiors a $200 \mathrm{~nm}$.

- Etapa 2: Activació del CO. Aquesta etapa es pot portar a terme en presència de sòlids o altres sistemes heterogenis, hidrogen, humitat o una altra font d'hidrogen, emprant longituds d'ona a la zona UV proper o fins i tot llum solar o exclusivament llum visible.

A més, tal com hem indicat, el $\mathrm{CO}_{2}$ és una molècula àcida mentre que el CO interacciona molt bé amb metalls de transició pel que el procés de 
transformació del CO podria requerir del concurs de catalitzadors metàl-lics. L'Esquema 1.5 resumeix la transformació del $\mathrm{CO}_{2}$ a hidrocarburs en dues etapes.

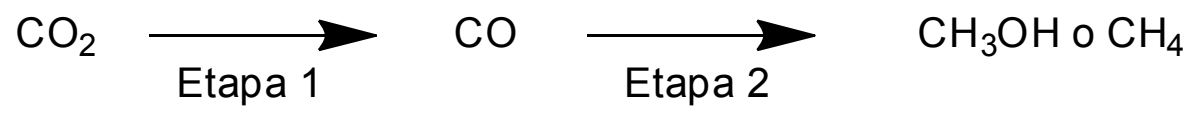

Esquema 1.5. Procés d'activació del $\mathrm{CO}_{2}$ a combustibles solars en dues etapes.

La viabilitat del procés en dues etapes dependria que els rendiments $\mathrm{i}$ eficiències de cadascuna de les dues etapes individuals fóra elevat.

En definitiva, en aquesta tesi doctoral i de forma general es podria resumir com l'aplicació de radiacions a la zona UV Ilunyana per a l'activació de molècules poc reactives com ara $\mathrm{CH}_{4} \mathrm{i} \mathrm{CO}_{2}$. Aquest tipus de reaccions fotoquímiques es durien a terme amb i sense la participació de superfícies sòlides que poden proporcionar espècies intermèdies que ajuden a millorar l'eficiència global del procés. A manera de resum, podem indicar que la present tesi doctoral s'enquadra dins de les línies d'investigació actuals encaminades a la transformació de molècules de molt baixa reactivitat i de gran interés industrial com són hidrocarburs lleugers, fonamentalment $\mathrm{CH}_{4} \mathrm{i} \mathrm{CO}_{2}$. 



\section{Referències}

1. Turro, N.J., V. Ramamurthy, and J.C. Scaiano, Principles of molecular photochemistry: an introduction. 2009: Univ Science Books.

2. Mahan, B.H."Photolysis of carbon dioxide", J. Chem. Phys., 1960. 33: p. 959-65.

3. Reeves, R.R., P. Harteck, B.A. Thompson, and R.W. Waldron."Photochemical Equilibrium Studies of Carbon Dioxide and Their Significance for the Venus Atmosphere", The Journal of Physical Chemistry, 1966. 70: p. 1637-1640.

4. Warneck, P." Reactions of 1D oxygen atoms in the photolysis of carbon dioxide", Discuss. Faraday Soc., 1964. No. 37: p. 57-65.

5. Getoff, N. and G.O. Schenk."Primary products of Iliquid water photolysis at 1236, 1470 and 1849 amstrong", Photochem. Photobiol., 1968. 8: p. 167-178.

6. Sastre, F., A. Corma, and H. García." $185 \mathrm{~nm}$ Photoreduction of $\mathrm{CO}$ to Methane by Water. Influence of the Presence of a Basic Catalyst", Journal of the American Chemical Society, 2012. 134: p. 1413714141.

7. Sastre, F., V. Fornés, A. Corma, and H. García."Selective, RoomTemperature Transformation of Methane to C1 Oxygenates by Deep UV Photolysis over Zeolites", Journal of the American Chemical Society, 2011. 133: p. 17257-17261.

8. Sastre, F., V. Fornés, A. Corma, and H. García."Conversion of Methane into C1 Oxygenates by Deep-UV Photolysis on Solid Surfaces: Influence of the Nature of the Solid and Optimization of Photolysis Conditions", Chemistry - A European Journal, 2012. 18: p. 1820-1825. 
9. Gonzalez, M.G., E. Oliveros, M. Wörner, and A.M. Braun."Vacuumultraviolet photolysis of aqueous reaction systems", Journal of Photochemistry and Photobiology C: Photochemistry Reviews, 2004. 5: p. 225-246.

10. Bar-nun, A. and H. Hartman."Synthesis of organic compounds from carbon monoxide and water by UV photolysis", Origins of life, 1978. 9: p. 93-101.

11. Maeda, K., Y. Inoue, H. Nishikawa, et al."Involvement of melanin monomers in the skin persistent UVA-pigmentation and effectiveness of vitamin Cethyl on UVA-pigmentation", Nippon Koshohin Kagakkaishi, 2003. 27: p. 257-268.

12. Moyal, D., L. Duteil, C. Queille-Roussel, et al."Comparison of UVA protection afforded by sunscreens with a high sun protection factor", Eur. J. Dermatol., 2002. 12: p. ii-iii.

13. Tegner, E. and A. Bjornberg."Induction of UVA pigmentation in pressure areas by hydrogen peroxide", Acta Derm Venereol, 1986. 66: p. 65-7.

14. Iqbal, M.Z., S. Siddique, M.W. Iqbal, and J. Eom."Formation of $p-n$ junction with stable $p$-doping in graphene field effect transistors using deep UV irradiation", J. Mater. Chem. C, 2013. 1: p. 3078-3083.

15. Komura, M., K. Kamata, T. Iyoda, and K. Nagai."Hexagonally arranged nanopore film fabricated via selective etching by $172-\mathrm{nm}$ vacuum ultraviolet light irradiation", Fusion Sci. Technol., 2013. 63: p. 257264.

16. Rakhimova, T.V., A.T. Rakhimov, Y.A. Mankelevich, et al."Modification of organosilicate glasses low-k films under extreme and vacuum ultraviolet radiation", Appl. Phys. Lett., 2013. 102: p. 111902/1$111902 / 4$.

17. Corma, A., I. Gimenez, S. Leiva, et al."An study of cyclohexylpyrrolidinederived quaternary organic cations as structure directing agents for synthesis of zeolites", Stud. Surf. Sci. Catal., 2004. 154A: p. 265-274.

18. Corma, A., S. Iborra, M. Mifsud, et al."A new environmentally benign catalytic process for the asymmetric synthesis of lactones: synthesis of the flavoring $\delta$-decalactone molecule", Adv. Synth. Catal., 2004. 346: p. 257-262.

19. Corma, A., M.T. Navarro, F. Rey, and S. Valencia."Synthesis of pure polymorph C of Beta zeolite in a fluoride-free system", Chemical Communications, 2001: p. 1486-1487.

20. Martinez, C. and A. Corma."Inorganic molecular sieves: Preparation, modification and industrial application in catalytic processes", Coord. Chem. Rev., 2011. 255: p. 1558-1580. 
21. Corma, A., V. Fornes, J.M. Guil, et al."Preparation, characterisation and catalytic activity of ITQ-2, a delaminated zeolite", Microporous and Mesoporous Materials, 2000. 38: p. 301-309.

22. Corma, A., F. V., M.T. Navarro, and J. Pérez-Pariente."Acidity and Stability of MCM-41 Crystalline Aluminosilicates", J. Catal., 1994. 148: p. 569-574.

23. Siegel, H., R. Schoellner, J. Hoffmann, and W. Oehme."Air separation by adsorption with synthetic zeolites", Z. Chem., 1989. 29: p. 77-88.

24. Yoshimatsu, Y., S. Harada, and K. Someya, 1997, Hitachi, Ltd., Japan . p. 4 pp.

25. Grajciar, L., J. Cejka, A. Zukal, et al."Controlling the Adsorption Enthalpy of $\mathrm{CO}_{2}$ in Zeolites by Framework Topology and Composition", ChemSusChem, 2012. 5: p. 2011-2022, S2011/1-S2011/2.

26. Ishikawa, N., 1999, Toyota Motor Corp., Japan . p. 7 pp.

27. Katada, N., K. Suzuki, T. Noda, et al."Correlation of the cracking activity with solid acidity and adsorption property on zeolites", Appl. Catal., A, 2010. 373: p. 208-213.

28. Shevade, S., R. Ford, P. Kaiser, and J. Wilson."Zeolites: Effective water purifiers", Prepr. Ext. Abstr. ACS Natl. Meet., Am. Chem. Soc., Div. Environ. Chem., 2003. 43: p. 367-369.

29. Mylvaganam, K., G.B. Bacskay, and N.S. Hush."Homogeneous Conversion of Methane to Methanol. 1. Catalytic Activation and Functionalization of Methane by cis-Platin in Sulfuric Acid: A Density Functional Study of the Thermochemistry", J. Am. Chem. Soc., 1999. 121: p. 4633-4639.

30. Periana, R.A., D.J. Taube, S. Gamble, et al."Platinum Catalysts for the High-Yield Oxidation of Methane to a Methanol Derivative", Science, 1998. 280: p. 560-564.

31. Kavitha, V. and K. Palanivelu."The role of ferrous ion in Fenton and photo-Fenton processes for the degradation of phenol", Chemosphere, 2004. 55: p. 1235-1243.

32. Armor, J.N."The multiple roles for catalysis in the production of $\mathrm{H}_{2}$ ", Applied Catalysis a-General, 1999. 176: p. 159-176.

33. Fierro, J.L.G."Catalysis in C1 Chemistry -Future an prospect", Catalysis Letters, 1993. 22: p. 67-91.

34. Hu, Y.H. and E. Ruckenstein, Catalytic conversion of methane to synthesis gas by partial oxidation and $\mathrm{CO}_{2}$ reforming, in Advances in Catalysis, Vol 482004. p. 297-345.

35. Pena, M.A., J.P. Gomez, and J.L.G. Fierro."New catalytic routes for syngas and hydrogen production", Applied Catalysis a-General, 1996. 144: p. 7-57. 
36. Tsang, S.C., J.B. Claridge, and M.L.H. Green. "Recent advances in the conversion of methane to synthesis gas", Catalysis Today, 1995. 23: p. 3-15.

37. Vanhook, J.P. "Methane steam reforming", Catalysis Reviews-Science and Engineering, 1980. 21: p. 1-51.

38. Ashcroft, A.T., A.K. Cheetham, M.L.H. Green, and P.D.F. Vernon. "Partial oxidation of methane to synthesis gas usin Carbon Dioxide", Nature, 1991. 352: p. 225-226.

39. Lunsford, J.H."Catalytic conversion of methane to more useful chemicals and fuels: a challenge for the 21st century", Catalysis Today, 2000. 63: p. 165-174.

40. Wang, H. and Z.M. Liu."Progress in direct conversion of methane", Progress in Chemistry, 2004. 16: p. 593-602.

41. Rostrup-Nielsen, J.R., J. Sehested, and J.K. Norskov, Hydrogen and synthesis gas by steam- and $\mathrm{CO}_{2}$ reforming, in Advances in Catalysis, Vol 472002. p. 65-139.

42. Foster, N.R."Direct Catalytic oxidation of methane to methanol a review", Applied Catalysis, 1985. 19: p. 1-11.

43. Gesser, H.D., N.R. Hunter, and C.B. Prakash."The direct conversion of methant to methanol by controlled oxidation", Chemical Reviews, 1985. 85: p. 235-244.

44. Otsuka, K. and Y. Wang."Direct conversion of methane into oxygenates", Applied Catalysis a-General, 2001. 222: p. 145-161.

45. Choudhary, T.V., E. Aksoylu, and D.W. Goodman."Nonoxidative activation of methane", Catalysis Reviews-Science and Engineering, 2003. 45: p. 151-203.

46. Guisnet, M., N.S. Gnep, and F. Alario."Aromatization of short chain alkanes on zeolite catalysts", Applied Catalysis a-General, 1992. 89: p. 1-30.

47. Ismagilov, Z.R., E.V. Matus, and L.T. Tsikoza."Direct conversion of methane on Mo/ZSM-5 catalysts to produce benzene and hydrogen: achievements and perspectives", Energy \& Environmental Science, 2008. 1: p. 526-541.

48. Connell, D.P., D.A. Lewandowski, S. Ramkumar, et al."Process simulation and economic analysis of the Calcium Looping Process (CLP) for hydrogen and electricity production from coal and natural gas", Fuel, 2013. 105: p. 383-396.

49. Kim, D.J., J.H. Kim, K.F. Barry, and H.-Y. Kwak."Thermoeconomic analysis of high-temperature gas-cooled reactors with steam methane reforming for hydrogen production", Nucl. Technol., 2011. 176: p. 337351. 
50. Luk, H.T., H.M. Lei, W.Y. Ng, et al."Techno-economic analysis of distributed hydrogen production from natural gas", Chin. J. Chem. Eng., 2012. 20: p. 489-496.

51. Goetsch, D.A., K.B. Arcuri, S.J. Schmit, et al., 2012, Syngas Technology Inc., USA . p. 8pp.

52. Loginova, A.N., S.A. Sviderskii, S.N. Potapova, et al., 2012, "SINTOP", Russia . p. 18pp.

53. Pour, A.N., S.M.K. Shahri, Y. Zamani, et al."Deactivation studies of bifunctional Fe-HZSM5 catalyst in Fischer-Tropsch process", J. Nat. Gas Chem., 2008. 17: p. 242-248.

54. Ma, X., X. Ge, J. Shang, et al., 2012, Shaanxi Coal and Chemical Industry Technology Development Center Co., Ltd., Peop. Rep. China . p. 8pp.

55. Sudheesh, N., J.N. Parmar, and R.S. Shukla."Hydroformylation of propene heterogeneously catalyzed by $\mathrm{HRh}(\mathrm{CO})\left(\mathrm{PPh}_{3}\right)_{3}$ encapsulated in to hexagonal mesoporous silica-Parametric variation and mass transfer study", Appl. Catal., A, 2012. 415-416: p. 124-131.

56. Trzeciak, A.M."Hydroformylation in an ionic liquid medium", Wiad. Chem., 2011. 65: p. 1003-1020.

57. Erisman, J.W., M.A. Sutton, J. Galloway, et al."How a century of ammonia synthesis changed the world", Nat. Geosci., 2008. 1: p. 636639.

58. Tan, L., F. Liu, and P.B. Armentrout."Thermochemistry of the activation of $\mathrm{N} 2$ on iron cluster cations: Guided ion beam studies of the reactions of $\mathrm{Fe}+\mathrm{n}(\mathrm{n}=1-19)$ with $\mathrm{N}_{2}{ }^{\prime}$, J. Chem. Phys., 2006. 124: p. 084302/1084302/14.

59. Zhao, F. and L. He. Catalytic conversion of vegetable oils to clean transportation fuels over $\mathrm{Ru} / \mathrm{TiO}_{2}$ catalysts. 2012. American Chemical Society.

60. Xie, M.-S., X. Yang, W.-H. Chen, et al."The aromatization of methane over Mo/HZSM-5 zeolites without using oxidants", Stud. Surf. Sci. Catal., 1997. 105B: p. 869-876.

61. Iliuta, M.C., B.P.A. Grandjean, and F. Larachi." Methane Nonoxidative Aromatization over Ru-Mo/HZSM-5 at Temperatures up to $973 \mathrm{~K}$ in a Palladium-Silver/Stainless Steel Membrane Reactor", Ind. Eng. Chem. Res., 2003. 42: p. 323-330.

62. Kinage, A.K., R. Ohnishi, and M. Ichikawa."Marked Enhancement of the Methane Dehydrocondensation Toward Benzene Using Effective Pd Catalytic Membrane Reactor with Mo/ZSM-5", Catal. Lett., 2003. 88: p. 199-202.

63. Ahmed, S. and M. Krumpelt."Hydrogen from hydrocarbon fuels for fuel cells", Int. J. Hydrogen Energy, 2001. 26: p. 291-301. 
64. Kreuer, K.D."On the development of proton conducting polymer membranes for hydrogen and methanol fuel cells", J. Membr. Sci., 2001. 185: p. 29-39.

65. Centi, G. and S. Perathoner."Towards Solar Fuels from Water and CO2", ChemSusChem, 2010. 3: p. 195-208.

66. Hammarstrol^m, L. and S. Hammes-Schiffer."Artificial Photosynthesis and Solar Fuels", Accounts of Chemical Research, 2009. 42: p. 18591860.

67. Liu, G., N. Hoivik, K. Wang, and H. Jakobsen."Engineering $\mathrm{TiO}_{2}$ nanomaterials for $\mathrm{CO}_{2}$ conversion/solar fuels", Sol. Energy Mater. Sol. Cells, 2012. 105: p. 53-68.

68. Roy, S.C., O.K. Varghese, M. Paulose, and C.A. Grimes."Toward Solar Fuels: Photocatalytic Conversion of Carbon Dioxide to Hydrocarbons", ACS Nano, 2010. 4: p. 1259-1278.

69. Abanades, $\mathrm{S}$. and H.I. Villafan-Vidales." $\mathrm{CO}_{2}$ and $\mathrm{H}_{2} \mathrm{O}$ conversion to solar fuels via two-step solar thermochemical looping using iron oxide redox pair", Chem. Eng. J. (Amsterdam, Neth.), 2011. 175: p. 368-375.

70. Inoue, T., A. Fujishima, S. Konishi, and K. Honda."Photoelectrocatalytic reduction of carbon dioxide in aqueous suspensions of semiconductor powders", Nature (London), 1979. 277: p. 637-8.

71. Licht, S. "STEP (Solar Thermal Electrochemical Photo) Generation of Energetic Molecules: A Solar Chemical Process to End Anthropogenic Global Warming", J. Phys. Chem. C, 2009. 113: p. 16283-16292.

72. Dhakshinamoorthy, A., S. Navalon, A. Corma, and H. Garcia. "Photocatalytic $\mathrm{CO}_{2}$ reduction by $\mathrm{TiO}_{2}$ and related titanium containing solids", Energy Environ. Sci., 2012. 5: p. 9217-9233.

73. Beek, W.J.E., M.M. Wienk, and R.A.J. Janssen. "Efficient hybrid solar cells from zinc oxide nanoparticles and a conjugated polymer", Adv. Mater. (Weinheim, Ger.), 2004. 16: p. 1009-1013.

74. Fujishima, A., D.A. Tryk, and T.N. Rao. "New approaches in $\mathrm{CO}_{2}$ reduction", Stud. Surf. Sci. Catal., 1998. 114: p. 31-42.

75. Izumi, Y. "Recent advances in the photocatalytic conversion of carbon dioxide to fuels with water and/or hydrogen using solar energy and beyond", Coord. Chem. Rev., 2013. 257: p. 171-186.

76. Bard, A.J. and M.A. Fox."ARTIFICIAL PHOTOSYNTHESIS - SOLAR SPLITTING OF WATER TO HYDROGEN AND OXYGEN", Accounts of Chemical Research, 1995. 28: p. 141-145.

77. Gratzel, M. "Artificial photosyntesis water cleavage into hydrogen and oxygen by visible lightT", Accounts of Chemical Research, 1981. 14: $p$. 376-384. 
78. Gust, D., T.A. Moore, and A.L. Moore."Solar fuels via artificial photosynthesis", Accounts of Chemical Research, 2009. 42: p. 18901898.

79. Lee, W.-H., C.-H. Liao, M.-F. Tsai, et al."A novel twin reactor for $\mathrm{CO}_{2}$ photoreduction to mimic artificial photosynthesis", Appl. Catal., B, 2013. 132-133: p. 445-451. 



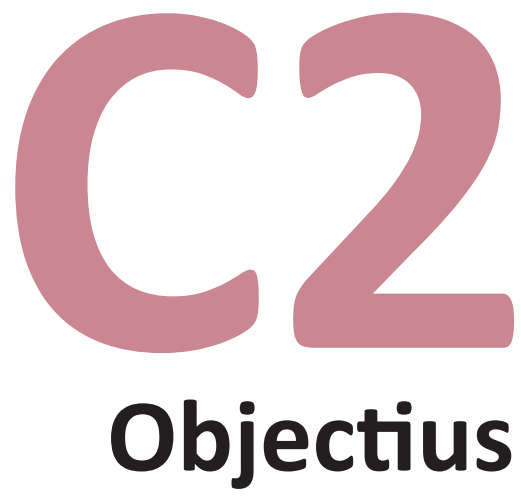



Tal com hem comentat al final del capítol d'introducció, els objectius generals d'aquesta tesi doctoral són l'aplicació de radiacions UV de la zona Ilunyana per l'activació d'hidrocarburs i $\mathrm{CO}_{2}$, amb el propòsit final d'establir mètodes alternatius fotoquímics o fotocatalítics per a l'activació d'aquestes molècules.

En el primer cas, pel que fa a l'activació d'hidrocarburs, persegueim transformar aquests compostos en derivats líquids de fàcil transport o en compostos d'elevat interés industrial, com en el cas del fenol i anilina a partir del benzé.

Pel que fa al $\mathrm{CO}_{2}$ l'objectiu és aconseguir combustibles solars que eventualment poguessen ser aplicats en transport de manera eficient $i$ selectiva.

En particular, els objectius específics de cada un dels capítols de la secció de resultats i discussió d’aquesta tesi doctoral són els següents:

- Estudi de la transformació del $\mathrm{CH}_{4}$ per irradiació de superfícies sòlides que presenten una elevada població de grups hidroxil amb llum UV de longitud d'ona inferior a $200 \mathrm{~nm}$ en presència d'aquest hidrocarbur. 
Pretenem determinar la influència de la naturalesa del sòlid en els rendiments de transformació del $\mathrm{CH}_{4}$ i en la distribució del producte. Les reaccions es duran a terme en atmosferes que continguen o no oxigen, que és un gas capaç d'atrapar radicals centrats en el carboni. Calcularem el consum d'energia per al cas i les condicions més favorables, comparant aquests consums amb processos industrials convencionals com el reformat al vapor de $\mathrm{CH}_{4}$.

- Activació de l'età per irradiació de superfícies sòlides amb llum UV Ilunyana en presència d'aquest hidrocarbur. S'estudiarà la influència que la naturalesa del sòlid té en la conversió i en la distribució de productes, així com la influència que té la presència d'oxigen en aquest procés. Es compararà l'activitat del procés fotoquímic de l'età i el consum d'energia amb l'activació del metà en condicions similars.

- Activació del benzè i el seu transformació selectiva en fenol o anilina per irradiació de superfícies de materials sòlids que contenen una alta densitat de grups hidroxils amb llum UV de la zona llunyana. S'establirà la influència que el contingut d'humitat i vapor d' $\mathrm{H}_{2} \mathrm{O}$ té en la distribució de fotoproductes. D'especial interès és determinar el balanç de matèria de la transformació i específicament la formació d'oligòmers i polímers per transformació dels productes primaris.

- Activació del $\mathrm{CO}_{2}$ en presència d' $\mathrm{H}_{2}$ O vapor d' $\mathrm{H}_{2} \mathrm{O}$ per irradiació amb Ilum UV Ilunyana de sòlids de caràcter bàsic en presència d'atmosferes que contenen aquests gasos. Pretenem determinar la influència que la naturalesa del sòlid exerceix en la conversió del $\mathrm{CO}_{2} \mathrm{i}$ en la selectivitat dels productes formats. Especial interès té poder establir si el procés en fase gas en absència de sòlid és més o menys avantatjós que les irradiacions anàlogues on hi haja aquest sòlid que puga actuar com a adsorbent i fotocatalitzador. 
- Processos d'activació del $\mathrm{CO}_{2}$ en dues etapes, la primera de les quals consisteix en la irradiació en fase gas de $\mathrm{CO}_{2}$ anhidre amb llum UV llunyana. La segona etapa consistiria en la reacció promoguda per llum del $\mathrm{CO}$ en presència d' $\mathrm{H}_{2} \mathrm{O}$ vapor $\mathrm{d}^{\prime} \mathrm{H}_{2} \mathrm{O}$. Aquesta segona etapa seria equivalent al procés industrial denominat desplaçament per gas d'aigua ("water gas shift") i es duria a terme en presència de fotocatalitzadors i amb irradiació amb llum UV o llum visible i fins i tot llum solar simulada.

La importància dels objectius proposats deriva de la consideració de que en cas d'assolir-se s'haurien desenvolupat processos d'activació de $\mathrm{CH}_{4}$, hidrocarburs i $\mathrm{CO}_{2}$ que serien de gran interès aplicat mitjançant l'ús de radiacions fotoquímiques en una regió de longituds d'ona que no ha estat objecte d'estudi tan exhaustiu com altres zones de l'espectre electromagnètic i especialment I'UV proper i les radiacions visibles. 



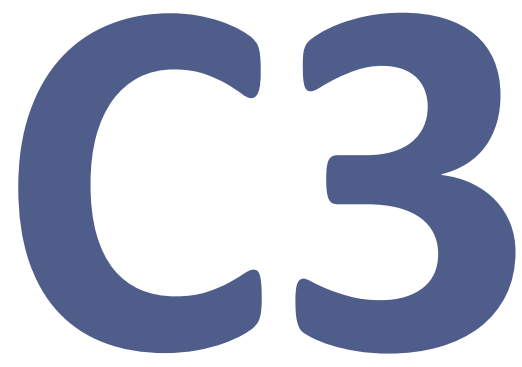

\section{Transformació selectiva} de metà a compostos oxigenats d'un carboni 



\section{Introducció}

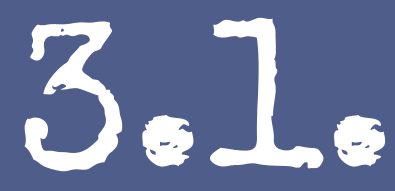

El metà és el principal component del gas natural i l'hidrocarbur més abundant. ${ }^{[1-4]}$ Un dels principals problemes és que els camps d'extracció dels jaciments de gas natural es troben molt sovint en llocs geogràfics remots $i$ n'és necessari el transport des del seu punt d'extracció fins al lloc on serà processat. Com a conseqüència dels baixos punts d'ebullició, el gas natural ha de ser transportat com gas comprimit en la seua major part en vaixells metaners, un fet que n'encareix significativament el transport. Actualment el metà es consumeix directament com a font d'energia en la generació d'electricitat $\mathrm{i}$ en refineries. Un altre percentatge significatiu de metà se sotmet al procés denominat reformat on es produeix gas de síntesi per a metanol, s'utilitza com a substrat en les unitats del procés Fischer-Tropsch o fins i tot es consumeix metà per a la producció industrial d'hidrogen ${ }^{[5-11]}$ Des del punt de vista del transport i ús del metà seria de gran interès si aquest hidrocarbur es convertisca directament en un compost líquid i particularment en metanol o altres compostos oxigenats d'un àtom de carboni.

D'altra banda la funcionalització d'alcans amb alta selectivitat constitueix encara avui un repte des del punt de vista químic a causa de la seua baixa reactivitat. ${ }^{[12-14]} A$ més d'un problema de gran interès econòmic, la funcionalització de metà planteja també reptes des del punt de vista fonamental. 
La majoria dels estudis relacionats amb la conversió directa del metà en compostos líquids duen aparellades reaccions catalítiques que són dutes a terme a temperatures molt superiors als $500{ }^{\circ} \mathrm{C}$. Els tres processos que s'estan desenvolupant actualment i que encara estan en fase d'investigació per transformar el metà són:

- La conversió del metà en compostos aromàtics emprant zeolites que contenen molibdè com a catalitzador. ${ }^{[15,16]}$

- L'acoblament oxidatiu del metà per a formar etilé. ${ }^{[15,17,18]}$

- L'oxidació directa del metà en metanol . ${ }^{[19,20,12]}$

Tot i que s'han aconseguit avanços significatius en aquest tipus de reaccions, la selectivitat d'aquests processos en desenvolupament i el temps d'operació del catalitzador són encara punts importants que necessiten millorar satisfactòriament abans que puguen ser aplicats a escala industrial. ${ }^{[21,16,22,3]}$

És possible dur a terme la funcionalització d'alcans, incloent el metà, fins $i$ tot a temperatura ambient en fase gas, mitjançant un mecanisme radicalari en cadena iniciat per radicals hidroxil. ${ }^{[23-26]}$ Desafortunadament aquests processos ocorren amb molt baixa selectivitat donant lloc a mescles complexes extremadament difícils de purificar. ${ }^{[23-26]}$ La raó d'aquesta selectivitat tan baixa és que, a mesura que la reacció progressa, els productes primaris que es formen són més o en tot cas igual de reactius que el metà, $\mathrm{i}$ pateixen una sèrie de reaccions secundàries no desitjades. A més a més, el cost de generar radicals hidroxil pot ser significatiu.

En aquest capítol descriurem un procés fotocatalític original que converteix metà en compostos oxigenats d'un carboni a temperatura ambient o fins i tot inferior. Aquest es basa en la irradiació amb llum a la zona de l'ultraviolada llunyana $(\lambda<200 \mathrm{~nm})$ del metà en els espais confinats de materials porosos que contenen grups hidroxil interns, com ara les zeolites. D'aquesta manera, s'obtenen hidrocarburs lleugers i compostos oxigenats 
d'un àtom de carboni. En aquest capítol descriurem que quan l'oxigen es troba present es pot aconseguir una selectivitat en la transformació de fins al 95\% en la conversió del metà cap a compostos oxigenats d'un carboni, a un nivell de conversió superior al $10 \%$ en minuts. És més, l’energia requerida per assolir aquesta conversió s'estima al voltant de la meitat que consumeixen alguns processos industrials actualment en ús per convertir el metà en gas de síntesi. ${ }^{[27]}$ 



\section{Resultats $i$ discussió}

En el curs de la irradiació amb llum ultraviolada a la zona llunyana es va analitzar la composició de la fase gas i del sòlid a diferents temps d'irradiació per a cada un dels materials estudiats. La composició de la fase gas es va quantificar en base al contingut de nitrogen molecular inicial que es va considerar com a patró i que s'assumeix que roman inalterat i en concentració constant durant el procés.

La composició de la fase sòlida es va determinar emprant com a substrat metà marcat isotòpicament $a m b{ }^{13} \mathrm{C}$ i realitzant espectres de RMN de ${ }^{13} \mathrm{C}$ en estat sòlid per al fotocatalitzador després de la irradiació. En tots els casos l'espectroscòpia de $\mathrm{RMN}{ }^{13} \mathrm{C}$ va mostrar la presència de metanol adsorbit $\mathrm{i}$ espècies metoxi en les superfícies del sòlid ( $\delta=47-61 \mathrm{ppm}$ ) acompanyats de quantitats variables de la forma acetàlica del formaldehid (formol, $\delta=90 \mathrm{ppm})$ i àcid fòrmic $(\delta=160 \mathrm{ppm})$. A més, depenent de la presència o absència de l'oxigen en la reacció, es va observar igualment en el sòlid la formació d'età i altres alcans de pes molecular baix (vejeu les Figures 3.1 i 3.2$)$

Els experiments control en absència de qualsevol sòlid no hi van detectar cap fotoproducte, pel que podem concloure que, sota les nostres condicions de reacció, la contribució de la fotòlisi directa en fase gas a la generació de fotoproductes deu ser menyspreable. 


\subsubsection{Reaccions fotoquímiques}

implicades

El procés que descrivim en aquest capítol, per a l'activació del metà a temperatura ambient, està basat en la capacitat dels radicals hidroxils (i presumiblement d'altres radicals oxíl) d'abstraure un àtom d'hidrogen d'un hidrocarbur, incloent el metà. No obstant això, per tal de millorar la selectivitat associada amb les reaccions hidroxil en fase gas, en aquest capítol, els radicals (hidr)oxils generats es troben localitzats en una superfície sòlida o en un espai confinat constituït pels microporus d'un sòlid. Esperem que, a diferència del que passa en fase gas, la restricció de la mobilitat d'aquests radicals desfavoreisca les reaccions consecutives. El procés que es descriu ací requereix la síntesi de materials sòlids amb una alta densitat de grups silanols interns i possiblement d'aigua coabsorbida. Quan aquests materials sòlids de gran àrea i que poden presentar porositat se sotmeten a irradiació amb llum ultraviolada llunyana (165 o $185 \mathrm{~nm}$ ), es produeix un trencament homolític de l'enllaç $\mathrm{OH}$ i es genera un àtom d'hidrogen i un radical sililoxil a la superfície del material. Eventualment, si existeix aigua coabsorbida, aquest procés d'irradiació pot donar lloc a la generació de radicals hidroxil. La hipòtesi de partida ha estat que els radicals sililoxil enllaçats a la superfície poden ser capaços de generar radicals metil per abstracció d'un àtom d'hidrogen del metà o poden acoblar amb radicals metil per formar silil metil èters associats a la superfície. Aquests processos presenten una analogia amb els que se sap 
que ocorren per reacció de radicals hidroxil lliures en fase gas. Les equacions 3.1 a 3.3 resumeixen els processos fotoquímics i radicalaris que poden ser originats en la fotòlisi de longitud d'ona de l'ultraviolat llunyà.

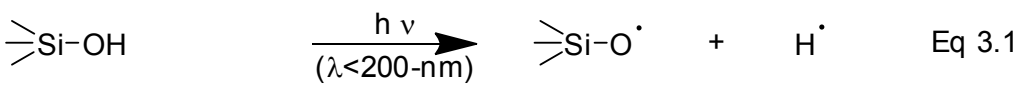

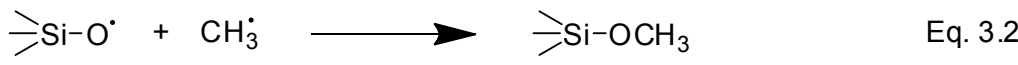

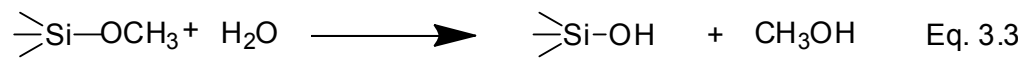

Mentre que els grups $\mathrm{OH}$ són transparents en el rang de longituds d'ona de l'ultraviolat i visible, aquests grups tenen un coeficient d'absorció elevat per les radiacions a la regió de l'ultraviolat llunyà on poden ser fotolizats, produint-se el trencament homolític de l'enllaç $\mathrm{O}-\mathrm{H}$. Aquests grups $\mathrm{OH}$ es troben presents en les superfícies de gran nombre d'òxids inorgànics. Per tant, seria possible l'activació fotoquímica dels grups $\mathrm{OH}$ superficials per irradiació amb longituds d'ona inferiors als 200 nm (ultraviolat llunyà). Precedents en la literatura han descrit que la fotòlisi directa de l'aigua per irradiació amb Ilum UV de longitud d'ona inferior a $200 \mathrm{~nm}$ genera radicals hidroxil amb un rendiment quàntic proper a la unitat. ${ }^{[28]}$ Tenint en compte aquesta alta eficiència, podem assumir que la fotòlisi dels grups silanols (Equació 3.1) hauria de passar igualment amb un alt rendiment quàntic.

En una prova experiment control preliminar per donar suport a la possibilitat de fotolizar grups silanols, es va dur a terme la irradiació amb Ilum ultraviolada llunyana una zeolita Beta, detectant la formació d'una xicoteta quantitat d'hidrogen en la fase gas. L'aparició d'hidrogen constitueix una prova experimental a favor del trencament homolític de l'enllaç $\mathrm{OH}$ dels grups silanols per fotòlisi amb radiacions de I'UV Ilunyà. 


\section{2 .2 Influència de la presència d'oxigen}

La distribució de fotoproductes i la conversió del metà depenen considerablement de la presència en el medi d'oxigen. En les condicions d'irradiació emprades en aquest estudi, la quantitat d'oxigen es troba en excés respecte al metà convertit de manera que aquest gas no és el reactiu limitant en la formació de productes.

D'acord amb les equacions 3.1 a 3.3, el paper de l'oxigen podria ser l'atrapament d'un percentatge elevat dels radicals metil primaris generats per abstracció d'hidrogen al metà per part dels radicals silanoxil a la superfície. En presència d'oxigen aquests radicals metils formarien radicals metil-peroxil, els quals donarien lloc a una sèrie de processos que condueixen a la formació de metanol i altres reactius oxigenats. La sobreoxidació del metanol donaria lloc a formaldehid i l'àcid fòrmic, hi requerisca igualment la presència d'oxigen.

Quan la fotòlisi amb llum UV Ilunyana es porta a terme en absència d'oxigen en el nostre cas, una atmosfera que conté només metà i nitrogen, s'observen tres efectes diferents. En primer lloc, el percentatge de productes presents en la fase gas després de la fotòlisi augmenta significativament respecte a la situació anàloga en què l'oxigen està present. L'anàlisi de la fase gas indica la formació d'età, propà, i altres alcans de baix pes molecular com productes predominants. Les Taules 3.1 i 3.2 recullen els resultats de la fotòlisi 
del metà amb llum UV llunyana en zeolites Beta en presència de nitrogen. Estes taules contenen els percentatges de metà inicial que ha estat convertit, de productes que es troben presents en la fase gas i la seva distribució en fase gas depenent de si la irradiació es duia a terme amb 165 o amb 185 nm.

Taula 3.1. Dades d'activitat i distribució de productes observada en la fotòlisi de metà a $165 \mathrm{~nm}$ ó $185 \mathrm{~nm}$ i temperatura ambient sobre una mostra de zeolita Beta comercial en presència de nitrogen. ${ }^{[a]}$

\begin{tabular}{|c|c|c|c|c|c|c|c|c|c|c|}
\hline \multirow[b]{2}{*}{ Temps (h) } & \multicolumn{4}{|c|}{$165 \mathrm{nnm}$} & \multicolumn{6}{|c|}{$185 \mathrm{~nm}$} \\
\hline & 1 & 2.5 & 5 & 11 & 0.083 & 0.5 & 1 & 2.5 & 5 & 11 \\
\hline Conversió total(\%) & 1.5 & 1.7 & 1.8 & 2.3 & 0.6 & 0.6 & 1.1 & 3.6 & 5 & 6.3 \\
\hline Balanç molar (\%) & $>99$ & 83 & 95 & 93 & $>99$ & $>99$ & $>99$ & $>99$ & $>99$ & 86 \\
\hline \multirow{3}{*}{$\begin{array}{l}\text { Conversió de } \mathrm{CH}_{4} \\
\text { en fase gas }{ }^{[b]}{ }^{2} \\
\text { Conversió de } \mathrm{CH}_{4} \\
\text { en la fase sòlida [c] }\end{array}$} & 0.3 & 0.3 & 0.3 & 1.1 & 0.03 & 0.3 & 1.1 & 1.3 & 1.7 & 3.1 \\
\hline & 1.2 & 1.4 & 1.5 & 1.2 & 0.58 & 0.3 & 0.54 & 2.2 & 3.1 & 3.2 \\
\hline & \multicolumn{10}{|c|}{ Productos en la fase gas ${ }^{[c]}$} \\
\hline Hidrogen & 69 & 63 & 63 & 67 & 100 & 51.4 & 56.4 & 60.7 & 69.8 & 53.8 \\
\hline $\mathrm{CO}_{2}{ }^{[\mathrm{e}]}$ & $<0.5$ & 2 & 7 & 3 & $-{ }^{[\mathrm{e}]}$ & 11 & 22.9 & 15.6 & 10.2 & 3.2 \\
\hline Metanol & ${ }_{--}^{[e]}$ & $<0.5$ & $<0.5$ & $<0.5$ & ${ }_{-}^{\left[{ }^{[}\right]}$ & $-{ }_{-}{ }^{[\mathrm{e}]}$ & $-^{[e]}$ & 0.7 & 0.4 & 5.4 \\
\hline Etanol & $-^{[\mathrm{e}]}$ & $-{ }_{-}^{[e}$ & 2 & 0.5 & $-^{[e]}$ & $-^{[\mathrm{e}]}$ & $-^{[e]}$ & 1.6 & 0.7 & 26.3 \\
\hline Età & 31 & 27 & 28 & 25 & $--^{[e]}$ & 37.5 & 17.3 & 13.8 & 13.1 & 11.1 \\
\hline
\end{tabular}

[a] Condicions d'irradiació: volum reactor $116 \mathrm{ml}$, temperatura ambient, barreja de $\mathrm{CH}_{4}\left(35 \%\right.$ vol), $\mathrm{N}_{2}$ (65\% vol).

[b] Determinat per cromatografia de gasos, emprant $\mathrm{N}_{2}$ com a patró.

[c] Determinat per anàlisi químic de combustió.

[d] Percentatge de $\mathrm{CH}_{4}$ convertit present en la fase gas.

[e] Originat per una quantitat residual d'oxigen present en el sistema.

[f] Per sota del límit de detecció. 
Taula 3.2. Dades d'activitat i distribució de productes observats en la fotòlisi de l' $\mathrm{CH}_{4}$ sobre una mostra de zeolita Beta comercial en presència d'oxígen en ser irradiats a165 $\mathrm{nm}$ o a $185 \mathrm{~nm}$ i temperatura ambient. ${ }^{[a]}$

\begin{tabular}{|c|c|c|c|c|c|c|c|}
\hline & \multicolumn{3}{|c|}{$165 \mathrm{~nm}$. } & \multicolumn{4}{|c|}{$185 \mathrm{~nm}$. } \\
\hline Temps (h) & 1 & 2.5 & 11 & 0.083 & 1 & 2.5 & 11 \\
\hline Conversió total(\%) & 1.7 & 5.4 & 5.9 & 2. & 3.95 & 2.23 & 13.0 \\
\hline Balanç molar (\%) & $>99$ & 91.0 & 91.9 & 97.6 & 75.15 & 41.4 & 36.01 \\
\hline Conversió de $\mathrm{CH}_{4}$ en fase gas ${ }^{[b]}$ & 0.1 & 2.5 & 1.7 & 0.01 & 0.2 & 0.1 & 0.8 \\
\hline $\begin{array}{c}\text { Conversió de } \mathrm{CH}_{4} \text { en la fase } \\
\text { sòlida [c] }\end{array}$ & 1.7 & 2.9 & 4.2 & 2 & 3.7 & 2.1 & 13.1 \\
\hline \multirow[t]{2}{*}{$\% \mathrm{C}$} & 0.8 & 1.1 & 1.7 & 0.87 & 1.5 & 0.8 & 4.1 \\
\hline & \multicolumn{3}{|c|}{$\begin{array}{l}\text { Productes en la fase gas } \\
(\%)[d]\end{array}$} & \multicolumn{4}{|c|}{$\begin{array}{c}\text { Productes en la fase gas } \\
(\%) \text { [d }\end{array}$} \\
\hline Hidrogen & 37.6 & 81.0 & 16.2 & 50.4 & 13.5 & 42 & 35.7 \\
\hline $\mathrm{CO}_{2}{ }^{[\mathrm{e}]}$ & -_[e] & 8.5 & 13.0 & 49.57 & 24.61 & 26.55 & 1.6 \\
\hline Metanol & -_[e] & 0.1 & 4.2 & --[e] & 57.33 & 20.76 & 2.4 \\
\hline Etanol & -_[e] & 0.0 & 1.2 & --[e] & --[e] & --[e] & -_[e] \\
\hline Età & 18.5 & 10.4 & 58.7 & --[e] & 2.25 & 10.60 & 44.8 \\
\hline
\end{tabular}

[a] Condicions d'irradiació: volum del reactor $300 \mathrm{ml}$, temperatura ambient, barreja de $\mathrm{CH}_{4}\left(25 \%\right.$ vol), $\mathrm{N}_{2}\left(55 \%\right.$ vol) $\mathrm{O}_{2}(20 \%$ vol).

[b] Determinat per cromatografia de gasos, emprant $\mathrm{N}_{2}$ com a patró.

[c] Determinat per anàlisi químic de combustió.

[d] Percentatge de $\mathrm{CH}_{4}$ convertit present en la fase gas.

[e] Originat per una xicoteta quantitat residual d'oxigen present en el sistema.

[f] Per sota del límit de detecció.

La segona diferència principal quan la irradiació es va fer en absència d'oxigen com a agent d'atrapament dels radicals metil generats durant la fotòlisi amb radiació UV Ilunyà va ser que el material sòlid continguè adsorbit hidrocarburs de baix pes molecular, com es posa de manifest mitjançant espectroscòpia $\mathrm{RMN}{ }^{13} \mathrm{C}$ en angle màgic usant $\mathrm{CH}_{4}$ marcat isotòpicament amb ${ }^{13} \mathrm{C}$ com a substrat. Com a exemple la Figura $3.1 \mathrm{i}$ la Figura 3.2 proporcionen una comparació dels espectres de $\mathrm{RMN}$ de ${ }^{13} \mathrm{C}$ en estat sòlid, registrats per a una mostra de zeolita Beta comercial que ha estat sotmesa a irradiació durant 
1h a 165 o $185 \mathrm{~nm}$, respectivament en presència de ${ }^{13} \mathrm{CH}_{4}$ i en absència o presència de $\mathrm{O}_{2}$. Alguns pics a la regió de camp alt corresponen a alcans de baix pes molecular i estan presents en els experiments duts a terme sota $\mathrm{N}_{2}$, però estan absents en la irradiació sota atmosfera d' $\mathrm{O}_{2}$. Com a resultat de la formació d'alcans de baix pes molecular, la selectivitat del metà cap a productes oxigenats d'un carboni disminueix sensiblement.

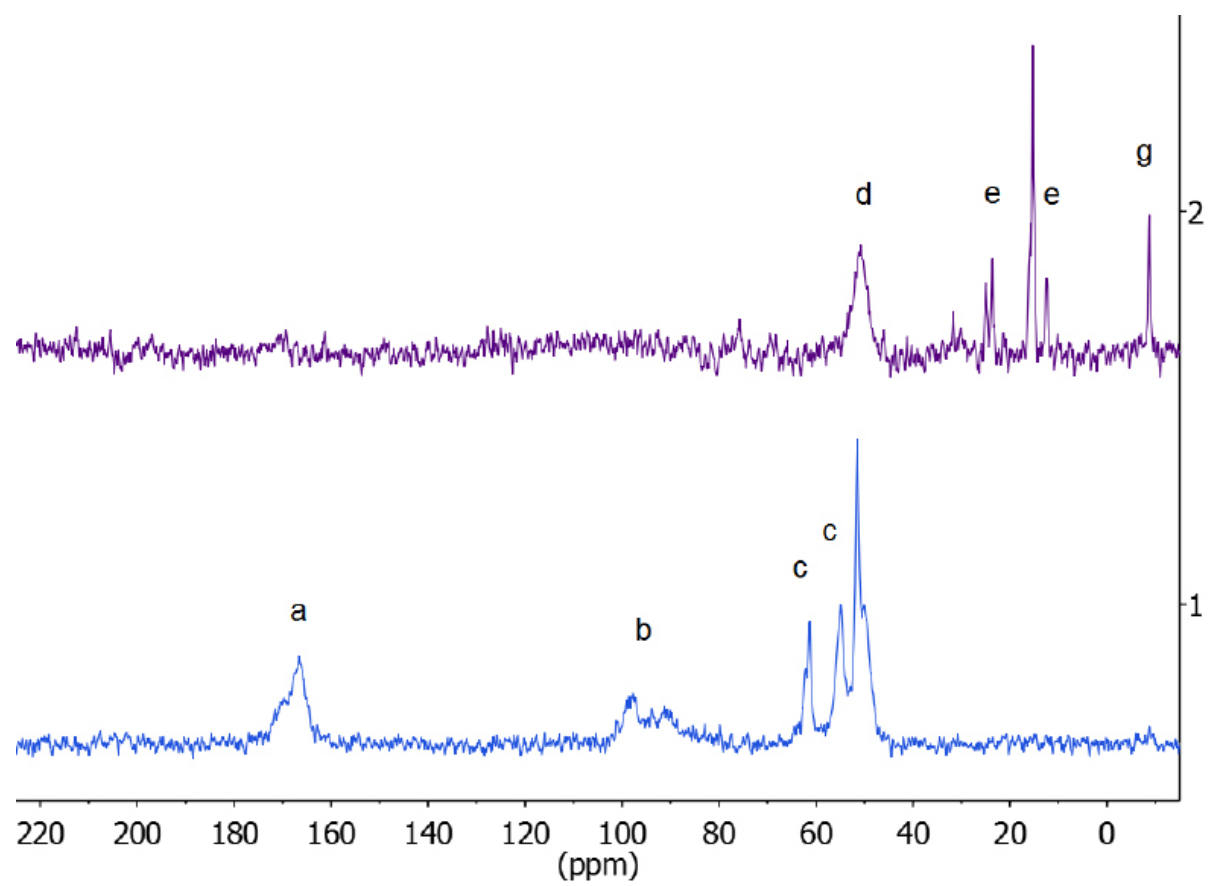

Figura 3.1. Espectre de RMN del ${ }^{13} \mathrm{C}$ en angle màgic registrat per a una zeolita Beta comercial després de ser irradiada en contacte amb metà. Condicions d'irradiació: 1) Irradiació a $165 \mathrm{~nm}$ i temperatura ambient d'una barreja de $\mathrm{CH}_{4}\left(25 \%\right.$ vol), $\mathrm{N}_{2}$ (55\% vol) i $\mathrm{O}_{2}(20 \%$ vol). 2) Irradiació a $165 \mathrm{~nm}$ i temperatura ambient d'una barreja de $\mathrm{CH}_{4}{ }^{2} \mathrm{~N}_{2}(65 \%)$ durant $1 \mathrm{~h}$. Els pics indicats amb les lletres a-g són assignats a àcid fòrmic, acetals de formaldehid, grups metoxils, metanol fisisorbid, n-butà, propà i metà, respectivament. 


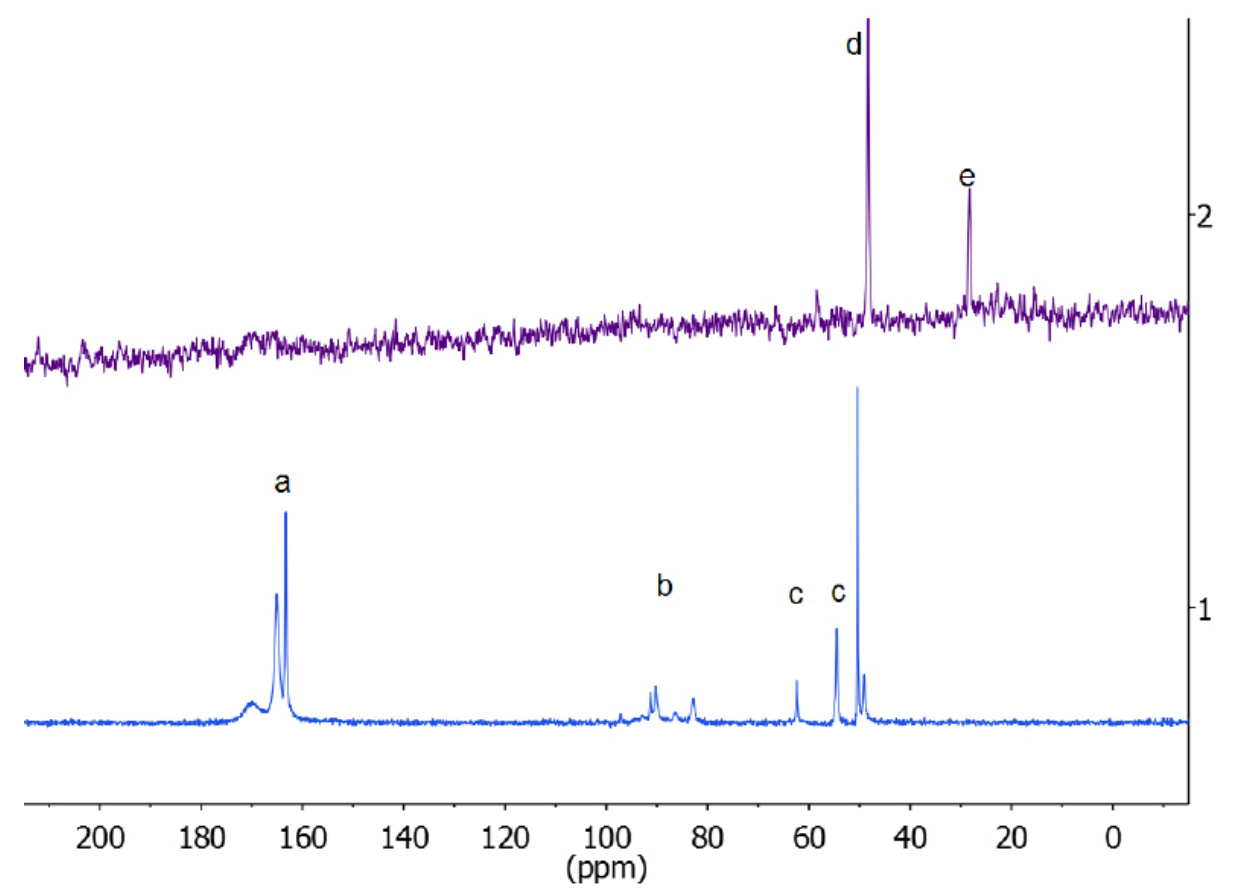

Figura 3.2. Espectre de $\mathrm{RMN}$ de ${ }^{13} \mathrm{C}$ d'angle màgic registrat per a una mostra de zeolita Beta comercial després de la seva irradiació en presència de metà marcat isotòpicament. Condicions d'irradiació: 1) Irradiació a $185 \mathrm{~nm}$ i temperatura ambient d'una barreja de ${ }^{13} \mathrm{CH}_{4}\left(25 \%\right.$ vol), $\mathrm{N}_{2}(55 \%$ vol) i $\mathrm{O}_{2}(20 \%$ vol). 2) Irradiació a $185 \mathrm{~nm}$ i temperatura ambient en una barreja de ${ }^{13} \mathrm{CH}_{4}(25 \%)$ i $\mathrm{N}_{2}(75 \%)$ durant $1 \mathrm{~h}$. Els pics marcats amb les lletres a-e són assignats a àcid fòrmic, acetals de formaldehid, grups metoxi, metanol fisisorbid i età, respectivament.

La tercera diferència important entre les irradiacions en absència o presència de $\mathrm{O}_{2}$ és la distribució dels productes oxigenats d'un carboni. En absència d'oxigen, els únics compostos oxigenats que són detectables per espectroscòpia de RMN de ${ }^{13} \mathrm{C}$ han estat metanol absorbit i metoxisilans. En particular espècies de formaldehid iàcid fòrmic, les quals s'observen a la fotòlisi en presència $d^{\prime} \mathrm{O}_{2}$, no apareixen quan la irradiació es porta a terme sota $\mathrm{N}_{2}$. Aquest resultat demostra que aquests composts o bé deriven del hidroperòxid de metil o s'originen per oxidació aeròbica del metanol i metoxisilans. Com que la formació del metanol a partir del metà, la formació de formaldehid a partir del metanol i la formació d'àcid fòrmic a partir de formaldehid redueix 
gradualment la calor de combustió i la densitat d'energia del compost, seria preferible des del punt de vista d'aplicació com a combustible poder aturar el procés en l'estat d'hidrocarburs i metanol, per tal de mantenir el màxim possible contingut energètic dels productes derivats de la transformació del metà. Des d'aquest punt de vista, la fotòlisi amb llum UV llunyana sota nitrogen podria ser avantatjosa ja que alcans de baix punt molecular poden ser fàcilment separables de la mostra de reacció.

Pel que fa a la longitud d'ona de la irradiació, encara que la selectivitat i la distribució de productes van ser molt similars en els dos casos (165 o 185 $\mathrm{nm}$ ), es va trobar que el llum de $185 \mathrm{~nm}$ era més eficient i promovia majors conversions en temps més curts i amb un consum d'energia menor que quan la fotòlisi es duia a terme emprant el sistema de $165 \mathrm{~nm}$. Els precedents en la bibliografia química han estimat que el rendiment quàntic de la ruptura homolítica de l'enllaç $\mathrm{OH}$ en aigua utilitzant fotons en la regió de l'ultraviolat profund és essencialment la unitat, i el mateix es pot assumir aquí tant per a la fotòlisi amb longitud d'ona de 165 com $185 \mathrm{~nm}$. Per tant, les diferències observades en el nostre cas per ambdues llums haurien de reflectir diferències en el disseny dels sistemes i les potències dels llums a diferències reals en rendiments quàntics. 


\section{Consum d'energia en la conversió Se Lee de $\mathrm{CH}_{4}$ per fotòlisi amb llum UV llunyana}

Atés que els processos de fotòlisi ocorren en la superfície d'un sòlid, podria ser que, a mesura que la reacció progressa, un percentatge significatiu d'aquesta superfície fóra bloquejada per atrapament de grups metil (Equació 3.3.). La conseqüència de la disminució de la població dels grups hidroxil superficials que es reflecteix en el perfil temporal de la conversió és que l'energia consumida per mol de $\mathrm{CH}_{4}$ convertit augmenta a mesura que la conversió també augmenta. Aquesta correlació és de la major activitat de la superfície del sòlid inicial, comparada amb les superfícies de sòlid que han anat augmentat gradualment la densitat de productes sobre ella.

Una alta eficiència en el procés requereix que tots els fotons que entrin en el sistema es troben amb un grup hidroxil, de manera que s'hauria de produir el trencament homolític de l'enllaç $\mathrm{OH}$ i la generació de radicals sililoxil. El procés de trecament homolític de l'enllaç $\mathrm{OH}$ es considera que en principi té un rendiment quàntic proper a la unitat, ja que aquesta és l'eficiència de la ruptura homolítica de l'enllaç $\mathrm{OH}$ de l'aigua amb Ilum UV Ilunyana. ${ }^{[27]}$

A més cal considerar que una alta població de grups hidroxil és avantatjosa pel fet que aquests poden ser convertits en grups metoxils o en metanol fisisorbid. Per tant és interessant estudiar la influència que la quantitat de zeolita present al fotorreactor exerceix sobre la conversió del 
metà i el consum d'energia. Aquest estudi assumeix que un augment en el pes de zeolita emprada en la irradiació és proporcional a un augment en la població de grups hidroxil superficials exposats a la llum UV fins arribar a un valor màxim. D’acord amb aquestes hipòtesis la Figura 3.3 mostra un gràfic de la conversió del metà i el consum d'energia per mol de metà convertit en funció de la massa de zeolita Beta present al fotoreactor.

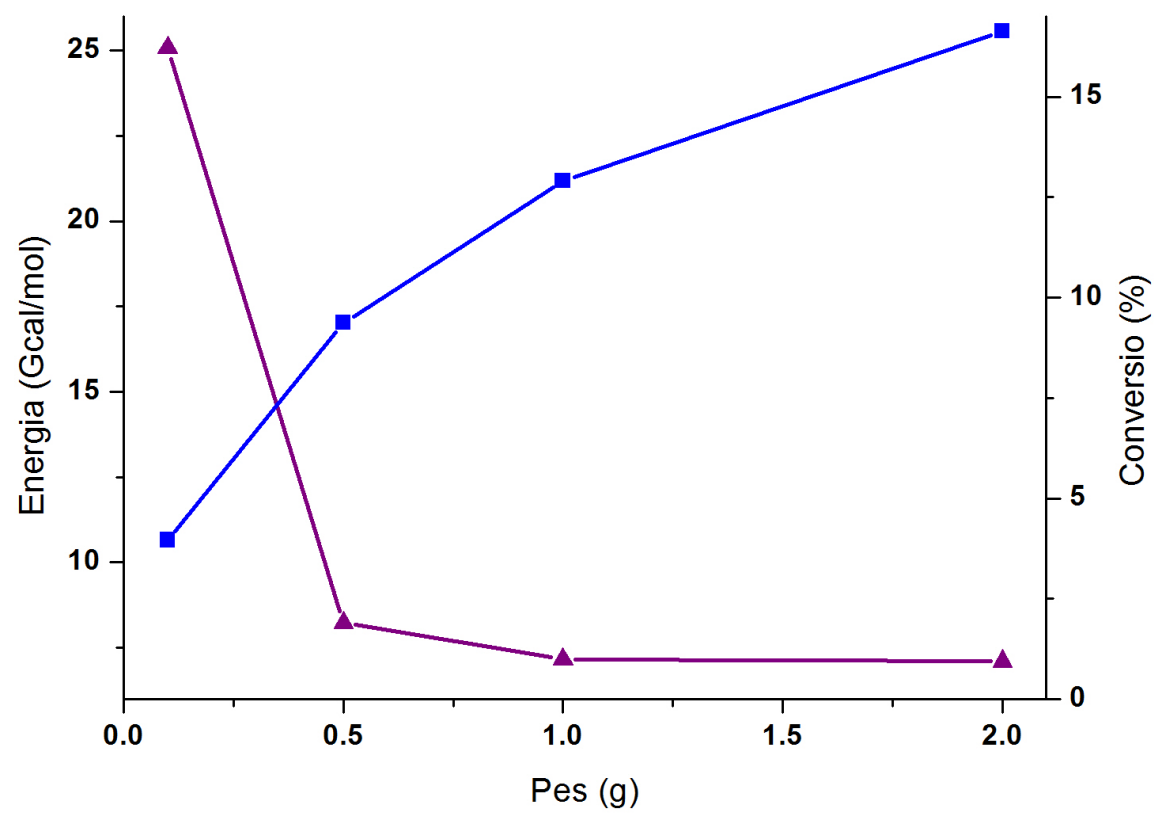

Figura 3.3. Gràfics de la influència del pes de la zeolita comercial Beta sobre la conversió del $\mathrm{CH}_{4}$ i sobre l'energia consumida per mol de metà consumit. Les condicions d'irradiació varen ser: longitud d'ona $185 \mathrm{~nm}$, volum del reactor $300 \mathrm{ml}$, temperatura ambient, barreja inicial $\mathrm{CH}_{4}(25 \%$ vol $), \mathrm{O}_{2}(20 \% \mathrm{vol})$ i $\mathrm{N}_{2}$ (55\% vol) durant $1 \mathrm{~h}$.

Com es pot veure a la Figura 3.3, per al mateix rang de massa estudiat entre 0.1 i $2 \mathrm{~g}$ per un temps d'irradiació costant d'1h, la conversió de metà augmenta notablement, fins a 4 vegades, a mesura que la massa de zeolita augmenta. Es va aconseguir una conversió màxima a $1 \mathrm{~h}$ del $16.5 \%$ quan es 
van utilitzar $2 \mathrm{~g}$ de zeolita Beta. La influència positiva de la quantitat de sòlid es reflecteix igualment en la disminució de l'energia consumida per mol de $\mathrm{CH}_{4}$ convertit, que es redueix a menys de la meitat quan la quantitat de zeolita emprada va ser superior a $1 \mathrm{~g}$. A la Taula 3.3 es poden veure les dades obtingudes per a la variació del la massa estudiada a un temps d'irradiació de 5 minuts. De les dades presentades en la Taula 3.3 cal destacar que es poden aconseguir conversions superiors al 13\% en només $1 \mathrm{~h}$ d'irradiació emprant la llum de $185 \mathrm{~nm}$ amb selectivitats cap a productes oxigenats superiors al $99 \%$.

Taula 3.3 Conversió del metà i altres dades catalítics en funció de la quantitat de zeolita Beta 811 comercial emprada com a catalitzador en la fotòlisi a temperatura ambient amb llum de $185 \mathrm{~nm}$ del metà en presència d' $\mathrm{O}_{2}(20 \%$ volum $)$, mesurats als 5 min d'irradiació. ${ }^{[a]}$

\begin{tabular}{ccccc}
\hline Massa fotocatalizador $(\mathrm{g})$ & 0.1 & 1 & 2 & $1^{[\mathrm{c}]}$ \\
\hline Conversió total (\%) $^{[\mathrm{b}]}$ & 1.8 & 3.9 & 6.20 & 13 \\
& \multicolumn{4}{c}{$\begin{array}{c}\text { Productes en la fase gas (\%) } \\
\text { (menys que l'1\% total) }\end{array}$} \\
\cline { 2 - 5 } $\mathrm{C}_{2}$ & -- & -- & -- & 32.15 \\
$\mathrm{H}_{2}$ & 100 & 100 & 100 & 53.12 \\
$\mathrm{CH}_{3} \mathrm{OH}$ & -- & -- & -- & -- \\
& Productes en la fase sòlida (\%) \\
& \multicolumn{4}{c}{ (al voltant del 99\% del total) } \\
\cline { 2 - 5 } Àcid fòrmic & 23.9 & 25.4 & 17.7 & 36 \\
Formaldehid & 25.8 & 24.3 & 25.8 & 22.5 \\
Metanol & 50.2 & 50.3 & 56.5 & 40.5 \\
\hline
\end{tabular}

[a] Condicions d'irradiació: volum reactor $300 \mathrm{ml}$, longitud d'ona $185 \mathrm{~nm}$, temperatura ambient, barreja de $\mathrm{CH}_{4}\left(25 \%\right.$ vol), $\mathrm{N}_{2}(55 \%$ vol) i $\mathrm{O}_{2}(20 \%$ vol).

[b] Balanç molar superior al $90 \%$

[c] Després d'irradiar $1 \mathrm{~h}$. 


\section{2 .4 Naturalesa del sòlid inorgànic}

Per tal de demostrar la possibilitat de dur a terme la funcionalització del metà per fotòlisi amb llum Ultraviolada a la zona llunyana d'un sòlid es va estudiar el comportament de sis zeolites seleccionades en una atmosfera que contenia metà. La sèrie de zeolites triades inclouen dues estructures diferents, una amb mida de porus mitjà i una altra amb una mida de porus gran, contenint o no alumini en la xarxa cristal-lina i on es va variar la població de grups silanols interns. A efectes de comparació es va triar com a material de referència una sílice amorfa no porosa.

Es va avaluar l'activitat i selectivitat d'aquests materials en la funcionalització del metà mitjançant el procés fotoquímic, per donar lloc a compostos oxigenats d'un carboni. Les característiques de les diferents zeolites utilitzades en aquesta primera part de l'estudi es mostren a la Taula 3.4. Les mostres de zeolita Beta en aquesta Taula 3.4 es denoten indicant la presència o absència d'alumini en el reticle cristal.lí i la naturalesa de l'agent de mineralització. ${ }^{[29]}$ Convé indicar que la zeolita Beta amb mida de porus gran constituït per 12 àtoms d'oxigen ha estat sintetitzada utilitzant dos agents mineralitzants diferents, com ara $\mathrm{l}^{\prime} \mathrm{OH}^{-}$i el $\mathrm{F}^{-}$. La zeolita Beta sintetitzada en mig $\mathrm{F}^{-}$és considerablement més cristal-lina que la sintetitzada utilitzant hidròxid com a agent mineralitzant. Aquesta major cristal-linitat és en un menor nombre de grups hidroxil superficials, tal com es dedueix de 
la comparació dels espectres de $\mathrm{RMN}^{29} \mathrm{Si}$ en estat sòlid (Figura 3.4) de les dues mostres. Un segon tipus de grups hidroxil diferents dels silanols són els hidroxil àcids ponts del tipus $\equiv \mathrm{Al}(\mathrm{OH}) \mathrm{Si} \equiv$ que estan igualment presents en la mostra de zeolita Beta sintetitzada en $\mathrm{mig} \mathrm{OH}^{-}$, en posseir aquesta $\mathrm{Al}^{+3} \mathrm{en}$ posicions de xarxa (veure Figura 3.5). Amb els materials indicats a la Taula 3.5 es pot discutir el paper que la porositat i la mida de la cavitat, el nombre de centres actius (població de grups hidroxil) així com l'impacte que els diferents tipus d'OH (grups silanols $\mathrm{OH}$ àcids ponts) juguen en l'activitat i selectivitat dels fotocatalitzadors per a la transformació del metà per irradiació amb llum de longituds d'ona a la zona d'ultarviolat llunyà.

Experiments control demostren que en absència de qualsevol sòlid el metà no pateix cap conversió quan aquest alcà s'irradia amb llum Ultraviolada llunyana en una càmera saturada amb vapor d'aigua.

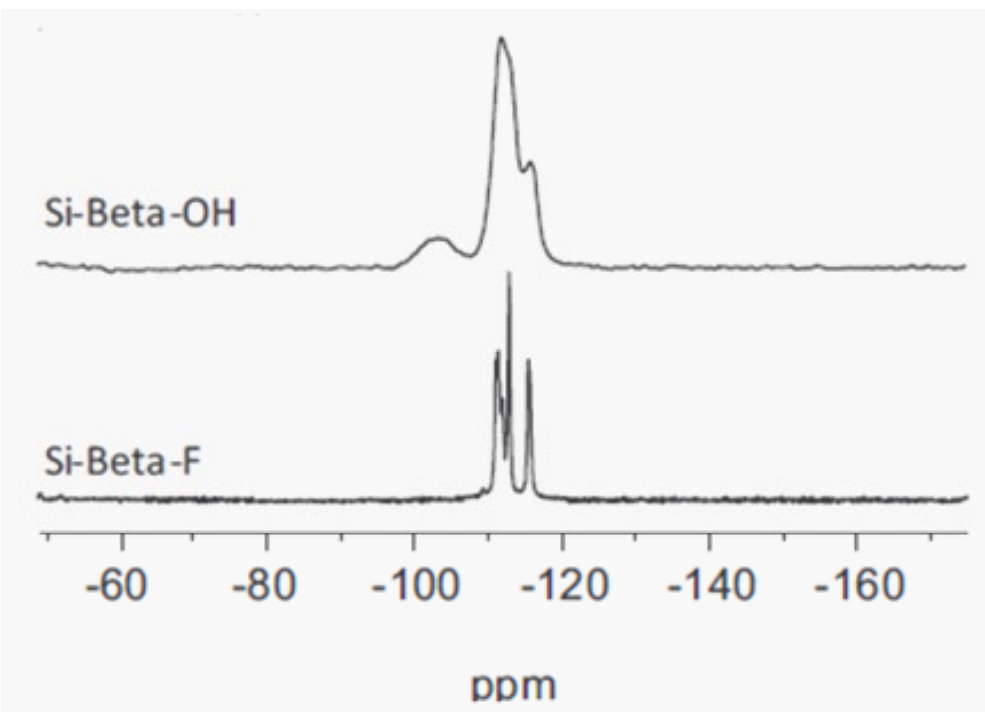

Figura 3.4. Espectre de RMN ${ }^{29} \mathrm{Si}$ corresponent a les zeolites Si-beta-OH i Sibeta-F. L'estudi sobre la influència de la naturalesa del sòlid en la conversió del $\mathrm{CH}_{4}$ amb llum UV Ilunyana es va ampliar a altres zeolites i aluminosilicats. 


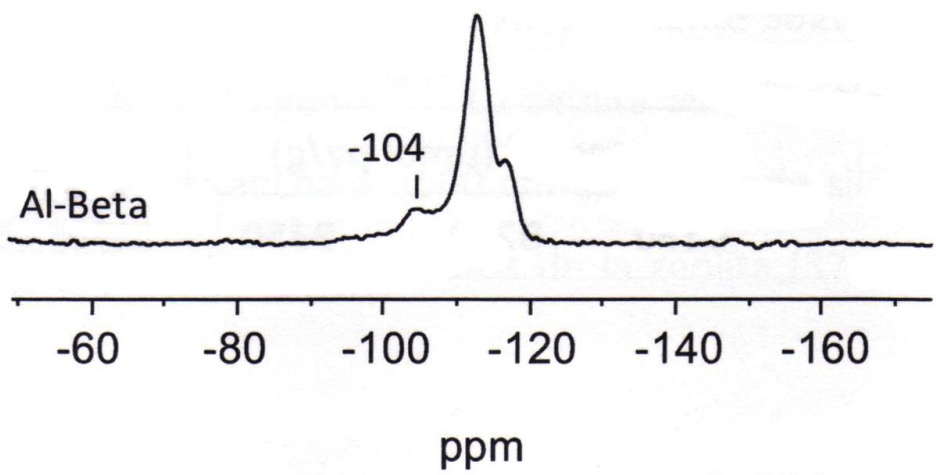

Figura 3.5. Espectre de $\mathrm{RMN}{ }^{29} \mathrm{Si}$ corresponent a la zeolita Al-beta. L'estudi sobre la influència de la naturalesa del sòlid en la conversió del $\mathrm{CH}_{4}$ amb llum UV Ilunyana es va ampliar a altres zeolites i aluminosilicats.

Taula 3.4 Dades analítiques i propietats texturals de les zeolites i la sílice emprades en aquest capítol.

\begin{tabular}{cccccc}
\hline Zeolita & Si/Al & $\begin{array}{c}\text { Grandària } \\
\text { de porus }(\AA)\end{array}$ & $\begin{array}{c}\text { Àrea } \\
\text { superficial } \\
\left(\mathrm{m}^{2} / \mathrm{g}\right)\end{array}$ & $\begin{array}{c}\text { Volum de } \\
\text { porus } \\
\left(\mathrm{cm}^{3} / \mathrm{g}\right)\end{array}$ & $\begin{array}{c}\text { Població } \\
\text { de grups } \\
\text { silanols }^{[\mathrm{a}]}\end{array}$ \\
\hline Silica & $\infty$ & $\begin{array}{c}\text { Sense } \\
\text { microporus }\end{array}$ & -- & 100 \\
Silicalite & $\infty$ & $5.5 \times 5.1$ & 386 & 0.20 & 10 \\
Beta (Si,F) & $\infty$ & 481 & 0.22 & 20 \\
Beta (Al, F) & 22 & & 503 & 0.23 & 22 \\
Beta (Si,OH) & $\infty$ & $7.1 \times 6.6$ & 490 & 0.22 & 33 \\
Beta (Al, OH) & 22 & & 540 & 0.24 & 30 \\
Beta & 12.5 & & 607 & 0.17 & 31 \\
comercial & & & & & \\
\hline
\end{tabular}

[a] Població relativa dels grups silanos 
Quan experiments anàlegs tenen lloc en presència de zeolites, tant en absència com en presència d'oxigen, la formació d'alcans lleugers i hidrogen en la fase gas és detectable. La diferència entre la irradiació en presència d'oxigen respecte a la que es porta a terme en absència d'aquest gas és la reducció del percentatge d'hidrocarburs lleugers, amb el consegüent augment en el percentatge de formació de metanol i compostos oxigenats C1 d'un carboni que té lloc quan la irradiació es fa en presència d'oxigen.

A més dels productes que s'observen en la fase gas, una quantitat important de fotoproductes es troben igualment presents adsorbits en el sòlid, la quantitat de productes en la fase gas freqüentment és molt baixa comparatda amb la matèria orgànica absorbida en el sòlid. La Taula 3.4 resumeix les dades texturals determinades en la fotòlisi amb llum ultraviolada llunyana.

La quantitat total de matèria orgànica adsorbida en el catalitzador després de la irradiació en presència d'oxigen es va determinar mitjançant anàlisi elemental de combustió. La naturalesa dels fotoproductes adsorbits a la fase sòlida es va estudiar mitjançant espectroscòpia de $\mathrm{RMN}{ }^{13} \mathrm{C}$ en estat sòlid utilitzant $\mathrm{CH}_{4}{ }^{13} \mathrm{C}$ com a substrat. Un exemple representatiu de la sèrie d'espectres de $\mathrm{RMN}{ }^{13} \mathrm{C}$ registrats per als sòlids després de la seva irradiació en presència d'oxigen es mostra a la Figura 3.6. Com es pot observar a la figura, en presència d'oxigen, els espectres de $\mathrm{RMN}{ }^{13} \mathrm{C}$ presenten senyals corresponents a metanol fisisorbid (48 ppm) grups metoxi (54, 58 ppm) així com el dimetil acetal del formaldehid (97-99 ppm) i àcid fòrmic (168-175 ppm). La presència de metanol adsorbit i grups metoxisilil dóna suport a la proposta mecanística basada en les equacions 3.1 i 3.2. És digne de destacar que els espectres de RMN de ${ }^{13} \mathrm{C}$ en presència d'oxigen revelen l'absència d'età i alcans lleugers adsorbits en el sòlid.

Espectroscòpia de $\mathrm{RMN}^{13} \mathrm{C}$ de correlació heteronuclear bidimensional 2D confirma que els pics entre 167 i 169 ppm assignats a àcid fòrmic no estan associats a cap grup metil. D’altra banda, el fet que els pics al voltant 
de 55 ppm correspoguen a grups metil, es confirmà registrant els espectres de $\mathrm{RMN}{ }^{13} \mathrm{C}$ propers a la zona de resonància en els protons i observant el desdoblament d'aquestes senyals en quartets causa del acoblament residual amb tres protons. Així mateix l'espectroscòpia de $\mathrm{RMN}{ }^{13} \mathrm{C}$ prova clarament que en presència d'oxigen la selectivitat cap a metanol $i$ altres compostos oxigenats està al voltant $99 \%$ per conversions de metà al voltant del $10 \%$. Aquest valor de selectivitat és destacable i no té precedent en la bibliografia química. D'acord amb la formació de compostos oxigenats, el percentatge d'oxigen en fase gas disminueix gradualment des del valor inicial del $8 \%$ al $6 \%$ final, indicant que un percentatge d'oxigen ha estat consumit durant la irradiació.

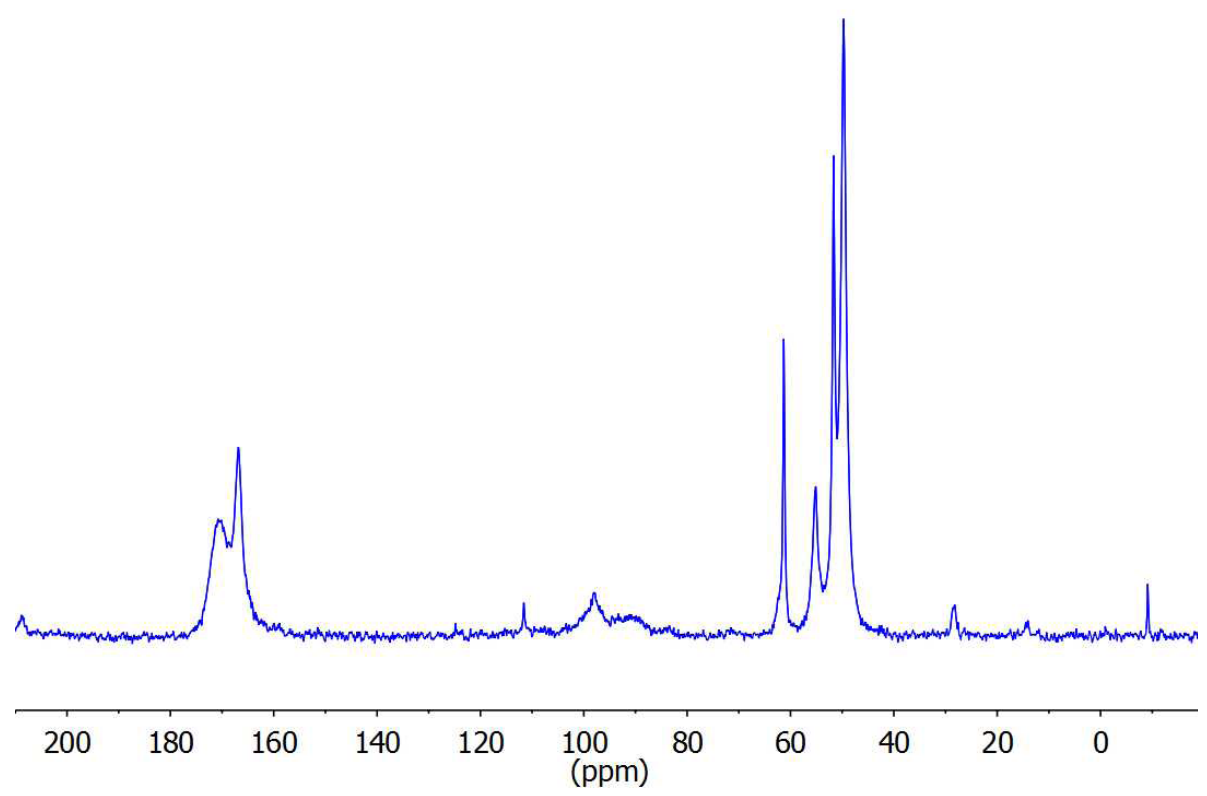

Figura 3.6. Espectre de $\mathrm{RMN}{ }^{13} \mathrm{C}$ registrat en estat sòlid mitjançant gir amb angle màgic per la zeolita Beta(Al, F) després de ser irradiada durant $1 \mathrm{~h}$ amb Ilum de $165 \mathrm{~nm}$ a temperatura ambient en presència de ${ }^{13} \mathrm{CH}_{4}(25 \%$ vol), $\mathrm{N}_{2}\left(55 \%\right.$ vol) i d'O $\mathrm{O}_{2}(20 \%$ vol $)$. 
L'avantatge d'utilitzar sòlids microporosos com són les zeolites davant d'altres sòlids que no tenen porositat es dedueix clarament de la comparació dels resultats aconseguits en la fotòlisi en presència de sílice, on s'observa una conversió menor, tot i que la quantitat de grups silanols és molt més gran en aquesta sílice amorfa. Pel que fa a la influència de la composició de la zeolita i la presència d'alumini a la xarxa a la selectivitat, l'espectroscòpia de $\mathrm{RMN}^{13} \mathrm{C}$ indica que la presència d'alumini a la xarxa afavoreix la sobreoxidació del metanol a formaldehid i àcid fòrmic, mentre que zeolites purament sílice exhibeixen una major selectivitat cap al metanol per valors de conversió de metà similars.

D'acord amb el mecanisme de reacció proposat a les equacions 3.1 a 3.3, sembla que el major nombre de grups silanols interns en els porus de la zeolita afavoreix una major activitat del material per a la transformació del metà en les condicions d'irradiació. Aquesta conclusió es pot deduir dels resultats mostrats a la Taula 3.5, on la conversió del metà segueix l'ordre zeolita Beta $(\mathrm{Si}, \mathrm{OH})<$ Beta $(\mathrm{Al}, \mathrm{OH})<\operatorname{Beta}(\mathrm{Al}, \mathrm{F})<\operatorname{Beta}(\mathrm{Si}, \mathrm{F})$. Aquest ordre està d'acord amb la densitat relativa de grups silanols interns en la mostra. Per tant, podem concloure que, pel que fa al catalitzador sòlid, materials microporosos semblen els més adequats produint conversions majors que la sílice amorfa. Entre les zeolites com més gran és el nombre de grups silanols interns, major és l'activitat catalítica. D’acord amb aquesta tendència, la conversió del metà podria ser incrementada, augmentant la relació zeolita/ $\mathrm{CH}_{4}$ fins a un punt en el qual tots els fotons que entren a la cambra d'irradiació siguin absorbits per la zeolita.

Un punt digne de ser estudiat va ser determinar la influència que la quantitat d'aigua co-adsorbida pot tenir en la distribució de productes formats en la fotòlisi del metà per llum ultraviolada llunyana sobre zeolites. Atés que les zeolites en general, adsorbeixen major quantitat d'aigua quan més gran és el nombre de grups silanols, vam dur a terme la irradiació amb mostres de zeolites Beta ( $\mathrm{Si}, \mathrm{OH}$ ) hidratades en equilibri amb l'ambient. Per tal de discutir la influència de l'aigua co-adsorbida es van fer experiments 
Taula 3.5. Dades d'activitat i distribució de productes observats després de 5 minuts de fotòlisi a temperatura ambient amb llum de $185 \mathrm{~nm}$ d'una barreja de $\mathrm{CH}_{4}(25 \%$ vol $) \mathrm{O}_{2}(20 \% \mathrm{vol})$ i $\mathrm{N}_{2}(55 \%$ vol). en presència de silicats.

\begin{tabular}{cccccccc}
\hline Sòlid & $\begin{array}{c}\text { Silica } \\
\text { gel }\end{array}$ & Silicalita & $\begin{array}{c}\text { Beta } \\
\text { (Si F) }\end{array}$ & $\begin{array}{c}\text { Beta } \\
\text { (Al F) }\end{array}$ & $\begin{array}{c}\text { Beta } \\
\text { (Si OH) }\end{array}$ & $\begin{array}{c}\text { Beta } \\
\text { (Al OH) }\end{array}$ & $\begin{array}{c}\text { Sense } \\
\text { catalitzador }\end{array}$ \\
\hline $\begin{array}{c}\text { Conversió } \\
\text { total (\%) }\end{array}$ & 0.50 & 0.85 & 0.86 & 1.63 & 2.01 & 1.66 & $0.49^{[b]}$ \\
$\begin{array}{c}\text { Percentatge a } \\
\text { la fase sòlida }\end{array}$ & 82 & 91 & 99 & $>99$ & $>99$ & 98 & 0 \\
& & \multicolumn{7}{c}{ Productes en la fase gas (\%) } \\
$\mathrm{C}_{2}$ & 54.2 & 53.3 & -- & -- & -- & 84.2 & 73.5 \\
$\mathrm{H}_{2}$ & 29.1 & 8.9 & 20.7 & 100 & 100 & 15.8 & 3.8 \\
$\mathrm{CH}_{3} \mathrm{OH}$ & -- & 37.8 & 79.3 & -- & -- & -- & 5.1 \\
& & \multicolumn{7}{c}{ Productes en la fase sòlida (\%) } & \\
Àcid fòrmic & 19.6 & 15.9 & 23.8 & 25.8 & 21.2 & 16.4 & 23.9 \\
Formaldehid & 28.3 & 37.6 & 25.5 & 24.4 & 30.8 & 28.7 & 25.8 \\
Metanol & 52.1 & 46.5 & 50.7 & 49.8 & 48.0 & 54.9 & 50.3 \\
\hline
\end{tabular}

[a] La quantitat inicial de metà en aquests experiments fou de 3.7 milimols.

[b] Balanç molar del 85\%.

paral·lels en els quals vam emprar la zeolita Beta $(\mathrm{Si}, \mathrm{OH})$ en la seva forma hidratada o després de la seva deshidratació tèrmica.

Encara que vam observar alguna variació en la proporció de productes adsorbits a la zeolita, els resultats que obtenirem permeten concloure que el contingut d'aigua en la zeolita en els nivells en què es va estudiar no és rellevant en la conversió del metà. Per al càlcul del TOF hem suposat un valor mig de grups hidroxils als nostres materials de $0.2 \mathrm{mmol} / \mathrm{gram}$ material. Amb aquest valor, per a la zeolita Beta $(\mathrm{Si} \mathrm{OH})$, obtenim un valor de TOF de $17.9 \mathrm{~s}^{-1}$.

En la majoria d'experiments duts a terme en presència d'oxigen, els fotoproductes adsorbits en el catalitzador sòlid corresponien a més del $99 \%$ del metà transformat. L'anàlisi elemental de combustió s'utilitzà per a determinar el contingut en carboni de les oblees de zeolita i mostrà que el 
contingut de carboni varia igualment depenent de l'estructura de la zeolita, la longitud d'ona d'irradiació i del temps d'exposició a la llum UV Ilunyana. A més vam trobar que la conversió de metà augmenta amb la quantitat de fotocatalitzador present al fotoreactor. Els experiments de control consistents en la irradiació del $\mathrm{CH}_{4}$ en presència d'una atmosfera d' $\mathrm{O}_{2}$ saturada amb humitat a $185 \mathrm{~nm}$ mostren conversions no significatives, reforçant d'aquesta manera la hipòtesi que els grups silanols són els responsables de promoure la conversió del metà.

Altres materials que han estat investigats per a demostrar l'aplicabilitat de la reacció es mostresn a la Taula 3.6, al mateix temps que proporciona informació analítica i textural útil dels mateixos. La Taula 3.4 resumeix igualment els resultats aconseguits en la fotòlisi del metà per a cada un dels sòlids estudiats. En aquesta llista addicional s'incloula ZSM-5 de porus mitjà amb diverses relacions Si-Al. La zeolita ZSM-5 és una zeolita amb porus de 10 membres el sistema de microporus està definit per dos tipus de canals independents que es creuen perpendicularment I'un a l'altre. ${ }^{[30]}$ Un tipus de canals té una forma oval de dimensions 5.4×5.6 $\AA^{2} \mathrm{i}$ transcorren al llarg de l'eix $z$ del cristall. El segon sistema de canals està constituït per porus circulars al voltant $5.6 \AA$ de diàmetre que canvien de direcció amb cada encreuament amb els canals perpendiculars definint una trajectòria en ziga-zaga. Comparat amb la zeolita Beta, la zeolita ZSM-5 posseeix menors dimensions de microporus, tot i que encara són de suficient grandària, com per absorbir metà $\mathrm{i}$ els seus derivats. Les menors dimensions dels canals podrien, d'altra banda, ser responsables d'un major efecte de confinament del procés radicalari en cadena. 
Taula 3.6. Dades d'activitat i distribució de productes per a zeolites i materials mesoporosos o laminars mesurats després de 5 minuts d'irradiació en presència de $\mathrm{CH}_{4}(25 \%$ vol $) \mathrm{O}_{2}\left(20 \%\right.$ vol) i $\mathrm{N}_{2}(55 \%$ vol $)$. Les reaccions es van dur a terme amb llum de $185 \mathrm{~nm}$.

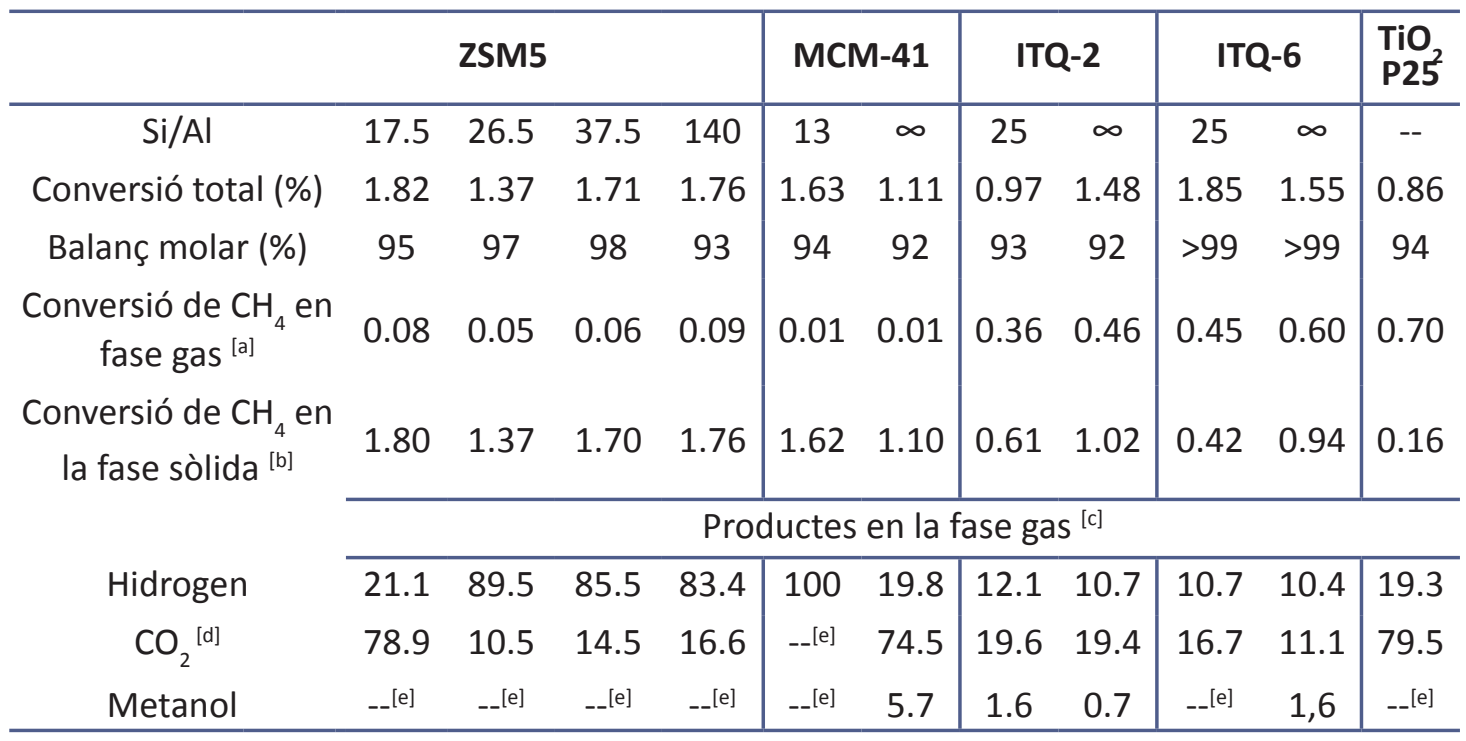

[a] Determinat per cromatografia de gasos utilitzant $\mathrm{N}_{2}$ com a referència.

[b] Determinat mitjançant anàlisi elemental de combustió.

[c] Percentatge respecte al $\mathrm{CH}_{4}$ convertit en fase gas.

[d] A causa de la presència d'una quantitat residual $d^{\prime} \mathrm{O}_{2}$.

[e] Per sota del límit de detecció.

A més de la zeolita ZSM-5 es van assajar materials zeolítics laminars, com ara la ITQ- $2^{[31]}$ i la ITQ-6, ${ }^{[32,31]}$ les quals exhibeixen una elevada àrea superficial, principalment externa i una baixa microporositat, pel que haurien d'exhibir un baix efecte de confinament.

Una situació intermèdia pel que fa a les dimensions de la cavitat de reacció hauria de tenir lloc en aluminosilicats mesoporosos del tipus MCM-41. L'estructura porosa del material MCM-41 està composta d'una sèrie de canals paral-lels al voltant a $3.8 \mathrm{~nm}$ de diàmetre. Les dues mostres de MCM-41 aquí assajades difereixen en la presència o absència d'Al a la xarxa. El material MCM-41 té una alta població de grups silanols, però a 
causa de les majors dimensions de porus pel que fa a zeolites ha d'exhibir una baixa restricció a la mobilitat dels radicals implicats en la reacció. La llista de materials assajats inclou igualment una mostra de $\mathrm{TiO}_{2}$ comercial (P25) que no conté micro o mesoporus i que posseeix un àrea superficial molt menor que la resta de materials. $\mathrm{El} \mathrm{TiO}_{2}$ P25 és un dels fotocatalitzadors més àmpliament usats i se sap que per irradiació amb longituds d'ona menors de $400 \mathrm{~nm}$ en presència d' $\mathrm{O}_{2}$ pot donar lloc a l'oxidació d'un gran nombre de compostos orgànics. D'acord amb el paper proposat per als grups hidroxil superficials i la baixa àrea superficial del $\mathrm{TiO}_{2} \mathrm{P} 25$, la conversió de $\mathrm{CH}_{4}$ sobre aquest semiconductor va ser la més baixa de totes les mostres avaluades i els baixos percentatges de conversió corresponen gairebé completament a productes presents a la fase gas, sent menyspreable la presència de compostos orgànics en el sòlid. Una situació intermèdia va ser observada per als sòlids ITQ-2 i ITQ-6 provinents de la deslaminació de precursors zeolítics, per als quals els productes en la fase gas i aquells que estaven adsorbits sobre el sòlid contribueixen en percentatges similars.

Aquests resultats són compatibles amb l'anomenat efecte de confinament en microporus, el qual és responsable d'augmentar la selectivitat de fotoproductes a les reaccions fotocatalítiques a l'interior de microporus que fa a les reaccions anàlogues dutes a terme en fase gas. Les dades experimentals mostren que la naturalesa del sòlid no només influeix en la proporció de productes en fase gas sinó també en la distribució. És interessant destacar que en el cas de la fotòlisi en presència de $\mathrm{TiO}_{2} \mathrm{P} 25$, el principal component en fase gas va ser el $\mathrm{CO}_{2}$. Una situació oposada es va observar en el cas de la zeolita ZSM-5 tant amb relació SI/AI 37.5 com 140 per a les quals el percentatge de productes en fase gas va ser baix, sent el $\mathrm{H}_{2}$ el principal component en aquesta fase. En general vam observar que quan l'atmosfera inicial té oxigen, a igualtat de nivell de conversió, la presència d'Al en la zeolita augmenta la reacció d'oxidació del metanol a formaldehid i àcid fòrmic. La Figura 3.7 mostra alguns espectres de $\mathrm{RMN}{ }^{13} \mathrm{C}$ en estat sòlid representatius d'aquesta oxidació. 


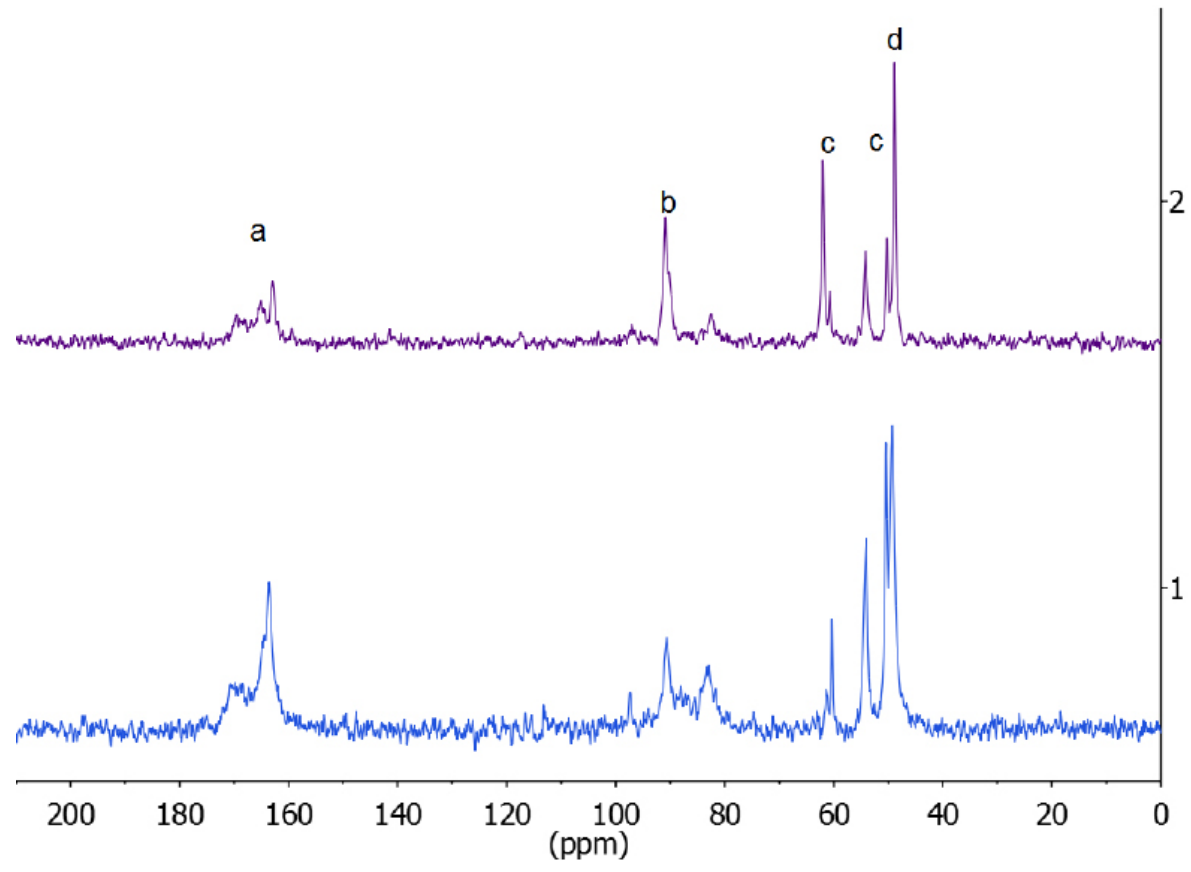

Figura 3.7. Espectres de RMN ${ }^{13} \mathrm{C}$ en estat sòlid registrat per a 1) zeolita ZSM-5 (Si/Al 37.5) i 2) zeolita deslaminada ITQ-2. Condicions d'irradiació: Llum 185 $\mathrm{nm}$ a temperatura ambient d'una barreja de $\mathrm{CH}_{4}(25 \%$ vol $), \mathrm{N}_{2}\left(55 \%\right.$ vol) i $\mathrm{O}_{2}$ $(20 \% \mathrm{vol})$ durant 5 minuts. Els pics indicats com a-d corresponen a àcid fòrmic, formaldehid, grups metoxils, metanol fisisorbid, respectivament.

Un punt a considerar en futurs estudis és la possibilitat de que traces de metalls de transició presents en les zeolites comercials puguen jugar un paper en el mecanisme de reacció. S'ha descrit que totes les zeolites comercials contenen quantitats detectables de $\mathrm{Fe}$ i $\mathrm{Cu}$. Aquests metalls presents a nivells d'impureses juguen un paper determinant en l'oxidació $d^{\prime} \mathrm{H}_{2} \mathrm{O}_{2}{ }^{[33]}$ Es molt possible que també al nostre cas les zeolites continguen aquests $\mathrm{i}$ altres metalls, ja que son molt abundants i estan àmpliament distribuïts a nivell de traces. Aquests metalls poden participar com centres generadors de radicals influint al procés fotoquímic. 
És conegut que sòlids que contenen ions $\mathrm{Fe}^{2+}, \mathrm{Mn}^{+}, \mathrm{Cu}^{2+}, \mathrm{Ag}^{+}, \mathrm{i}$ altres metalls son capaços de descomposar peròxids $\mathrm{i}_{2} \mathrm{O}_{2}$ formant productes d'oxidació que depenent de les condicions deriven de la generació de radicals hidroxils o oxometalls. ${ }^{[34]}$ En el nostre cas es bastant probable que, en les condicions d'irradiació amb longituds d'ona d'UV Ilunyana i en presència d'oxigen es gènere una quantitat estacionària $d^{\prime} \mathrm{H}_{2} \mathrm{O}_{2}$, hidroperòxids i peròxids orgànics. Aquesta quantitat ha de ser baixa, ja que igual que l'aigua en forma de vapor pateix fotocatàlisi també la patirien els peròxids o hidroperòxids descomposant-se alhora que es formen, podent arribar a una concentració estacionària baixa. Anàlisi de la fase gas mitjançant el mètode colorimètric basat en $\mathrm{TiO}^{2+}$ en medi àcid mesurat a $400 \mathrm{~nm}$ no detecta la formació de cap espècie. Per altra banda la quantitat de metalls de transició que pot haver en els materials emprats és també baixa. No obstant, seria necessari realitzar estudis addicionals per a poder aprofundir en el paper que els peròxids o impureses metàl-liques poden jugar en la reacció. 


\section{Cicle en dues etapes}

\section{2 .5$.}

Basats en la caracterització dels productes de reacció és possible dissenyar un cicle en dues etapes consistent en: (a) irradiació del metà sobre zeolita per formar espècies oxigenades, i (b) desorció d'aquests compostos oxigenats formats en la fotòlisi i regeneració del sòlid. Per tal d'aportar dades sobre la possibilitat d'operació d'un procés en dues etapes com el proposat, la zeolita Beta $(\mathrm{Si}, \mathrm{OH})$ va ser sotmesa a 2 cicles; cada un d'ells implicava la fotòlisi en atmosfera de metà/aire, seguida d'un rentat del sòlid amb aigua, per eliminar els fotoproductes adsorbits. Un resum dels espectres de $\mathrm{RMN}{ }^{13} \mathrm{C}$ en estat sòlid registrats en aquesta sèrie de tres experiments consecutius d'irradiació/desorció es mostren a la Figura 3.8. Com es pot veure en aquesta figura, la fase aquosa provinent dels rentats de la zeolita Beta ( $\mathrm{Al}, \mathrm{OH}$ ) clarament conté metanol, formol i àcid fòrmic (espectres b y e, a la Figura 3.8), mentre que els sòlids resultants de l'extracció es troben gairebé lliures de compostos orgànics (espectres c i f, a la Figura 3.8). A més, aquests experiments també indiquen que la zeolita pot ser reutilitzada sense que s'observen canvis significatius en el comportament del material. 


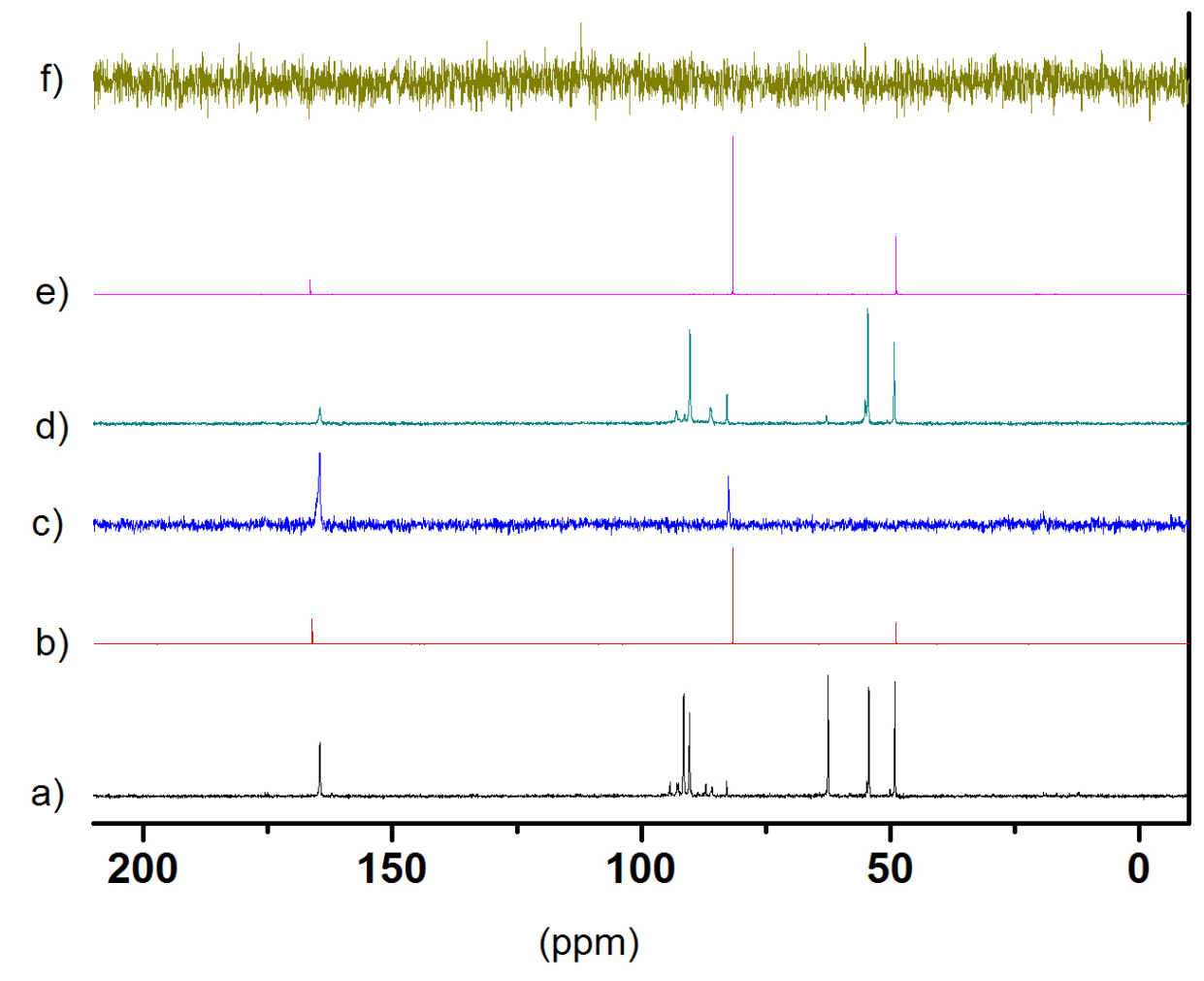

Figura 3.8. Espectres de $\mathrm{RMN}{ }^{13} \mathrm{C}$ registrats a temperatura ambient per: (a) zeolita Beta $(\mathrm{Si}, \mathrm{OH})$ després $11 \mathrm{~h}$ d'irradiació a $165 \mathrm{~nm}$ en contacte amb una atmosfera de ${ }^{13} \mathrm{CH}_{4}$ contenint $8 \%$ en volum $\mathrm{d}^{\prime} \mathrm{O}_{2}$; (b) espectre de la dissolució aquosa provinent de la desorció de productes presents a la zeolita per tractament a $150^{\circ} \mathrm{C}$ durant $1.5 \mathrm{~h}$; (c) zeolita beta $(\mathrm{Si}, \mathrm{OH})$ després de ser fotolitzada i haver estat sotmesa a extracció amb aigua a $150{ }^{\circ} \mathrm{C}$ durant $1.5 \mathrm{~h}$; (d) zeolita Beta $(\mathrm{Si}, \mathrm{OH})$ després d'una segona fotòlisi durant $11 \mathrm{~h}$ a $165 \mathrm{~nm}$ en presència de metà contenint $8 \%$ en volum $\mathrm{d}^{\prime} \mathrm{O}_{2} ;(\mathrm{e})$ espectre de l'aigua utilitzada en la desorció fotoproductos presents en la zeolita després de la irradiació mitjançant tractament a $150^{\circ} \mathrm{C}$ durant $1.5 \mathrm{~h}$; i (f) zeolita Beta ( $\left.\mathrm{Si}, \mathrm{OH}\right)$ després de la segona desorció amb aigua. 
Pel que fa al mecanisme de transformació del metà proposem que la irradiació amb llum de longitud d'ona a la zona de I'UV llunyà hauria de produir la ruptura homolítica dels grups silanols en radicals sililoxil i un àtom d'hidrogen, tal com s'ha descrit en la literatura per a la ruptura de l'aigua en fase vapor. ${ }^{[28]}$ Aquests radicals sililoxil generarien radicals metil a partir del metà tal com és conegut que ocorre en la química radicalària en fase gas, en reaccionar els radicals hidroxil amb metà. Depenent de la presència $o$ absència d'oxigen, aquests radicals metil evolucionarien donant lloc a espècies oxigenades o hidrocarburs, respectivament. La selectivitat observada sorgiria com a conseqüència que la reacció té lloc sobre una superfície sòlida i en un espai confinat que hauria de restringir la mobilitat dels radicals intermedis, els quals estarien fonamentalment enllaçats a la superfície del sòlid. El contacte de les zeolites la humitat regeneraria els hidroxils superficials mitjançant la hidròlisi de grups alcòxids i altres tipus de sililèters. 
Com s'ha comentat anteriorment, la presència d'aigua no influeix significativament en la selectivitat, almenys en el rang de conversions i en les condicions assajades en aquest estudi. En contrast, la presència d'oxigen és crucial per atrapar els radicals metil i evitar la formació d'hidrocarburs. L’Esquema 3.1 resumeix la nostra proposta mecanística.

Esquema 3.1. Mecanisme proposat per a la conversió de metà sobre la superfície sílice mitjançant irradiació amb llum Ultraviolada de la zona llunyana.

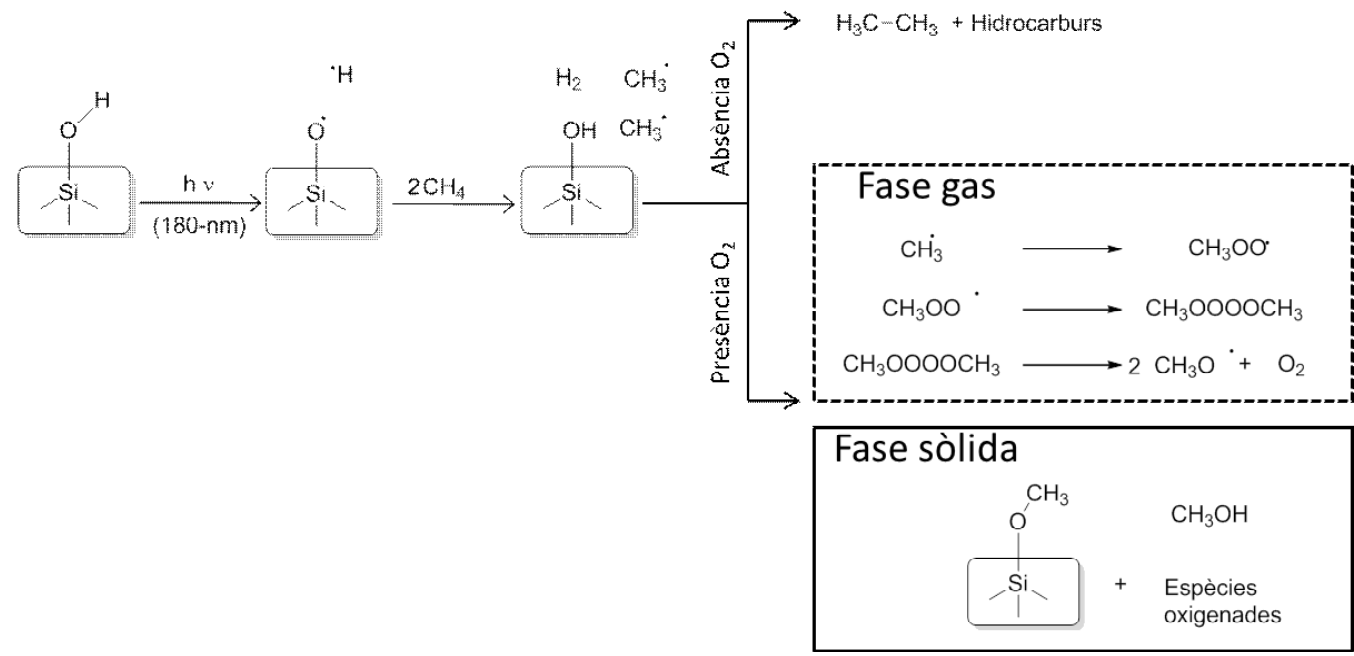




\section{Consum d'energia}

\section{2 .7}

Una primera estimació de l'energia requerida per l'activació de metà a temperatura ambient basada en la fotòlisi amb llum UV de la zona llunyana sobre un suport sòlid ha estat realitzada determinant el consum d'energia de la llum necessari per assolir una certa conversió de metà. Els resultats indiquen que, mentre la transformació d'un mol de metà mitjançant el procés industrial conegut com "syn gas" requereix aproximadament $15.9 \mathrm{Gcal}^{*} \mathrm{~mol}^{-1}{ }^{[27]}$ per assolir un $13 \%$ de conversió de metà emprant un llum de $185 \mathrm{~nm}$ (60 min d'irradiació), l'energia consumida és de $7.16 \mathrm{Gcal}^{*} \mathrm{~mol}^{-1}$. 



\section{Conclusions}

Utilitzant metà marcat $a m b{ }^{13} \mathrm{C}$ i determinant la distribució de productes mitjançant espectroscòpia $\mathrm{RMN}{ }^{13} \mathrm{C}$ en estat sòlid, hem demostrat que la fotòlisi amb Ilum UV Ilunyana del metà sobre zeolites Beta contenint grups silanols interns permet la transformació selectiva del metà a temperatura ambient en compostos oxigenats un àtom de carboni. Quan es troba present una petita quantitat d'oxigen, la selectivitat conjunta del metà cap a productes oxigenats d'un carboni, és a dir, metanol, formaldehid i àcid fòrmic, és superior al 95\%. La naturalesa de la zeolita juga un paper en la conversió i selectivitat ja que és el material més apropiat d'entre els que s'han estudiat la zeolita Beta pura sílice preparada enmig d'hidròxid, la qual maximitza la densitat de grups silanols a l'interior dels microporus. D'altra banda hem observat que la presència d'aigua co-adsorbida no altera la conversió o la distribució de productes en les condicions experimentals assajades. El consum d'energia estimat en el procés per a la conversió d'una mol de metà és al voltant de la meitat que l'energia requerida per a la conversió del metà, per al procés de reformat al vapor.

La irradiació amb llum UV profunda de superfícies sòlides en presència de $\mathrm{CH}_{4}$ condueix a la formació de radicals metil, els quals poden ser atrapats sobre la superfície d'un sòlid o poden acoblar-se per formar alcans de baix pes molecular. La presència d' $\mathrm{O}_{2}$ en el sistema augmenta considerablement 
la selectivitat cap a compostos oxigenats d'un àtom de $\mathrm{C}$ i redueix significativament la proporció d'età i altres alcans en fase gas. L'eficiència del sòlid per promoure aquest procés i el percentatge de compostos oxigenats d'un àtom de $C$ requereix porositat adequada al material. El material més adequat de la sèrie estudiada ha resultat ser una zeolita ZSM-5 contenint una alta relació Si/Al. Per contra, sòlids no porosos (en particular $\mathrm{TiO}_{2}$ P25) donen proporcions molts majors de productes, en la fase gas dels quals el $\mathrm{CO}_{2}$ pot arribar a ser el component predominant. Pel que fa a l'eficiència energètica, hem trobat que quantitats elevades de fotocatalitzador augmenten significativament la conversió i, d'acord amb això, redueixen el consum d'energia per mol de $\mathrm{CH}_{4}$ convertit. Aquest efecte és la conseqüència de la necessitat d'una elevada població de grups $\mathrm{OH}$ superficials, que són els cromòfors que resulten ser activats per llum UV Ilunyana. D’aquesta manera s'han aconseguit conversions de $\mathrm{CH}_{4}$ a compostos oxigenats d'un carboni al voltant del $17 \%$, irradiant a $185 \mathrm{~nm}$ durant $1 \mathrm{~h}$ sobre zeolita Beta. Aquests resultats són d'interès en el context d'activació del metà a temperatures baixes i en condicions suaus. 


\section{Referències}

1. Ashcroft, A.T., A.K. Cheetham, M.L.H. Green, and P.D.F. Vernon. "Partial oxidation of methane to synthesis gas-using carbon dioxide", Nature, 1991. 352: p. 225-226.

2. Lunsford, J.H. "Catalytic conversion of methane to more useful chemicals and fuels: a challenge for the $21^{\text {st }}$ century", Catalysis Today, 2000. 63: p. 165-174.

3. Wang, H. and Z.M. Liu. "Progress in direct conversion of methane", Progress in Chemistry, 2004. 16: p. 593-602.

4. Wang, S.B., G.Q.M. Lu, and G.J. Millar. "Carbon dioxide reforming of methane to produce synthesis gas over metal-supported catalysts: State of the art", Energy \& Fuels, 1996. 10: p. 896-904.

5. Armor, J.N."The multiple roles for catalysis in the production of $\mathrm{H}_{2}$ ", Applied Catalysis a-General, 1999. 176: p. 159-176.

6. Fierro, J.L.G."Catalysis in C1 Chemistry future and prospect", Catalysis Letters, 1993. 22: p. 67-91.

7. Hu, Y.H. and E. Ruckenstein, Catalytic conversion of methane to synthesis gas by partial oxidation and $\mathrm{CO}_{2}$ reforming, in Advances in Catalysis, Vol 482004. p. 297-345.

8. Pena, M.A., J.P. Gomez, and J.L.G. Fierro."New catalytic routes for syngas and hydrogen production", Applied Catalysis a-General, 1996. 144: p. 7-57.

9. Rostrup-Nielsen, J.R., J. Sehested, and J.K. Norskov, Hydrogen and synthesis gas by steam- and $\mathrm{CO}_{2}$ reforming, in Advances in Catalysis, Vol 472002. p. 65-139. 
10. Tsang, S.C., J.B. Claridge, and M.L.H. Green."Recent advances in the converion of methane to synthesis gas", Catalysis Today, 1995. 23: p. 3-15.

11. Vanhook, J.P. "Methane steam reforming", Catalysis Reviews-Science and Engineering, 1980. 21: p. 1-51.

12. Otsuka, K. and Y. Wang."Direct conversion of methane into oxygenates", Applied Catalysis a-General, 2001. 222: p. 145-161.

13. Schwarz, H. "Activation of methane", Angewandte Chemie, 1991. 30: p. 820-821.

14. Xu, Y.D. and L.W. Lin. "Recent advances in methane dehydroaromatization over transition metal ion-modified zeolite catalysts under non-oxidative conditions", Applied Catalysis a-General, 1999. 188: p. 53-67.

15. Amenomiya, Y., V.I. Birss, M. Goledzinowski, et al. "Conversion of methane by oxidative coupling", Catalysis Reviews-Science and Engineering, 1990. 32: p. 163-227.

16. Guisnet, M., N.S. Gnep, and F. Alario."Aromatization of short chain alkanes on zeolite catalysts", Applied Catalysis a-General, 1992. 89: p. 1-30.

17. Keller, G.E. and M.M. Bhasin."Synthesis of ethylene via oxidative coupling of methane. Determination of active catalysts", Journal of Catalysis, 1982. 73: p. 9-19.

18. Lee, J.S. and S.T. Oyama. "Oxidative coupling of methane to higher hydrocarbons", Catalysis Reviews-Science and Engineering, 1988. 30: p. 249-280.

19. Foster, N.R."Direct catalytic-oxidation fo methane to methanol. A review", Applied Catalysis, 1985. 19: p. 1-11.

20. Gesser, H.D., N.R. Hunter, and C.B. Prakash."The direct conversion of methane to methanol by controlled oxidation", Chemical Reviews, 1985. 85: p. 235-244.

21. Choudhary, T.V., E. Aksoylu, and D.W. Goodman."Nonoxidative activation of methane", Catalysis Reviews-Science and Engineering, 2003. 45: p. 151-203.

22. Ismagilov, Z.R., E.V. Matus, and L.T. Tsikoza."Direct conversion of methane on Mo/ZSM-5 catalysts to produce benzene and hydrogen: achievements and perspectives", Energy \& Environmental Science, 2008. 1: p. 526-541. 
23. Basch, H., K. Mogi, D.G. Musaev, and K. Morokuma."Mechanism of the Methane to Methanol Conversion Reaction Catalyzed by Methane Monooxygenase: A Density Functional Study", J. Am. Chem. Soc., 1999. 121: p. 7249-7256.

24. Fontecave, M. and J.L. Pierre."Activation and toxicity of oxygen. 2. Iron and hydrogen peroxide: Biochemical aspects", Bull. Soc. Chim. Fr., 1993. 130: p. 77-85.

25. Paczesniak, T. and A. Sobkowiak."The influence of solvent on the reaction between iron(II), (III) and hydrogen peroxide", J. Mol. Catal. A: Chem., 2003. 194: p. 1-11.

26. Yoshizawa, K., Y. Shiota, T. Yumura, and T. Yamabe."Direct MethaneMethanol and Benzene-Phenol Conversions on Fe-ZSM-5 Zeolite: Theoretical Predictions on the Reaction Pathways and Energetics", J. Phys. Chem. B, 2000. 104: p. 734-740.

27. E, W., D. Phylipsen, Einstein D, and M. D, LBNL-44314, Editor 2000.

28. Getoff, N. and G.O. Schenk."Primary products of Iliquid water photolysis at 1236, 1470 and 1849 amstrong", Photochem. Photobiol., 1968. 8: p. 167-178.

29. Camblor, M.A., A. Corma, and S. Valencia."Synthesis in fluoride media and characterisation of aluminosilicate zeolite beta", Journal of Materials Chemistry, 1998. 8: p. 2137-2145.

30. Meier, W.M., D.H. Olson, and C. Baerlocher."Atlas of Zeolite Structure Types", Zeolites, 1996. 17: p. 1-229.

31. Corma, A., V. Fornes, J.M. Guil, et al."Preparation, characterisation and catalytic activity of ITQ-2, a delaminated zeolite", Microporous and Mesoporous Materials, 2000. 38: p. 301-309.

32. Corma, A., U. Diaz, M.E. Domine, and V. Fornes."New aluminosilicate and titanosilicate delaminated materials active for acid catalysis, and oxidation reactions using $\mathrm{H}_{2} \mathrm{O}_{2}$ ", Journal of the American Chemical Society, 2000. 122: p. 2804-2809.

33. C. Hammond, M. M. Forde, M. H. Ab Rahim, et al. "Direct Catalytic Conversion of Methane to Methanol in an Aqueous Medium by using Copper-promoted Fe-ZSM-5", Angewandte Chemie, 2012. 58: p. 51295133

34. Hammond, C., Jenkins, R. L., Dimitratos, N, et al. "Catalytic and mechanistic insights of the low temperature selective oxidation of methane over Cu-promoted Fe-ZSM-5", J. Chem-Eur J 2012, 18, 15735-15745. 



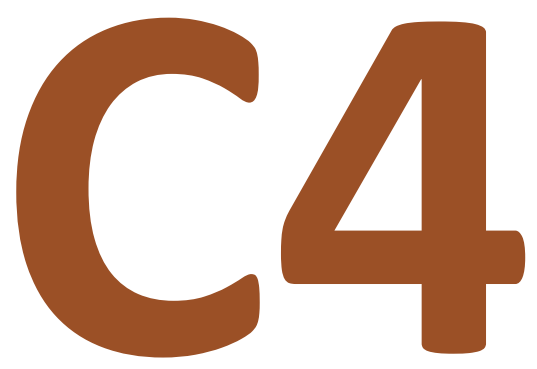

Activació fotocatalítica de l'età sobre superfícies de sílice mitjançant llum ultraviolada a la zona profunda 

L'activació de metà, età i alcans lleugers encara constitueix un repte per a la química del segle XXI a causa de la baixa reactivitat d'aquests compostos $^{[1-5]}$. A més, la conversió selectiva de metà i età cap derivats líquids és un tema de gran impacte econòmic ja que aquests alcans són els principals components del gas natural i molt freqüentment els jaciments d'aquest combustible fòssil es troben en àrees geogràfiques remotes, per la qual cosa és necessari el seu transport fins als llocs on és consumit o processat. Processos tecnològicament simples per a la conversió d'aquests dos alcans en derivats líquids a temperatura i pressió ambient serien d'un gran interés pel seu impacte en el sector de l'energia. Aquesta transformació en derivats líquids simplificaria notablement el transport de gas natural, minimitzant riscos i reduint costos.

Hi ha diferents estratègies per a la transformació d'aquests hidrocarburs, incloent l'acoblament oxidatiu de metà a alquens, l'aromatització i la conversió directa d'aquests alcans en alcohols. ${ }^{[6-15]}$ No obstant això, la majoria d'aquests processos presenten com a limitació un elevat consum d'energia i no existeixen encara catalitzadors eficients per dur-los a terme. 
En el capítol anterior hem mostrat com el metà pot ser convertit en metanol amb una selectivitat de més del $95 \%$ a un nivell de conversió de metà del $13 \%$, consumint una energia estimada de $7.2 \mathrm{Gcal}^{*} \mathrm{~mol}^{-1} \cdot{ }^{116,17]} \mathrm{El}$ procés descrit en aquest capítol consisteix igualment en la irradiació amb longituds d'ona a la regió de l'UV llunyà $(\lambda<200 \mathrm{~nm})$ de superfícies amb una elevada densitat de grups hidroxil per l'activació de l'età. $S$ 'ha proposat que aquesta irradiació a la superfície del sòlid genera radicals sililoxil per la ruptura homolítica dels enllaços $\mathrm{OH}$ i que aquests radicals oxil són capaços d'abstraure hidrogen de l'età generant radicals etil. En presència d'oxigen aquests radicals etils són atrapats i convertits en radicals etil peròxid, que eventualment donarien Iloc a etanol $i$ a altres espècies oxidades de dos carbonis. La selectivitat en aquest procés oxidatiu deriva que el procés té lloc sobre una superfície d'un sòlid o a l'interior dels espais confinats de zeolites i altres sòlids microporosos. Aquests microporus per una banda proporcionen una alta població de grups hidroxil i per un altre proporcionen una cavitat de reacció que limita l'espai que experimenten els radicals lliures, per la qual cosa desfavoreixen les etapes d'acoblament radicalari i afavoreixen l'atrapament

Esquema 4.1. Mecanisme proposat per a la transformació d'età a temperatura ambient per irradiació amb llum UV Ilunyana de superfícies de sílice.
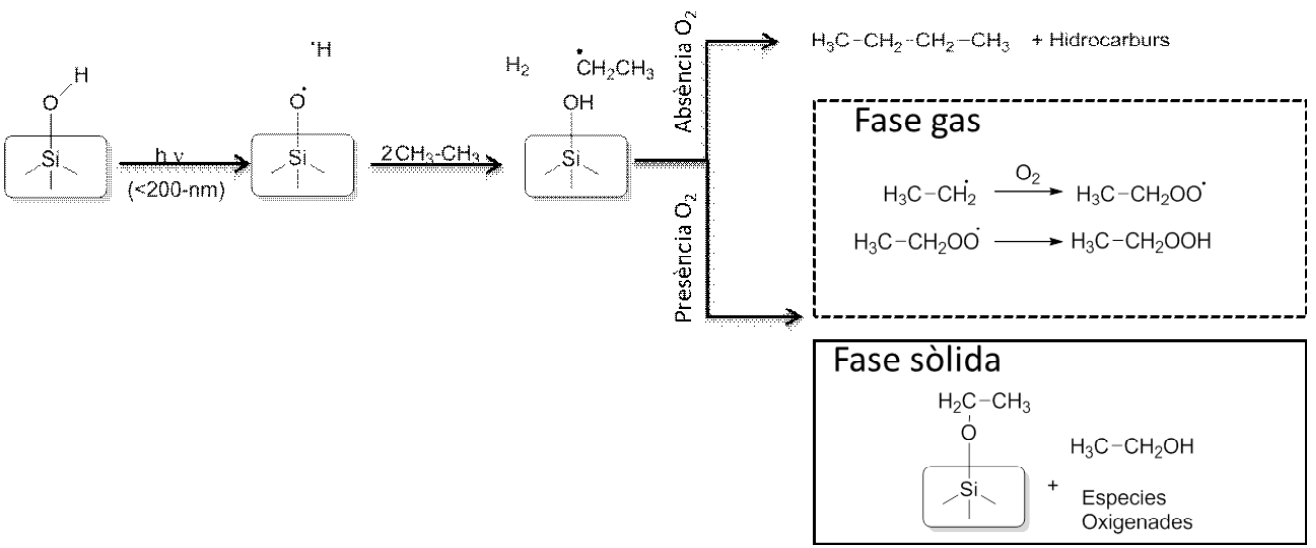
d'aquests radicals primaris per la superfície o per l'oxigen present en el medi. L'Esquema 4.1 resumeix els processos que han estat proposats per a l'activació de l'età a temperatura baixa per irradiació amb llum UV Ilunyana de superfícies sòlides.

Continuant amb aquesta metodologia, en el present capítol descrivim la conversió età en etanol, alcans lleugers i compostos oxigenats d'un i dos carbonis mitjançant la irradiació amb longituds d'ona curtes de sòlids que estan en contacte amb una atmosfera que conté età, o età i oxigen. Aquest capítol suggereix que el procediment descrit per a l'età pot servir igualment per a promoure la transformació d'alcans lleugers i altres hidrocarburs a temperatura ambient. 



\section{Resultats $i$ discussió}

Atesa la disponibilitat de làmpades de deuteri i de mercuri que emeten de forma quasi monocromàtica de 165 i $185 \mathrm{~nm}$, respectivament, es van dur a terme experiments preliminars per comparar l'eficiència relativa d'aquestes dues fonts d'irradiació en l'activació del età. La fotòlisi amb llum UV Ilunyana de la superfície de sílice converteix l'età en contacte amb aquesta superfície en mescles d'etanol, alcans lleugers (particularment, quan l' $\mathrm{O}_{2}$ està absent) i compostos oxigenats d'un i dos $\mathrm{C}$ (particularment quan l' $\mathrm{O}_{2}$ està present en el mitjà), i n'aconsegueix una distribució de productes a igualtat de conversió similar per a ambdues llums. No obstant això a causa de la diferència en potència entre ambdues fonts, a la diferència en les longituds d'ona i l'energia d'emissió, vam observar que l'eficiència en la conversió età i el consum d'energia és diferent depenent del llum d'irradiació. Aquest estudi preliminar es va dur a terme utilitzant una mostra de zeolita Beta comercial (Si/AI 11) com a promotor. Vam establir que la llum de mercuri era la font d'excitació més adequada i amb que s'aconsegueix una major conversió i, a partir d'aquest moment, els assaigs següents es van dur a terme amb aquest llum.

Tenint en compte la naturalesa del sistema on dues fases (gas i sòlid) estan presents, el balanç de masses i la determinació de la distribució de productes requereix analitzar ambdues fases sòlida i gasosa. Les anàlisis de la fase gas es van dur a terme mitjançant cromatografia de gasos mentre 
que l'estudi de la distribució de productes en el sòlid va ser dut a terme inicialment usant età doblement marcat $\mathrm{amb}{ }^{13} \mathrm{C}$ de la màxima qualitat disponible comercialment i determinant la composició de la matèria orgànica en el sòlid mitjançant espectroscòpia de $\mathrm{RMN}{ }^{13} \mathrm{C}$ en estat sòlid. Vam observar diferències significatives depenent que la irradiació es duguéra a terme en absència o presència d' $\mathrm{d}_{2}$ al fotoreactor. Els resultats obtinguts usant una mostra de zeolita Beta comercial es resumeixen en les Taules 4.1 i 4.2, on s'indica la conversió total de l'età, el percentatge del mateix que roman adsorbit a la fase sòlida després de la reacció i la distribució de productes en fase gas, tant per les irradiacions tant a $165 \mathrm{~nm}$ com a $185 \mathrm{~nm}$.

Taula 4.1. Dades d'activitat i distribució de productes observats en la fotòlisi a temperatura ambient amb llum UV Ilunyana de l'età sobre zeolita Beta comercial en absència d' $\mathrm{O}_{2}$. La composició inicial de la fase gas va ser 82 i $18 \%$ de nitrogen i età, respectivament.

\begin{tabular}{|c|c|c|c|c|c|c|c|c|c|c|c|}
\hline & \multicolumn{6}{|c|}{$165 \mathrm{~nm}$} & \multicolumn{5}{|c|}{$185 \mathrm{~nm}$} \\
\hline Temp & 0.08 & 0.5 & 1 & 5 & 14 & 0.08 & 0.5 & 1 & 2.5 & 5 & 14 \\
\hline $\begin{array}{r}\text { Convers } \\
(\%)\end{array}$ & 0 & 0.6 & 3.2 & 3.3 & 7.5 & $\perp$ & 3.9 & 4.5 & 7.2 & 10.2 & 28.4 \\
\hline \multirow{2}{*}{$\begin{array}{l}\text { Percentatge de } \\
\text { la conversió total } \\
\text { en el sòlid }\end{array}$} & 99.6 & 96.0 & 98.9 & 95.8 & 97.1 & 99.1 & 99.4 & 95.6 & 96.6 & 96.5 & 96.7 \\
\hline & \multicolumn{11}{|c|}{ Productes observats en la fase gas (\%) ${ }^{[b]}$} \\
\hline $\mathrm{H}$ & 100 & 2.7 & 3.8 & 3.1 & 1.6 & 54.3 & 56.6 & 39.5 & 65.6 & 66.2 & 83.2 \\
\hline $\mathrm{CO}_{2}$ & $--[c]$ & 7.3 & 9.5 & 1.1 & .8 & 45.7 & 43.4 & 7.3 & 6.2 & 10.2 & 1.5 \\
\hline $\mathrm{CO}^{2}$ & ${ }_{--}^{-[c]}$ & $-{ }_{-}^{-[c]}$ & ${ }_{-[-[c]}$ & $--^{[c]}$ & ${ }_{-[-[c]}$ & $-[-[c]$ & $-_{-[c]}$ & -_-[c] $^{-[c}$ & $-[-[c]$ & 3.1 & 2.0 \\
\hline Metà & $-{ }_{--}^{[c]}$ & ${ }_{-}^{-}[c]$ & --[c] $^{-[c]}$ & 8.2 & 3.8 & $-[-[c]$ & $-_{-[c]}$ & ${ }_{-[-[c]}$ & $-[$-[c] & $-{ }_{--[c]}$ & 4.3 \\
\hline & --_cc] & $-{ }_{-}^{-[c]}$ & 6.7 & 7.4 & 6.5 & -_[c] & -_[c] $^{[}$ & 23.7 & 3.4 & 2.7 & 1.9 \\
\hline Butá & -_[c] & ${ }_{-}^{-}[c]$ & ${ }_{-}^{-[c]}$ & 1.3 & 11.3 & -_[c] & ${ }_{-}[c]$ & 6.5 & 24.8 & 17.8 & 7.1 \\
\hline
\end{tabular}

[a] Percentatge de les mols d'età inicials que han desaparegut en el temps indicat. Els balanços molars van ser superiors al $95 \%$.

[b] Dades que corresponen a un percentatge menut respecte a la conversió total ja que quasi tot l'età convertit roman adsorbit en el sòlid.

[c] Per sota del límit de detecció. 
Taula 4.2. Dades d'activitat i distribució de productes observats en la fotòlisi a temperatura ambient amb llum UV Ilunyana del età sobre una mostra de zeolita Beta comercial en presència d' $\mathrm{O}_{2}$. La composició inicial de la fase gas va ser $78,18,12 \%$ de $\mathrm{N}_{2} \mathrm{C}_{2} \mathrm{H}_{6} \mathrm{i} \mathrm{O}_{2}$ respectivament.

\begin{tabular}{|c|c|c|c|c|c|c|c|c|c|c|}
\hline & \multicolumn{4}{|c|}{$165 \mathrm{~nm}$} & \multicolumn{6}{|c|}{$185 \mathrm{~nm}$} \\
\hline Temps (h) & 0.08 & 0.5 & 2.5 & 14 & 0.08 & 0.5 & 1 & 2.5 & 14 & $14^{[\mathrm{d}]}$ \\
\hline $\begin{array}{c}\text { Conversió total } \\
(\%)^{[a]}\end{array}$ & 2.1 & 3.5 & 9.8 & 17.6 & 6.0 & 13.4 & 13.9 & 16.6 & 45.1 & 3.7 \\
\hline \multirow{2}{*}{$\begin{array}{l}\text { Percentatge } \\
\text { de la conversió } \\
\text { total en el sòlid }\end{array}$} & 99.9 & 99.6 & 99.8 & 95.2 & 99.4 & 97.8 & 97.1 & 93.4 & 92.1 & 0 \\
\hline & \multicolumn{10}{|c|}{ Productes observats en la fase gas (\%) ${ }^{[b]}$} \\
\hline $\mathrm{H}_{2}$ & 61.0 & 58.4 & 58.6 & 31.2 & 50.8 & 14.4 & 10.4 & 22.9 & 42.8 & 35.8 \\
\hline $\mathrm{CO}_{2}$ & 39.0 & 41.6 & 41.4 & 40.5 & 13.8 & 36.3 & 83.5 & 61.6 & 48.0 & 56.8 \\
\hline $\mathrm{CO}$ & - -_c] & $--[c]$ & $--_{-[c]}$ & 16.1 & -_[c] & $--[c]$ & $--[c]$ & 11.1 & 5.4 & 3.9 \\
\hline Metà & -_-[c] & -_-[c] & - -_[c] $_{1}$ & 8.2 & -_-[c] & 11.5 & 5.2 & 3.9 & 3.5 & 3.0 \\
\hline Propà & $-{ }_{--[c]}$ & -_-[c] & - -[c] $_{3}$ & 2.1 & 19.8 & 24.0 & 0.9 & 0.5 & 0.3 & 0.3 \\
\hline Butà & 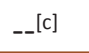 & $-{ }_{--}^{[c]}$ & ${ }_{-}[c]$ & 1.9 & 15.6 & 13.8 & $-{ }_{--}^{[c]}$ & ${ }_{--}^{[[c]}$ & ${ }_{-[-[c]}^{[c]}$ & $--^{[c]}$ \\
\hline
\end{tabular}

[a] Percentatge de les mols d'età inicials que han desaparegut en el temps indicat. Els balanços molars van ser superiors al $95 \%$.

[b] Dades que corresponen a un percentatge xicotet respecte a la conversió total, ja que quasi tot l'età convertit roman adsorbit en el sòlid.

[c] Per sota del límit de detecció

[d] Sense catalitzador.

Com es pot veure en aquestes taules, és possible aconseguir conversions superiors al $40 \%$ de l'età present en l'experiment en presència d' $\mathrm{O}_{2}$. Comparat amb els experiments similars duts a terme amb metà, s'aconsegueixen conversions més altes en el cas de l'età, un fet que concorda amb la reactivitat relativa esperada per tots dos alcans $\mathrm{i}$ amb les corresponents energies d'activació. És digne de destacar en les Taules 4.1 i 4.2 que més del $90 \%$ dels productes formats roman adsorbit en la zeolita Beta. El percentatge d'età transformat en fase gas és notablement petit (freqüentment un percentatge menor que l' $1 \%$ de la conversió total de l'età). En qualsevol cas, especialment des del punt de vista mecanístic, és digne de ser ressaltat que la fase gas conté un alt percentatge d'hidrogen que és major a temps d'irradiació curts 
i que disminueix a mesura que s'allarga el temps d'irradiació a causa de l'aparició d'altres compostos en fase gas. La formació d'hidrogen ha estat igualment observada quan la mostra de zeolita Beta comercial és irradiada sota atmosfera de $\mathrm{N}_{2}$. L'observació d'hidrogen en la irradiació del sòlid proporciona evidència ferma a favor de la hipòtesi que la fotòlisi d'aquest sòlid amb llum UV a la zona llunyana, produeix la ruptura homolítica de l'enllaç $\mathrm{OH}$, tot i donant lloc a la formació d'àtoms d'hidrogen (equació 4.1.), els quals es converteixen en una molècula de dihidrogen (equació 4.2). Durant el curs de la fotòlisi la formació d'hidrogen està acompanya amb l'aparició de butà i metà. El butà s'originaria per acoblament de dos radicals etil tal com s'indica en l'equació 4.6. És interessant destacar que el metà ha de sorgir probablement de la ruptura homolítica de l'enllaç C-C (equació 4.4) seguida d'abstracció d'hidrogen. Un experiment de control (vegeu la columna més a la dreta en la Taula 4.2 i la nota a peu de Taula) demostra que la conversió d'età per fotòlisi directa per llum UV en absència de sòlid no és zero, però sí un ordre de magnitud menor que la que s'aconsegueix en presència de zeolita. Aquest resultat de la fotòlisi directa de l'età en absència de sòlid és comprensible considerant que l'età pràcticament no absorbeix fotons de 185 $\mathrm{nm}$ i que l'absorció molar dels cromòfors $\mathrm{OH}$ per aquestes longituds d'ona són molt més grans que per a l'età. Igualment realitzem un experiment de control en què el sistema de zeolita Beta i età ser irradiat a $254 \mathrm{~nm}$ en presència i absència d' $\mathrm{O}_{2}$. Convé fer notar que la llum de mercuri emprada en la irradiació emet a $254 \mathrm{~nm}$ amb una intensitat dues vegades superior a l'emissió a $185 \mathrm{~nm}$. Els resultats experimentals demostren que té lloc una conversió d'età a les 15 h de 0.2 i $0.8 \%$ quan s'irradia amb 254 nm, en absència i en presència d' $\mathrm{O}_{2}$, respectivament. Aquestes conversions observades en la fotòlisi a $254 \mathrm{~nm}$ només són al voltant de 2 ordres de magnitud diferents a les que s'obtenen quan es fotolitza el sòlid amb llum UV a la zona llunyana. 


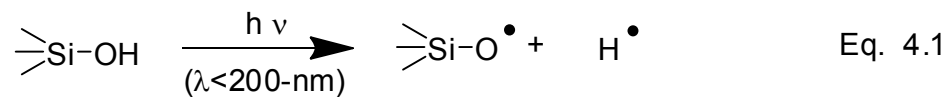

$$
\begin{aligned}
& 2 \mathrm{H}^{\bullet} \longrightarrow \mathrm{H}-\mathrm{H} \quad \text { Eq. } 4.2
\end{aligned}
$$

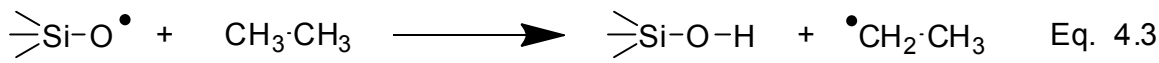

$$
\begin{aligned}
& \underset{7}{\nearrow} \mathrm{Si}-\mathrm{O}^{\bullet}+\mathrm{CH}_{3} \cdot \mathrm{CH}_{3} \longrightarrow \frac{\searrow}{>} \mathrm{Si}-\mathrm{O}-\mathrm{CH}_{3}+{ }^{\bullet} \mathrm{CH}_{3} \quad \text { Eq. } 4.4 \\
& { }^{\bullet} \mathrm{CH}_{3}+{ }^{\circ} \mathrm{CH}_{2} \cdot \mathrm{CH}_{3} \longrightarrow \mathrm{CH}_{3} \mathrm{CH}_{2} \mathrm{CH}_{3} \quad \text { Eq. } 4.5 \\
& 2^{\circ} \mathrm{CH}_{2} \mathrm{CH}_{3} \longrightarrow \mathrm{CH}_{3} \mathrm{CH}_{2} \mathrm{CH}_{2} \mathrm{CH}_{3} \quad \text { Eq. } 4.6 \\
& { }_{7} \mathrm{Si}-\mathrm{O}^{\bullet}+{ }^{\bullet} \mathrm{CH}_{2}-\mathrm{CH}_{3} \longrightarrow \varlimsup_{>} \mathrm{Si}-\mathrm{O}-\mathrm{CH}_{2} \mathrm{CH}_{3} \quad \text { Eq. } 4.7
\end{aligned}
$$

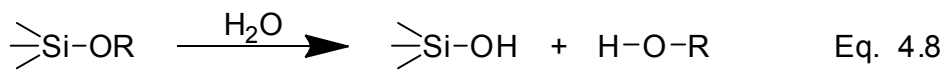

Per tal de conèixer la distribució de productes present en fase sòlida, la qual representa més del $90 \%$ de l'età convertit, vam emprar mostres d'età doblement marcat $a m b{ }^{13} \mathrm{C}$ com a substrat. És important comentar aquí que els experiments anteriors han estat portats a terme amb età de la més alta puresa disponible comercialment, 99.999\%. En contrast, la puresa de l'età disponible amb doble marcatge isotòpic va ser menor (99.4\%). No obstant això, convé ressaltar que no hem observat diferències tant en la conversió de l'età com en la distribució de productes en la fase gas entre aquestes dues mostres comercials d'età, un fet que suggereix que les possibles impureses, i particularment traces d'etilè, no deuen estar jugant un paper detectable en el procés fotoquímic.

Les anàlisis elementals de combustió del sòlid permeten determinar el balanç de masses i el percentatge global de productes derivats d'età que es troben adsorbits en el sòlid. No obstant això la distribució de productes presents en el sòlid requereix l'ocupació d'espectroscòpia de $\mathrm{RMN}{ }^{13} \mathrm{C}$ en estat sòlid. La Figura 4.1 mostra l'espectre de $\mathrm{RMN}{ }^{13} \mathrm{C}$ registrat en angle màgic corresponent a la zeolita Beta comercial després de ser fotolizada amb Ilum UV a la zona llunyana en presència d'età i nitrogen. Com es pot veure en 
aquesta figura els pics principals de l'espectre corresponen a etanol adsorbit, metanol adsorbit, butà $i$ hexà. Mentre que la formació d'etanol $i$ butà pot ser racionalitzada per acoblament de radicals com indiquen les equacions 4.3, 4.6, 4.7 i 4.8 la formació del metanol, requereix la ruptura homolítica de l'enllaç C-C i la formació de metoxisilà, el qual patiria hidròlisi a metanol (equacions 4.4 i 4.8). L'hexà derivaria de l'acoblament dels radicals etil i n-butil, aquest últim provinent d'un procés secundari que implicaria el butà com a material de partida.

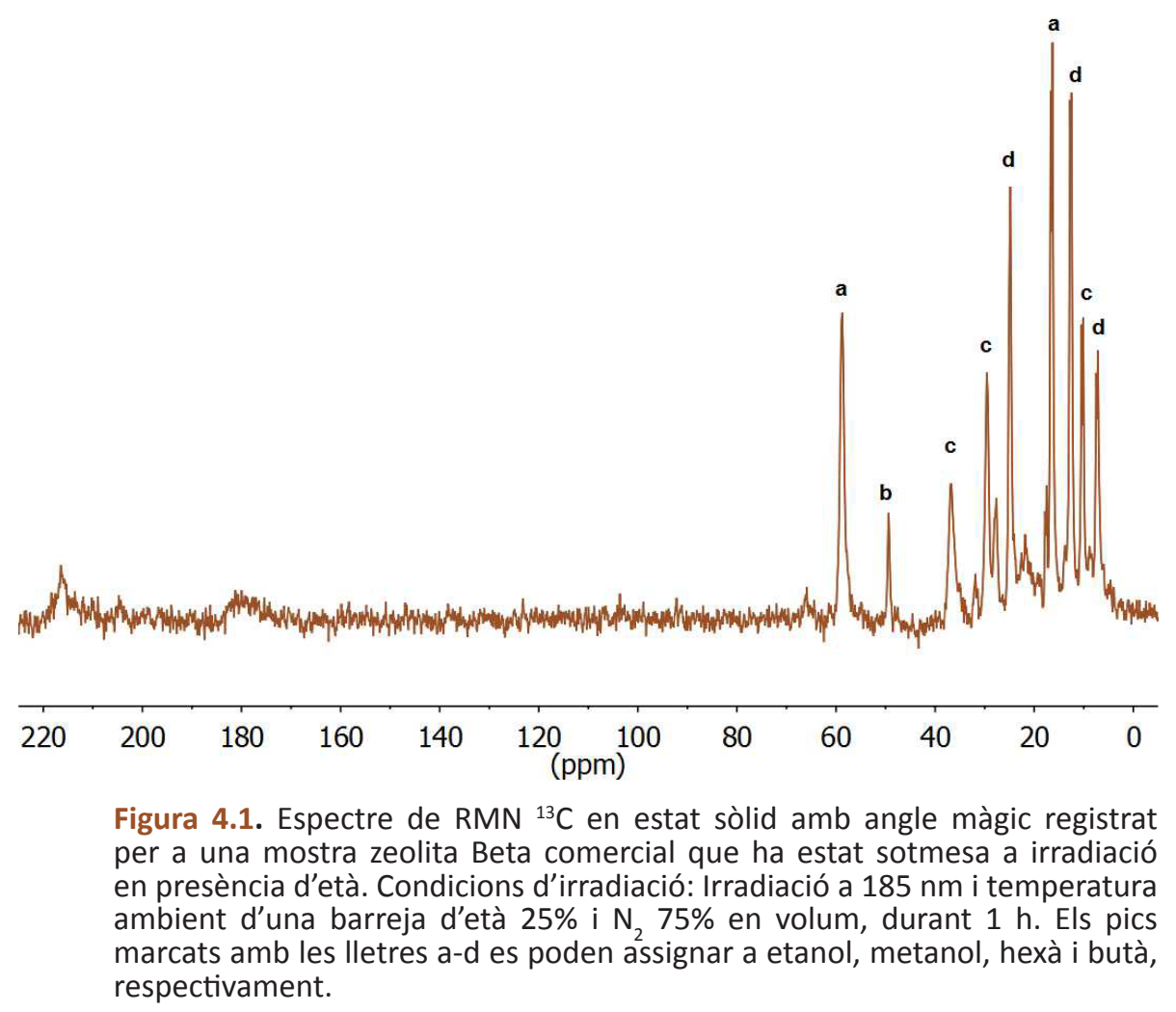


El punt mecanísticament més rellevant és la formació dels alcohols C2 i C1 en absència d'oxigen i que podrien derivar de l'acoblament radicalari dels radicals sililoxil amb els radicals metil i etil seguits d'una hidròlisi posterior tal com indiquen les equacions $4.6,4.7$ i 4.8 .

Quan l'oxigen està present en la barreja de reacció s'observa un augment notable en la conversió d'età, qualsevol que siga la longitud d'ona d'irradiació respecte a assajos anàlegs duts a terme en absència d'oxigen (compareu conversions d'età a les Taules 4.1 i 4.2). Aquest fet pot ser comprés considerant que opera un mecanisme radicalari en cadena en el qual l'atrapament inicial de radicals alquil per oxigen condueix a la formació de radicals peroxil, dels quals reaccionarien amb altres molècules d'età o alcans per donar lloc a altres radicals alquil per abstracció d'hidrogen des de l'alcà cap al radical peroxil (equacions 4.9 i 4.10). D’aquesta manera, la generació d'un radical alquil primari en l'etapa d'iniciació conduiria a la transformació de diverses molècules d'età durant el cicle de propagació.

$$
\begin{aligned}
& \mathrm{CH}_{3} \cdot \mathrm{CH}_{2}+\mathrm{O}_{2} \longrightarrow \mathrm{CH}_{3} \mathrm{CH}_{2} \mathrm{O}-\mathrm{O}^{\cdot} \\
& \mathrm{CH}_{3} \mathrm{CH}_{2} \mathrm{O}-\mathrm{O}^{\cdot}+\mathrm{CH}_{3} \cdot \mathrm{CH}_{3} \longrightarrow \mathrm{CH}_{3} \mathrm{CH}_{2} \mathrm{O}-\mathrm{OH}+{ }^{\circ} \mathrm{CH}_{2} \cdot \mathrm{CH}_{3}
\end{aligned}
$$

A causa de l'augment en la conversió d'età, la diferència més rellevant que té lloc a la irradiació amb llum UV profunda en presència d'oxigen té a veure amb la distribució de productes i en particular amb la presència al costat del metanol i etanol d'altres compostos oxigenats d' 1 i 2 carbonis en detriment d'hidrocarburs lleugers com propà i butà. La Figura 4.2 presenta l'espectre de RMN ${ }^{13} \mathrm{C}$ en estat sòlid registrat per a la zeolita Beta comercial, després de la fotòlisi amb llum UV llunyana, en contacte amb una atmosfera contenint età i oxigen. Per motius de claredat, els pics més rellevants de la Figura 4.2 han estat marcats amb lletres i assignats als corresponents fotoproductes. La formació d'acetaldehid i àcid acètic pot ser racionalitzada considerant que deriva del radical etilperoxil que pateix una oxidació posterior. El formaldehid i l'àcid fòrmic derivarien al seu torn del radical metilperoxil originat per trencament homolític de l'enllaç $\mathrm{C}-\mathrm{C}$ i posterior atrapament per oxigen. 


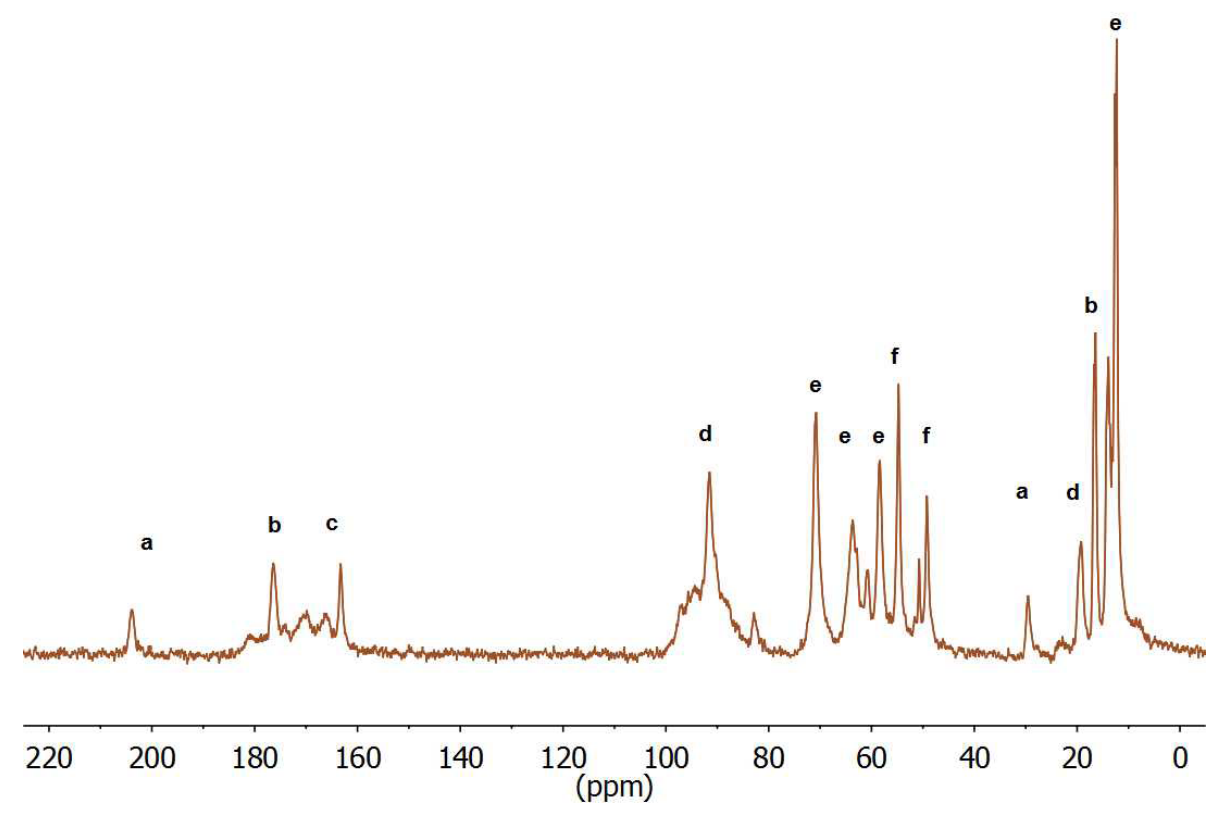

Figura 4.2. Espectre de $\mathrm{RMN}{ }^{13} \mathrm{C}$ en estat sòlid registrat en angle màgic per a una mostra de zeolita Beta comercial després de la seva fotòlisi en presència d'età i $\mathrm{O}_{2}$. Condicions d'irradiació: irradiació a $185 \mathrm{~nm}$, temperatura ambient d'una barreja de 70, 18 i $12 \%$ de nitrogen, età i oxigen, respectivament. Els pics marcats amb les lletres a-f han estat assignats a acetaldehid, àcid acètic, àcid fòrmic, metàdiol, etanol, i metanol (adsorbit i com metoxisilil), respectivament.

Per tal de demostrar que els productes polars adsorbits sobre la zeolita poden ser recuperats per extracció sòlid líquid, una mostra de zeolita Beta sotmesa a irradiació amb una irradiació de longitud d'ona de $185 \mathrm{~nm}$ en presència d'età i oxigen va ser sotmesa a extracció, utilitzant $\mathrm{D}_{2} \mathrm{O}$ i registrant els espectres de $\mathrm{RMN}{ }^{1} \mathrm{H}$ i ${ }^{13} \mathrm{C}$ dels extractes líquids en $\mathrm{D}_{2} \mathrm{O}$. A més, aquests espectres de RMN permeten una estimació quantitativa de la distribució de productes. No obstant això, convé esmentar que aquesta extracció amb $\mathrm{D}_{2} \mathrm{O}$ no és adequada per dur a terme l'extracció d'alcans lleugers que s'hagueren pogut formar en el procés, ja que aquests, per una banda no són solubles i, per altra podrien pujar-ne l'evaporació durant el procés d'extracció. Per tant l'extracció amb $\mathrm{D}_{2} \mathrm{O}$ ha sobreestimat que en la transformació de 112 l'età la formació de productes solubles en aigua. No obstant això, aquesta manca de solubilitat en aigua seria particularment problemàtica en aquelles 
fotòlisis dutes a terme en absència d'oxigen, on, d'acord amb els espectres de $\mathrm{RMN}{ }^{13} \mathrm{C}$ en estat sòlid es forma un major percentatge d'hidrocarburs. De la mateixa manera l'extracció amb $\mathrm{D}_{2} \mathrm{O}$ sembla adequada per analitzar els fotoproductes obtinguts en la irradiació en presència $d^{\prime} \mathrm{O}_{2}$, on, segons les dades de $\mathrm{RMN}{ }^{13} \mathrm{C}$, en estat sòlid es formen productes oxigenats i no volàtils. A manera d'exemple, la Figura 4.3 presenta l'espectre de $\mathrm{RMN}^{13} \mathrm{C}$ en dissolució per l'extracte obtingut en la irradiació de la zeolita Beta comercial en presència d' $\mathrm{O}_{2}$. Basats en aquestes consideracions i en la similitud entre els espectres en estat sòlid registrats per a la zeolita Beta i els espectres en dissolució per l'extracte $\mathrm{D}_{2} \mathrm{O}$ quan la irradiació es porta a terme en presència $\mathrm{d}^{\prime} \mathrm{O}_{2}$, podem estimar la distribució de productes utilitzant dades de RMN en estat sòlid. Les estimacions basades en els espectres de RMN de la zeolita Beta minimitzen els problemes associats amb la manca de solubilitat dels alcans en aigua, els quals són particularment importants quan la irradiació es porta a terme en absència d' $\mathrm{O}_{2}$. Els resultats es resumeixen en les Taules 4.3. i 4.4 .

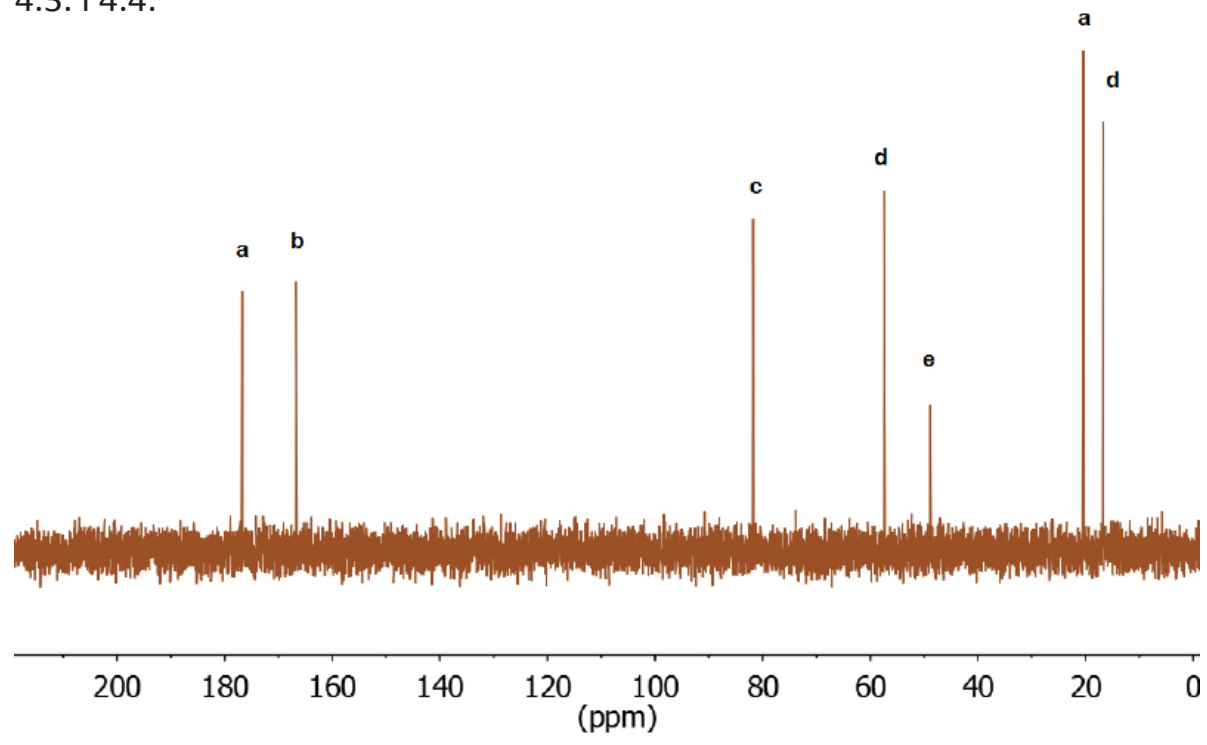

Figura 4.3. Espectre de $\mathrm{RMN}$ de ${ }^{13} \mathrm{C}$ en $\mathrm{D}_{2} \mathrm{O}$, l'extracte obtingut per a la mostra de zeolita Beta que ha estat sotmesa prèviament a fotòlisi en atmosfera d'età i oxigen. Condicions d'irradiació: temps d'irradiació 1 h, llum 185 nm a temperatura ambient per a una barreja de 7018 i $12 \%$ en volum de $\mathrm{N}_{2}, \mathrm{C}_{2} \mathrm{H}_{6} \mathrm{i}$ $\mathrm{O}_{2}$, respectivament. Els pics indicats amb les lletres a-e poden ser assignats a àcid acètic, àcid fòrmic, metanodiol, etanol i metanol, respectivament. 
Taula 4.3. Dades de conversió i distribució de productes determinats per a la fotòlisi a temperatura ambient amb Ilum UV llunyana de la zeolita Beta comercial en contacte amb età, en absència d'oxigen. Han estat estimades en base a l'àrea dels pics corresponents a l'espectre de $\mathrm{RMN}$ de ${ }^{13} \mathrm{C}$ en estat sòlid. La composició inicial de la fase gas va ser $82 \mathrm{i} 18 \%$ en volum de $\mathrm{N}_{2}$ i C $_{2} \mathrm{H}_{6}$, respectivament. El temps d'irradiació va ser de $1 \mathrm{~h}$ i la longitud d'ona va ser de $185 \mathrm{~nm}$.

\begin{tabular}{ccc}
\hline Conversió total (\%) & & 4.5 \\
Conversió del gas (\%) & & 0.2 \\
Conversió en el sòlid(\%) & 4.3 \\
Balanç molar (\%) & & 96 \\
\hline & Etanol & 31.6 \\
$\begin{array}{c}\text { Selectivitat als productes } \\
\text { en la fase sòlida (\%) }\end{array}$ & Metanol & 2.1 \\
& Hexà & 26.7 \\
& Butà & 39.6 \\
\hline
\end{tabular}

Taula 4.4. Dades de conversió i distribució de productes determinats per a la fotòlisi a temperatura ambient amb Ilum UV Ilunyana de la zeolita Beta comercial en contacte amb una atmosfera d'età i oxigen, basat en l'àrea dels pics corresponents, estimada en l'espectre de RMN de ${ }^{13} \mathrm{C}$ en l'estat sòlid. La composició inicial de la fase gas va ser 70, 18 i $12 \%$ vol de $\mathrm{N}_{2}, \mathrm{C}_{2} \mathrm{H}_{6}$ i O $\mathrm{O}_{2}$ ' respectivament. El temps d'irradiació va ser d'1h i la longitud d'ona d'excitació va ser de $185 \mathrm{~nm}$.

\begin{tabular}{lll}
\hline \multicolumn{2}{c}{ Conversió total (\%) } & 13.9 \\
\multicolumn{2}{l}{ Conversió del gas (\%) } & 0.4 \\
\multicolumn{2}{l}{ Conversió en el sòlid (\%) } & 13.5 \\
Balanç molar (\%) & 93 \\
\hline & Acetaldehid & 3.2 \\
Selectivitat als productes & Àcid acètic & 14.1 \\
en la fase sòlida (\%) & Àcid fòrmic & 3.2 \\
& Metadiol & 17.8 \\
& Etadiol & 47.7 \\
& Metanol & 14 \\
\hline
\end{tabular}


Per a demostrar l'aplicabilitat general de la nostra metodologia basada en la irradiació amb llum UV Ilunyana dels grups silanols que activen l'età a temperatura ambient vam procedir a ampliar els resultats obtinguts amb la zeolita Beta comercial a altres sílices per tal d'establir quina és la influència de la naturalesa del sòlid en la conversió total de l'età i en la distribució de productes corresponent. Els sòlids seleccionats per al present estudi van ser una sílice amorfa no porosa de gran àrea superficial com ara l'Aerosil 200, una zeolita de porus mitjà ZSM-5 una altra zeolita monodireccional de porus gran (Mordenita). El nostre estudi també inclou dues sílices mesoporoses estructurades del tipus MCM-41 que difereixen en la presència o absència d'Al a la xarxa. Els resultats obtinguts emprant aquests sòlids com fotocatalitzadors es mostren a la Taula 4.5 .

Taula 4.5. Dades d'activitat i distribució de productes determinats després d'1h d'irradiació a $185 \mathrm{~nm}$ i temperatura ambient de l'età en presència d'O en contacte amb diferents sílices. La composició de la fase gas va ser 70, 18 i $12 \%$ vol de $\mathrm{N}_{2}, \mathrm{C}_{2} \mathrm{H}_{6}$ doblement marcat ${ }^{13} \mathrm{C}_{\text {i O }}$, respectivament.

\begin{tabular}{|c|c|c|c|c|c|}
\hline Catalitzador & $\begin{array}{l}\text { Aerosil } \\
200\end{array}$ & H-ZMS-5 & $\mathrm{NH}_{4}-\mathrm{Mord}$ & $\begin{array}{l}\text { MCM } 41 \\
(\mathrm{Si} / \mathrm{Al} \infty)\end{array}$ & $\begin{array}{l}\text { MCM } 41 \\
\text { (Si/Al 13) }\end{array}$ \\
\hline Conversió total (\%) ${ }^{[a]}$ & 2.2 & 10.6 & 8.7 & 11.5 & 12.2 \\
\hline \multirow[t]{2}{*}{$\begin{array}{l}\text { Percentatge de la } \\
\text { conversió total que } \\
\text { roman en el sòlid.(\%) }\end{array}$} & 72.7 & 94.3 & 93.1 & 94.8 & 95.1 \\
\hline & \multicolumn{5}{|c|}{ Productes observats en la fase gas (\%) } \\
\hline Hidrogen & 5.8 & 8.6 & 6.2 & 7.0 & 6.2 \\
\hline $\mathrm{CO}_{2}$ & 75.3 & 66.2 & 73.4 & 86.3 & 76.3 \\
\hline $\mathrm{CO}$ & 13.6 & 19.6 & 15.4 & $--^{[b]}$ & 12.1 \\
\hline Metà & 5.3 & 5.6 & 5.1 & 6.7 & 5.3 \\
\hline
\end{tabular}

[a] Percentatge de les moles inicials d'età que ha desaparegut en el temps indicat. Els balanços de massa han estat superiors al $95 \%$.

[b] Sota del límit de detecció. 
Com es pot veure a la Taula 4.5, la conversió d'età després d'1h d'irradiació va ser similar en la majoria de les mostres excepte en la sílice Aerosil 200, que va ser significativament inferior. Aquestes dades es poden interpretar considerant que la presència de microporus proporcionen un espai confinat que promou la conversió età. A més de la conversió, els sòlids micro-/mesoporosos també retenen la major part de l'età convertit. Que tinga una conversió més alta i que es trobe retinguda a la superfície del sòlid estan d'acord amb les dades comentades anteriorment per a la irradiació del metà en condicions similars.

Pel que fa a la distribució de productes, tot i que qualitativament s'observen els mateixos compostos tant en la irradiació en presència de zeolita Beta comercial com en altres sílices, quantitativament s'han detectat diferències en el percentatge de cada compost. Per tal d'il/lustrar aquestes variacions la Figura 4.4 compara els espectres de $\mathrm{RMN}{ }^{13} \mathrm{C}$ en estat sòlid registrats en angle màgic per les mostres MCM41 (Si/Al $\infty)$ i MCM-41 (Si/Al 13).

Com a conclusió general de la Taula 4.5, es pot afirmar que la mostra MCM41 (Si/Al 13) és el material més eficient per dur a terme l'activació fotocatalítica de l'età aconseguint la conversió més alta i el percentatge de fotoproductes adsorbits més elevat amb una distribució de productes relativament simple. 


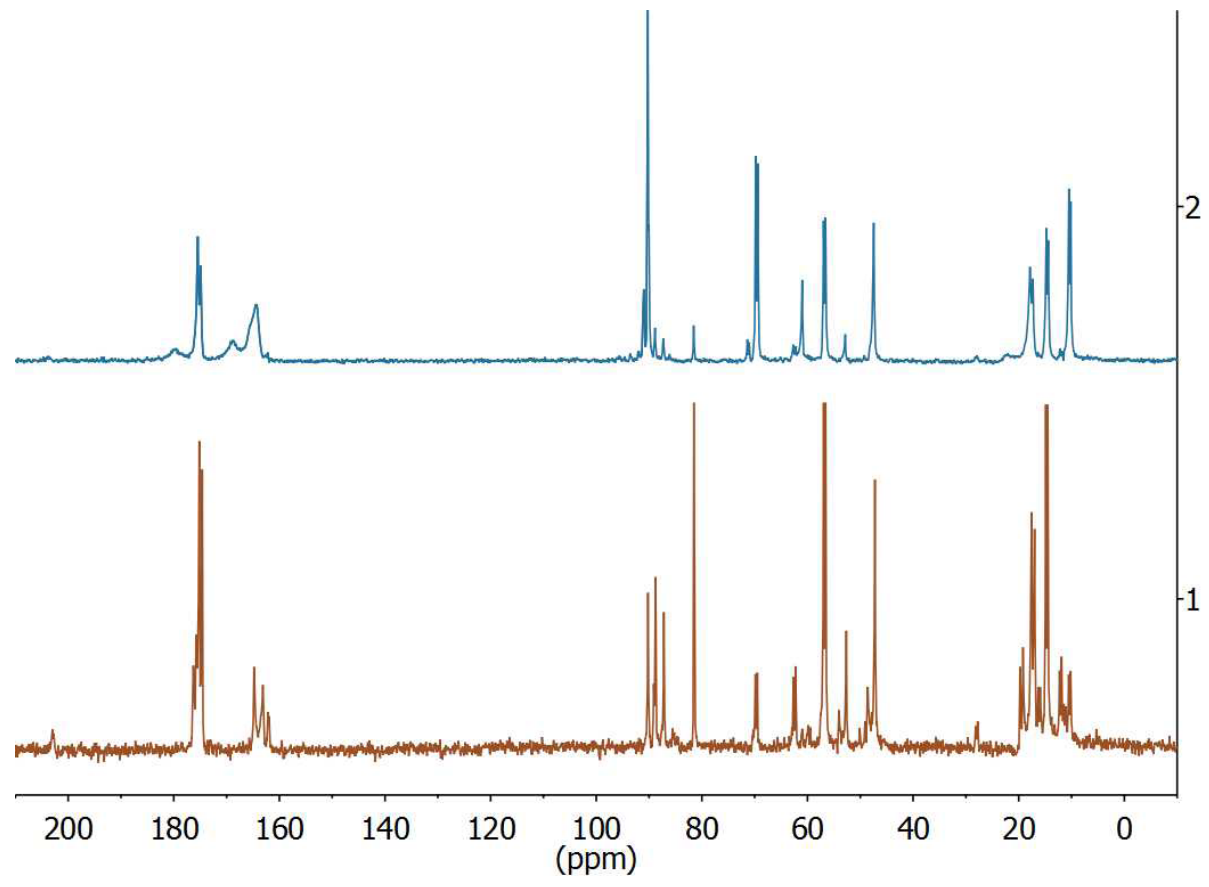

Figura 4.5. Espectres de $\mathrm{RMN}$ de ${ }^{13} \mathrm{C}$ en estat sòlid registrats en angle màgic per les mostres MCM-41 (Si/Al $\infty$ ) (1) Al-MCM-41 (Si/Al 13) (2) després d'1 h d'irradiació a $185 \mathrm{~nm}$ i temperatura ambient en presència d'età i oxigen. Composició de la fase gas inicial: percentatge en volum 70, 18 i $12 \% ~ N 2 \mathrm{C}_{2} \mathrm{H}_{6}$ $\mathrm{i}_{2}$, respectivament. 
Per tal d'avaluar la possibilitat de dur a terme l'activació fotocatalítica de l'età per irradiació amb llum ultraviolada profunda, es va determinar el consum d'energia per mol d'età convertit basant-nos en la potència elèctrica nominal del llum de mercuri emprada i considerant el temps d'irradiació i la conversió assolida per aquest temps. Es va estimar, que per a una conversió $6 \%$ aconseguida en $5 \mathrm{~min}$, el consum de $2 \mathrm{Gcal}^{*} \mathrm{~mol}^{-1}$ d'età convertit. Si comparem aquest valor amb el que hem proporcionat per a l'activació de metà en el capítol anterior, és favorable, i és aproximadament 8 vegades inferior al consum d'energia corresponent al reformat per vapor de l'età que es considera entorn dels $15.96 \mathrm{Gcal}^{*} \mathrm{~mol}^{-1}{ }^{[18-20]}$ Quan es consideren aquests valors de consum energètic convé recordar que el consum d'energia està estretament lligat a un procés específic i que els resultats comentats anteriorment es refereixen a un procés per càrregues en els quals els productes romanen adsorbits en el sòlid. Per tant, el consum d'energia en un procés optimitzat hauria de ser menor. A majors escales es podria considerar un procés que opererara de forma cíclica en diverses etapes que podrien incloure la irradiació amb llum UV Ilunyana, l'extracció de fotoproductes i la reactivació del material. 


\section{Conclusions}

\section{4

En el present capítol hem demostrat que la irradiació amb llum UV de la zona llunyana de superfícies contenint grups hidroxils és capaç de promoure la transformació de l'età en etanol, alcans lleugers i compostos oxigenats $\mathrm{C} 1$ i C2. La presència d'oxigen en el medi augmenta la conversió i inhibeix la formació d'alcans. A pesar d'observar-se un comportament similar per a totes les sílices, la sílice estudiada mesoporosa Al-MCM41(Si/Al13) és la que ha resultat ser més eficient com a fotocatalitzador d'entre els materials estudiats, un fet que pot ser probablement a causa d'una alta població de grups silanols. El consum d'energia en el procés fotocatalític de transformació de l'età és al voltant de 3.6 vegades inferior al procés anàleg de transformació del metà, seguint un procediment similar, un fet que concorda amb la reactivitat relativa d'ambdós alcans. 

1. Crabtree, R.H. "Aspecst of methane Chemistry", Chemical Reviews, 1995. 95: p. 987-1007.

2. Fierro, J.L.G. "Catalysis in C1 Chemistry future and prospect-", Catalysis Letters, 1993. 22: p. 67-91.

3. Labinger, J.A. and J.E. Bercaw. "Understanding and exploiting $\mathrm{C}-\mathrm{H}$ bond activation", Nature, 2002. 417: p. 507-514.

4. Lunsford, J.H."Catalytic conversion of methane to more useful chemicals and fuels: a challenge for the 21st century", Catalysis Today, 2000. 63: p. 165-174.

5. Schwarz, H. "Activation of methane", Angewandte Chemie, 1991. 30: p. 820-821.

6. Amenomiya, Y., V.I. Birss, M. Goledzinowski, et al. "Conversion of methane by oxidative coupling", Catalysis Reviews-Science and Engineering, 1990. 32: p. 163-227.

7. Basch, H., K. Mogi, D.G. Musaev, and K. Morokuma."Mechanism of the Methane to Methanol Conversion Reaction Catalyzed by Methane Monooxygenase: A Density Functional Study", J. Am. Chem. Soc., 1999. 121: p. 7249-7256.

8. Gesser, H.D., N.R. Hunter, and C.B. Prakash."The direct conversion of methan to methanol by controlled oxidation", Chemical Reviews, 1985. 85: p. 235-244.

9. Guisnet, M., N.S. Gnep, and F. Alario."Aromatization of short chain alkanes on zeolite catalystsS", Applied Catalysis a-General, 1992. 89: p. 1-30. 
10. Ismagilov, Z.R., E.V. Matus, and L.T. Tsikoza."Direct conversion of methane on Mo/ZSM-5 catalysts to produce benzene and hydrogen: achievements and perspectives", Energy \& Environmental Science, 2008. 1: p. 526-541.

11. Keller, G.E. and M.M. Bhasin."Synthesis of ethylene via oxidative coupling of methane. 1. Determination of active catalysts", Journal of Catalysis, 1982. 73: p. 9-19.

12. Lee, J.S. and S.T. Oyama."Oxidative coupling of methane to higher hydrocarbons", Catalysis Reviews-Science and Engineering, 1988. 30: p. 249-280.

13. Otsuka, K. and Y. Wang." Direct conversion of methane into oxygenates", Applied Catalysis a-General, 2001. 222: p. 145-161.

14. Xu, Y.D. and L.W. Lin."Recent advances in methane dehydroaromatization over transition metal ion-modified zeolite catalysts under non-oxidative conditions", Applied Catalysis a-General, 1999. 188: p. 53-67.

15. Yoshizawa, K., Y. Shiota, T. Yumura, and T. Yamabe."Direct MethaneMethanol and Benzene-Phenol Conversions on Fe-ZSM-5 Zeolite: Theoretical Predictions on the Reaction Pathways and Energetics", J. Phys. Chem. B, 2000. 104: p. 734-740.

16. Sastre, F., V. Fornés, A. Corma, and H. García."Selective, RoomTemperature Transformation of Methane to C1 Oxygenates by Deep UV Photolysis over Zeolites", Journal of the American Chemical Society, 2011. 133: p. 17257-17261.

17. Sastre, F., V. Fornés, A. Corma, and H. García."Conversion of Methane into C1 Oxygenates by Deep-UV Photolysis on Solid Surfaces: Influence of the Nature of the Solid and Optimization of Photolysis Conditions", Chemistry - A European Journal, 2012. 18: p. 1820-1825.

18. Hu, Y.H. and E. Ruckenstein, Catalytic conversion of methane to synthesis gas by partial oxidation and $\mathrm{CO}_{2}$ reforming, in Advances in Catalysis, Vol 482004. p. 297-345.

19. Rostrup-Nielsen, J.R., J. Sehested, and J.K. Norskov, Hydrogen and synthesis gas by steam- and $\mathrm{CO}_{2}$ reforming, in Advances in Catalysis, Vol 472002. p. 65-139.

20. Vanhook, J.P."Methane steam reforming", Catalysis Reviews-Science and Engineering, 1980. 21: p. 1-51. 


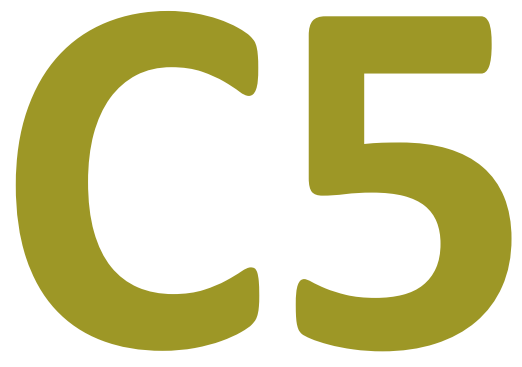

Activació del benzé per irradiació amb llum UV llunyana en superfícies de zeolites ZSM-5. 



\section{Introducció}

En els capítols anteriors hem mostrat com la irradiació de grups hidroxils superficials amb llum UV llunyana pot servir per transformar metà $i$ età mitjançant processos radicalaris. Continuant amb aquest tipus d'estudis encaminats a aplicar la llum UV Ilunyana a l'activació d'hidrocarburs, en el present capítol es descriuen els resultats obtinguts en la transformació del benzé per irradiació amb Ilum UV Ilunyana d'aquest compost aromàtic en presència de zeolita ZSM-5 en condicions on es pot trobar present amoníac, aire i humitat.

En capítols precedents, especialment el que fa referència a l'activació del metà, hem conclòs que la zeolita ZSM-5 era un material sòlid microporós adequat per aconseguir una alta selectivitat en la conversió de metà a metanol. ${ }^{[1,2]}$ La Zeolita ZSM-5 és un aluminosilicat cristal.lí de porus mitjà amb estructura cristal-lina MFI. Els sistemes de microporus estan constituït per dos tipus de canals perpendiculars de 8 àtoms d'oxígens. Un tipus de canals està constituït per tubs paral-lels dels quals s'intersecten perpendicularment amb un segon sistema de canals en ziga-zaga. La Figura 5.1 mostra una estructura de la zeolita ZSM-5. 


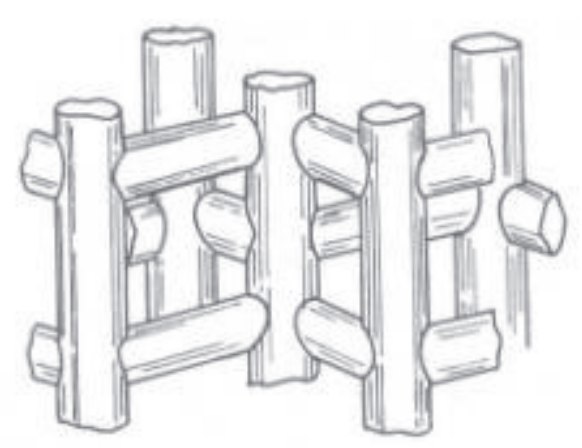

Figura 5.1. Estructura de la zeolita ZSM-5.

El principal ús de la zeolita ZSM-5 és com a catalitzador en la indústria petroquímica a la desproporció de tolué i en la metilació de benzé. ${ }^{[3-6]}$ En aquest tipus de processos les dimensions dels canals d'aquesta zeolita permeten la difusió del benzé, tolué i derivats dimetilats, on els grups metil es troben en posició para. El major diàmetre cinètic dels isòmers orto i meta n'impedeix la difusió i el trànsit dels mateixos pels canals d'aquest material. D'aquesta manera s'aconsegueix la formació selectiva del para-xilé en processos on d'una altra manera es formarien mescles en equilibri dels isòmers orto, meta i para (Figura 5.2). Aquest procés de formació selectiva d'un únic isòmer es coneix com "selectivitat de forma", ja que la raó principal per la qual es forma el compost són les seues dimensions moleculars i no l'estabilitat termodinàmica del producte.

A la vista d'aquests antecedents i d'altres similars, es pot concloure que la zeolita ZSM-5 és molt adequada per introduir selectivitat en la reactivitat de benzé, pel que és aconsellable el seu ús també en el present capítol.

De forma similar al metà, l'activació del benzé davant de reactius tals com aigua o amoníac constitueix un repte en catàlisi. De fet, és ben conegut que el fenol no es pot obtenir per reacció directa del benzé amb aigua ${ }^{[7,8]}$ (Figura 5.3). De manera similar, tampoc el benzé reacciona amb amoníac 

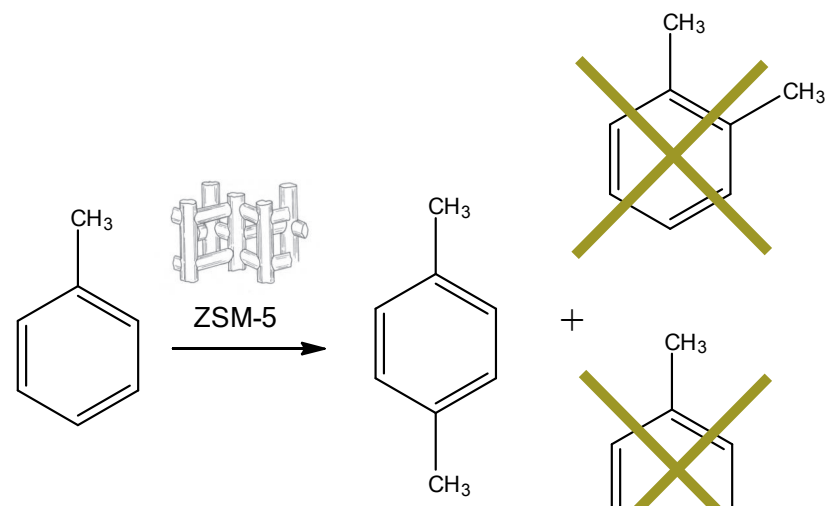

Figura 5.2. Selectivitat de forma.

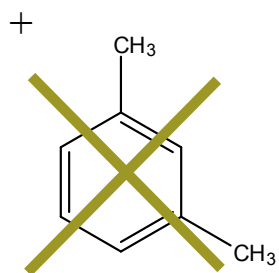

per donar anilina i la síntesi d'aquest compost, important industrialment, requereix de dues etapes consistents en la nitració seguida de la reducció del grup nitro. ${ }^{[9]}$ En aquest context, seria d'interès si es pogueren desenvolupar processos alternatius que condugueren directament fenol o anilina per reacció del benzé amb aigua i amoníac respectivament, tal com indica la Figura 5.3. En aquest sentit, vam pensar que l'activació fotoquímica amb llum UV llunyana, del benzé o del $\mathrm{NH}_{3}$ i $\mathrm{H}_{2} \mathrm{O}$ en superfícies, podia donar lloc a la formació directa d'aquests compostos aromàtics, fenol i anilina, de gran interès industrial. En el present capítol es descriuen els resultats que hem aconseguit en aquest procés fotoquímic.

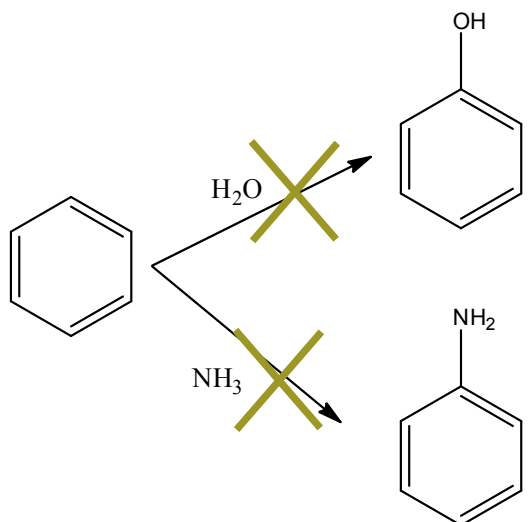

Figura 5.3. Reacció directa del benzè $a m b \mathrm{H}_{2} \mathrm{O} O \mathrm{NH}_{3}$ per a donar fenol i anilina. 



\section{Resultats $i$ discussió}

Els estudis preliminars en la foscor van demostrar que la barreja de vapors de benzé i $\mathrm{NH}_{3}$ en atmosfera d'aire no dóna lloc a la formació de productes fins $i$ tot quan es troba present la zeolita ZSM-5 (Taula 5.1, entrada 1). Aquesta prova control va servir, a més, per a establir el balanç de matèria com a conseqüència de l'adsorció d'una quantitat de benzé a l'interior dels microporus de la zeolita ZSM-5 en la seva forma àcida, en posar-la en contacte amb vapors de benzé, i que no és recuperable per extracció. De fet, anàlisi elemental de combustió de la zeolita després de dur a terme l'assaig control indica la presència de carboni en el sòlid en un percentatge en pes de $0.94 \%$.

Quan estudis similars es van dur a terme per irradiació del sistema amb llum UV profunda es van obtenir, segons les condicions, fenol i anilina, acompanyat de vegades de la formació de $\mathrm{CO}_{2}$ i CO. La Taula 5.1 resumeix les dades obtingudes i les condicions d'irradiació utilitzades.

Així, en un primer assaig (Taula 5.1, entrada 2) es va dur a terme la irradiació de vapors de benzé en presència d'una atmosfera aeròbica que contenia una certa quantitat d'amoníac. En aquestes condicions es va observar la desaparició d'un elevat percentatge de benzé de la fase gas, tal com indica la columna de la Taula 5.1 corresponent a conversió. Part d'aquest benzé es va transformar en $\mathrm{CO}_{2}$ i $\mathrm{CO}$, que es detecta en la fase gasosa del 
sistema. La formació de $\mathrm{CO}_{2}$ i $\mathrm{CO}$ podria provenir de la descomposició per oxidació degradativa del benzé o fenol, tot i requerint la presència d'oxigen molecular. En aquest sentit, d'acord amb la Taula 5.1, l'observació d'aquests gasos va gairebé sempre acompanyada de la detecció de fenol.

Una altra part del benzé es troba absorbida a la superfície del sòlid ZSM-5. De fet, aquest material conté una quantitat de carboni substancialment superior a la que es mesura en la prova control portada a terme en la foscor. L'extracció del sòlid permet recuperar part del benzé adsorbit, sent el fet més notable l'observació de la formació d'un cert percentatge de fenol. Convé fer notar que encara que la reacció es va dur a terme en contacte amb una atmosfera que contenia $\mathrm{NH}_{3}$, la formació d'anilina no va poder ser detectada en aquestes condicions (Taula 5.1, entrada2).

Taula 5.1. Conversió i selectivitat de la reacció fotoquímica de benzé i aigua o amoníac sobre zeolita H-ZSM-5 (Si/Al 26.5). Condicions de reacció: Irradiació de $1.15 \mathrm{mmol}$ de benzé a temperatura ambient en presència de $250 \mathrm{mg}$ d'H-ZSM5. Longitud d'ona $185 \mathrm{~nm}$.

\begin{tabular}{|c|c|c|c|c|c|c|c|c|c|}
\hline \multirow{2}{*}{ Assaig } & \multicolumn{3}{|c|}{$\begin{array}{c}\text { Atmosfera } \\
(\mathrm{mmol})\end{array}$} & \multirow{2}{*}{$\begin{array}{c}\text { Conversió } \\
(\%)\end{array}$} & \multirow{2}{*}{$\begin{array}{c}\text { Balanç } \\
\text { molar } \\
(\%)\end{array}$} & \multicolumn{4}{|c|}{ Rendiments (\%) } \\
\hline & $\mathrm{N}_{2}$ & $\mathrm{O}_{2}$ & $\mathrm{NH}_{3}$ & & & $\mathrm{CO}_{2}^{[\mathrm{a}]}$ & $\mathrm{CO}^{[\mathrm{a}]}$ & fenol $^{[\mathrm{b}]}$ & anilina $^{[b]}$ \\
\hline $1^{[c]}$ & 17 & 4 & 0.53 & $<5$ & 94.6 & -- & -- & -- & -- \\
\hline 2 & 17 & 4 & 0.53 & 78 & 85.9 & 5.3 & 5.3 & 1.6 & -- \\
\hline 3 & 21 & -- & -- & 89 & 22.5 & 0.3 & 0.08 & 10 & -- \\
\hline $4^{[\mathrm{d}]}$ & 21 & -- & -- & 69 & 78.3 & 5.6 & -- & 0.5 & -- \\
\hline 5 & 17 & 4 & 3.87 & 51 & 80.7 & -- & -- & -- & 6 \\
\hline $6^{[\mathrm{e}]}$ & 21 & -- & -- & 81 & 35 & 1.6 & -- & -- & -- \\
\hline
\end{tabular}

[a] Determinat en la fase gas i considerant que l'estequiometria de formació és de sis mols de gas per cada mol de benzé consumit.

[b] Determinat després de l'extracció de la zeolita ZSM-5 amb $5 \mathrm{ml} \mathrm{d} \mathrm{H}_{2} \mathrm{O}$ després de la reacció sense llum.

[c] Sense llum.

[d] $11 \mathrm{mmol} \mathrm{H}_{2} \mathrm{O}$.

[e] Forma amònica. 
A fi de determinar l'origen del fenol i, en particular, la procedència de l'àtom d' $\mathrm{O}_{2}$, vam dur a terme assaigs addicionals en què varem eliminar I' $\mathrm{O}_{2}$ molecular present en l'atmosfera de l'assaig anterior o vam reduir la quantitat $d^{\prime} \mathrm{H}_{2} \mathrm{O}$ que contenia la zeolita ZSM-5. Tal com indica la Taula 5.1, quan la reacció amb UV llunyana del benzé en contacte amb la zeolita ZSM-5 es va dur a terme en una atmosfera que no contenia $\mathrm{O}_{2}$, vam observar igualment la formació de fenol, fins i tot en un percentatge més elevat que quan l'O $\mathrm{O}_{2}$ i el $\mathrm{NH}_{3}$ estaven presents en el sistema. Per altra banda, quan la irradiació es portà a terme en una atmosfera que no contia $\mathrm{O}_{2}$, i on es va reduïr considerablement l'aigua present a la ZSM-5, vam observar una disminució considerable en la formació de fenol (Taula 5.1, entrada 4).

Aquestes dades suggereixen que el fenol es forma per reacció entre benzé i aigua, promoguda per llum UV Ilunyana i que l' $\mathrm{O}_{2}$ no està implicat en el procés. Una explicació raonable per a la formació del fenol, per reacció de benzé i aigua, implicaria la fotòlisi de l' $\mathrm{H}_{2} \mathrm{O}$ per generar radicals hidroxil i àtoms d'hidrogen. Seguidament el radical hidroxil, com que és una espècie molt electrofílica, atacaria l'anell de benzé, i en resultaria la formació de fenol. La formació de fenol per reacció del benzé amb radicals hidroxil es troba ben documentada en la literatura. ${ }^{[10-12]}$ Igualment hem comentat anteriorment que és conegut que la irradiació amb $185 \mathrm{~nm}$ de l'aigua produeix aquest tipus de radicals hidroxil amb una gran eficiència. La Figura 5.4 resumeix la proposta mecanística per racionalitzar la formació del fenol. D’altra banda, la formació d'anilina podria provenir de l'atac del radical $\bullet \mathrm{NH}_{2}$ (aminil) al benzé. Aquest radical aminil provindria del trencament homolític de l'enllaç $\mathrm{NH}$ de la molècula de $\mathrm{NH}_{3}$ després de ser excitada amb llum UV llunyana. Aquest procés és anàleg al de la generació de radicals hidroxil per trencament de la molècula d' $\mathrm{H}_{2} \mathrm{O}$. El radical aminil es comportaria com un electròfil capaç d'atacar a l'anell de benzé donant lloc a l'anilina.

Per tal d'afavorir la formació d'anilina per reacció entre el benzé i l'amoníac i desafavorir la formació de fenol, vam dur a terme un altre assaig on vam augmentar el percentatge d'amoníac present en la fase gas 
(Taula 5.1, entrada 5). En aquestes condicions vam observar la formació d'anilina, no vam detectar la presència de fenol.

En un intent d'augmentar la selectivitat cap a la formació d'anilina, vam procedir a realitzar una altra reacció fotoquímica on la fase gas contenia exclusivament $\mathrm{N}_{2}$; la zeolita ZSM-5 emprada es troba en la seva forma amònica. No obstant això, en aquestes condicions, no vam poder detectar la presència d'anilina ni de fenol. Aquest fet podria ser a causa de la no difusió del benzé per l'interior dels canals de la ZSM- 5 quan el catió $\mathrm{NH}_{4}^{+}$està ocupant els espais interiors.

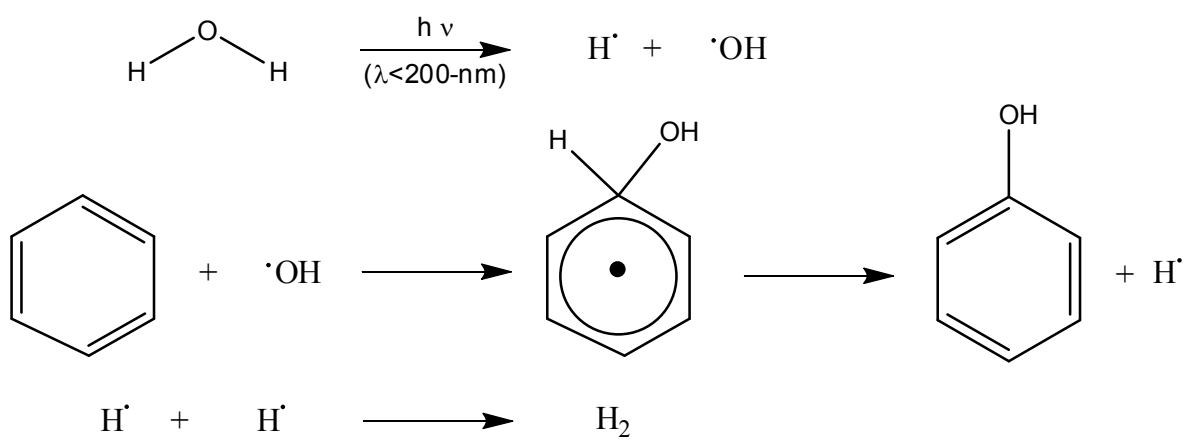

Figura 5.4. Mecanisme proposat per a la formació de fenol.

A la vista de les dades de la Taula 5.1 es pot concloure que com a norma general el balanç molar disminueix a mesura que la conversió augmenta, per la qual cosa aquests balanços molars són notablement insatisfactoris en alguns casos (Taula 5.1, entrades 3 i 6). Aquest fet podria donar-se a causa de l'existència de reaccions secundàries on els productes formats inicialment pateixen una reacció consecutiva posterior a causa de la seva major reactivitat. En efecte, el problema general en la funcionalització del 132 benzé és que la reactivitat del fenol i la de l'anilina és molt més gran que 
la del benzé, de manera que aquests productes primaris tendeixen a patir descomposició en les reaccions de formació. Un altre problema addicional consisteix en què, a diferència d'allò que comentat en els capítols d'activació del metà i de l'età, en el cas present, la irradiació fotoquímica no és selectiva, i pot irradiar simultàniament tant la superfície de la zeolita ZSM-5 present en el reactor com l'aigua i l'amoníac present en fase gas, així com el benzé distribuït en la fase gas i en el sòlid. De fet, el benzé, així com els seus productes primaris fenol i anilina, posseeixen una absorció molt intensa en I'UV i, per tant, poden patir reacció fotoquímica en fase gas sense necessitat d'estar adsorbits a l'interior del sòlid. Així, una observació general en aquest capítol va ser la formació de pel-lícules de material no identificat damunt de les parets del fotoreactor. Encara que la natura d'aquest material no va poder ser determinada, la coloració (entre marró i roig) i el fet de no ser analitzable per cromatografia de gasos suggereixen que es tracta d'un material d'elevat pes molecular. Pel que fa a la formació de compostos polimèrics acolorits convé esmentar que la formació de polianilines per oxidació d’anilina és un procés ben conegut en la literatura ${ }^{[5,13,14]}$ i que aquestes polianilines poden presentar diferents coloracions des del vermell al verd depenent de seu estat d'oxidació.

Amb l'objecte d'avançar en el coneixement de les causes per les quals el balanç molar és incomplet es va dur a terme un estudi per espectroscòpia de RMN de ${ }^{13} \mathrm{C}$ en estat sòlid del material ZSM-5 emprant benzé marcat isotòpicament $a m b{ }^{13} \mathrm{C}$. La sèrie d'espectres obtinguts es mostra a la Figura 5.5. Com es pot veure allà, temps curts d'irradiació permeten l'observació d'un pic intens a 128 ppm corresponent al benzé adsorbit juntament amb pics poc intensos a la zona alifàtica. La prolongació del temps d'irradiació dóna lloc a una disminució gradual del pic corresponent al benzé i un augment en la intensitat dels pics corresponents a carbonis alifàtics juntament amb l'aparició de senyals atribuïbles a l'anilina quan la irradiació es va dur a terme en atmosfera que contenia amoníac. 


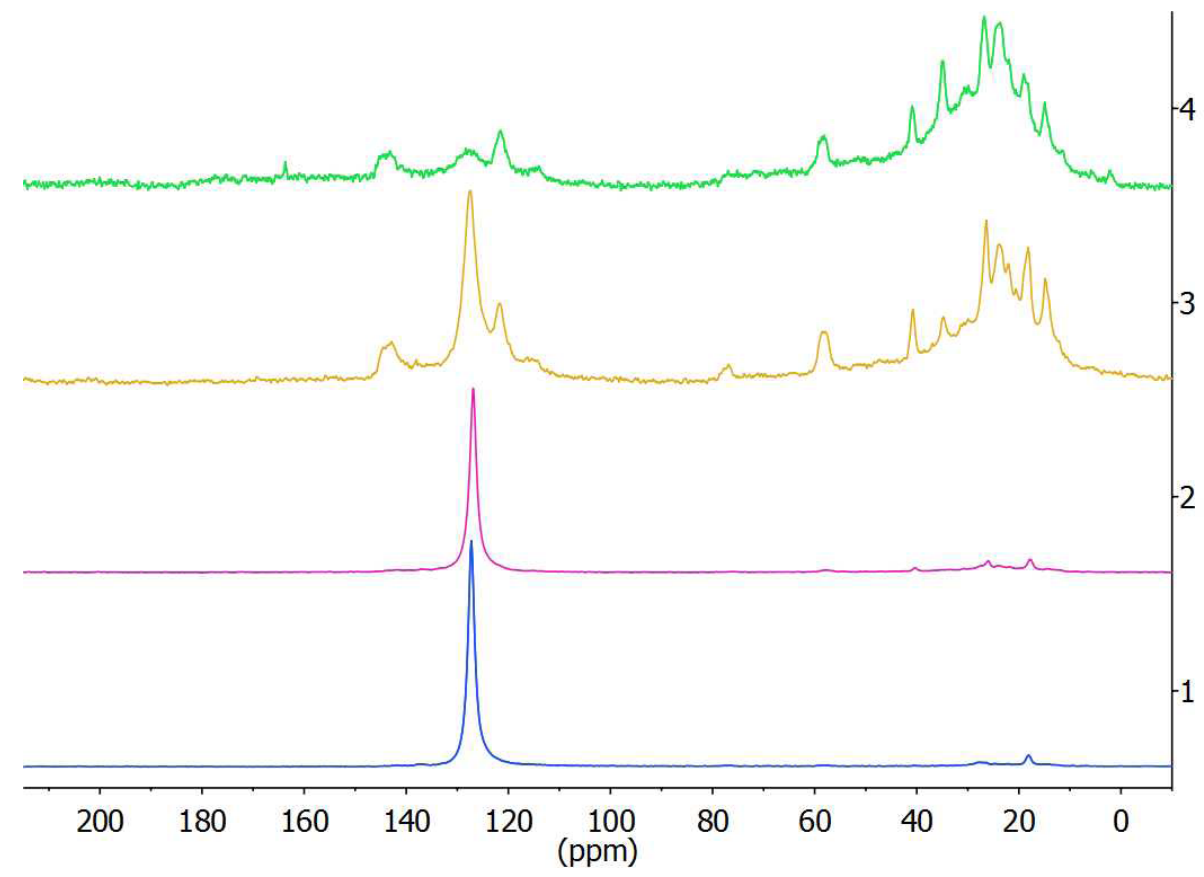

Figura 5.5. Espectres $\mathrm{RMN}{ }^{13} \mathrm{C}$ per la irradiació de ZSM-5 $185 \mathrm{~nm} 0.083 \mathrm{~h}(1)$, $0: 25$ (2), $1 \mathrm{~h}$ (3) i $4 \mathrm{~h}(4)$. Condicions de reacció: $1.5 \mathrm{mmol}$ de benzé marcat isotòpicament $\mathrm{amb}^{13} \mathrm{C}$ i 0.53 mols $\mathrm{NH}_{3}$ i $\mathrm{N}_{2}$.

D'aquest estudi de RMN cal destacar com inesperat, l'observació de senyals corresponents a carbonis alifàtics, ja que la formació d'aquest tipus de productes no ha pogut ser detectada ni en les anàlisis de la fase gas, ni en les extraccions del sòlid. La posició d'aquestes bandes seria compatible amb la formació de ciclohexilamina i ciclohexanol. Aquests productes provindrien de la hidrogenació del fenol i l'anilina. Ja que els assajos es duen a terme a temperatura ambient i la zeolita ZSM-5 no és un catalitzador d'hidrogenació, sembla que la formació d'aquests subproductes saturats implicaria d'alguna manera etapes d'activació fotoquímica. La Figura 5.6 resumiria aquesta proposta. 
La formació d'aquests compostos requereixen probablement la generació d' $\mathrm{H}_{2}$. Tenint en compte els components del sistema, l'origen més probable de l' $\mathrm{H}_{2}$ hauria de ser l'aigua, bé en fase vapor o adsorbida, i/o l'amoníac en fase gas. Tal com s'ha indicat en capítols anteriors la presència d'hidrogen ha estat detectada en diverses irradiacions incloent la seva detecció per irradiació de la superfície de la zeolita Y.

Per tal de proporcionar alguna evidència experimental a aquesta interpretació, vam procedir a extreure amb aigua àcida la mostra de ZSM-5 després de la irradiació en atmosfera contenint $\mathrm{NH}_{3}$ i on es detecta la formació d'anilina o en condicions on es detecta fenol. Les Figures 5.7. i 5.8. mostren els espectres de $\mathrm{RMN}{ }^{13} \mathrm{C}$ en estat sòlid abans i després de l'extracció havent empleat benzé marcat isotòpicament. S'observa que quan la irradiació es porta a terme en atmosfera de $\mathrm{NH}_{3}$, l'espectre de $\mathrm{RMN}$ a temps final presenta senyals aromàtiques compatibles amb la formació d'anilina a més dels compostos alifàtics probablement derivats de la hidrogenació d'aquest compost. L'extracció amb aigua àcida elimina del material gran part de l'anilina però roman atrapat en el sòlid una quantitat significativa de subproductes alifàtics.

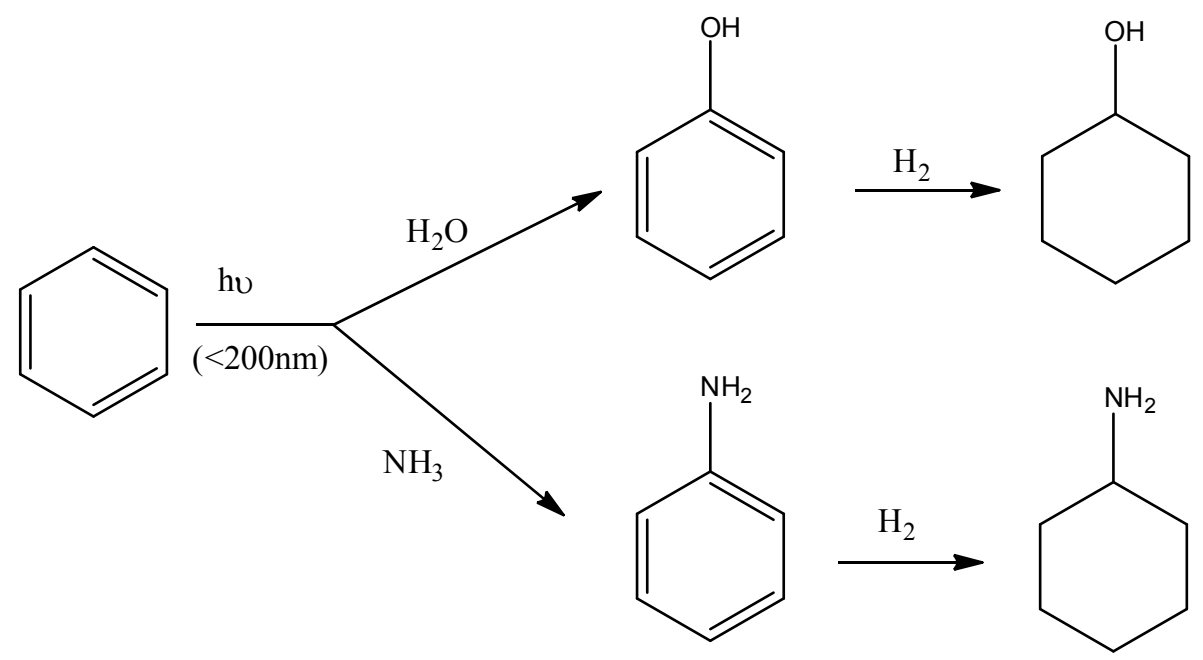

Figura 5.6. Mecanisme proposat per a la formació de subproductes saturats a partir de benzé. 


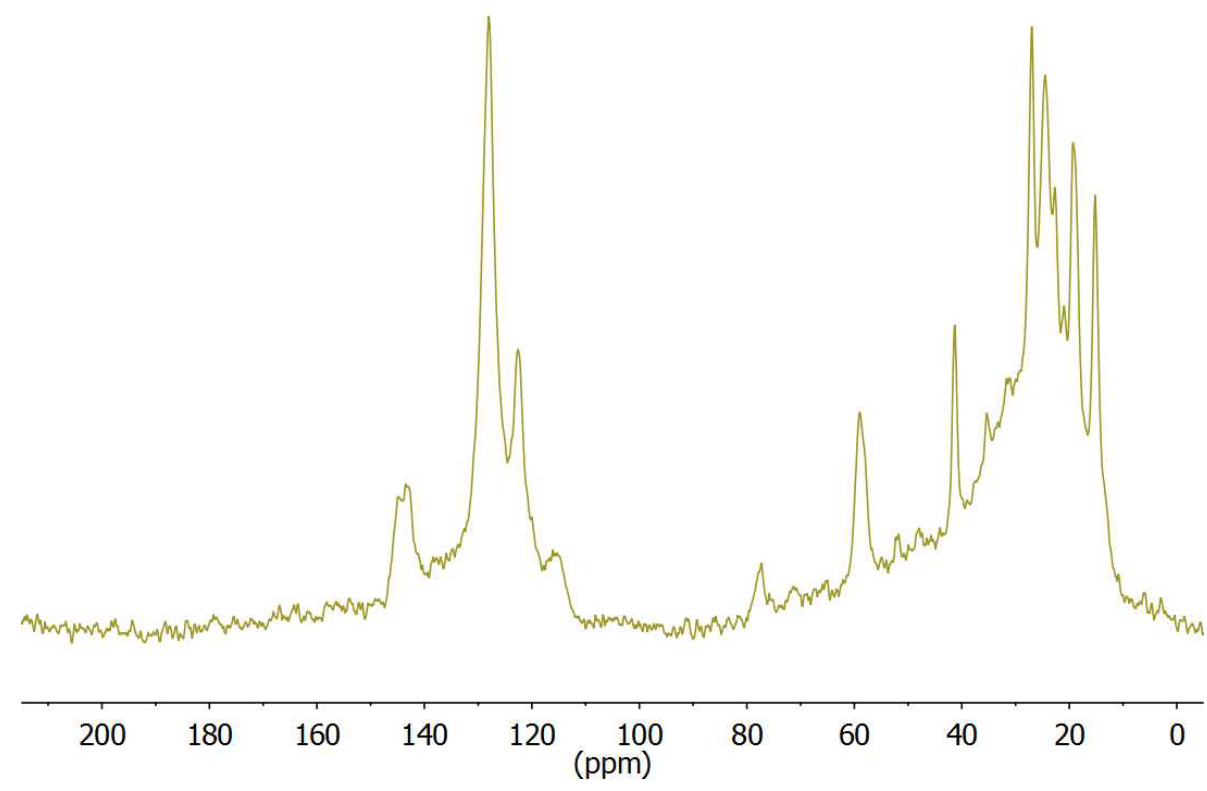

Figura 5.7. Espectre $\mathrm{RMN}{ }^{13} \mathrm{C}$ en fase sòlida enregistrat per la irradiació de ZSM-5-185 $\mathrm{nm}$ de ${ }^{13} \mathrm{C}$ benzé després de $3 \mathrm{~h}$ d'irradiació. Condicions de reacció: $1.5 \mathrm{mmol}$ de ${ }^{13} \mathrm{C}$ benzé i 0.53 mols $\mathrm{NH}_{3}$ i $\mathrm{N}_{2}$.

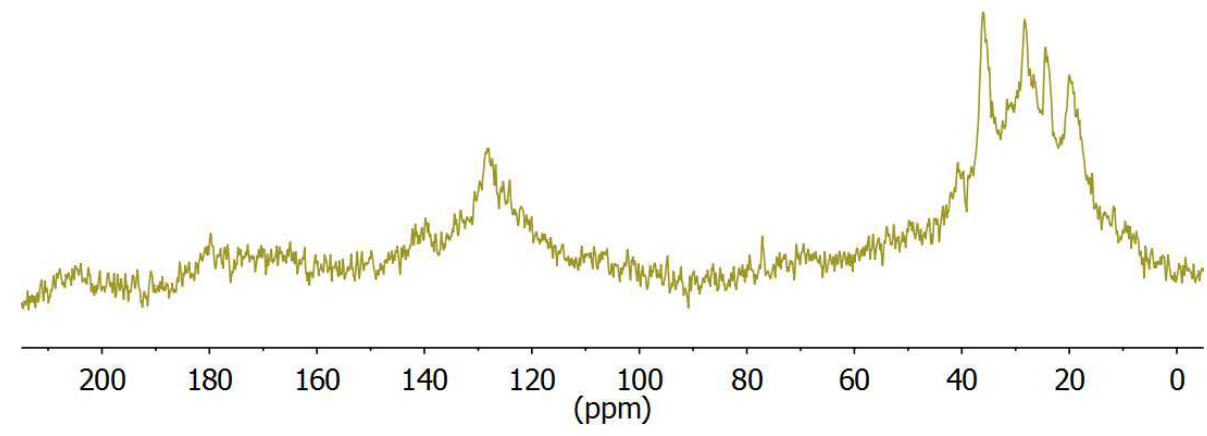

Figura 5.8. Espectre $\mathrm{RMN}{ }^{13} \mathrm{C}$ en la fase sòlid enregistrat per la irradiació de ZSM-5-185 nm de ${ }^{13} \mathrm{C}$-benzé després de $3 \mathrm{~h}$ d'irradiació i extracció amb $\mathrm{H}_{2} \mathrm{O}$

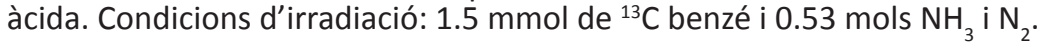




\section{Conclusions}

\section{3.}

En el present capítol hem mostrat l'activació del benzé amb llum UV Ilunyana, encara que la selectivitat del procés i els balanços de matèria són insuficients o incompletes. Aquest fet sembla donar-se a causa de la manca de selectivitat de l'activació fotoquímica, ja que els fotons UV Ilunyans poden produir tant l'activació de la superfície del material com la de l'aigua, amoníac i benzé; i per tant, les reaccions tenen lloc tant en fase gas com a l'interior de la zeolita ZSM-5. Es proposa que la formació del fenol, passa per la reacció del benzé amb radicals hidroxil, generats pel trencament fotoquímic de l'aigua. De la mateixa manera, la formació d'anilina, la qual requereix la presència de concentracions suficients d'amoníac, podria transcórrer per atac del radical aminil damunt el benzé. De manera inesperada, l'espectroscòpia de RMN en estat sòlid ha posat de manifest la formació en el material de quantitats significatives de compostos alifàtics. Es proposa que aquests compostos alifàtics provenen de la hidrogenació del fenol, anilina i del benzé promogut per la llum UV. La formació d'aquests productes així com material polimèric explicarien els baixos balanços de matèria observats per al procés. 

1. Sastre, F., V. Fornés, A. Corma, and H. García."Selective, RoomTemperature Transformation of Methane to C1 Oxygenates by Deep UV Photolysis over Zeolites", Journal of the American Chemical Society, 2011. 133: p. 17257-17261.

2. Sastre, F., V. Fornés, A. Corma, and H. García."Conversion of Methane into C1 Oxygenates by Deep-UV Photolysis on Solid Surfaces: Influence of the Nature of the Solid and Optimization of Photolysis Conditions", Chemistry - A European Journal, 2012. 18: p. 1820-1825.

3. Adebajo, M.O., R.F. Howe, and M.A. Long."Methylation of benzene with methanol over zeolite catalysts in a low pressure flow reactor", Catalysis Today, 2000. 63: p. 471-478.

4. Ahn, J., R. Kolvenbach, S. Al-Khattaf, et al."Methanol usage in toluene methylation with medium and large pore zeolites", ACS Catal.: p. Ahead of Print.

5. Corma, A."State of the art and future challenges of zeolites as catalysts", Journal of Catalysis, 2003. 216: p. 298-312.

6. Xiong, Y., P.G. Rodewald, and C.D. Chang."On the Mechanism of Toluene Disproportionation in a Zeolite Environment", J. Am. Chem. Soc., 1995. 117: p. 9427-31.

7. Sakamoto, T., T. Takagaki, A. Sakakura, et al."Hydroxylation of benzene to phenol under air and carbon monoxide catalyzed by molybdovanadophosphates", Journal of Molecular Catalysis A: Chemical, 2008. 288: p. 19-22.

8. Zhang, X."Direct hydroxylation of benzene to phenol", Huaxue Jinzhan, 2008. 20: p. 386-395. 
9. Saha, B., S. De, and S. Dutta."Recent Advancements of Replacing Existing Aniline Production Process With Environmentally Friendly One-Pot Process: An Overview", Crit. Rev. Environ. Sci. Technol., 2013. 43: p. 84-120.

10. Bremner, D.H., A.E. Burgess, and F.B. Li."Coupling of chemical, electrochemical and ultrasonic energies for controlled generation of hydroxyl radicals. Direct synthesis of phenol by benzene hydroxylation", Appl. Catal., A, 2000. 203: p. 111-120.

11. Heath, A.A., F.S. Ehrenhauser, and K.T. Valsaraj. Atmospheric oxidation of benzene: The effect of $\mathrm{pH}$, ionic strength, and temperature on biphenyl formation and yield. 2012. American Chemical Society.

12. Kahan, T.F., R. Zhao, and D.J. Donaldson."Hydroxyl radical reactivity at the air-ice interface", Atmos. Chem. Phys., 2010. 10: p. 843-854.

13. Stejskal, J., P. Kratochvil, and A.d. Jenkins."Polyaniline: forms and formation", Collect. Czech. Chem. Commun., 1995. 60: p. 1747-55.

14. Stejskal, J., P. Kratochvil, and A.D. Jenkins."The formation of polyaniline and the nature of its structures", Polymer, 1996. 37: p. 367-9. 


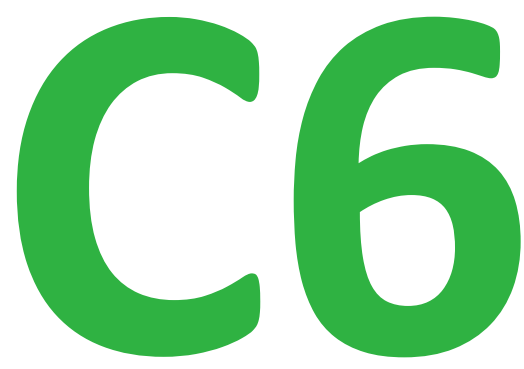

Reducció fotocatalítica del $\mathrm{CO}_{2}$ a metà per irradiació amb llum UV Ilunyana 



\section{Introducció}

L'activació del $\mathrm{CO}_{2}$ per a donar compostos de reducció és un dels reptes actuals de la química. ${ }^{[1-3]}$ Una línia d'investigació que està relacionada amb les energies renovables és el reemplaçament dels combustibles fòssils per fonts d'energia sostenibles que no influeixen negativament en el medi ambient. ${ }^{[4-6]}$ En aquest context una possibilitat és la reducció fotoquímica del $\mathrm{CO}_{2}$ per donar lloc a metanol, metà i $\mathrm{CO}$ entre d'altres productes possibles. ${ }^{[5-7]}$ La majoria de les estratègies que s'estan estudiant per aconseguir aquesta transformació es basen en l'ús de llum UV o visible en combinació amb un fotocatalitzador. ${ }^{[8,9]}$

En el present capítol es descriu una metodologia innovadora en la qual la reducció fotoquímica del $\mathrm{CO}_{2}$ es porta a terme mitjançant irradiació amb longitud d'ona UV Ilunyana (longituds d'ona menors que $200 \mathrm{~nm}$ ). Els fotons a la zona de I'UV llunyana poden ser absorbits directament per aigua i $\mathrm{CO}_{2}$ i tenen suficient energia com per produir la fotòlisi monofotònica directa en fase gas d'aquestes dues molècules altament estables. La fotòlisi per irradiació amb llum UV llunyana del $\mathrm{CO}_{2}$ per donar lloc a $\mathrm{CO}$ i àtoms d'oxigen ha estat descrita a la literatura que transcorre amb una alta eficiència quàntica. ${ }^{[10-12]} \mathrm{A}$ més és conegut que la fotòlisi del $\mathrm{CO}$ i l' $\mathrm{H}_{2} \mathrm{O}$ amb llum UV Ilunyana en fase gas pot formar alcohols i aldehids entre altres productes. ${ }^{[13]}$ Però no hi ha res descrit sobre la influència què en presència de sòlids pot exercir en l'eficiència d'aquests processos fotoquímics. 
La reacció del $\mathrm{CO}_{2}$ i $\mathrm{H}_{2} \mathrm{O}$ promoguda per irradiació és similar en certa manera la fotosíntesi natural mitjançant llum solar, en la qual aquestes dues molècules són els substrats que donen lloc a la formació de carbohidrats i oxigen. ${ }^{[14-16]}$ En els capítols anteriors hem demostrat que, de manera anàloga a com passa la fotòlisi directa de l'aigua en fase gas amb formació de radicals per trencament homolític de l'enllaç, els fotons a la zona UV Ilunyana poden igualment produir el trencament de l'enllaç $\mathrm{OH}$ en la superfície de sòlids que d'altra manera són fotoquímicament inerts tant a la radiació UV com a la visible. ${ }^{[17,18]}$ La fotoquímica amb llum UV ha estat generalment descartada com un procediment per a produir transformacions d'interès industrial a causa del fet que la majoria de dissolvents i gasos absorbeixen en aquesta regió mentre que alguns cromòfors orgànics poden ser excitats selectivament si se'ls irradia amb major longitud d'ona, en general superior a $250 \mathrm{~nm}$. No obstant, això la fotoquímica amb llum UV Ilunyana pot ser extremadament útil i d'àmplia aplicació en l'activació de molècules simples i de forma particular en l'activació de I' $\mathrm{H}_{2} \mathrm{O}, \mathrm{CO}_{2}$ i $\mathrm{CH}_{4}$, tant en fase gas com sobre la superfície de sòlids. En aquest context mereix ser comentat que hi ha fonts d'il.luminació simples disponibles comercialment per a efectuar irradiacions a la zona UV llunyana basades en l'emissió del vapor de mercuri (185 nm) o deuteri gas $(165 \mathrm{~nm})$. Els materials òpticament transparents en aquesta regió espectral que són els més convenients per construir cel·les i dispositius d'irradiació són els halurs metàl-lics i, particularment, el fluorur de calci.

En aquest capítol descrivim que la irradiació a $185 \mathrm{~nm}$ del $\mathrm{CO}_{2}$ i $\mathrm{H}_{2} \mathrm{O}$ és un procediment simple i eficient per promoure la reducció del $\mathrm{CO}_{2}$ a $\mathrm{CH}_{4}$ amb un consum d'energia en el rang d'altres processos industrials d'ús massiu com ara el reformat al vapor ("steam reforming") o el desplaçament amb vapor $\mathrm{d}^{\prime} \mathrm{H}_{2} \mathrm{O}$ ("water gas shift"). Encara que l'estratègia descrita aquí no serveix per a la conversió del $\mathrm{CO}_{2}$ amb llum solar, té en comú l'ocupació de llum i un fotocatalitzador per efectuar la reducció del $\mathrm{CO}_{2}$ per hidrogen o aigua. En el context de la producció de combustibles solars, el nostre procediment requeriria la conversió de llum solar en energia elèctrica seguida de la 
fotoreducció del $\mathrm{CO}_{2}$ amb llum artificial, però tot i així podria ser competitiva amb la conversió fotocatalítica directa amb llum solar del $\mathrm{CO}_{2}$ a causa de la major eficiència inherent dels processos monofotònics basats en llum UV llunyana comparada amb els mecanismes que requereixen l'absorció de diversos fotons, com seria el cas si s'emprara llum solar. 



\section{Resultats $i$ discussió}

Primerament, vam procedir a estudiar la fotoreducció del $\mathrm{CO}_{2}$ amb hidrogen tant en absència com en presència d'un material sòlid per, a continuació, procedir a determinar quin dels sòlids estudiats proporciona millors conversions de $\mathrm{CO}_{2}$.

\section{Reducció del $\mathrm{CO}_{2}$ amb $\mathrm{H}_{2}$ promoguda per fotòlisi a $185 \mathrm{~nm}$

Els gasos $\mathrm{H}_{2}$ i $\mathrm{N}_{2}$ no presenten absorció a longituds d'ona de $185 \mathrm{~nm}$, mentre que el $\mathrm{CO}_{2}$ absorbeix entre 165 i $205 \mathrm{~nm} \cdot{ }^{[19]}$ Quan una barreja de $\mathrm{CO}_{2}$ i hidrogen, diluït en $\mathrm{N}_{2}$, és irradiada a $185 \mathrm{~nm}$, s'observa la formació amb una alta selectivitat de metà, acompanyat per la presència de quantitats molt menors de CO. No s'observa, durant el curs de la irradiació, la presència de metanol o d'altres productes. La Figura 6.1 mostra el perfil temporal de la conversió del $\mathrm{CO}_{2}$, així com els rendiments de formació del metà i $\mathrm{CO}$. Com es pot veure en aquesta figura, baix les condicions de reacció assajades, la conversió del $\mathrm{CO}_{2}$ augmenta quasi linealment amb el temps d'irradiació en 
l'interval fins a $3 \mathrm{~h}$. Es van aconseguir altes conversions de $\mathrm{CO}_{2}$ al voltant del $40 \%$ a les $80 \mathrm{~h}$ d'irradiació. Aquestes conversions no tenen precedent en l'activació fotoquímica del $\mathrm{CO}_{2}{ }^{\left[{ }^{[5]}\right.}$ És interessant esmentar que l'aparició de $\mathrm{CO}$ té lloc amb anterioritat a la formació de $\mathrm{CH}_{4}$ (vegeu el requadre de la Figura 6.1), aconseguint un baix percentatge quasiestacionari que es manté constant a temps d'irradiació més llargs. En contrast, la formació del $\mathrm{CH}_{4}$ presenta un període d'inducció, però després d'aquest període inicial, la seva concentració creix en el temps de forma gairebé coincident amb la conversió del $\mathrm{CO}_{2}$.

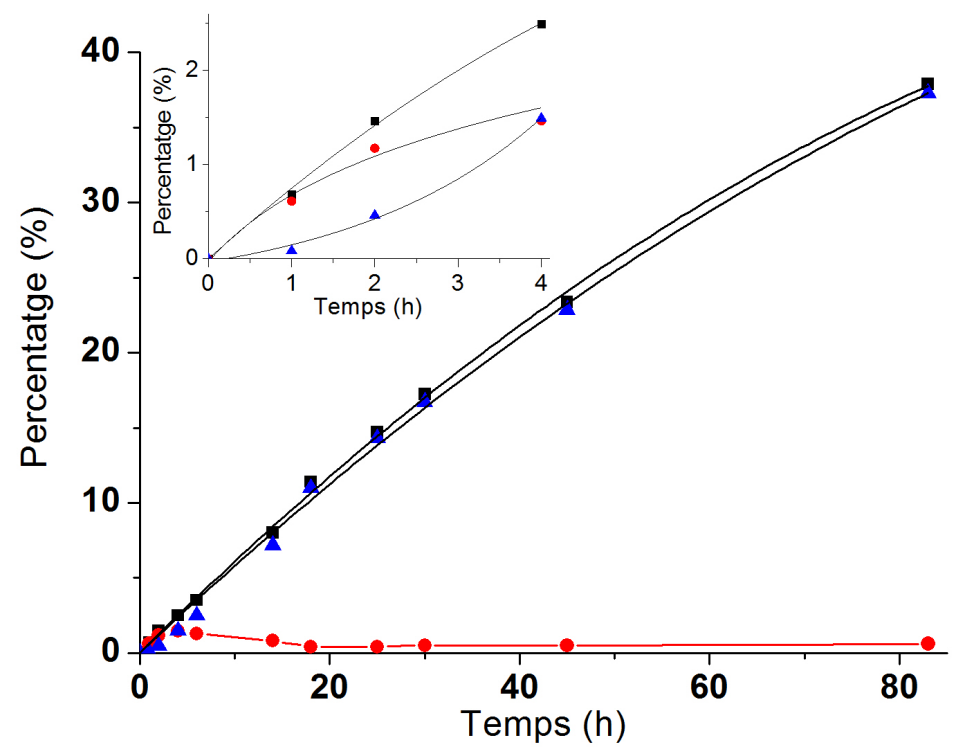

Figura 6.1: Perfil temporal de la conversió $\mathrm{CO}_{2}(\boldsymbol{\square})$ i rendiment del $\mathrm{CO}(\bullet)$ i $\mathrm{CH}_{4}(\boldsymbol{\Delta})$. Llum de $185 \mathrm{~nm}$ a $65^{\circ} \mathrm{C}$ d'una barreja la composició inicial en volum va ser $d^{\prime} \mathrm{H}_{2}(44 \%), \mathrm{CO}_{2}(45 \%)$ i $\mathrm{N}_{2}(11 \%)$. 
Per tal d'aconseguir informació sobre l'estequiometria de la reacció i particularment els productes que sorgeixen a partir de l'oxigen provinent del $\mathrm{CO}_{2}$, es van dur a terme experiments anàlegs utilitzant mostres de $\mathrm{CO}_{2}$ marcades isotòpicament $a m b{ }^{13} \mathrm{C}^{18} \mathrm{O}_{2}$, seguint-ne la reacció mitjançant espectrometria de masses. Encara que vam detectar la presència de xicotetes quantitats $\mathrm{d}^{\prime 18} \mathrm{O}_{2}$, el producte oxigenat predominant que acompanya la formació de ${ }^{13} \mathrm{CH}_{4}$ fou $\mathrm{I}^{\prime} \mathrm{H}_{2}{ }^{18} \mathrm{O}$. L'equació 6.1 resumeix l'estequiometria proposada per a la reducció fotoquímica del $\mathrm{CO}_{2}$ que està d'acord amb els productes detectats.

$$
\mathrm{CO}_{2}+4 \mathrm{H}_{2} \underset{(<200 \mathrm{~nm})}{\stackrel{\mathrm{hv}}{\longrightarrow}} \mathrm{CH}_{4}+2 \mathrm{H}_{2} \mathrm{O} \quad \text { Eq. } 6.1
$$

La major part dels estudis duts a terme en el present capítol han fet servir un llum de mercuri que emet a dues longituds d'ona, de $185 \mathrm{~nm}$ i 254 $\mathrm{nm}$, sent aquesta segona longitud d'ona la que presenta una major intensitat de llum, corresponent aproximadament al doble que la intensitat emesa a $185 \mathrm{~nm}$ (vegeu espectre d'emissió de la làmpada de vapor de mercuri al Capítol 8 Experimental). Experiments de control usant llum filtrada de 254 $\mathrm{nm}$ provinents d'un llum de vapor de $\mathrm{Hg}$ de baixa pressió, van indicar que els fotons que originen la conversió fotoquímica del metà són els fotons emesos a $185 \mathrm{~nm}$, i l'emissió a $254 \mathrm{~nm}$ és completament ineficaç per a promoure la reacció indicada a l'equació 6.1 . 
Considerant que la fotòlisi directa del $\mathrm{H}_{2} \mathrm{O}$ amb llum UV llunyana ha estat un dels processos que van ser estudiats en els primers articles on es descriu I'ús de radiació UV Ilunyana, ${ }^{[20]}$ i que aquesta fotòlisi condueix al trencament homolítica de l'enllaç $\mathrm{OH}$ (equació 6.2) amb un rendiment quàntic proper a la unitat, considerem l'opció d'acoblar la ruptura directa del $\mathrm{H}_{2} \mathrm{O}$ amb generació $d^{\prime} \mathrm{H}_{2}$ i la reducció fotoquímica del $\mathrm{CO}_{2}$. Per estudiar aquesta possibilitat, vam dur a terme la irradiació de $\mathrm{CO}_{2}$, diluït amb $\mathrm{N}_{2}$ saturat d'humitat a temperatura ambient. La relació molar de $\mathrm{CO}_{2}$ i aigua en el temps inicial va ser d'1 a 20. En aquestes condicions es va observar la generació gradual d'hidrogen, el que indica que l'equació 6.2 està sent operativa. Convé comentar que encara que els fotons UV Ilunyans poden produir el trencament homolític de l'aigua, tal com indica l'equació 6.2, per generar àtoms d'hidrogen i radicals hidroxil, els assaigs de control emprant indicadors colorimètrics no han estat capaços de detectar la formació de quantitats mesurables de peròxid d'hidrogen en la fase gas. El peròxid d'hidrogen hauria de resultar de l'acoblament de dos radicals hidroxil. 
La concentració d'hidrogen provinent de l'aigua, augmenta de forma continuada amb el temps. A més d'hidrogen, vam observar després d'un període d'inducció la formació de metà. Les Figures 6.2 i 6.3 mostren l'evolució temporal de la conversió de $\mathrm{CO}_{2}$ i formació d'hidrogen i metà quan s'irradia en fase gas una barreja de $\mathrm{CO}_{2}$ i aigua en proporció 1:20 en absència o en presència d'una hidrotalcita laminar que conté $\mathrm{Zn}$ i Ti. En les condicions assajades no vam aconseguir detectar ni la formació de metanol ni la de CO a qualsevol temps d'irradiació. L'absència de $\mathrm{CO}$, que és un producte que ha estat prèviament observat en la fotòlisi de $\mathrm{l}^{\prime} \mathrm{CO}_{2}$ en presència d'hidrogen, sembla indicar que el trencament homolític directe del $\mathrm{CO}_{2}$ té lloc a una velocitat considerablement inferior quan hi ha $\mathrm{H}_{2} \mathrm{O}$ en el medi. Aquest fet estaria concordaria amb l'absorció preferent de fotons per part de l' $\mathrm{H}_{2} \mathrm{O}$.

A fi de determinar l'estequiometria de la reducció del $\mathrm{CO}_{2}$ per $\mathrm{H}_{2} \mathrm{O}$ i la possible evolució d' $\mathrm{O}_{2}$ durant la fotòlisi, estudiem la reacció emprant $\mathrm{CO}_{2}$ marcat isotòpicament amb ${ }^{13} \mathrm{C}^{18} \mathrm{O}_{2}$, seguint el transcurs de la reacció per espectroscòpia de masses. En aquestes condicions hi ha un excés $d^{\prime} \mathrm{H}_{2} \mathrm{O}$ respecte al ${ }^{13} \mathrm{C}^{18} \mathrm{O}_{2}$, hi observem un ràpid intercanvi del ${ }^{18} \mathrm{O}$ des del ${ }^{13} \mathrm{C}^{18} \mathrm{O}_{2}$ a $\mathrm{I}^{\prime} \mathrm{H}_{2} \mathrm{O}$ així com la formació de ${ }^{16} \mathrm{O}_{2},{ }^{16} \mathrm{O}^{18} \mathrm{O}^{\mathrm{i}}{ }^{18} \mathrm{O}_{2}$ en proporcions relatives 100 , 0.1 y $0,08 \%$, respectivament. Aquests resultats indicarien que es produeix un equilibri ràpid, possiblement implicant la formació d'àcid carbònic, amb intercanvi d'oxigen entre $\mathrm{C}^{18} \mathrm{O}_{2} \mathrm{i}_{2}{ }_{2}^{16} \mathrm{O}$ abans que ocórrega la reacció fotoquímica (equació 6.3). Aleshores, depenent de quina és la proporció inicial ${ }^{18} \mathrm{O} /{ }^{16} \mathrm{O}$ tant per al $\mathrm{CO}_{2}$ com per al $\mathrm{H}_{2} \mathrm{O}$ es produeix una evolució cap a aconseguir una distribució estadística a les poblacions de l'oxigen molecular entre ${ }^{16} \mathrm{O} \mathrm{i}^{18} \mathrm{O}$.

$\mathrm{C}^{18} \mathrm{O}_{2}+\mathrm{H}_{2} \mathrm{O} \rightleftharpoons \mathrm{OHC}{ }^{18} \mathrm{OH} \rightleftharpoons \mathrm{C}^{16} \mathrm{O}^{18} \mathrm{O}+\mathrm{H}_{2}{ }^{18} \mathrm{O} \quad$ Eq. 6.3 


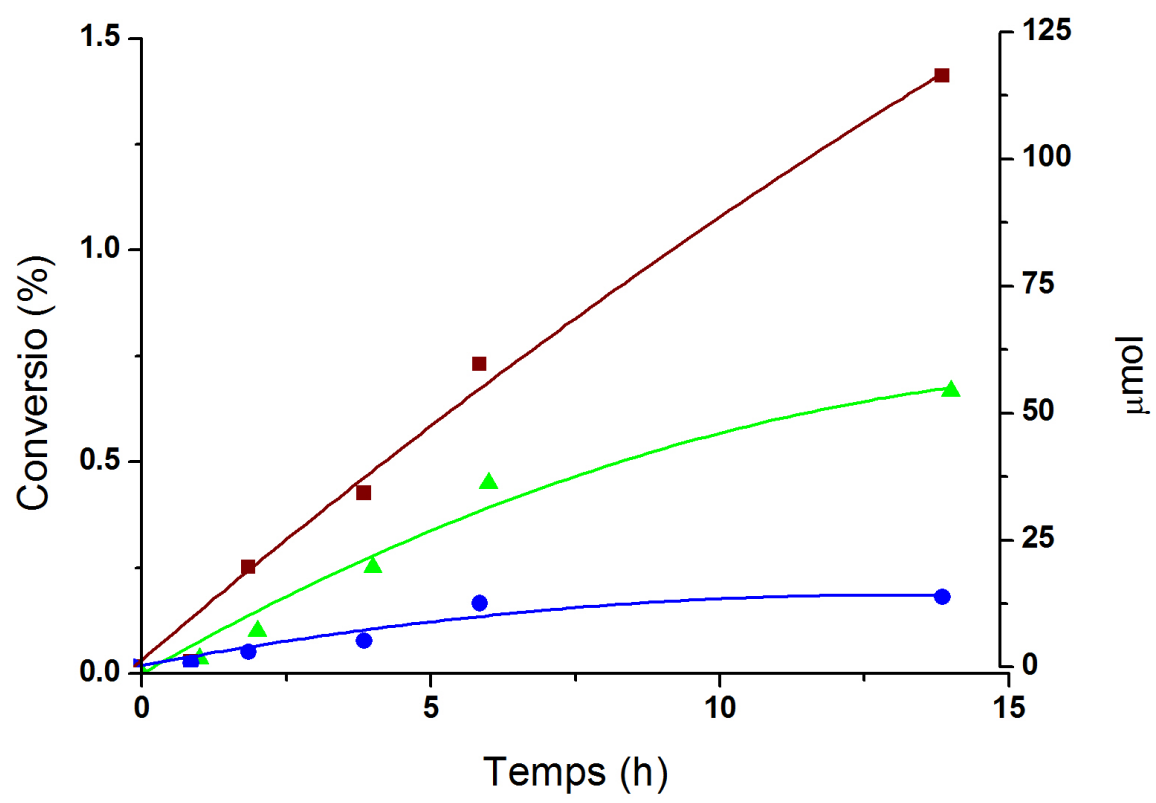

Figura 6.2. Perfil temporal de la conversió de $\mathrm{CO}_{2}$ ( $\square$, eix vertical esquerre) i formació $\mathrm{d}^{\prime} \mathrm{H}_{2}\left(\Delta\right.$, eix vertical dret) i $\mathrm{CH}_{4}$ ( $\bullet$, eix vertical dret) durant la irradiació del $\mathrm{CO}_{2}$ i l' $\mathrm{H}_{2} \mathrm{O}$ amb llum UV Ilunyana. Condicions d'irradiació: llum de mercuri emetent a $185 \mathrm{~nm}$, temperatura del reactor $60^{\circ} \mathrm{C}$, composició de la mescla inicial en volum de $\mathrm{CO}_{2}(9.5 \%)$ i $\mathrm{N}_{2}(90.5 \%)$, el sistema conté aigua en proporció 1:1 $\left(\mathrm{H}_{2} \mathrm{O}: \mathrm{CO}_{2}\right)$.

És convenient indicar que la conversió del $\mathrm{CO}_{2}$ en presència d'un excés $d^{\prime} \mathrm{H}_{2} \mathrm{O}$ és al voltant de 15 vegades menor que la irradiació del $\mathrm{CO}_{2}$ en presència d' $\mathrm{H}_{2}$. Això és a causa que l'hidrogen molecular no absorbeix la radiació a 185 $\mathrm{nm}$ i l'aigua té una banda d'absorció intensa a aquesta longitud d'ona. [21] Encara més, pel fet d'estar en un gran excés, $\mathrm{I}^{\prime} \mathrm{H}_{2} \mathrm{O}$ ha d'actuar com a filtre intern i prevé la fotòlisi del $\mathrm{CO}_{2}$. Per tal d'augmentar la conversió del $\mathrm{CO}_{2}$ es va dur a terme la fotòlisi amb un excés d' $\mathrm{H}_{2} \mathrm{O}$ molt menor. Així, quan es fotolitza una barreja de $\mathrm{CO}_{2}$ i $\mathrm{H}_{2} \mathrm{O}$ en una proporció molar d'1:1 s'aconsegueix fins a $420 \mu \mathrm{mol} \mathrm{d}^{\prime} \mathrm{H}_{2}, 60 \mu \mathrm{mol}$ de $\mathrm{CO}$ i $15 \mu \mathrm{mol}$ de $\mathrm{CH}_{4}$ amb un consum d'energia de $20 \mathrm{Gcal}^{*} \mathrm{~mol}^{-1}$. 


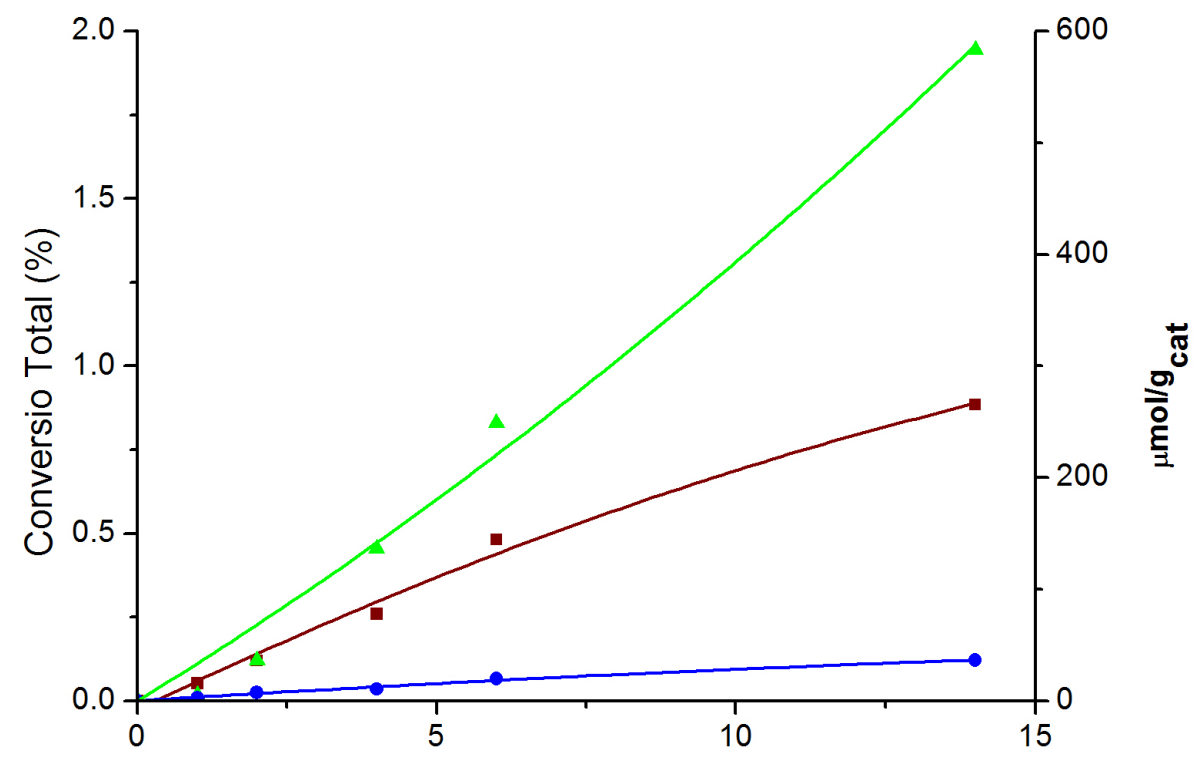

Temps $(h)$

Figura 6.3. Perfils temporals de conversió de $\mathrm{CO}_{2}(\square$, eix vertical esquerre) i de formació d' $\mathrm{H}_{2}\left(\Delta\right.$, eix vertical dret) i de $\mathrm{CH}_{4}(\bullet$, eix vertical dret) per irradiació de $\mathrm{CO}_{2}$ i $\mathrm{H} 2 \mathrm{O}$ amb llum ultraviolada Ilunyana. Condicions d'irradiació: Ilum de $\mathrm{Hg}$ emetent a $185 \mathrm{~nm}$, temperatura de la cambra $60^{\circ} \mathrm{C}$, composició inicial del gas a volum de $\mathrm{CO}_{2}(9.5 \%)$ i $\mathrm{N}_{2}(90.5 \%)$, respectivament, i està present la hidrotalcita de $\mathrm{Zn} / \mathrm{Ti}(0.5 \mathrm{~g})$. El sistema es troba saturat amb vapor d'aigua.

Tot i que el metà és el producte final més comú que hem observat en la fotòlisi amb llum UV Ilunyana del $\mathrm{CO}_{2}$ tant quan s'empra $\mathrm{H}_{2}$ com quan s'usa $\mathrm{H}_{2} \mathrm{O}$ com a agent reductor, és previsible que els mecanismes de reacció han de ser diferents almenys en part per als dos substrats. La diferència ha de sorgir del fet que $\mathrm{H}_{2}$ no absorbeix fotons de $185 \mathrm{~nm}$ i, per tant, en aquest cas, la conversió a $\mathrm{CH}_{4}$ ha de provenir necessàriament de la irradiació del $\mathrm{CO}_{2}$, probablement que s'aconsegueix usant $\mathrm{H}_{2}$ tot i que la distribució de productes és la mateixa amb els dos agents, suggereix que la fotòlisi de l'aigua podria actuar exclusivament proporcionant $\mathrm{H}_{2}$ i que el radical hidroxil i altres espècies intermediàries possibles en la fotòlisi de $\mathrm{I}^{\prime} \mathrm{H}_{2} \mathrm{O}$ no haurien d'estar implicades en la formació de $\mathrm{CH}_{4}$. 
En el capítol anterior hem mostrat com la fotòlisi amb llum UV Ilunyana pot conduir a l'activació de metà per irradiació de la superfície d'un sòlid i que l'eficiència d'aquest procés depén de la naturalesa d'aquest sòlid. ${ }^{[17,18]}$ Així hem presentat que la fotòlisi amb llum UV Ilunyana dels grups silanols superficials en silicats pot servir per activar metà cap a la formació de productes oxigenats d'un C. ${ }^{[17,18]}$

En el present estudi la situació és una mica diferent, ja que, en contrast al metà, la fotòlisi directa del $\mathrm{CO}_{2}$ pot tenir lloc en fase gas per irradiació a $185 \mathrm{~nm}$ independentment de la presència o absència de qualsevol sòlid. No obstant això, la presència d'una superfície sòlida podria produir un augment en l'eficiència del procés fotoquímic causa de l'adsorció i confinament del $\mathrm{CO}_{2}$ en un espai 2D o 3D. A més, la presència d'un sòlid podria fer possibles noves rutes al trencament fotoquímic.

Per tal de determinar la influència que superfícies sòlides puguen exercir en la fotòlisi de l' $\mathrm{CO}_{2}$ a $185 \mathrm{~nm}$, es va dur a terme una sèrie d'assajos en presència de diferents sòlids incloent ( $\mathrm{Ti}) \operatorname{Beta}$, Beta(OH) i zeolita $\mathrm{HY}$, així com òxids metàl-lics tal com $\mathrm{TiO}_{2} \mathrm{CeO}_{2}$ i $\mathrm{MgO}$. En tots aquests casos, es va observar que la conversió del $\mathrm{CO}_{2}$ fent servir hidrogen com $\mathrm{H}_{2} \mathrm{O}$ com a agent reductor patia una disminució considerable. D’aquesta manera aquests 
resultats demostren la influència negativa, que la presència d'aquests sòlids opacs pot exercir en la fotoreducció del $\mathrm{CO}_{2}$ en fase gas. Vam assajar igualment la influència d'una zeolita de porus gran de caràcter bàsic (KY) i dos hidrotalcites laminars (Zn/Ti LDH i Zn/Ce LDH) com a sòlids promotors de la reducció fotocatalítica del $\mathrm{CO}_{2}$ amb aigua.

El cas del $\mathrm{TiO}_{2}$ és interessant de comentar, considerant que aquests experiments es van dur a terme amb una font d'irradiació que conté a més de radiacions de $185 \mathrm{~nm}$, també emissió a $254 \mathrm{~nm}$ (vegeu el Capítol 8 d'experimental, que mostra l'espectre d'emissió de la llum de vapor de mercuri utilitzada en l'estudi) i que el $\mathrm{TiO}_{2}$, com s'ha descrit, presenta activitat fotocatalítica en la reducció del $\mathrm{CO}_{2}$ amb llum UV. ${ }^{[21-24]}$ Per tant, en principi seria possible l'existència d'una sinergia entre la irradiació directa amb llum UV llunyana $\left(185 \mathrm{~nm}\right.$ ) i la reducció fotocatalítica del $\mathrm{CO}_{2}$ promoguda pel $\mathrm{TiO}_{2}$ amb Ilum UV (254 nm). El fet que la conversió del $\mathrm{CO}_{2}$ disminuesca quan la reacció es porta a terme en presència de $\mathrm{TiO}_{2}$ indica clarament que la contribució de la fotòlisi directa del $\mathrm{CO}_{2}$ representa un percentatge molt més gran que la de qualsevol possible conversió fotocatalítica que implicara l'excitació del $\mathrm{TiO}_{2} \mathrm{i}$ la creació de buits i electrons en aquest semiconductor. Aquesta prevalença de la ruta originada per la llum UV Ilunyana pot ser fàcilment comprensible considerant que el mecanisme acceptat en la reducció fotocatalítica intervinguda pel $\mathrm{CO}_{2}$ implica diverses etapes que requereixen l'absorció de Ilum i que és un procés diferent al que promou la llum UV Ilunyana que causa la ruptura directa de l'enllaç $\mathrm{CO}$ amb un únic fotó.

És conegut que el $\mathrm{CO}_{2}$ és adsorbit en sòlids bàsics i aquesta adsorció és un dels fenòmens clau en què es basa el desenvolupament de materials eficients per a l'atrapament del $\mathrm{CO}_{2}{ }^{[25-27]}$. En el cas de zeolites microporoses s'ha demostrat que es pot introduir basicitat per intercanvi dels cations $\mathrm{Na}^{+}$per altres cations de metalls alcalins de major radi iònic. ${ }^{[28,29]}$ La zeolita $Y$ és un aluminosilicat cristal-lí microporós que posseeix cavitats gairebé esfèriques al voltant d'1.3 nm de diàmetre que es troben interconnectades per finestres al voltant de $0.7 \mathrm{~nm}$ desposades tetraèdricament. ${ }^{[30]}$ D'altra 
banda, les hidrotalcites (LDH) són materials laminars que contenen un catió divalent juntament amb una proporció de fins al 30\% com a màxim d'un altre catió tri- o tetravalent. Aquest catió tri- o tetravalent últim reemplaça isomòrficament algunes de les posicions en la làmina del catió divalent. ${ }^{[31,}$ ${ }^{32]}$ La presència del catió tri- o tetravalent introdueix càrregues positives a la làmina que requereixen la presència d'anions de compensació de càrrega en l'espai interlaminar. ${ }^{[31,32]} \mathrm{El}$ carbonat és un dels anions que es troba més comunament present en els materials LDH i, fins i tot, si un altre ió està inicialment present en el sòlid, aquest pot ser reemplaçat per carbonat a causa de la major afinitat que presenten les LDH per a aquests anions dinegatius. ${ }^{[131,32]}$ Les LDHs han estat també usades per catalitzar reaccions de condensació de compostos carbonílics i de substitució nucleofílica entre d'altres processos. ${ }^{[33,34]}$

Taula 6.1. Conversió de $\mathrm{CO}_{2}$, balanç molar, selectivitat i consum energètic per a la fotòlisi amb irradiació ultraviolada profund de $\mathrm{CO}_{2}$ en presència de sòlids bàsics. Condicions de la fotòlisi: mescla de $\mathrm{N}_{2}(90.5 \%)$ saturada en aigua i $\mathrm{CO}_{2}$ (9.5\%). Temps d'irradiació, 14 h. Quantitat sòlid 500 mg o la quantitat indicada al peu de la taula. Distribució del catalitzador en forma de capa fina uniforme de superfície $4 \times 13 \mathrm{~cm}^{2} \mathrm{i}$ il-luminat amb una potència de $86 \mathrm{w} / \mathrm{cm}^{2}$.

\begin{tabular}{|c|c|c|c|c|c|c|c|}
\hline \multirow{2}{*}{ Catalitzador } & \multirow{2}{*}{$\begin{array}{l}\text { Conversió } \\
\text { de } \mathrm{CO}_{2}(\%)\end{array}$} & \multirow{2}{*}{$\begin{array}{l}\text { Balanç } \\
\text { molar }\end{array}$} & \multicolumn{2}{|c|}{ Selectivitat } & \multirow{2}{*}{$\begin{array}{c}\text { Consum } \\
\text { d'energia } \\
\text { (Gcal/mol) }\end{array}$} & \multirow{2}{*}{$\underset{\left(g_{\text {cat }} h\right)^{2}}{\mu \operatorname{mol} H_{2} /}$} & \multirow{2}{*}{$\underset{\left(\mathrm{g}_{\text {cat }} \mathrm{h}\right)}{\mu \mathrm{CH}_{4} /}$} \\
\hline & & & $\mathrm{CO}$ & $\mathrm{CH}_{4}$ & & & \\
\hline $\begin{array}{c}\text { Sense } \\
\text { catalitzador }\end{array}$ & 0.67 & 96.8 & 0 & 100 & 14.9 & $9.9^{[c]}$ & $2.1^{[c]}$ \\
\hline KY & 0.85 & 98.6 & 0 & 100 & 11.7 & 63.2 & 3.1 \\
\hline $\mathrm{HT} \mathrm{Zn} / \mathrm{Ce}$ & 1.14 & 99.9 & 0 & 100 & 8.7 & 33.1 & 4.3 \\
\hline $\mathrm{HT} \mathrm{Zn} / \mathrm{Ti}$ & 0.88 & 99.9 & 0 & 100 & 11.2 & 41.4 & 3.3 \\
\hline $\mathrm{HT} \mathrm{Zn} / \mathrm{Ti}^{[\mathrm{a}]}$ & 2.21 & 95.3 & 0 & 100 & 4.5 & 740 & 77 \\
\hline $\mathrm{HT} \mathrm{Zn} / \mathrm{Ti}^{[\mathrm{b}]}$ & 1.75 & 99.9 & 0 & 100 & 5.4 & 31.2 & 3.77 \\
\hline $\mathrm{MgO}$ & 0.23 & 98.9 & 0 & 100 & 42.8 & 14 & 0.63 \\
\hline
\end{tabular}

[a] $100 \mathrm{mg}$ catalitzador.

[b] $50 \mathrm{mg}$ catalitzador.

[c] $\mu \mathrm{mol} \mathrm{CH}_{4} / \mathrm{h}$. 
En aquest context la influència positiva de la presència de la zeolita $\mathrm{KY}$ ○ LDH com a catalitzadors en les fotoreduccions de $\mathrm{CO}_{2}$ per $\mathrm{H}_{2} \mathrm{O}$ pot ser racionalitzada considerant que per la seva basicitat aquests sòlids són adsorbents de $\mathrm{CO}_{2}$. Així, a causa de l'adsorció de $\mathrm{CO}_{2}$ a la superfície d'aquests sòlids, la fotoreducció de $\mathrm{CO}_{2}$ per aigua, podria ocórrer preferentment sobre la superfície del sòlid on hi hauria una elevada concentració d'aquestes dues molècules. En favor d'aquesta proposta vam dur a terme experiments usant $\mathrm{H}_{2}$ en lloc d'aigua com a agent reductor. En aquestes condicions i considerant que l'adsorció d' $\mathrm{H}_{2}$ gas sobre la superfície del sòlid a $60^{\circ} \mathrm{C}$ deu ser menyspreable en contrast amb la forta absorció de $\mathrm{CO}_{2}$, vam observar que la presència de qualsevol dels sòlids juga un paper negatiu reduint la conversió de $\mathrm{CO}_{2}$ respecte a les conversions que s'observen en absència de qualsevol material. Per tant, la comparació de les conversions en presència de sòlids utilitzant $\mathrm{H}_{2}$ gas $\mathrm{o}_{2} \mathrm{O}$ com a agent reductor, indiquen clarament les diferències notables en el mecanisme de reacció en funció dels substrats i permeten implementar l'ús de superfícies sòlides com fotocatalitzadors per augmentar la conversió de $\mathrm{CO}_{2}$ a la fotòlisi amb llum UV Ilunyana.

Respecte a la possibilitat que les LDH de ( $\mathrm{Zn} / \mathrm{Ti})$ o ( $\mathrm{Zn} / \mathrm{Ce})$ actuaren simplement com sòlids adsorbents de $\mathrm{CO}_{2}$ o si, a més de la seva capacitat d'adsorció aquestes $\mathrm{LDH}$ contenint $\mathrm{Zn}$, promouen la reducció de $\mathrm{CO}_{2}$ també fotocatalíticament, absorbint llum i injectant-la al $\mathrm{CO}_{2}$, és digne de comentar la diferència en el comportament d'aquestes LDH de Zn respecte a altres LDHs bàsiques o MgO. En principi, totes les LDH així com el MgO haurien adsorbir quantitats significatives de $\mathrm{CO}_{2}$ si l'adsorció fos l'únic factor que operés en el mecanisme de reacció, és a dir, no hi hauria fotocatàlisi. Totes elles haurien de mostrar un comportament similar activant la reacció. Aparentment aquest no és el cas, i la composició de les LDH i la naturalesa del sòlid juguen un paper en la fotoreducció del $\mathrm{CO}_{2}$. Aquesta influència dels metalls presents en el LDH i particularment el fet que les LDH de $\mathrm{Zn}$ tinguen activitat fotocatalítica per promoure el trencament de $l^{\prime} \mathrm{H}_{2} \mathrm{O}^{[35]}$ suggereixen que també en el cas que ens ocupa hi ha alguna contribució de fotocatàlisi quan la fotòlisi es porta a terme 
en presència de certs LDH. Per tant, sembla que, per tal de desenvolupar materials més actius per dur a terme la reducció fotocatalítica del $\mathrm{CO}_{2}$, els sòlids s'haurien de combinar amb una elevada capacitat d'adsorció del $\mathrm{CO}_{2}$ juntament amb una fotoresposta a la longitud d'ona de la irradiació. Considerant l'àmplia diversitat en els metalls que poden estar presents en la composició de hidrotalcites, aquests materials posseeixen un gran potencial per a dur a terme la reducció fotocatalítica del $\mathrm{CO}_{2}$. 


\section{Conclusions}

En el present capítol hem mostrat que la fotòlisi a $185 \mathrm{~nm}$ del $\mathrm{CO}_{2}$ en presència d' $\mathrm{H}_{2} \mathrm{O} \mathrm{d}^{\prime} \mathrm{H}_{2} \mathrm{O}$, condueix a la formació de $\mathrm{CH}_{4}$. Quan l'agent reductor és $\mathrm{H}_{2} \mathrm{O}$ hi ha la possibilitat d'augmentar l'eficiència del procés duent a terme la reacció a la superfície de sòlids d'una basicitat adequada. El consum d'energia per mol de $\mathrm{CO}_{2}$ convertit varia depenent de les condicions, però quan és $\mathrm{H}_{2} \mathrm{O}$ l'agent reductor és de $4.5 \mathrm{Gcal}^{*} \mathrm{~mol}^{-1} \mathrm{CO}_{2}$ convertit. Aquest valor està en el mateix rang que altres processos industrials que es duen a terme a gran escala com ara el reformat de metà al vapor. ${ }^{[17,18]}$ Els nostres resultats obrin la possibilitat d'emprar sòlids com a fotocatalitzadors per a augmentar l'eficiència en la fotoreducció del $\mathrm{CO}_{2}$ amb $\mathrm{H}_{2} \mathrm{O}$ utilitzant radiació de longitud d'ona en I'UV Ilunyà. 



\section{Referències}

1. Anpo, M., H. Yamashita, Y. Ichihashi, et al."Photocatalytic reduction of $\mathrm{CO}_{2}$ with $\mathrm{H} 2 \mathrm{O}$ on titanium oxides anchored within micropores of zeolites: Effects of the structure of the active sites and the addition of Pt", Journal of Physical Chemistry B, 1997. 101: p. 2632-2636.

2. Sayama, K. and H. Arakawa."Photocatalytic decomposition of water and photocatalytic reduction of carbon dioxide over $\mathrm{ZrO}_{2}$ catalyst", Journal of Physical Chemistry, 1993. 97: p. 531-533.

3. Song, C.S."Global challenges and strategies for control, conversion and utilization of $\mathrm{CO}_{2}$ for sustainable development involving energy, catalysis, adsorption and chemical processing", Catalysis Today, 2006. 115: p. 2-32.

4. Centi, G. and S. Perathoner."Towards Solar Fuels from Water and $\mathrm{CO}_{2}$ ", ChemSusChem, 2010. 3: p. 195-208.

5. Hammarstrom, L. and S. Hammes-Schiffer."Artificial Photosynthesis and Solar Fuels", Accounts of Chemical Research, 2009. 42: p. 18591860.

6. Roy, S.C., O.K. Varghese, M. Paulose, and C.A. Grimes."Toward Solar Fuels: Photocatalytic Conversion of Carbon Dioxide to Hydrocarbons", ACS Nano, 2010. 4: p. 1259-1278.

7. Serpone, N., D. Lawless, and R. Terzian."Solar fuels: status and perspectives", Solar Energy, 1992. 49: p. 221-34.

8. Hwanga, J.-S., J.-S. Changa, S.-E. Parkb, et al."Photoreduction of carbondioxide on surface functionalized nanoporous catalysts", Top. Catal., 2005. 35: p. 311-319.

9. Mori, K., H. Yamashita, and M. Anpo."Photocatalytic reduction of $\mathrm{CO}_{2}$ with $\mathrm{H}_{2} \mathrm{O}$ on various titanium oxide photocatalysts", RSC Adv., 2012. DOI: 10.1039/c2ra01332k. 
10. Mahan, B.H."Photolysis of carbon dioxide", J. Chem. Phys., 1960. 33: p. 959-65.

11. Reeves, R.R., P. Harteck, B.A. Thompson, and R.W. Waldron."Photochemical equilibrium studies of carbon dioxide and their significance for the Venus atmosphere", J. Phys. Chem., 1966. 70: p. 1637-40.

12. Warneck, P."Reactions of ${ }^{1} D$ oxygen atoms in the photolysis of carbon dioxide", Discuss. Faraday Soc., 1964. No. 37: p. 57-65.

13. Bar-Nun, A. and H. Hartman."Synthesis of organic compounds from carbon monoxide and water by UV photolysis", Orig Life, 1978. 9: $p$. 93-101.

14. Bard, A.J. and M.A. Fox."Artificial Photosynthesis: Solar Splitting of Water to Hydrogen and Oxygen", Accounts of Chemical Research, 1995. 28: p. 141-5.

15. Gratzel, M."ARTIFICIAL PHOTOSYNTHESIS - WATER CLEAVAGE INTO HYDROGEN AND OXYGEN BY VISIBLE-LIGHT", Accounts of Chemical Research, 1981. 14: p. 376-384.

16. Gust, D., T.A. Moore, and A.L. Moore."Mimicking Photosynthetic Solar Energy Transduction", Accounts of Chemical Research, 2001. 34: p. 40-48.

17. Sastre, F., V. Fornes, A. Corma, and H. Garcia."Selective, RoomTemperature Transformation of Methane to C1 Oxygenates by Deep UV Photolysis over Zeolites", Journal of the American Chemical Society, 2011. 133: p. 17257-17261.

18. Sastre, F., V. Fornes, A. Corma, and H. Garcia."Conversion of Methane into C1 Oxygenates by Deep-UV Photolysis on Solid Surfaces: Influence of the Nature of the Solid and Optimization of Photolysis Conditions", Chemistry-a European Journal, 2012. 18: p. 1820-1825.

19. Parkinson, W.H., J. Rufus1, and K. Yoshino."Absoluteabsorptioncross sectionmeasurements of in the wavelength region 163 ? $200 \mathrm{~nm}$ and the temperature dependence ", Chemical Physics, 2003. 293: p. 251256.

20. Getoff, N. and G.O. Schenk."Primary products of Iliquid water photolysis at 1236, 1470 and 1849 amstrong", Photochem. Photobiol., 1968. 8: p. $167-178$.

21. Koci, K., L. Obalová, L. Matejová, et al."Effect of $\mathrm{TiO}_{2}$ particle size on the photocatalytic reduction of $\mathrm{CO}_{2}$ ", Appl. Catal. B-Environ., 2009. 89: p. 494-502.

22. Dey, G.R."Chemical Reduction of $\mathrm{CO}_{2}$ to Different Products during Photo Catalytic Reaction on TiO2 under diverse Conditions: an Overview", J. Nat. Gas Chem., 2007. 16: p. 217-226. 
23. Fujishima, A., X. Zhang, and D.A. Tryk." $\mathrm{TiO}_{2}$ photocatalysis and related surface phenomena", Surf. Sci. Rep., 2008. 63: p. 515-582.

24. Ilie, M., B. Cojocaru, V.I. Parvulescu, and H. Garcia."Improving $\mathrm{TiO} 2$ activity in photo-production of hydrogen from sugar industry wastewaters", International Journal of Hydrogen Energy. 36: p. 1550915518.

25. Gascon, J., U. Aktay, M.D. Hernandez-Alonso, et al."Amino-based metal-organic frameworks as stable, highly active basic catalysts", Journal of Catalysis, 2009. 261: p. 75-87.

26. Lavalley, J.C."Infrared spectrometric studies of the surface basicity of metal oxides and zeolites using adsorbed probe molecules", Catalysis Today, 1996. 27: p. 377-401.

27. Plaza, M.G., C. Pevida, A. Arenillas, et al."CO, capture by adsorption with nitrogen enriched carbons", Fuel, 2007. 86: p. 2204-2212.

28. Barthomeuf, D."Basic zeolites: Characterization and uses in adsorption and catalysis", Catalysis Reviews-Science and Engineering, 1996. 38: p. 521-612.

29. Barthomeuf, D., G. Coudurier, and J.C. Vedrine."Basicity and basic catalytic properties of zeolites", Materials Chemistry and Physics, 1988. 18: p. 553-575.

30. Meier, W.M., D.H. Olson, and C. Baerlocher."Atlas of Zeolite Structure Types", Zeolites, 1996. 17: p. 1-229.

31. Cavani, F., F. Trifiro, and A. Vaccari."Hydrotalcite type anionic Clays: preparation, properties and applications", Catalysis Today, 1991. 11: p. 173-301.

32. Miyata, S."Anion-exange properties of hydrotalcite like compounds", Clays and Clay Minerals, 1983. 31: p. 305-311.

33. Climent, M.J., A. Corma, S. Iborra, and J. Primo."Base catalysis for fine chemicals production Claisen-Schmidt condensation on zeolites and hydrotalcites for the poduction of chalcones and flavanones of pharmaceutical interest", Journal of Catalysis, 1995. 151: p. 60-66.

34. Sels, B.F., D.E. De Vos, and P.A. Jacobs."Hydrotalcite-like anionic clays in catalytic organic reactions", Catalysis Reviews-Science and Engineering, 2001. 43: p. 443-488.

35. Silva, C.u.G., Y.s. Bouizi, V. Fornés, and H. García."Layered Double Hydroxides as Highly Efficient Photocatalysts for Visible Light Oxygen Generation from Water", Journal of the American Chemical Society, 2009. 131: p. 13833-13839. 



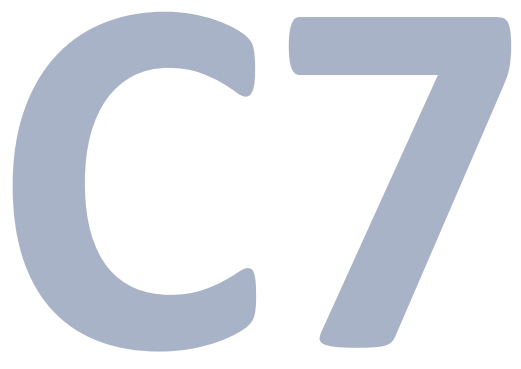

\section{Generació d' $\mathrm{H}_{2} \mathrm{O} \mathrm{CH}_{4}$ a partir de $\mathrm{CO}_{2}$ per reducció en dues etapes}



Com venim comentanta la present tesi doctoral, la reducció fotocatalítica del $\mathrm{CO}_{2}$ podria servir per a obtenir d'una manera sostenible combustibles que puguen ser emprats en el transport. ${ }^{[1-5]}$ En el capítol anterior s'ha descrit la reducció fotocatalítica amb llum UV llunyana de $\mathrm{CO}_{2}$ emprant $\mathrm{H}_{2} \circ \mathrm{H}_{2} \mathrm{O}$ com a agent reductor. Tenint en compte que el $\mathrm{CO}_{2}$ presenta absorció entre 180 i $200 \mathrm{~nm}$ hem observat que, tal com hem descrit en el capítol anterior, la fotorreacció del $\mathrm{CO}_{2}$ amb $\mathrm{H}_{2}$ transcorre en absència de qualsevol sòlid en fase gas amb elevats rendiments. És més, per a aquest procés de reducció fotoquímica la presència de sòlids juga un paper advers, disminuint les conversions de $\mathrm{CO}_{2}$ que s'aconsegueixen a un temps determinat.

La consideració del mecanisme del procés de fotorreducció del $\mathrm{CO}_{2}$ per $\mathrm{H}_{2}$ en absència de qualsevol sòlid porta a proposar que el substrat que absorbeix llum és el $\mathrm{CO}_{2}$ el qual, considerant l'energia tan elevada d'un fotó a la zona de I'UV llunyana, podria patir ruptura homolítica de l'enllaç C-O per donar $\mathrm{CO}$ que de fet s'observa com a producte primari a temps curts de reacció. A partir del $\mathrm{CO}$, les següents etapes podrien implicar alguna forma de C elemental com a intermedi de reacció seguida d'hidrogenació no catalitzada per $\mathrm{H}_{2}$ gas, possiblement amb la formació de metilè com a intermedi. Les equacions 7.1 a 7.7 descriuen els processos elementals que podrien justificar la formació de $\mathrm{CH}_{4}$ per irradiació de $\mathrm{CO}_{2}$, justificant la presència de xicotetes quantitats de $\mathrm{CO}$ en la mescla de reacció. 

$\mathrm{CO}_{2}$
$\underset{(<200 \mathrm{~nm})}{\stackrel{h v}{(<v)}}$
$\mathrm{CO}+1 / 2 \mathrm{O}_{2}$
Eq. 7.1
$\begin{array}{llll}\mathrm{CO}+2 \mathrm{H}_{2} \underset{(<200 \mathrm{~nm})}{\mathrm{C}+\mathrm{H}_{2}} \mathrm{CH}_{4}+1 / 2 \mathrm{O}_{2} & \text { Eq. } 7.2 \\ \mathrm{CH}_{2} & \text { Eq. } 7.3\end{array}$
$\mathrm{CH}_{2}+\mathrm{H}_{2} \longrightarrow \mathrm{CH}_{4} \quad$ Eq. 7.4
$\mathrm{CH}_{2}+\mathrm{CH}_{4} \longrightarrow \mathrm{CH}_{3} \mathrm{CH}_{3}+\mathrm{H}_{2}$ Eq. 7.5
$\mathrm{CH}_{2}+\mathrm{CH}_{3} \mathrm{CH}_{3} \longrightarrow \mathrm{CH}_{3} \mathrm{CH}_{2} \mathrm{CH}_{3}+\mathrm{H}_{2}$ Eq. 7.6

A la vista d'aquest mecanisme de reacció seria possible considerar un procés d'activació del $\mathrm{CO}_{2}$ en dues etapes. En la primera d'elles, la irradiació del $\mathrm{CO}_{2}$ es faria en fase gas i, en absència de qualsevol agent reductor amb llum de longitud d'ona de la zona de I'UV profund, hauria de donar lloc a la formació de $\mathrm{CO}$ o $\mathrm{CO}$ més $\mathrm{C}_{\mathrm{i}} \mathrm{O}_{2}$. Sorprenentment no hem trobat a la bibliografia l'estudi de la fotòlisi directa del $\mathrm{CO}_{2}$ en absència d'agents reductors que contenen hidrogen, de manera que aquesta primera etapa en fase gas mereix ser estudiada. La segona etapa consistiria en la reacció del CO amb un agent reductor. Desacoblar aquesta segona etapa consisteix en la irradiació del $\mathrm{CO}$ de la primera, on el substrat a irradiar és el $\mathrm{CO}_{2}$; aquest fet permetria l'ocupació de condicions diferents que les que són necessàries per activar el $\mathrm{CO}_{2}$. Així la reacció del $\mathrm{CO}$ amb agents reductors que contenen $\mathrm{H}_{2}$ es podria dur a terme irradiant amb radiació de longituds d'ona majors que les que són necessàries en el capítol anterior per activar el $\mathrm{CO}_{2}$. En particular seria interessant provar longituds d'ona de l'UV proper i fins i tot llum visible o Ilum solar. En aquestes condicions es requeriria l'ús d'un fotocatalitzador que 168 fóra capaç d'activar el CO. Tenint en compte l'elevada reactivitat del CO que 
és capaç de coordinar-se com lligant amb centres metàl-lics, a més de la seua naturalesa anfotèrica, capaç d'actuar com a espècie acceptora o donadora d'electrons, reduint-se a formaldehid o altres espècies, i oxidant-se a $\mathrm{CO}_{2}$, la fotoreactivitat d'aquesta espècie seria completament diferent a la del $\mathrm{CO}_{2}$. En altres paraules un procés en dues etapes permetria la irradiació del $\mathrm{CO}_{2}$ en fase gas amb llum UV Ilunyana per formar CO i la posterior irradiació del $\mathrm{CO}$ amb llum visible o solar emprant un fotocatalitzador. Les equacions 7.7 a 7.10 resumeixen aquesta hipotètica ruta d'activació del $\mathrm{CO}_{2}$ tenint el $\mathrm{CO}$ com a compost intermedi.

$$
\begin{aligned}
& \mathrm{CO}_{2} \stackrel{\mathrm{h} v}{\longrightarrow} \mathrm{CO}+1 / 2 \mathrm{O}_{2} \text { Eq. } 7.7 \\
& \mathrm{CO}+2 \mathrm{H}_{2} \underset{\text { (UV o visible) }}{\mathrm{h} \mathrm{v}} \mathrm{CH}_{4}+1 / 2 \mathrm{O}_{2} \text { Eq. } 7.8
\end{aligned}
$$

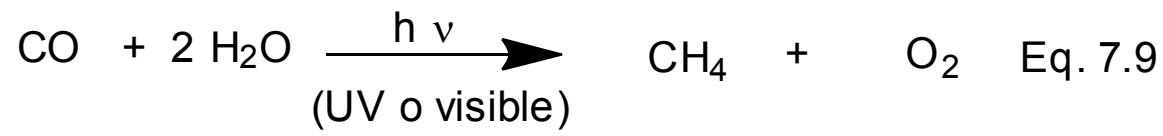

$$
\begin{aligned}
& \mathrm{CO}+\mathrm{H}_{2} \mathrm{O} \underset{\text { (UV o visible) }}{\mathrm{hv}} \mathrm{CO}_{2}+\mathrm{H}_{2} \text { Eq. } 7.10
\end{aligned}
$$

A la vista d'aquestes consideracions, seria possible una ruta en dues etapes d'activació de $\mathrm{CO}_{2}$. El present capítol descriu els resultats que s'obtenen per:

a) Irradiació del $\mathrm{CO}_{2}$ en fase gas amb llum UV Ilunyana.

b) Irradiació fotocatalítica del $\mathrm{CO}$ en presència de compostos contenint $\mathrm{H}_{2}$.

Els resultats que es presenten ací són d'interès en el context de desenvolupar processos que tinguen com a material de partida el $\mathrm{CO}_{2}$. 



\section{Resultats $i$

En el capítol anterior hem comentat com la irradiació del $\mathrm{CO}_{2}$ amb llum UV Ilunyana de $185 \mathrm{~nm}$ pot ser promoguda per la presència de materials bàsics quan la irradiació es porta a terme amb un gran excés de vapor d $\mathrm{d}^{\prime} \mathrm{H}_{2} \mathrm{O}$. Les condicions del capítol anterior presentaven un excés de fins a 20 vegades la quantitat d' $\mathrm{H}_{2} \mathrm{O}$ respecte al $\mathrm{CO}_{2}$. El motiu d'aquest excés tan gran és la dificultat d'aconseguir mostres on el vapor $\mathrm{d}^{\prime} \mathrm{H}_{2} \mathrm{O}$ estiguera en una quantitat inferior. La presència de vapor $\mathrm{d}^{\prime} \mathrm{H}_{2} \mathrm{O}$ pot tenir un paper desfavorable en la conversió del $\mathrm{CO}_{2}$ a causa que l' $\mathrm{H}_{2} \mathrm{O}$ presenta un coeficient d'absorció molar en I'UV Ilunyà superior al del $\mathrm{CO}_{2}$, un fet que implica que aquesta molècula actua en certa manera com a filtre intern evitant la irradiació directa del $\mathrm{CO}_{2} \cdot{ }^{[6]}$

Per tal de superar aquest problema, en aquesta secció es descriuen els resultats de dues irradiacions amb llum UV Ilunyana alternatives on $s^{\prime}$ ha procedit a reduir la proporció $\mathrm{d}^{\prime} \mathrm{H}_{2} \mathrm{O}$ present en el medi bé mitjançant 
deshidratació parcial amb $\mathrm{H}_{2} \mathrm{SO}_{4}$, alimentant el reactor amb gasos que han bombollejat en aquest àcid o bé mitjançant la irradiació a temperatura per baix del punt de congelació de l' $\mathrm{H}_{2} \mathrm{O}$ amb el que es redueix notablement la pressió de vapor $\mathrm{d}^{\prime} \mathrm{H}_{2} \mathrm{O}$ en la fase gas del fotorreactor.

Els resultats obtinguts en aquestes dues condicions es resumeixen a la Taula 7.1.

Taula 7.1. Irradiació directa amb llum de longitud d'ona de $185 \mathrm{~nm}$ del $\mathrm{CO}_{2}$ en absència de sòlids. Temps d'irradiació, $4 \mathrm{~h}$.

\begin{tabular}{|c|c|c|c|c|}
\hline \multirow{2}{*}{ Condicions } & \multirow{2}{*}{$\begin{array}{c}\text { Conversió } \\
\text { total (\%) }\end{array}$} & \multirow{2}{*}{$\begin{array}{c}\text { Balanç molar } \\
(\%)\end{array}$} & \multicolumn{2}{|c|}{ Rendimient (\%) } \\
\hline & & & $\mathrm{CO}$ & $\mathrm{CH}_{4}$ \\
\hline Gasos saturats d' $\mathrm{H}_{2} \mathrm{O}$ & 0.2 & 97 & 0 & 0.7 \\
\hline $\begin{array}{l}\text { Temperatura inferior al } \\
\text { punt de congelació }\end{array}$ & 0.7 & 97 & 0.7 & -- \\
\hline $\begin{array}{l}\text { Gasos assecats } \\
\text { mitjançant } \mathrm{H}_{2} \mathrm{SO}_{4}\end{array}$ & 1.7 & 99.9 & 0.2 & 1.5 \\
\hline
\end{tabular}

Com es pot veure a la Taula 7.1 quan la irradiació es porta a terme amb un menor contingut d'aigua s'aconsegueixen conversions de $\mathrm{CO}_{2}$ notablement superiors a les que s'han presentat en el capítol anterior per a les irradiacions en presència d'un excés d' $\mathrm{H}_{2} \mathrm{O}$. Dels dos experiments duts a terme en el present capítol, aquell en què certa quantitat d'aigua va estar present (gasos assecats amb $\mathrm{H}_{2} \mathrm{SO}_{4}$ ) va donar lloc a un alt contingut en $\mathrm{CH}_{4}$, el qual va ser el producte observat amb una selectivitat superior al $90 \%$. Per a aquest procés se suggereix un mecanisme com l'indicat en les equacions 7.1

172 a 7.4. En elles, de forma independent, té lloc la fotòlisi de l' $\mathrm{H}_{2} \mathrm{O}$ per generar 
$\mathrm{H}_{2}$ i $\mathrm{O}_{2}$ i la fotòlisi de $\mathrm{CO}_{2}$ a $\mathrm{CO}, \mathrm{C}$ elemental, carbè i $\mathrm{CH}_{4}$. Aquests dos últims processos requereixen la presència d' $\mathrm{H}_{2}$ format en la fotòlisi de $\mathrm{l}^{\prime} \mathrm{H}_{2} \mathrm{O}$.

En contrast, la reacció de deshidratació que va ser duta a terme disminuint la temperatura de la cel·la va donar lloc com a únic producte de reacció el CO i, com resultaria lògic, considerant l'absència d'aigua i qualsevol altra font d'hidrogen en el medi, no es va formar cap hidrocarbur. En aquest procés la formació de carboni elemental pot tenir lloc igualment encara que el balanç de matèria (96\%) indica que el contingut de carboni elemental, cas de formar seria baix.

En qualsevol cas els experiments mostrats en el present capítol proven clarament que un procés possible per a l'activació del $\mathrm{CO}_{2}$ en seria la irradiació directa amb radiacions UV de la zona llunyana en presència o absència d'un substrat que continguera $\mathrm{H}_{2}$. 
Vam dur a terme una sèrie d'irradiacions en què vam emprar, en primer lloc llum, solar simulada i un fotocatalitzador per tal de promoure la reacció del $\mathrm{CO}$ amb $\mathrm{H}_{2} \mathrm{O}$.

Entre els fotocatalitzadors assajats, alguns d'ells van donar una fotoactividad nul·la o menyspreable, observant-se en el millor dels casos una conversió de CO inferior al 5\% a temps d'irradiació entorn a les 24h. La llista de fotocatalitzadors per als quals no es va observar cap conversió en el CO inclou $\mathrm{CdS}, \mathrm{ZnS}, \mathrm{Ga}_{2} \mathrm{O}$, i $\mathrm{ZnO}$ i el material reticular orgànic de coure $\mathrm{Cu}_{3}(\mathrm{BTC})_{2}$ (BTC: Benzè-1,3,5-tricarboxilat). En els casos de $\mathrm{I}^{\prime} \mathrm{Bi}_{2} \mathrm{O}_{5} \mathrm{i} \mathrm{V}_{2} \mathrm{O}_{5}$ es va observar una conversió detectable del CO però sensiblement inferior al 5\%.

$\mathrm{CH}_{4}+2 \mathrm{H}_{2} \mathrm{O} \longrightarrow \mathrm{CO}_{2}+4 \mathrm{H}_{2} \quad$ Eq. 7.11

$\mathrm{CO}+\mathrm{H}_{2} \mathrm{O} \longrightarrow \mathrm{CO}_{2}+\mathrm{H}_{2} \quad$ Eq.7.12 (WGS)

En contrast amb aquests resultats preliminars, l'ús de $\mathrm{P}_{25} \mathrm{TiO}_{2} \circ \mathrm{CeO}_{2}$ modificats amb nanopartícules metàl-liques van donar lloc a conversions significatives de $\mathrm{CO}$, el qual es va transformar en presència d'aigua en $\mathrm{CO}_{2}$ amb evolució d' $\mathrm{H}_{2}$. Les equacions 7.11 i 7.12 resumeixen el procés fotocatalític promogut per llum solar en presència de $\mathrm{TiO}_{2} \mathrm{i} \mathrm{CeO}_{2}$ modificats per metalls nobles. Aquesta equació és coneguda en la literatura química 
com desplaçament amb vapor d'aigua ("water gas shift", WGS), la qual és duta a terme a escala industrial per tal d'aconseguir generació d' $\mathrm{H}_{2}$ a partir de l'aigua i evitar la presència de $\mathrm{CO}$ en determinats efluents gasosos. De fet, la reacció WGS va acoblada amb la de reformat al vapor ("Steam Reforming", $S R$ ) i, en conjunt, les dues produeixen la generació d' $\mathrm{H}_{2} i \mathrm{CO}_{2}$ a partir de l' $\mathrm{H}_{2} \mathrm{O}$ i hidrocarburs o carbó mineral. ${ }^{[7-9]}$ Convé fer notar que la reacció de WGS és duta a terme industrialment a temperatures superiors al voltant dels $350^{\circ} \mathrm{C}$ i sense irradiació fotoquímica. En contrast, els resultats que descrivim en el present capítol han estat obtinguts a temperatura ambient utilitzant llum solar simulada o llum visible com a energia per promoure el procés de trencament de l'aigua i formació d' $\mathrm{H}_{2}$. Com a fotocatalitzadors vam emprar sis òxids de titani modificats que contenien nanopartícules metàl-liques i altres tres òxids de ceri, que contenien al seu torn nanopartícules d'Au depositades sobre la seua superfície. La Taula 7.2 conté una llista dels materials emprats com fotocatalitzadors, les seues propietats texturals i dades analítiques més rellevants.

Taula 7.2. Materials emprats com a fotocatalitzadors que contenen un metall noble i les seues propietats texturals i dades analítiques.

\begin{tabular}{cccc}
\hline Fotocatalitzador & $\begin{array}{c}\text { Contingut de } \\
\text { metall (pes \%) }\end{array}$ & $\begin{array}{c}\text { Àrea superficial } \\
\mathrm{BET}\left(\mathrm{m}^{2} / \mathrm{g}\right)\end{array}$ & $\begin{array}{c}\text { Grandària de la } \\
\text { nanopartícula } \\
(\mathrm{nm})\end{array}$ \\
\hline $\mathrm{P} 25 \mathrm{TiO}_{2}$ & -- & 50 & -- \\
$\mathrm{CeO}_{2}$ & -- & 250 & -- \\
$\mathrm{Pd} / \mathrm{TiO}_{2}$ & 1 & 50 & $5-10$ \\
$\mathrm{Cu} / \mathrm{TiO}_{2}$ & 1 & 50 & $15-30$ \\
$\mathrm{Pt} / \mathrm{TiO}_{2}$ & 1 & 50 & 10 \\
$\mathrm{Au} / \mathrm{TiO}_{2}$ & 1 & $40-50$ & 20 \\
$\mathrm{Ag} / \mathrm{TiO}_{2}$ & 1 & 50 & $15-20$ \\
$\mathrm{Au} / \mathrm{CeO}_{2}(0.2)$ & 0.2 & 252 & $3-8$ \\
$\mathrm{Au} / \mathrm{CeO}_{2}(0.5)$ & 0.5 & 252 & $3-8$ \\
$\mathrm{Au} / \mathrm{CeO}_{2}(1)$ & 1 & 252 & $1-3$ \\
\hline
\end{tabular}


La irradiació amb llum solar simulada dels òxids de titani i de ceri modificats amb nanopartícules metàl-liques en contacte amb $\mathrm{CO}$ saturat amb vapor d' $\mathrm{H}_{2} \mathrm{O}$ va donar lloc en tots els casos a la formació de $\mathrm{CO}_{2}$ i $\mathrm{H}_{2}$ amb rendiments variables depenent de cada fotocatalitzador.

A la vista dels resultats indicats a la Taula $7.3 \mathrm{cal}$ concloure que, tot i que el $\mathrm{TiO}_{2} \mathrm{P} 25 \mathrm{i}$ el $\mathrm{CeO}_{2}$ mostren una activitat baixa per promoure la versió

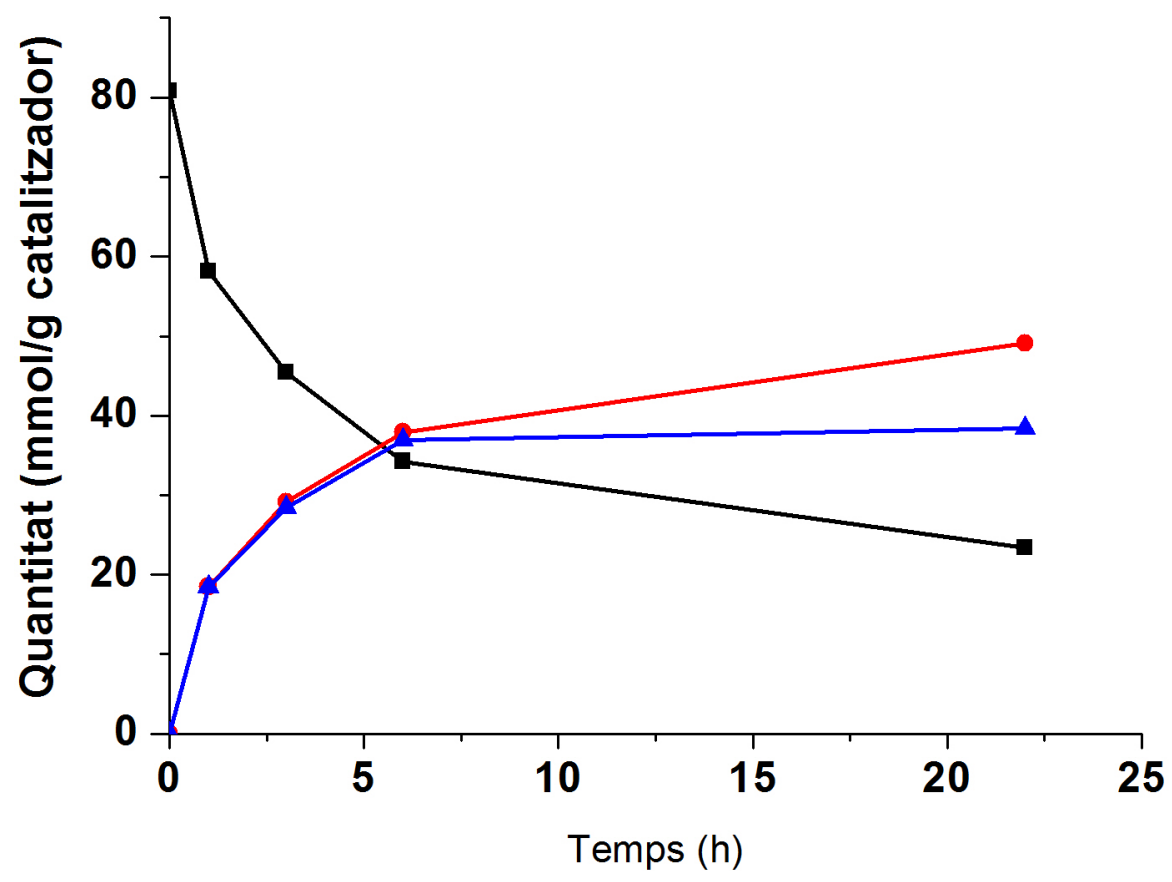

Figura 7.1. Perfil temporal de la conversió $\mathrm{CO}(\boldsymbol{\square})$, formació de $\mathrm{CO}_{2}(\bullet)$ i $\mathrm{H}_{2}(\mathbf{\Lambda})$. Condicions d'irradiació: Barreja de CO (20\%, $4.9 \mathrm{mmol}), \mathrm{N}_{2}(80 \%)$ saturades amb vapor d'aigua. $\mathrm{Au} / \mathrm{TiO}_{2} 250 \mathrm{mg}$. Irradiació amb llum solar simulada i concentrada. 
Taula 7.3. Activitat fotocatalítica per a l'evolució d'hidrogen i distribució de productes d'irradiació a les $22 \mathrm{~h}$ emprant com a font un simulador solar concentrat. Condicions d'irradiació: barreja de gasos saturada amb vapor $d^{\prime} \mathrm{H}_{2} \mathrm{O}$, que conté $\mathrm{CO}(20 \%, 4.9 \mathrm{mmol}), \mathrm{N}_{2}(80 \%)$; temps d'irradiació $22 \mathrm{~h}$; massa del fotocatalitzador 250mg; font d'irradiació simulador solar $\left(1000 \mathrm{~W} / \mathrm{cm}^{2}\right)$.

\begin{tabular}{|c|c|c|c|c|c|}
\hline \multirow{2}{*}{ Fotocatalitzador } & \multirow{2}{*}{$\begin{array}{l}\text { Conversió } \\
\text { CO (\%) }\end{array}$} & \multirow{2}{*}{$\begin{array}{l}\text { Balanç } \\
\text { Molar (\%) }\end{array}$} & \multicolumn{3}{|c|}{$\begin{array}{c}\text { Producció } \\
\text { ( } \mu \mathrm{mol} / \mathrm{g} \text { catalitzador) }\end{array}$} \\
\hline & & & $\mathrm{H}_{2}$ & $\mathrm{CO}_{2}$ & $\mathrm{CH}_{4}$ \\
\hline $\mathrm{TiO}_{2}$ & 3 & 99.99 & 264 & 649 & 4 \\
\hline $\mathrm{Pd} / \mathrm{TiO}_{2}(1 \%)$ & 24 & 99.11 & 4178 & 4585 & 1 \\
\hline $\mathrm{Cu} / \mathrm{TiO}_{2}(1 \%)$ & 4 & 99.99 & 591 & 851 & 7 \\
\hline $\mathrm{Pt} / \mathrm{TiO}_{2}(1 \%)$ & 25 & 99.27 & 4279 & 4763 & 64 \\
\hline $\mathrm{Au} / \mathrm{TiO}_{2}(1 \%)$ & 71 & 95.25 & 10506 & 13447 & 7 \\
\hline $\mathrm{Ag} / \mathrm{TiO}_{2}(1 \%)$ & 10 & 99.11 & 1650 & 1823 & 8 \\
\hline $\mathrm{CeO}_{2}$ & 4 & 99.98 & 350 & 607 & 5 \\
\hline $\mathrm{Au} / \mathrm{CeO}_{2}(0.2 \%)$ & 8 & 98.37 & 1380 & 1526 & 15 \\
\hline $\mathrm{Au} / \mathrm{CeO}_{2} \quad(0.5 \%)$ & 28 & 92.14 & 4880 & 4762 & 2 \\
\hline $\mathrm{Au} / \mathrm{CeO}_{2} \quad(1 \%)$ & 31 & 96.36 & 1358 & 1341 & $<1$ \\
\hline
\end{tabular}

fotocatalítica de la reacció WGS amb llum solar simulada, la presència de metalls nobles augmenta considerablement aquesta fotoactivitat. En particular, nanopartícules de Pd i Pt a l'1\% incrementen gairebé un ordre de magnitud la formació d' $\mathrm{H}_{2}$ respecte a l'activitat fotocatalítica del P25 sense modificar. De manera similar la presència d'Au augmenta gairebé un ordre de magnitud la fotoactivitat del $\mathrm{CeO}_{2}$. En aquest últim cas, hem trobat que el valor òptim de càrrega d'Au dipositat està al voltant de $0.5 \%$. El material 
més fotoactiu dels assajats va ser la mostra comercial $\mathrm{Au} / \mathrm{TiO}_{2}$ preparat pel World Gold Council, que permet assolir conversions de CO entorn del $40 \%$ a $6 \mathrm{~h}$. Els temps d'irradiació llargs condueixen a conversions majors, superiors al $71 \%$ en $22 \mathrm{~h}$. Cal comentar que l'activitat fotocatalítica d'ambdós materials $\mathrm{Au} / \mathrm{TiO}_{2}$ i $\mathrm{Au} / \mathrm{CeO}_{2}$ no tenen precedents i que aquests dos materials han estat els fotocatalitzadors més eficients per promoure el trencament fotocatalític de l'aigua amb llum visible. ${ }^{[10,11]}$

Els assajos anteriors s'han dut a terme emprant llum solar simulada concentrada que presenta un gran interés des del punt de vista de la possible aplicació del procés a escala industrial per tal d'aconseguir combustibles solars alternatius als combustibles fòssils emprats en transport. ${ }^{[4,12]}$ No obstant això, aquesta irradiació conté al voltant d'un $4 \%$ de llum UV i un $46 \%$ de llum visible, pel que no és possible determinar si l'activitat fotocatalítica d'aquests materials deriva de l'absorció de fotons en el rang de la zona visible o si aquesta fotoactivitat s'origina a causa del xicotet percentatge de radiació UV. Hi ha un gran interès en la preparació de fotocatalitzadors a base d'òxids metàl-lics estables que tinguen activitat fotocatalítica amb llum visible. ${ }^{[13-17]}$ Per això, a fi de determinar si els fotocatalitzadors a base de $\mathrm{TiO}_{2} \mathrm{i} \mathrm{CeO}_{2}$ modificats amb nanopartícules metàl-liques presenten activitat o no irradiant-les amb llum visible es van dur a terme una sèrie $d^{\prime}$ irradiacions anàlogues a les mostrades a la Figura 7.1, però emprant com a font d'excitació la llum provinent d'una font LED, la qual emet de forma quasi monocromàtica centrada a $450 \mathrm{~nm}$ (vegeu espectre d'emissió en el Capítol 8 experimental). Les diferències entre les fonts d'irradiació del simulador solar front al LED, a més de ser degudes a les longituds d'ona, també es deuen a la intensitat lluminosa pel que és difícil establir comparacions en els assajos emprant una o altra font d'irradiació. No obstant això, els resultats quant a la reacció WGS promoguda fotoquímicament amb la font d'irradiació LED de llum visible demostren que els fotocatalitzadors que contenen Au són encara actius en aquesta font d'irradiació, tot i que les conversions assolides són significativament menors que les obtingudes amb el simulador solar. Els resultats obtinguts en la 
irradiació emprant LED com a font d'excitació es resumeixen a la Taula 7.4. En ella es pot veure que la mostra de $\mathrm{Au} / \mathrm{TiO}_{2}$ comercial, que era la més activa sota irradiació amb llum solar simulada, continua sent la més activa en les condicions d'irradiació amb LED. En contrast, l'activitat fotocatalítica d'altres mostres de $\mathrm{TiO}_{2}$ que contenen $\mathrm{Pd}$ i Pt es redueix significativament, el que suggereix que en aquests casos l'activitat deriva principalment de l'excitació amb llum UV. De manera anàloga, la irradiació amb LED de les mostres de $\mathrm{Au} / \mathrm{CeO}_{2}$ també redueix sensiblement l'activitat fotocatalítica que fa a la il-luminació amb llum solar simulada, la qual cosa suggeriria de nou que són les longituds d'ona de la zona UV les que són responsables d'un percentatge elevat de l'activitat fotocatalítica d'aquests materials.

Taula 7.4. Activitat fotocatalítica per a l'evolució d'hidrogen i la distribució de productes quan se sotmet una barreja de $\mathrm{CO}$ i $\mathrm{H}_{2} \mathrm{O}$ a irradiació amb llum visible LED després $22 \mathrm{~h}$. Condicions d'irradiació: barreja de gasos saturada amb vapor d' $\mathrm{H}_{2} \mathrm{O}$, que conté $\mathrm{CO}(20 \%, 4.9 \mathrm{mmol}), \mathrm{N}_{2}(80 \%)$, temps d'irradiació $22 \mathrm{~h}$, massa del fotocatalitzador $250 \mathrm{mg}$, font d'irradiació llum LED visible.

\begin{tabular}{|c|c|c|c|c|c|c|}
\hline \multirow{2}{*}{ Suport } & \multirow{2}{*}{ Metall } & \multirow{2}{*}{$\begin{array}{c}\text { Conversió } \\
\text { de CO }\end{array}$} & \multirow{2}{*}{$\begin{array}{c}\text { Balanç } \\
\text { Molar (\%) }\end{array}$} & \multicolumn{3}{|c|}{$\begin{array}{c}\text { Producció } \\
\text { (umol/gr catalitzador) }\end{array}$} \\
\hline & & & & $\mathrm{H}_{2}$ & $\mathrm{CO}_{2}$ & $\mathrm{CH}_{4}$ \\
\hline \multirow{3}{*}{$\mathrm{TiO}_{2}$} & $\mathrm{Au}$ & 41 & 98 & 7695 & 7914 & 4 \\
\hline & $\mathrm{Pd}$ & 0.2 & 100 & 82 & 145 & -- \\
\hline & $\mathrm{Pt}$ & 1 & 100 & 40 & 76 & -- \\
\hline $\mathrm{CeO}_{2}$ & $\begin{array}{c}A u \\
(0.5 \text { pes\%) }\end{array}$ & 5 & 97 & 612 & 427 & -- \\
\hline
\end{tabular}


En vista dels resultats que hem obtingut, hem proposat dos possibles mecanismes fotocatalítics, que podrien actuar depenent si l'energia dels fotons d'excitació és major o menor que l'energia interbandes del semiconductor. En el primer mecanisme, els fotons de l'UV poden excitar directament al $\mathrm{TiO}_{2}$ el que condueix a carregar la separació i subsegüent migració dels electrons des de la banda de conducció del semiconductor a la de la nanopartícula de metall noble, que en aquest mecanisme operaria com a cocatalizador, facilitant la reducció d'aigua a hidrogen. En el segon mecanisme, sota irradiació de llum visible s'excitarà la banda de plasmó superficial de les nanopartícules d'Au i injectarà electrons a la banda de conducció del $\mathrm{TiO}_{2}$, romanent els buits en les nanopartícules d'Au que seran responsables de l'oxidació de CO. L'Esquema 7.1 mostra la nostra proposició per als diferents mecanismes depenent de l'energia dels fotons. En el segon mecanisme, la banda de plasmó superficial de les nanopartícules d'Au és responsable del típic color porpra de les nanopartícules d'Au que actuen com a antena per als fotons emesos en el visible. Això podria explicar també la manca de fotoresposta observada per als materials de $\mathrm{TiO}_{2}$ que contenien nanopartícules de Pt-i Pd-, ja que aquests metalls no exhibeixen una banda d'absorció de plasmó superficial.

Un fet destacable dels assaigs anteriors sobre la reacció fotocatalítica de $\mathrm{CO}$ amb vapor d' $\mathrm{H}_{2} \mathrm{O}$ consisteix en què la presència de $\mathrm{CH}_{4}$ es detecta només en quantitats molt petites. En contrast amb aquest comportament vam observar que altres òxids metàl-lics com ara els de $\mathrm{Ni}, \mathrm{Fe}, \mathrm{Co}$ i $\mathrm{Cu}$, tots ells colorits, presenten activitat fotocatalítica per a aquesta reacció però es diferencien del $\mathrm{CeO}_{2}$ i del $\mathrm{TiO}_{2}$ en què les quantitats de $\mathrm{CH}_{4}$ que es detecten en fase gas són significatives. Particularment notable és el cas del NiO i de la magnetita $\left(\mathrm{Fe}_{3} \mathrm{O}_{4}\right)$, on el rendiment de $\mathrm{CH}_{4}$ supera el $5 \%$. La sèrie d'òxids metàl-lics de la primera sèrie de transició assajats i els resultats obtinguts es resumeixen a la Taula 7.5 i a la Figura 7.2. 
a)

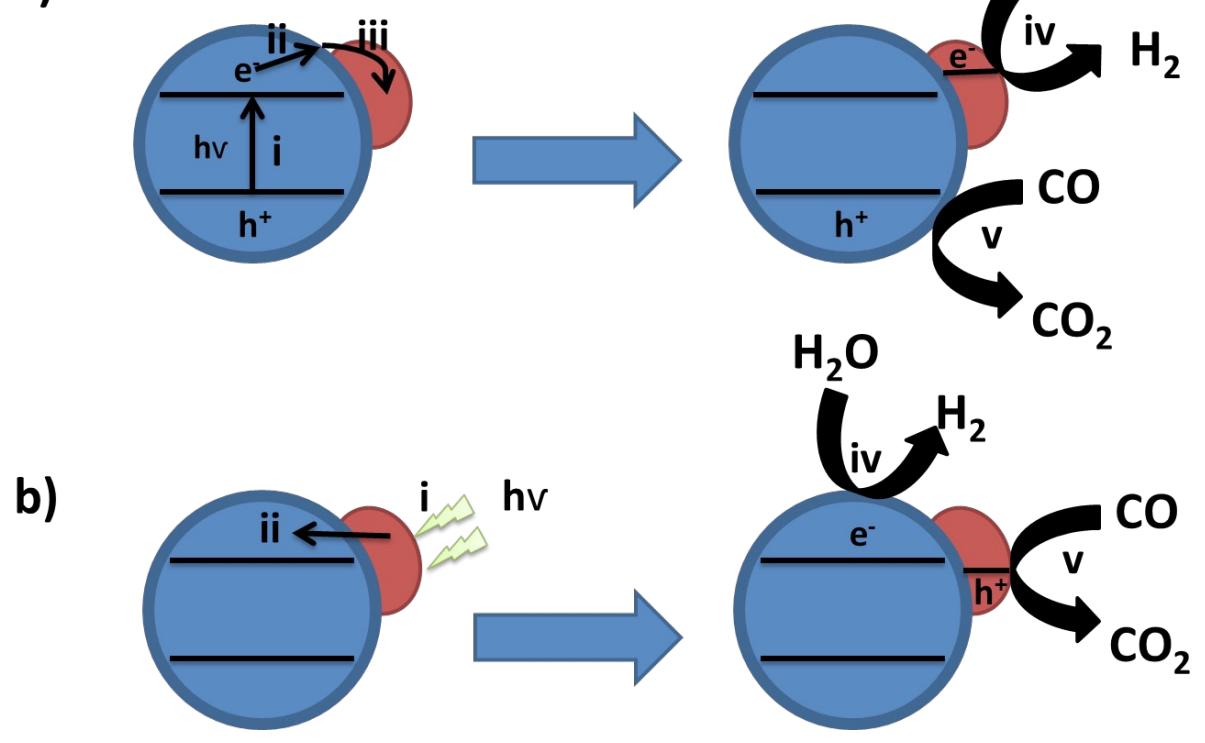

Esquema 7.1. Dos possibles mecanismes per racionalitzar les diferències en la i activitat fotocatalítica del $\mathrm{Au} / \mathrm{TiO}_{2}$ amb irradiació amb llum UV-visible o visible. i: absorció del fotó; ii: migraciô de l'electró; iii: migració interfacial de l'electró; iv: reducció d’aigua a hidrogen, v: oxidació de $\mathrm{CO}$ a $\mathrm{CO}_{2}$

Com es pot veure a la Taula 7.5, en contrast amb el control on es va posar en contacte els sòlids i la fase gas a temperatura ambient, no es van poder observar productes. En el cas del $\mathrm{TiO}_{2}$ es forma $\mathrm{CO}_{2}$ com a principal producte, per als semiconductors tipus-p d'òxids metàl-lics de Ni, $\mathrm{Cu}, \mathrm{Fe}$, i Co s'obtenen quantitats significatives de $\mathrm{CH}_{4}$ en la fase gas després de ser irradiades amb llum solar simulada. L'equació 7.13 proporciona la suposada estequiometria dels productes formats en la reducció fotocatalítica de $\mathrm{CO}$ i aigua utilitzant la llum solar, mentre que la Figura 7.2 mostra el gràfic de conversió per a la formació de $\mathrm{CH}_{4}$ en les mateixes condicions experimentals per als diferents fotocatalitzadors inclosos a la Taula 7.5. Mereix ser comentat que mentre $\mathrm{TiO}_{2}$ és un material pols blanca, la resta dels metalls de transició de la Taula 7.5 són colorides. Aquestes bandes d'absorció són presumptament responsables de la notable fotoactivitat davant la llum solar (fins a 20 vegades la de $\mathrm{TiO}_{2}$ ). Particularment notable és el cas de $\mathrm{NiO}$ i magnetita, on la producció de $\mathrm{CH}_{4}$ són els més elevats (9,4\%, a la barreja de la fase de gas en el cas de $\mathrm{NiO})$. 
Taula 7.5. Activitat fotocatalítica per a l'evolució de metà. Condicions d'irradiació: Barreja de $\mathrm{N}_{2}(80 \%) \mathrm{CO}(20 \%, 4.9 \mathrm{mmol})$ saturats amb $\mathrm{H}_{2} \mathrm{O}$. Temps d'irradiació $22 \mathrm{~h}$, massa del catalitzador, $250 \mathrm{mg}$. Irradiació amb simulador solar concentrat. ${ }^{\text {[a] }}$

\begin{tabular}{|c|c|c|c|c|c|c|c|}
\hline \multirow{2}{*}{ Fotocatalizador } & \multirow{2}{*}{$\begin{array}{c}\text { Conversió } \\
\text { CO (\%) }\end{array}$} & \multirow{2}{*}{$\begin{array}{l}\text { Balanç } \\
\text { molar }\end{array}$} & \multirow{2}{*}{$\begin{array}{c}C \\
(\%)^{[b]}\end{array}$} & \multicolumn{4}{|c|}{ Producció ( $\mu \mathrm{mol} / \mathrm{g}$ catalitzador) } \\
\hline & & & & $\mathrm{H}_{2}$ & $\mathrm{CO}_{2}$ & $\mathrm{CH}_{4}$ & $\mathrm{C}_{2} \mathrm{H}_{6}$ \\
\hline $\mathrm{TiO}_{2}$ & 3 & $>99$ & 0.1 & 260 & 650 & 4 & -- \\
\hline $\mathrm{NiO}$ & 95 & 93 & 3.3 & 820 & 12200 & 1700 & 3.3 \\
\hline $\mathrm{CuO}$ & 14 & 99 & 0.5 & 20 & 2900 & 270 & -- \\
\hline $\mathrm{CO}_{3} \mathrm{O}_{4}$ & 91 & 91 & 1.2 & 1000 & 12300 & 600 & -- \\
\hline $\mathrm{CoO}$ & 93 & 99 & 3.1 & 990 & 12500 & 200 & -- \\
\hline $\mathrm{Fe}_{3} \mathrm{O}_{4}$ & 59 & 90 & 0.1 & 3630 & 8200 & 900 & 0.6 \\
\hline $\mathrm{Fe}_{2} \mathrm{O}_{3}$ & 68 & 98 & 2.5 & 3760 & 10400 & 20 & 3.1 \\
\hline
\end{tabular}

[a] Controls en blanc irradiant en absència de qualsevol fase sòlida o posar en contacte el sòlid y el gas en la foscor, no es va detectar cap producte.

[b] Percentatge en pes de carboni en el sòlid després de l'experiment fotocatalític.

La Figura 7.3 presenta, per altra banda, els resultats obtinguts en l'evolució de la reacció de $\mathrm{CO}$ per a la formació de $\mathrm{CO}_{2}, \mathrm{CH}_{4}$ i $\mathrm{H}_{2} \mathrm{O}$ sota irradiació amb llum solar simulada en presència de $\mathrm{NiO}$ com a fotocatalitzador $\mathrm{i}_{2} \mathrm{O}$ com a agent reductor. Com es pot veure a la Figura 7.3, I' $\mathrm{H}_{2}$ apareix com a producte primari, però és inestable i la seva proporció es veu incrementada durant la primera hora d'irradiació, però després va decreixent gradualment. D'altra banda, el metà mostra un període d'inducció al principi, formant-se com un producte secundari. Aquest perfil temporal proporcionen suport cinètic per a un mecanisme de formació de $\mathrm{CH}_{4}$ que implica la generació prèvia d' $\mathrm{H}_{2}$ a partir de vapor d' $\mathrm{H}_{2} \mathrm{O}$ i la posterior reacció d'aquest $\mathrm{H}_{2}$ per formar $\mathrm{CH}_{4}$. 


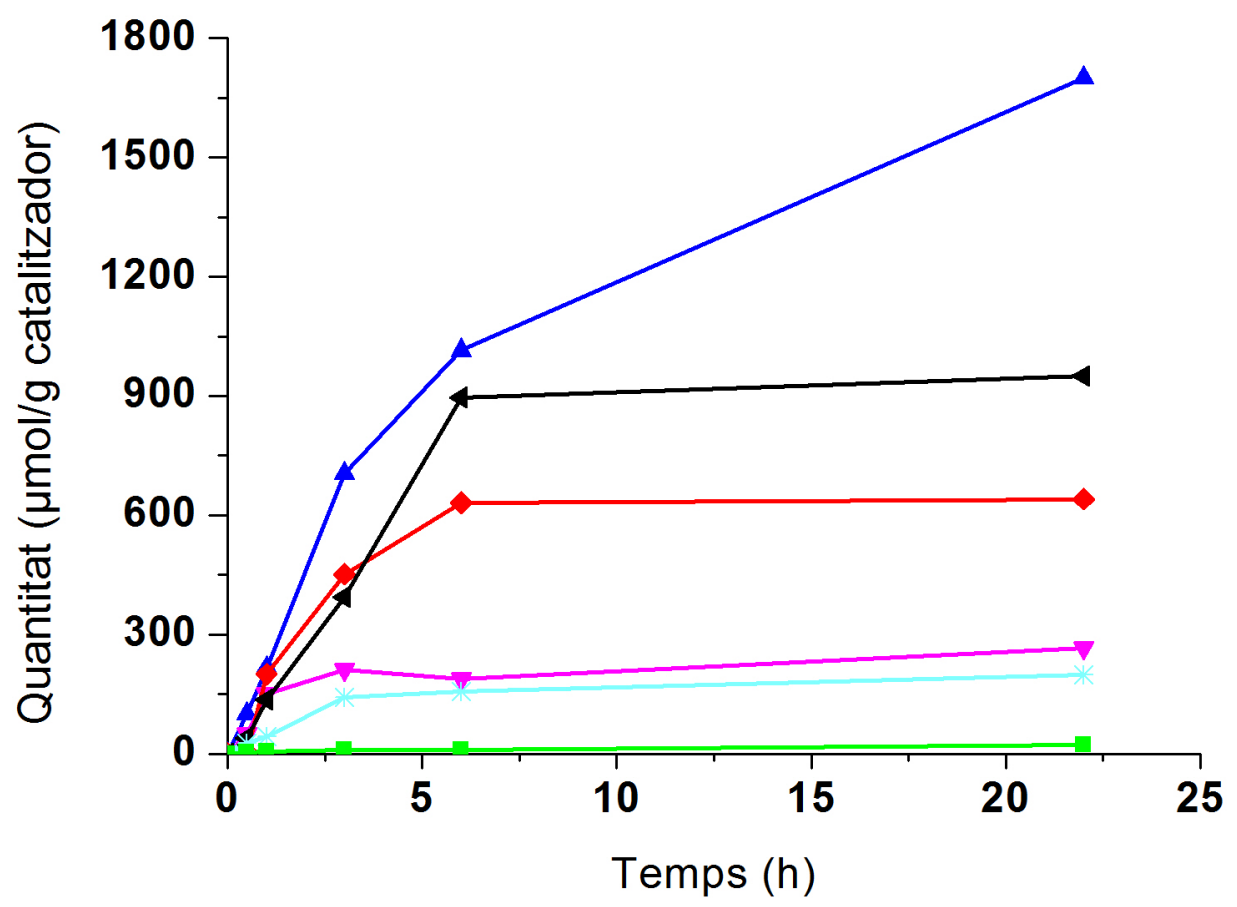

Figura 7.2. Perfil temporal de la formació de $\mathrm{CH}_{4}$ després de la irradiació de $\mathrm{CO} \mathrm{i}_{2} \mathrm{O}$ en presència de diferents òxids de metalls de transició com semiconductors tipus p: $\mathrm{NiO}(\boldsymbol{\Delta}), \mathrm{Fe}_{3} \mathrm{O}_{4}(\boldsymbol{4}) \mathrm{Co}_{3} \mathrm{O}_{4}(\boldsymbol{\nabla}), \mathrm{CuO}(\boldsymbol{\nabla}) \mathrm{CoO}(*)$ $\mathrm{Fe}_{2} \mathrm{O}_{3}(\square)$. Condicions d'irradiació: Irradiació d'una mescla saturada amb vapor $\mathrm{d}^{\prime} \mathrm{H}_{2} \mathrm{O}$ de $\mathrm{N}_{2}(80 \%)$ i CO (20\%, $\left.4.9 \mathrm{mmol}\right)$; massa del fotocatalitzador, $250 \mathrm{mg}$. Irradiació amb simulador solar concentrat. 


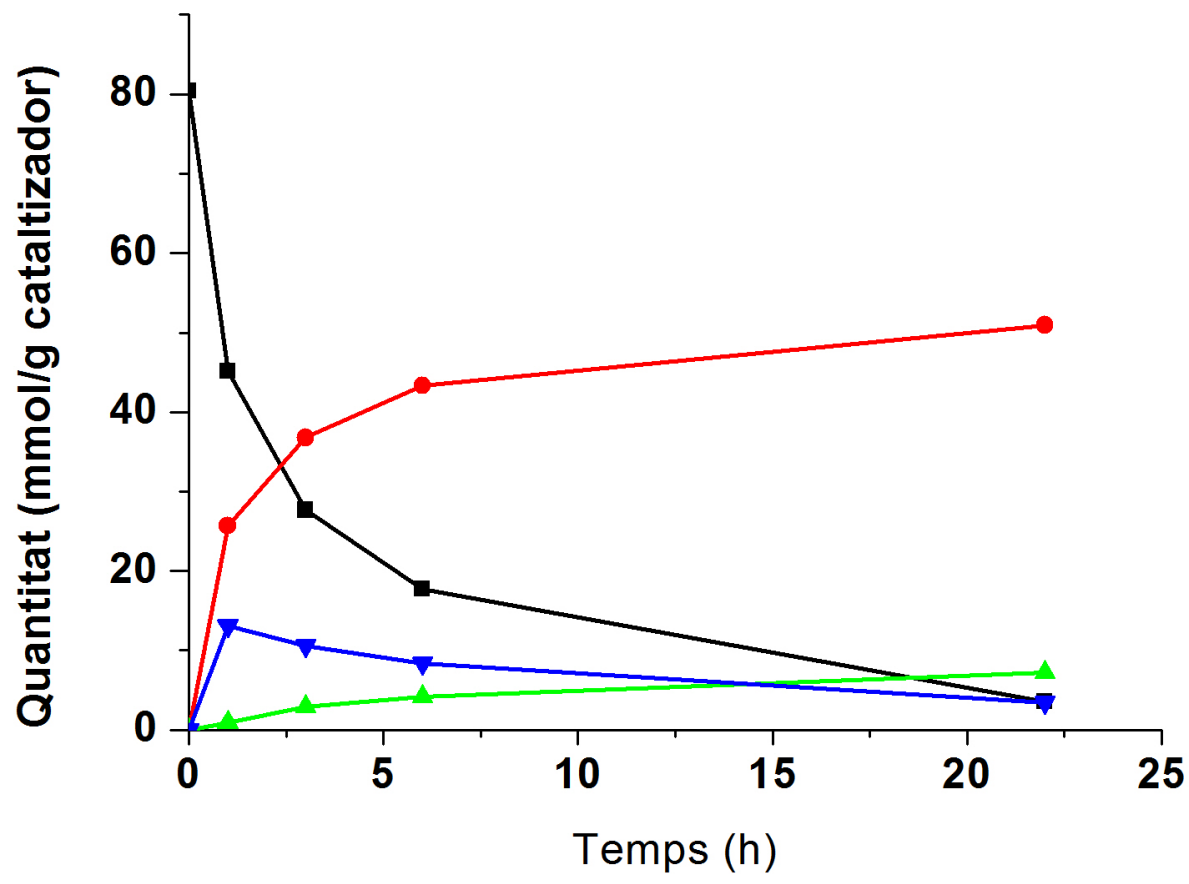

Figura 7.3 Perfil temporal de la conversió $\mathrm{CO}(\mathbf{\square})$, formació de $\mathrm{CO}_{2}(\bullet), \mathrm{CH}_{4}(\Delta)$ i $\mathrm{H}_{2}(\boldsymbol{\nabla})$. Condicions d'irradiació: Barreja gas, saturada amb vapor $\mathrm{d}^{\prime} \mathrm{H}_{2} \mathrm{O}$ de $\mathrm{N}_{2}(80 \%)$ i $\mathrm{CO}(20 \%, 4.9 \mathrm{mmol})$, massa NiO, $250 \mathrm{mg}$; irradiació amb simulador solar concentrat $\left(1000 \mathrm{~W} / \mathrm{m}^{2}\right)$.

Dels resultats mostrats a la Taula 7.5 cal destacar el fet de l'alt percentatge de carboni present sobre el catalitzador, particularment en el $\mathrm{NiO}, \mathrm{Fe}_{3} \mathrm{O}_{4} \mathrm{i} \mathrm{Co}_{3} \mathrm{O}_{4}$, el que suggereix la presència d'alguna espècie diferent de $\mathrm{CO}_{2} \mathrm{i} \mathrm{CH}_{4}$. Aquest residu carbonós adsorbit en el fotocatalitzador va ser caracteritzat mitjançant espectroscòpia Raman i XPS (vegeu les Figures 7.4 i 7.5). Tots dos espectres són compatibles amb l'assignació d'aquest residu com carboni grafític generat en el procés fotocatalític. En l'espectroscòpia Raman les dues bandes vibracionals característiques denotades com a G i D, característiques de la presència de dominis grafítics (banda $\mathrm{G}$ a $1600 \mathrm{~cm}^{-1}$ ) i de defectes en aquests dominis (banda $D$ a $1350 \mathrm{~cm}^{-1}$ ). La presència de pics 2D a la regió de $2500-2900 \mathrm{~cm}^{-1}$ també són característics de la presència de 184 carboni grafític (veure Figura 7.4). 
Per la seua banda, com es pot observar a la Figura 7.3, l'espectroscòpia de XPS revela la presència de $\mathrm{C}$ en la superfície del NiO després d'irradiar i la deconvolució del pic C1S experimental a 285.12 en tres components d'energia d'enllaç a $285.03,286.63$ i 289.23 ev en proporció $67 \%$, 25\% i 8\% poden ser assignats a carboni grafític $\mathrm{sp2}$, carboni unit a oxígens $\mathrm{sp} 2 \mathrm{i}$ àtoms de $\mathrm{C}$ sp3 respectivament. El percentatge de residu carbonós dipositat en cada material va ser determinat mitjançant anàlisi elemental de combustió. Atesa la quantitat de carboni suportada en el fotocatalitzador juntament amb el $\mathrm{CH}_{4}$ i CO 2 formats, en tots els casos, els balanços molars van ser satisfactoris (>95\%). Això ens indica que el CO no només es converteix en productes en la fase gas, sinó que també forma els dipòsits de carboni sobre la superfície de fotocatalitzador. D'acord amb la presència de carboni en el fotocatalitzador,

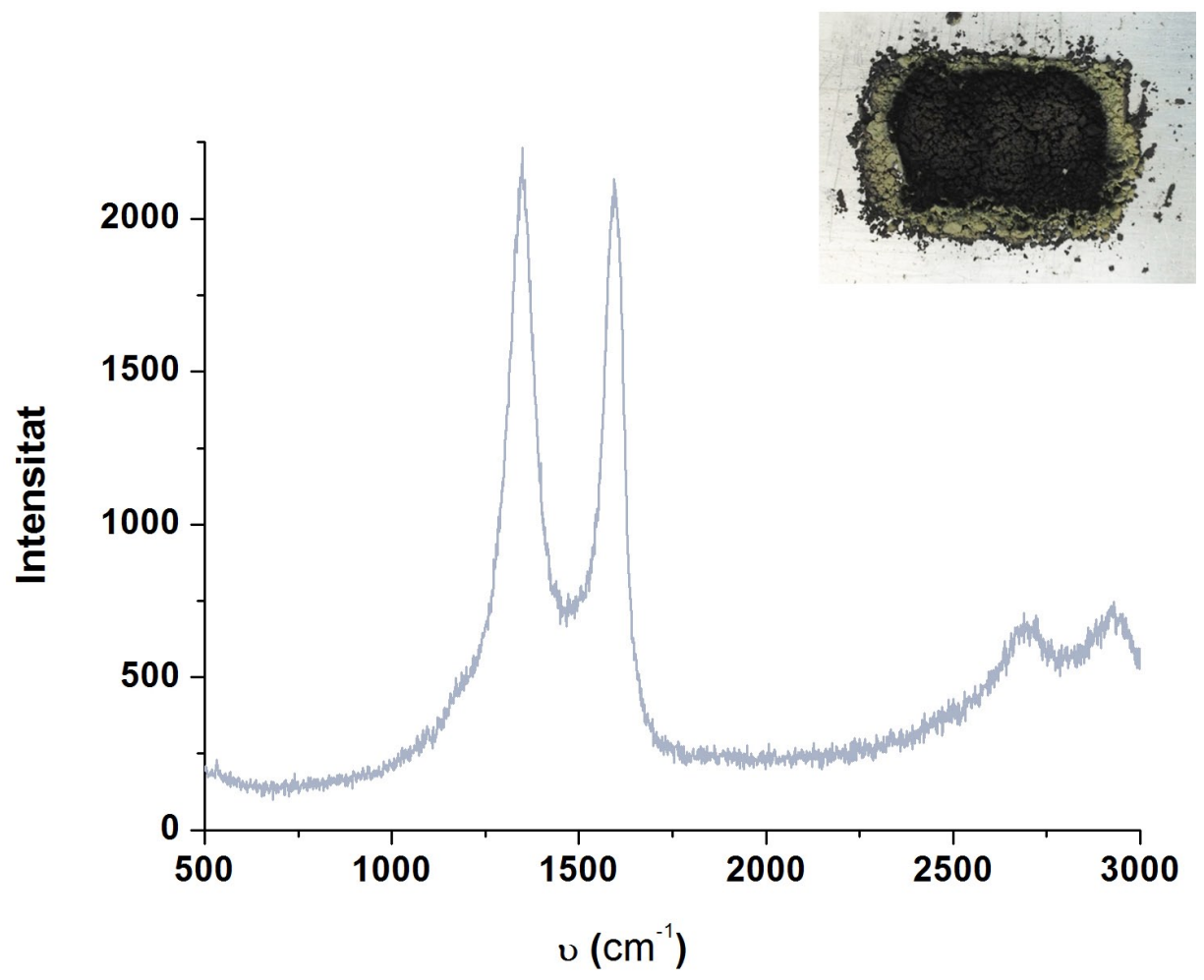

Figura 7.4. Espectre Raman del $\mathrm{Fe}_{3} \mathrm{O}_{4}$ després del seu ús en la transformació CO fotocatalítica sota llum solar simulada irradiació. El requadre mostra una fotografia del $\mathrm{NiO}$ després del seu ús com a fotocatalitzador on es pot observar l'aspecte visual negre. Condicions de reacció: Barreja de CO (20\%, $5 \mathrm{mmol})$, $\mathrm{H}_{2}, \operatorname{Ar} 75 \%$ (4,5\%); massa fotocatalitzador, $250 \mathrm{mg}$, temps de $2 \mathrm{~h}$ de reacció, la font de llum solar simulador de $1000 \times \mathrm{W}^{*} \mathrm{~m}^{-2}$. 


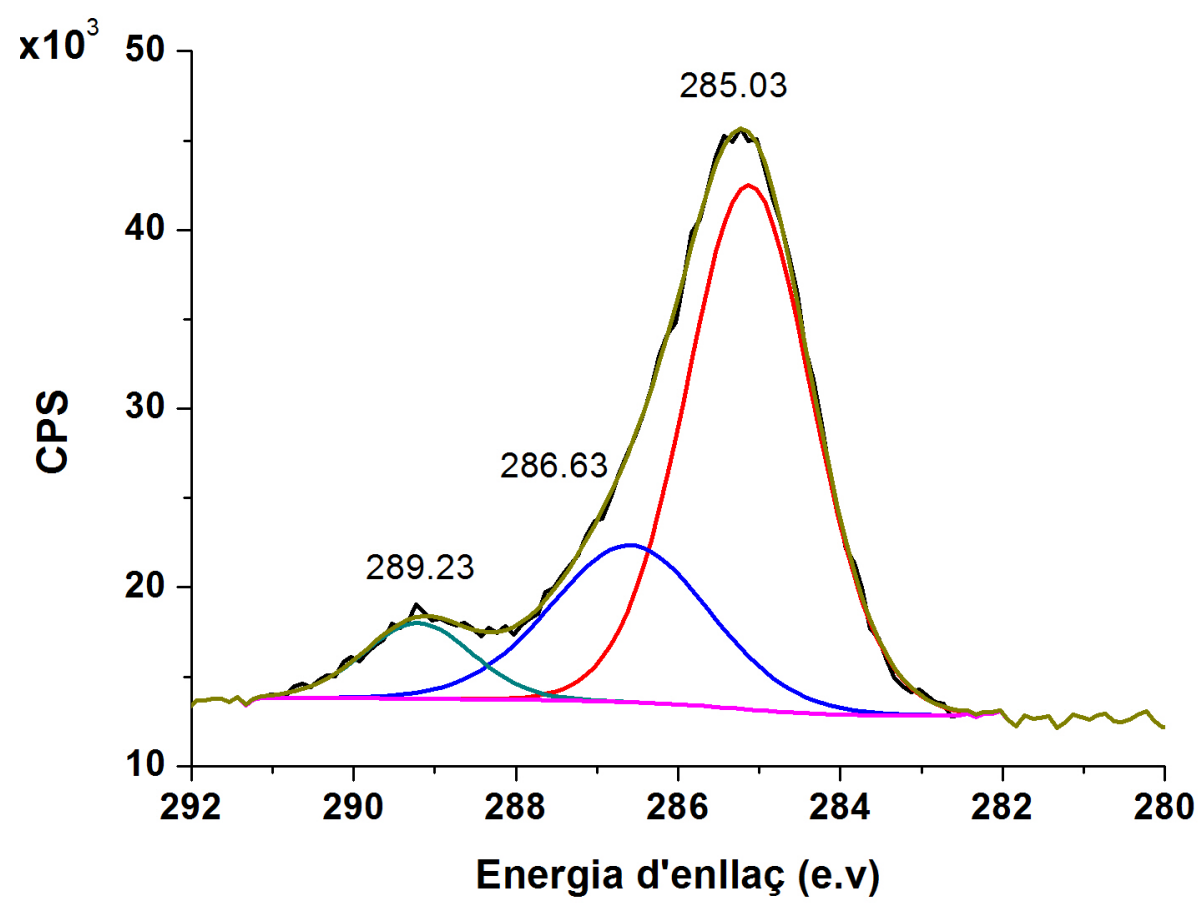

Figura 7.5. XPS experimental i el seu millor ajust a tres components registrats per al NiO després d'haver estat usat com fotocatalitzador per a la transformació de CO.

l'observació visual dels òxids metàl-lics va variar de color després de la reacció que es mostra, on en alguns casos els sòlids van adquirir un color negre (vegeu el requadre a la Figura 7.4), un fet que suggereix la deposició de carboni o possible reducció fotocatalítica de l'òxid de metall en les nanopartícules de metall. La formació de residu de carboni és l'explicació més probable per als canvis en la visió dels sòlids després del seu ús com a fotocatalitzador, considerant l'anàlisi químic, així com les dades de Raman i XPS, encara que no podem excloure algun grau de reducció fotocatalítica. 
Podem interpretar el gran percentatge de carboni en alguns fotocatalitzadors com a conseqüència de la deficiència $d^{\prime} \mathrm{H}_{2}$ en els experiments en què $\mathrm{H}_{2} \mathrm{O}$ s'utilitza com a agent reductor. Es pot observar a la Figura. 7.2 que el percentatge d' $\mathrm{H}_{2}$ derivat de l'aigua és baix durant el curs de la reacció fotocatalítica.

A fi d'establir si l'activitat fotocatalítica de reducció del $\mathrm{CO}$ a $\mathrm{CH}_{4}$ mitjançant fotocatalitzadors de tipus $p$ pot ser afavorida per la presència $d^{\prime} \mathrm{H}_{2}$ en lloc d' $\mathrm{H}_{2} \mathrm{O}$, vam dur a terme experiments amb llum solar simulada on vam irradiar $\mathrm{NiO}$ o $\mathrm{Fe}_{3} \mathrm{O}_{4}$ en contacte amb una atmosfera que contenia $\mathrm{CO}$ i $\mathrm{H}_{2}$. Vam assajar dues relacions molars $\mathrm{CO} / \mathrm{H}_{2}$, a saber $1: 1$ i $1: 3.5$. Els resultats obtinguts es resumeixen a la Taula 7.6 mentre que els perfils temporals de les irradiacions es mostren a les figures 7.6 i 7.7 .

A la vista dels resultats obtinguts es pot concloure que la formació de metà és afavorida per la presència $d^{\prime} \mathrm{H}_{2} \mathrm{i}$ que també en tots els casos s'observa la generació de $\mathrm{CO}_{2}$. La formació d'aquest últim producte es pot entendre com la fotooxidació de CO pels forats electrònics generats en el semiconductor. Tenint en compte la composició de la mescla reactiva, el CO és aparentment el que actua preferentment com a atrapador de buits generant en el procés $\mathrm{CO}_{2}$, encara que es forma amb rendiments considerablement inferiors a quan s'utilitza $\mathrm{H}_{2} \mathrm{O}$ com a agent reductor. Aquesta major activitat utilitzant $\mathrm{H}_{2}$ com a agent reductor es pot entendre fàcilment considerant la notable endergogeneitat de la reacció utilitzant $\mathrm{H}_{2} \mathrm{O}$ com a agent reductor (veure equació 7.13) i la major complexitat del mecanisme de reacció quan es parteix d' $\mathrm{H}_{2} \mathrm{O}$, ja que requereix primer la generació d' $\mathrm{H}_{2}$. 
Taula 7.6. Activitat fotocatalítica per a l'evolució del $\mathrm{CO}, \mathrm{CO}_{2}$ i $\mathrm{CH}_{4}$ emprant òxids de níquel i ferro com fotocatalitzadors. Condicions d'irradiació: barreja de $\mathrm{CO}(20 \%), \mathrm{H}_{2}(20$ o $75 \%), \operatorname{Ar}(4.5 \%)$ i $\mathrm{N}_{2}$ (completant fins al 100\%); pes catalitzador, $250 \mathrm{mg}$; temps d'irradiació, 3h; irradiació amb simulador solar concentrat.

\begin{tabular}{|c|c|c|c|c|c|c|c|c|c|}
\hline \multirow{2}{*}{$\begin{array}{l}\text { Ratio } \\
\mathrm{CO} / \mathrm{H}_{2}\end{array}$} & \multirow{2}{*}{ Fotocat. } & \multirow{2}{*}{$\begin{array}{c}\text { Conversió } \\
\text { CO (\%) }\end{array}$} & \multirow{2}{*}{$\begin{array}{l}\text { Balanç } \\
\text { molar }\end{array}$} & \multirow{2}{*}{$C(\%)^{[a]}$} & \multicolumn{5}{|c|}{ Producció ( $\mu \mathrm{mol} / \mathrm{g}$ catalitzador) } \\
\hline & & & & & $\mathrm{CO}_{2}$ & $\mathrm{CH}_{4}$ & $\mathrm{C}_{2} \mathrm{H}_{6}$ & $\mathrm{C}_{3} \mathrm{H}_{8}$ & $\mathrm{O}_{2}$ \\
\hline \multirow{2}{*}{$1: 1$} & $\mathrm{NiO}$ & 96 & 95 & 2.2 & 11240 & 8387 & -- & -- & 706 \\
\hline & $\mathrm{Fe}_{3} \mathrm{O}_{4}$ & 49 & 99 & 3.6 & 6590 & 733 & 18 & 10 & 1392 \\
\hline \multirow{3}{*}{$1: 3.5$} & $\mathrm{NiO}$ & 99 & 95 & 1.8 & 711 & 17266 & 387 & 150 & 7994 \\
\hline & $\mathrm{Fe}_{3} \mathrm{O}_{4}$ & 28 & 99 & 0.5 & 943 & 580 & 105 & 11 & 536 \\
\hline & $\mathrm{NiO}^{[b]}$ & 15.4 & 99 & 1.2 & 1386 & 1379 & 2.3 & -- & 731 \\
\hline
\end{tabular}

[a] Corresponent al percentatge en pes de carboni present en el fotocatalitzador després de la seua irradiació.

[b] Mostra irradiada amb simulador solar dotat amb un filtre que talla la radiació UV $(<400)$.

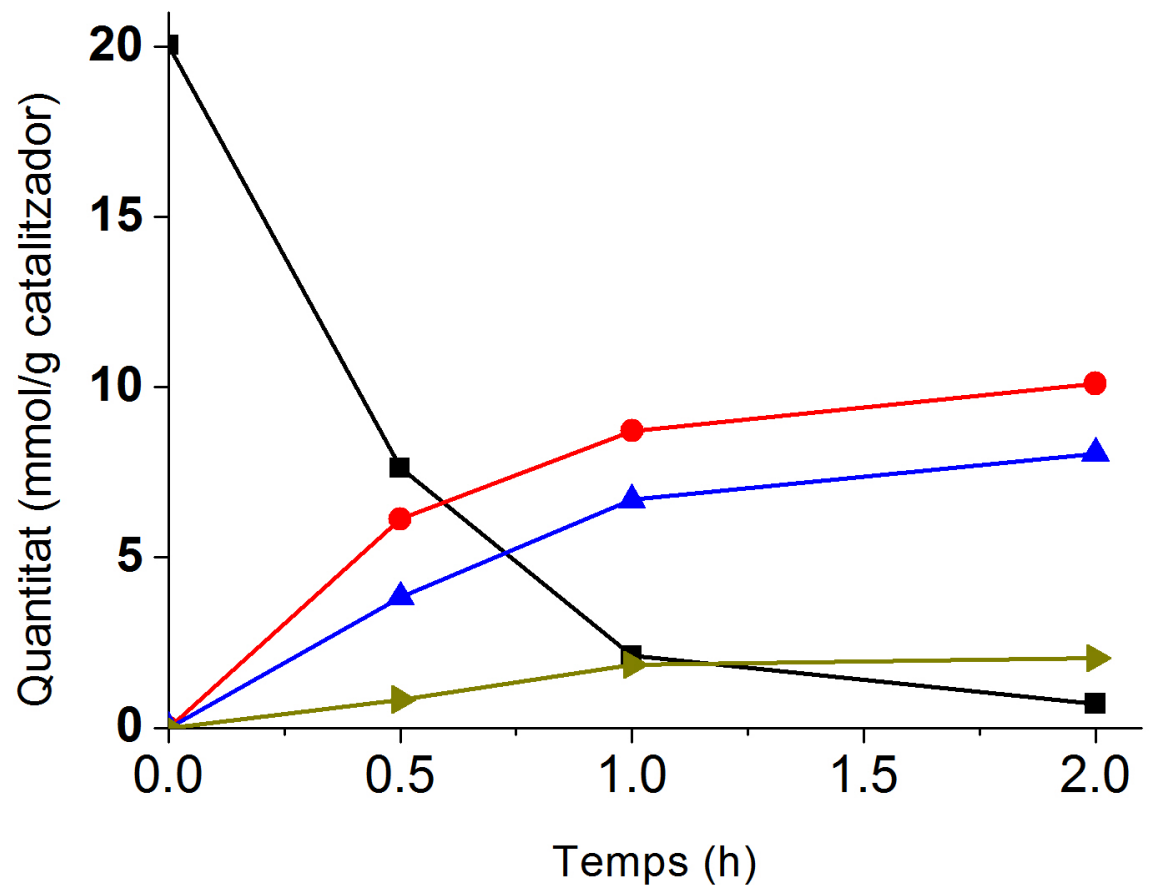

Figura 7.6. Perfil temporal de la conversió de $\mathrm{CO}(\bullet)$, formació de $\mathrm{CO}_{2}(\bullet), \mathrm{CH}_{4}$ $(\Delta), \mathrm{O}_{2}(\triangleright)$. Condicions d'irradiació: Barreja CO $(20 \%, 5 \mathrm{mmol}), \mathrm{H}_{2}^{2}(25 \% 5$ mmol), $\mathrm{Ar}(4.5 \%)$ i $\mathrm{N}_{2}$ (resta). Catalitzador NiO, 250mg; massa del catalitzador $250 \mathrm{mg}$; irradiació amb simulador solar concentrat $\left(1000 \mathrm{~W}^{*} \mathrm{~m}^{-2}\right)$. 


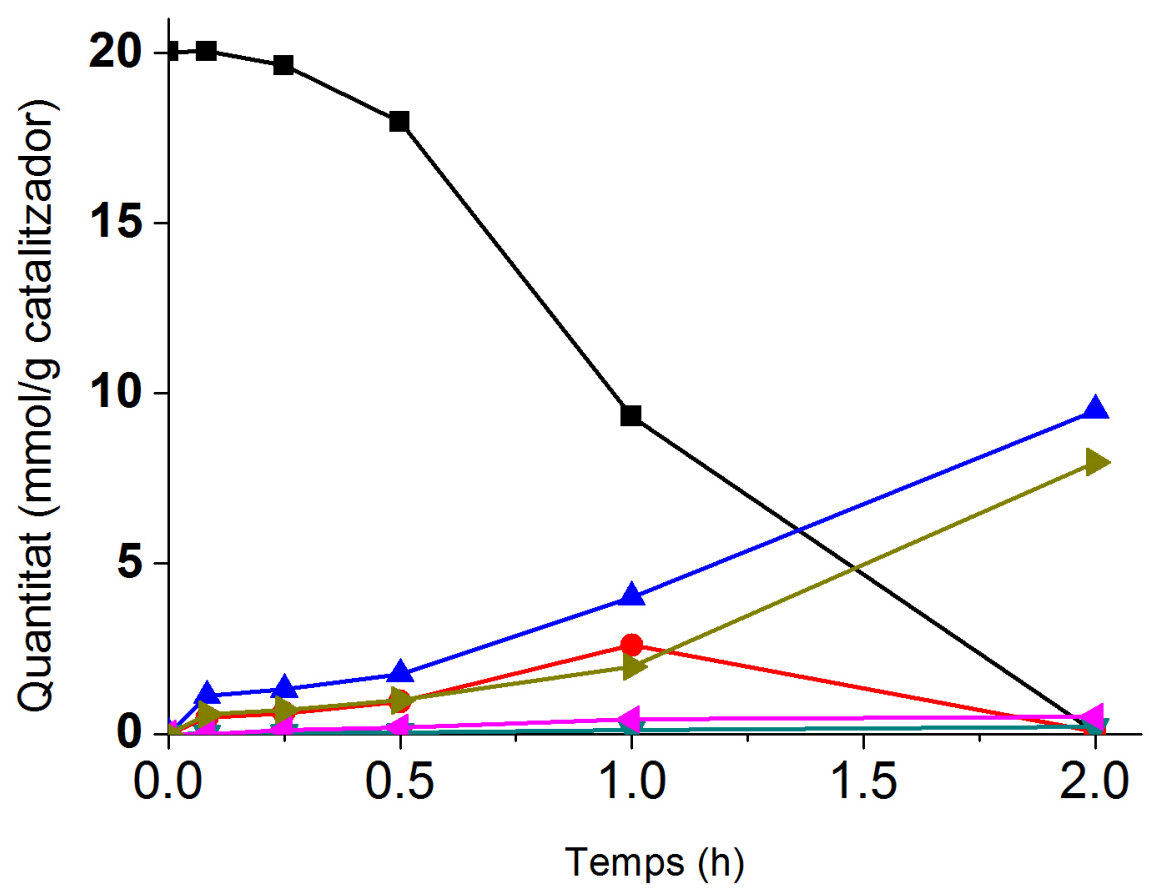

Figura 7.7. Perfil temporal de la conversió de $\mathrm{CO}(\boldsymbol{\square})$, formació de $\mathrm{CO}_{2}(\bullet), \mathrm{CH}_{4}$ $(\Delta), \mathrm{O}_{2}(\triangleright)$, Età $(<)$ i propà $(\nabla)$. Condicions d'irradiació: Barreja CO $(20 \%, 5$ $\mathrm{mmol}), \mathrm{H}_{2}$ (75\% $\left.15 \mathrm{mmol}\right), \operatorname{Ar}(4.5 \%)$,; Catalitzador $\mathrm{NiO} 250 \mathrm{mg}$; irradiació amb simulador solar concentrat $\left(1000 \mathrm{~W} \times \mathrm{m}^{-2}\right)$.

També és interessant mencionar que el percentatge de $C$ elemental dipositat sobre el fotocatalitzador es redueix considerablement quan la reacció fotocatalítica es porta a terme utilitzant $\mathrm{H}_{2}$ com a agent de reducció en comparació quan s'utilitza vapor d' $\mathrm{H}_{2} \mathrm{O}$. La formació de $\mathrm{CO}_{2}$ es pot entendre com el resultat de foto-oxidació de CO pels forats positius generats en la separació de la càrrega en el semiconductor. Tenint en compte la composició del gas de reacció, el CO seria l'espècie que actua com l'agent atrapador de buits, donant Iloc a la formació de $\mathrm{CO}_{2}$ (vegeu l’Esquema 7.2, a continuació). 
$\mathrm{CO}+2 \mathrm{H}_{2} \mathrm{O} \longrightarrow \mathrm{CH}_{4}+1.5 \mathrm{O}_{2}\left(\Delta \mathrm{G}^{0}=+541 \mathrm{~kJ} / \mathrm{mol}\right) \quad$ Eq. 7.13

D'altra banda, vam observar que l'evolució del perfil temporal del $\mathrm{CO}_{2}$ mostra un màxim i després disminueix a temps llargs de reacció (vegeu la Figura 7.7). Els controls en blanc mostren que el $\mathrm{CO}_{2}$ és capaç de sotmetre a una certa reducció fotocatalítica sota aquestes condicions en presència d' $\mathrm{H}_{2}$.

El fet que el $\mathrm{CH}_{4}$ provinga del consum d' $\mathrm{H}_{2}$ es posa en manifest pel fet que les irradiacions en què el $\mathrm{H}_{2}$ es troba en proporció 1:1 pel que fa al $\mathrm{CO}$, la generació de metà arriba a un valor asimptòtic i no creix més en el transcurs de la reacció (vegeu Figura 7.5), sent aquest valor límit inferior al valor que s'assoleix quan hi ha un excés d' $\mathrm{H}_{2}$.

La comparació dels fotocatalitzadors de $\mathrm{NiO}$ i la magnetita $\left(\mathrm{Fe}_{3} \mathrm{O}_{4}\right)$ revela que el primer és més selectiu per a la formació de metà, aconseguint un rendiment per a la formació de $\mathrm{CH}_{4}$, màxim quan la reacció es porta a terme en presència de $\mathrm{NiO}$ amb un excés de 3.5 equivalents $\mathrm{d}^{\prime} \mathrm{H}_{2}$ on s'obtenen 17.26 mmol de $\mathrm{CH}_{4} \mathrm{x}(\mathrm{g} \text { catalitzador })^{-1}$, de manera que el rendiment de $\mathrm{CO}_{2}$ és 3,2 vegades menor que la quantitat total d’alcans sota la irradiació amb llum solar simulada a una potència de $1000 \mathrm{~W} / \mathrm{m}^{2}$

És interessant indicar que quan l' $\mathrm{H}_{2}$ està present juntament $\mathrm{amb} \mathrm{CH}_{4}$ apareixen quantitats significatives d'età i propà. Aquest procés disminueix la selectivitat en la formació de $\mathrm{CH}_{4}$ i és un comportament que recorda el procés industrial de Ficher Tropsch, en el qual una barreja de $\mathrm{CO}$ i $\mathrm{H}_{2}$ dóna lloc a hidrocarburs lineals a temperatures de reacció elevades. En el nostre cas convé recordar que la temperatura del procés és pròxima a la de l'ambient.

Quant a la formació de carboni elemental en el fotocatalitzador correspon a un procés de reducció de CO i podria ser que aquest carboni elemental actuara com a intermedi en la formació de $\mathrm{CH}_{4}$. Per comprovar aquesta possibilitat, es va dur a terme una reacció en què el $\mathrm{CO}$ es va sotmetre a 
irradiació en absència d' $\mathrm{H}_{2}$ fins que el fotocatalitzador es va tornar visualment negre. En aquest moment, la irradiació es va aturar i es va fer buit durant 10 minuts al fotorreactor per tal d'eliminar l'atmósfera del reactor amb el CO. Llavors, es va carregar el fotoreactor amb una atmosfera d' $\mathrm{H}_{2} \mathrm{i}$ es va continuar amb la irradiació, tot i observant la formació de $\mathrm{CH}_{4}$ en la fase gasosa en absència de $\mathrm{CO}$. Aquest experiment es pot interpretar tenint en compte que després de la irradiació del catalitzador de $\mathrm{NiO}$, es formen a la superfície del semiconductor dipòsits de carboni quan I' $\mathrm{H}_{2}$ no està present. Posteriorment aquest residu de carboni és capaç de reaccionar fotocatalíticament amb $\mathrm{H}_{2}$ per formar $\mathrm{CH}_{4}$, fins i tot en absència de $\mathrm{CO}$. Experiments control, mostren que el metà no és capaç de formar-se en la foscor.

El mecanisme proposat per a la fotoreducció de $\mathrm{CO}$ amb $\mathrm{H}_{2}$ i un fotocatalitzador de tipus $p$ es mostra a l'Esquema 7.2. A aquest esquema destaca el fet que el $\mathrm{CO}$ actua com atrapador de buits, cosa que explica la formació de $\mathrm{CO}_{2}$. D'altra banda, el $\mathrm{CO}$ patiria reducció formant $\mathrm{C}$ elemental $\mathrm{O}_{2}$. L'anàlisi en fase gas ha detectat en certs casos el creixement de la concentració $\mathrm{d}^{\prime} \mathrm{O}_{2}$ quan hi ha una gran conversió de $\mathrm{CO}$, fent que la contaminació de la mostra per aire sigua menyspreable. La generació d' $\mathrm{O}_{2}$ ha estat particularment notable en el cas que s'ha fet servir $\mathrm{NiO}$ com fotocatalitzador i un excés d' $\mathrm{H}_{2}$ com a agent reductor (vegeu Figura 7.7). El C elemental es diposita sobre la superfície del catalitzador i la seva acumulació és responsable de l'augment del contingut de $\mathrm{C}$ al fotocatalitzador i es pot quantificar per anàlisi elemental (vegeu les taules $7.5 \mathrm{i} 7.6$ ). Aquest carboni elemental reaccionària ràpidament amb $\mathrm{H}_{2}$ en fase gas donant lloc a carbé com a intermedi de reacció. Aquest carbé s'inseriria en una molècula $\mathrm{d}^{\prime} \mathrm{H}_{2}$ per donar lloc a metà, però també podria inserir-se en un enllaç $\mathrm{C}-\mathrm{H}$ del $\mathrm{CH}_{4}$ donant lloc a la formació d'età. Una inserció de carbè anàloga sobre el $\mathrm{C}-\mathrm{H}$ o el $\mathrm{C}-\mathrm{C}$ de l'età donaria lloc a la formació de propà i, així ,successivament, depenent de la composició relativa de la fase gas. 
Per tal d'aportar proves a favor d'aquest mecanisme de reacció es van realitzar experiments addicionals en què, d'una banda, vam dur a terme la irradiació de $\mathrm{CO} \mathrm{i}_{2}$ en presència d'un agent sacrificial donador d'electrons tal com el metanol i, per altra, en presència de metà. En el primer cas, vam observar que la presència de metanol condueix a la inhibició en la formació de $\mathrm{CO}_{2}$, demostrant així que l'origen d'aquest compost és la fotooxidació en la superfície del semiconductor, tal com s'ha proposat a l'Esquema 7.2.

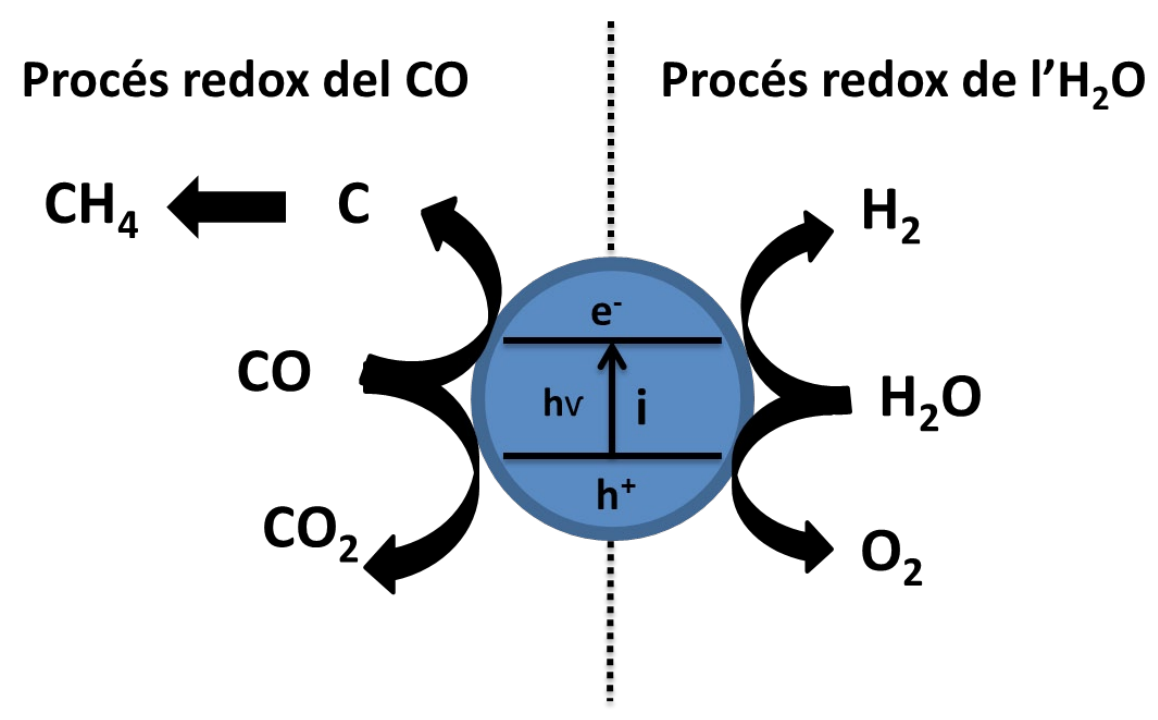

Esquema 7.2. Mecanisme proposat per racionalitzar la reducció de CO en presència d'un semiconductor tipus $p$.

En el segon cas, la irradiació amb llum solar simulada del $\mathrm{NiO}$ en una atmosfera que conté des de l'inici quantitats significatives de $\mathrm{CH}_{4}$ va donar lloc a l'observació d'età com a producte primari de la irradiació, el que estaria d’acord amb la generació de grups metilé a la fotoreacció del CO.

Una de les principals raons per les quals els òxids metàl-lics de tipus $p$ no s'han considerat amb freqüència com a fotocatalitzadors és a causa de la seua presumpta falta d'estabilitat i l'aparició de la corrosió. Aquestes proves 


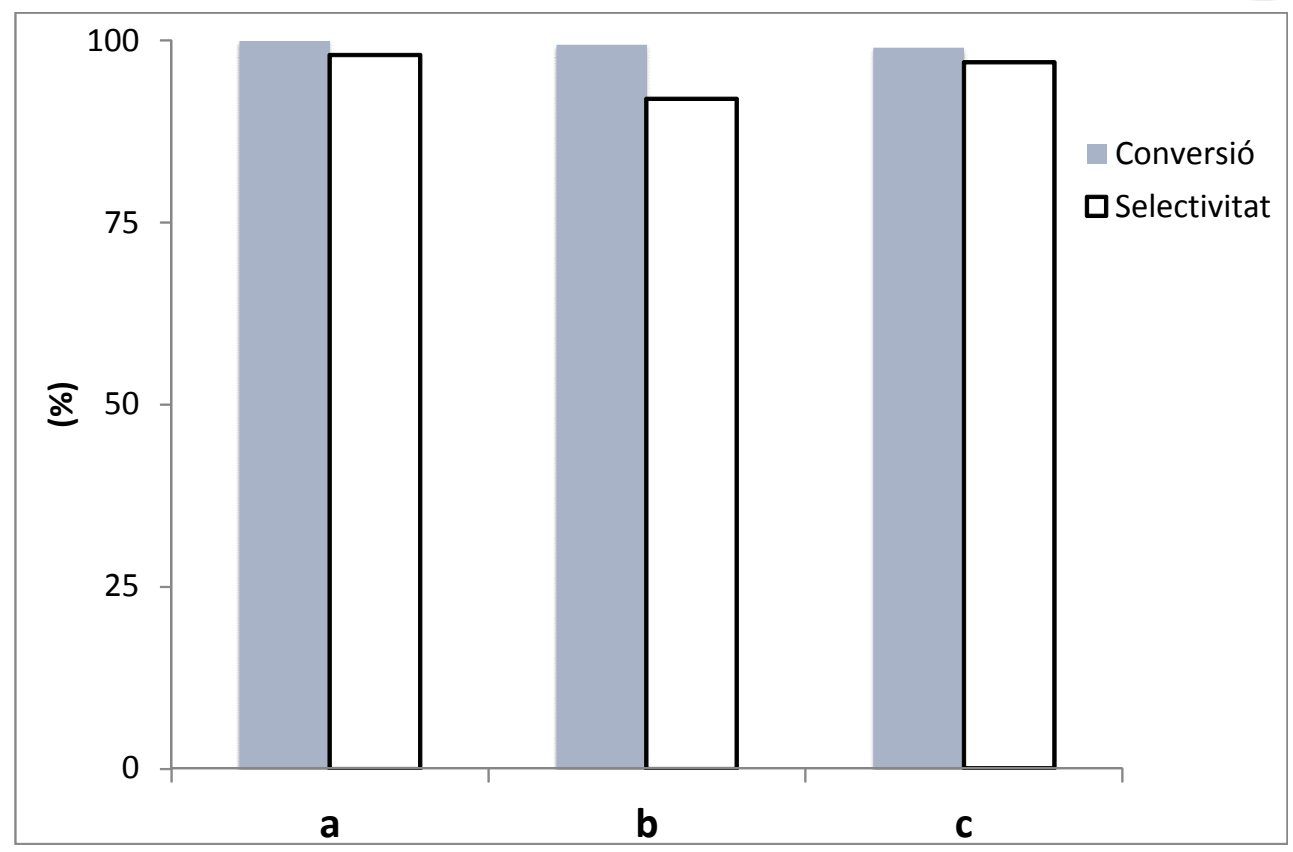

Figura 7.8. Conversió fotocatalítica del $\mathrm{CO}$ (barres grises) i selectivitat a $\mathrm{CH}_{4}$ (barres blanques) mesurada per a una mostra NiO: a) catalitzador nou, b) segon ús, c) tercer ús. Condicions de reacció: barreja de CO (20\%, 5 mmols), $\mathrm{H}_{2}(75 \% 18$ $\mathrm{mmols}$ ), $\mathrm{Ar}(5 \%)$; massa de $\mathrm{NiO}, 250 \mathrm{mg}$; font d'il.luminació solar simulada (100 $\mathrm{mW} / \mathrm{cm}^{2}$ ). Després de l'ús, el catalitzador s'activa a $450^{\circ} \mathrm{Camb}$ una corrent d'aire.

de fotocorrosió, s'han dut a terme principalment al tractament d'aigües residuals. En el present estudi hem comprovat l'estabilitat de l'activitat fotocatalítica del $\mathrm{NiO}$ mitjançant la realització de tres usos consecutius de la mateixa mostra. Després de cada ús, la mostra de NiO es va sotmetre a calcinació a $450^{\circ} \mathrm{C}$ sota aire per efectuar la combustió del residu carbonós. Els resultats es mostren a la Figura 7.8. Com es pot veure, es va obtenir la mateixa conversió de $\mathrm{CO}$ i selectivitat a $\mathrm{CH}_{4}$ per als tres usos. D’altra banda, difracció de raigs $\mathrm{X}$ de la mostra de $\mathrm{NiO}$ abans i després de tres usos consecutius van ser coincidents, indicant que l'estructura cristal-lina de les nanopartícules no ha patit canvis detectables. A més, la comparació dels espectres de FTIR de la mostra fresca amb NiO que després de tres usos només va mostrar diferències que corresponen a la quantitat d'aigua co-adsorbuda, sense la presència d'altres pics detectables. 
Els experiments fotocatalítics anteriors els vam realitzar utilitzant un simulador solar que emet al voltant d'un $5 \%$ de la potència a la regió UV. L'alta activitat fotocatalítica en termes de conversió de $\mathrm{CO}$, utilitzant el $\mathrm{NiO}$ com a catalitzador en comparació amb el $\mathrm{TiO}_{2} \mathrm{O} \mathrm{CeO}_{2}$ s'ha atribuït a la fotoresposta de la llum visible d'NiO en contrast amb $\mathrm{TiO}_{2}$. Hem dut a terme experiments addicionals en la reducció fotocatalítica de $\mathrm{CO}$ a $\mathrm{CH}_{4}$ amb $\mathrm{H}_{2}$, utilitzant $\mathrm{NiO}$, irradiant amb llum visible, dotant el sumulador solar amb un filtre que no deixa passar les longituds d'ona menors a $400 \mathrm{~nm}$ (vegeu la Figura 8.7 del Capítol 8) Com es pot veure a l'entrada de la Taula 7.6 NiO és també fotoactiu sota irradiació de llum visible a pesar que la conversió total disminueix, pel que un gran porcentatge de l'activitat catalítica del NiO prové de la regió d'UV. 
En el present capítol hem demostrat que la irradiació directa amb llum UV de la zona llunyana del $\mathrm{CO}_{2}$ dóna lloc a la formació de $\mathrm{CO}$ o $\mathrm{O}_{2}$ amb gran eficiència. Aquest procés no requereix la presència de cap fotocatalitzador i és desfavorit per la presència de vapor $d^{\prime} \mathrm{H}_{2} \mathrm{O}$, causa de l'elevat coeficient d'absorció de $\mathrm{I}^{\prime} \mathrm{H}_{2} \mathrm{O}$ que exerceix un paper de filtre intern competint amb la irradiació del $\mathrm{CO}_{2}$. D’aquesta manera, irradiant en absència d'humitat es poden aconseguir irradiar al $\mathrm{CO}_{2}$ aconseguint conversions elevades i donant lloc a la formació de $\mathrm{CO}$ i $\mathrm{O}_{2}$.

Per altra banda la conversió del $\mathrm{CO}_{2}$ en hidrogen o hidrocarburs es pot dur a terme en un procés en dues etapes de les quals la primera consisteix en la irradiació directa del $\mathrm{CO}_{2}$ en fase gas amb llum UV llunyana i en absència de fotocatalitzador per generar $\mathrm{CO}$ i la segona seria la reacció de reducció fotocatalítica del CO per a la formació d'hidrogen (reacció WGS) o hidrocarburs (procés Fischer Tropsh). Hem comprovat que la reacció del CO amb aigua dóna una distribució de productes diferent segons el caràcter $\mathrm{n} o$ $p$ del fotocatalitzador. Així, $\mathrm{CeO}_{2}$ i $\mathrm{TiO}_{2}$, convenientment dopats o modificats, produeixen una reacció anàloga al desplaçament per vapor d'aigua (WGS) però que pot ser duta a terme a temperatura ambient i emprant llum solar aconseguint conversions notables. 
En contrast, els semiconductors de tipus $\mathrm{p}$ com el $\mathrm{NiO} i \mathrm{FeO}_{x}$ en promouen, juntament amb la fotooxidació del $\mathrm{CO}_{\text {a }} \mathrm{CO}_{2}$, la fotoreducció a $\mathrm{CH}_{4}$. A més, quan el procés es porta a terme en presència d' $\mathrm{H}_{2}$ es poden aconseguir rendiments elevats cap a la conversió del $\mathrm{CO}$ a $\mathrm{CH}_{4}$ (procés Fischer-Tropsh), el qual s'afavoreix per un excés $\mathrm{d}^{\prime} \mathrm{H}_{2}$ en el medi. Sota les condicions òptimes, usant $\mathrm{H}_{2}$ com a agent reductor, la selectivitat a la formació de $\mathrm{CH}_{4}$ és del $80 \%$ a conversió de CO completa, emprant un simulador solar. 
1. Dey, G.R., "Chemical Reduction of $\mathrm{CO}_{2}$ to Different Products during Photo Catalytic Reaction on $\mathrm{TiO}_{2}$ under diverse Conditions: an Overview". J. Nat. Gas Chem., 2007. 16: p. 217-226.

2. Centi, G. and S. Perathoner, "Towards Solar Fuels from Water and $\mathrm{CO}_{2}$ ". ChemSusChem, 2010. 3(2): p. 195-208.

3. Gust, D., T.A. Moore, and A.L. Moore, "Mimicking photosynthetic solar energy transduction. Accounts of Chemical Research", 2001. 34(1): p. 40-48.

4. Gust, D., T.A. Moore, and A.L. Moore, "Solar Fuels via Artificial Photosynthesis". Accounts of Chemical Research, 2009. 42 p. 18901898.

5. Hammarstrom, L. and S. Hammes-Schiffer, "Artificial Photosynthesis and Solar Fuels. Accounts of Chemical Research", 2009. 42 p. 18591860.

6. Sastre, F., A. Corma, and H. García, $185 \mathrm{~nm}$ "Photoreduction of CO to Methane by Water. Influence of the Presence of a Basic Catalyst." Journal of the American Chemical Society, 2012. 134(34): p. 1413714141.

7. Haryanto, A., et al., "Current status of hydrogen production techniques by steam reforming of ethanol: A review". Energy and Fuels, 2005. 19(5): p. 2098-2106.

8. Newsome, D.S., "Water gas shift reaction". Catalysis reviews Softcover ed., 1980. 21(2): p. 275-281.

9. Song, C., "Fuel processing for low-temperature and high-temperature fuel cells: Challenges, and opportunities for sustainable development in the $21^{\text {st }}$ century". Catalysis Today, 2002. 77(1-2): p. 17-49. 
10. Primo, A., et al., "Efficient visible-light photocatalytic water splitting by minute amounts of gold supported on nanoparticulate $\mathrm{CeO}_{2}$ obtained by a biopolymer templating method". Journal of the American Chemical Society, 2011. 133(18): p. 6930-6933.

11. Silva, C.G., et al., "Influence of excitation wavelength (UV or visible light) on the photocatalytic activity of titania containing gold nanoparticles for the generation of hydrogen or oxygen from water". Journal of the American Chemical Society, 2011. 133(3): p. 595-602.

12. Balzani, V., A. Credi, and M. Venturi, "Photochemical conversion of solar energy". ChemSusChem, 2008. 1(1-2): p. 26-58.

13. Gust, D., T.A. Moore, and A.L. Moore, "Solar fuels via artificial photosynthesis. Accounts of Chemical Research", 2009. 42(12): p. 1890-1898.

14. Ni, M., et al., "A review and recent developments in photocatalytic water-splitting using $\mathrm{TiO}_{2}$ for hydrogen production. Renewable and Sustainable" Energy Reviews, 2007. 11(3): p. 401-425.

15. Zou, Z., et al., "Direct splitting of water under visible light irradiation with an oxide semiconductor photocatalyst". Nature, 2001. 414(6864): p. 625-627.

16. Youngblood, W.J., et al.,"Visible light water splitting using dye-sensitized oxide semiconductors". Accounts of Chemical Research, 2009. 42(12): p. 1966-1973.

17. Kamat, P.V., "Photophysical, photochemical and photocatalytic aspects of metal nanoparticles". Journal of Physical Chemistry B, 2002. 106(32): p. 7729-7744.

18. Sakthivel, S. and H. Kisch, Daylight "Photocatalysis by Carbon-Modified Titanium Dioxide". Angewandte Chemie - International Edition, 2003. 42(40): p. 4908-4911. 


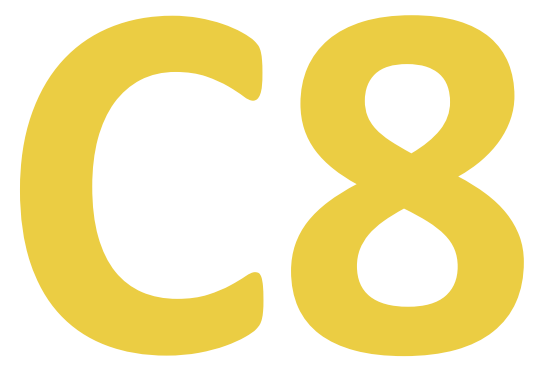

\section{Experimental}

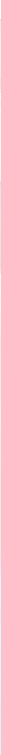



Els gasos que hem emprat han estat subministrats per la casa Linde Air Pack, mentre que els que estan marcats isotòpicament en el ${ }^{13} \mathrm{C}$ provenen de Sigma-Aldrich.

\section{Metà}

La puresa del metà emprat en la present tesi és del 99.995\%. La major impuresa és nitrogen, i el percentatge d'altres hidrocarburs inferior al $0.00020 \%$.

\section{Metà ${ }^{13} \mathrm{C}$}

El metà marcat isotòpicament en el ${ }^{13} \mathrm{C}$ que s'ha utilitzat va ser d'una puresa del 99.9\%. Les principals impureses que contenen són $\mathrm{Ar}, \mathrm{O}_{2}, \mathrm{~N}_{2}, \mathrm{CO}$ i $\mathrm{CO}_{2}$. El contingut d'altres hidrocarburs diferents al metà és del $0.0015 \%$. 


\section{Età}

L'età utilitzat en la present tesis tant per als experiments com per als balanços de masses i anàlisis de la fase gasosa foren d'una puresa del 99.999\%. La principal impuresa és el nitrogen i el percentatge d'altres hidrocarburs és inferior al $0.0020 \%$.

\section{Età ${ }^{13} \mathrm{C}$}

La puresa de l'età marcat en els dos carbonis en ${ }^{13} \mathrm{C}$ que es va usar és del 99.4\%. Aquest té com a principals impureses el $\mathrm{N}_{2}, \mathrm{O}_{2}, \mathrm{CO}_{2}, \mathrm{CO}$ i el contingut d'altres hidrocarburs diferents a l'età marcat $a \mathrm{mb}^{13} \mathrm{C}$ és del $0.4 \%$.

$\mathrm{CO}_{2}$

El $\mathrm{CO}_{2}$ utilitzat en la present tesis per a balanços de mases i anàlisis de la fase gasosa és del 99.999\%. La principal impuresa és el $\mathrm{N}_{2}<30 \mathrm{ppmV}$ seguit de l' $\mathrm{O}_{2}$ $<15$ ppmV, $\mathrm{CO}<1 \mathrm{ppmV}$ i altres hidrocarburs $\mathrm{C}_{\mathrm{n}} \mathrm{H}_{\mathrm{m}}<2$ ppmV. Aquest ha sigut subministrat en bales de 10 litres pressuritzades a 100 bars per Linde-gasos.

$$
\mathrm{CO}_{2}{ }^{13} \mathrm{C}
$$

El $\mathrm{CO}_{2}$ marcat isotòpicament en el ${ }^{13} \mathrm{C}$ té una puresa superior al 99.9\%. Les principals impureses són $\mathrm{Ar} / \mathrm{O}_{2} / \mathrm{N}_{2}<50$ ppm; $\mathrm{CO}<50$ ppm; la quantitat d'hidrocarburs $\left(\mathrm{CH}_{4}+\mathrm{C}_{2} \mathrm{H}_{6}\right)<30 \mathrm{ppm}$. 
NaY (PQ-CBV100), HBeta (PQ-CBV811), HZSM5 (PQ-CBV3020, PQ-CBV5020, PQ-CBV1520)) i Mordenita (Zeolyst CBV Si/Al) són zeolites comercials, procedents d'indústries PQ Corporation. L'Aerosil 200 va ser subministrat per Degusa.

\section{Beta (Al,F) i Beta (Si,F)}

Les zeolites Beta (Al) i Beta (Si) van ser obtingudes mitjançant una síntesi hidrotermal a $175{ }^{\circ} \mathrm{C}$ durant 5 dies a partir de gels de sílice i alúmina en àcid pfluorhífric seguint el procediment descrit per Corma i col·laboradors, ${ }^{[1,2]}$ respectivament.

\section{Zeolita ITQ-2}

La zeolita ITQ-2 va ser obtinguda seguint el procediment descrit per Corma i els seus col-laboradors. ${ }^{[3]}$ Primer se sintetitza un precursor laminar d'estructura MWW en un mitjà hidrotermal; després, es procedeix a l'intercanvi catiònic de l'agent corrector d'estructura, dispersant el sòlid en una dissolució aquosa del surfactant iònic bromur de cetiltrimetilamoni (CTABr, Aldrich, 29\% (p)) i hidròxid de tetrapropilamoni (TPAOH, Fluka, 40\% (p)). La suspensió es deixa a reflux durant $16 \mathrm{~h}$. La mostra se sotmet a un tractament en ultrasons (50W, $40 \mathrm{kHz}$ ) durant $1 \mathrm{~h}$ per tal de desordenar les làmines del material. El sòlid 
obtingut es recupera per ultra-centrifugació, i emprant $\mathrm{HCl}$ (aq) (37\% (p), Sigma-Aldrich) s'ajusta el $\mathrm{pH}$ de la suspensió a amb valor 2 , i s'asseca durant $12 \mathrm{~h}$. Finalment s'elimina la matèria orgànica calcinant-la durant 5 hores a 550 ${ }^{\circ} \mathrm{C}$ amb un flux d'aire $(50 \mathrm{ml} / \mathrm{min})$.

\section{Zeolita ITQ-6}

Les mostres de zeolita ITQ-6 van ser sintetitzades mitjançant un procediment similar al ITQ-2. La ITQ-6 pura sílice va ser obtinguda mitjançant inflament de les làmines del precursor de ferrita (PREFER) segons el procediment descrit per Corma i col·laboradors. ${ }^{[4]}$

\section{MCM-41}

La mostra MCM-41 es va sintetitzar a partir d'Aerosil-200 (Degusa) com a font de sílice, hidròxid de tetrametilamoni (TMAOH, Aldrich), i bromur d'hexadecil trimetil amoni (CTABr, Aldrich) com a agent plantilla, seguint el procediment descrit per Corma i col.laboradors. ${ }^{[5]}$ En un autoclau d'acer inoxidable, recobert de tefló, es carrega un gel amb una composició molar de $\mathrm{SiO}_{2}:$ 0,26 CTABr: $0,40 \mathrm{TMAOH}: 29 \mathrm{H}_{2} \mathrm{O}$. Es va calfar en règim estàtic a $408 \mathrm{k}$ durant $24 \mathrm{~h}$. El sòlid resultant es renta amb abundant aigua destilllada i s'assecà a $333 \mathrm{k}$ durant una nit. Per últim, la plantilla orgànica s'eliminà mitjançant una calcinació a $813 \mathrm{k}$ en una corrent de $\mathrm{N}_{2}$ durant $1 \mathrm{~h} \mathrm{i}$, després, una corrent d'aire a la mateixa temperatura durant $5 \mathrm{~h}$, obtenint el material MCM-41.

\section{Òxids metàl·lics}

Els òxids metàl-lics $\mathrm{MgO}, \mathrm{ZrO}_{2}, \mathrm{NiO}, \mathrm{CuO}, \mathrm{Co}_{3} \mathrm{O}_{4}, \mathrm{CoO}, \mathrm{Fe}_{3} \mathrm{O}_{4} \mathrm{Fe}_{2} \mathrm{O}_{3}$ són comercials de Sigma-Aldrich. El $\mathrm{CeO}_{2}$ va ser suminitstrat per Rhodia amb una grandària de partícula mitjana de $50 \mathrm{~nm}$. 


\section{$\mathrm{Au} / \mathrm{CeO}_{2}$}

Es dissol la quantitat necessària de $\mathrm{HAuCl}_{4} 3 \mathrm{H}_{2} \mathrm{O}$ en $100 \mathrm{ml}$ d'aigua milli $\mathrm{Q}$ plus. S'ajusta el pH a $10 \mathrm{amb}$ una dissolució aquosa de $\mathrm{NaOH}(0.2 \mathrm{~m})$ fins que s'estabilitza. Després s'afegeix $1 \mathrm{~g}$ d'òxid de ceri, i es reajusta el pH a 10. Es deixa agitar la suspensió durant $12 \mathrm{~h}$ i després es filtra el sòlid. Aquesta dissolució es renta amb abundant aigua Milli $Q$ per tal d'eliminar els clorurs presents. Es deixa assecar en una estufa a la temperatura de $110^{\circ} \mathrm{C}$ durant $12 \mathrm{~h}$. Finalment el sòlid sintetitzat es redueix dissolent amb 1-feniletanol a $160{ }^{\circ} \mathrm{C}$ durant $1 \mathrm{~h}$. Finalment, es torna a rentar el sòlid obtingut amb aigua Milli Q i s'asseca 12 més ha $110^{\circ} \mathrm{C}$.

\section{$\mathrm{Au} / \mathrm{TiO}_{2}$}

Aquest tipus de catalitzadors es preparen per precipitació-deposició d'or sobre l'òxid metàl-lic (TiO2-P25) a pH controlat. Per a això s'addiciona al $\mathrm{TiO}_{2}$ una dissolució aquosa de $\mathrm{HAuCl}_{4}$ prèviament ajustada a $\mathrm{pH} 9 \mathrm{amb}$ una dissolució $0.2 \mathrm{M}$ de $\mathrm{NaOH}$. La suspensió es manté en agitació controlant en tot moment el pH de síntesi. Finalment el sòlid es filtra i es renta exhaustivament amb aigua milli Q plus per tal d'eliminar tots els clorurs provinents del precursor d'or. El catalitzador s'asseca i es calcina en atmosfera d'aire a una temperatura determinada.

Aquest catalitzador va ser subministrat per STREM (referència 79-075).

$\mathrm{Pd} / \mathrm{TiO}_{2}$

Aquest catalitzador va ser preparat per impregnació d'1 g de $\mathrm{TiO}_{2}$ (Aeroxide P25) amb una solució de $36 \mathrm{mg}$ de $\mathrm{PdCl}_{2}$ (Aldrich) en $10 \mathrm{ml} \mathrm{d'} \mathrm{H}_{2} \mathrm{O}$ (Milli Q). La dissolució s'agita durant $4 \mathrm{~h}$ a temperatura ambient. Després, el líquid s'evapora i el sòlid es deixa assecar a $100{ }^{\circ} \mathrm{C}$ durant una nit. El catalitzador es redueix mitjançant un fluxe $d^{\prime} \mathrm{H}_{2}(80 \mathrm{ml} / \mathrm{min})$ a $300^{\circ} \mathrm{C}$ durant $4 \mathrm{~h}$. Després, el catalitzador es renta amb abundant aigua Milli-Q, i s'asseca a temperatura ambient $12 \mathrm{~h}$. Finalment es torna a calcinar a una temperatura de $300{ }^{\circ} \mathrm{C}$ durant $4 \mathrm{~h}$ i un flux d' $\mathrm{H}_{2}$. 
Per a la preparació de $\mathrm{Cu} / \mathrm{TiO}_{2}$ (1 pes\%), $\mathrm{Ag} / \mathrm{TiO}_{2}$ (1 pes\%) i $\mathrm{Pt} / \mathrm{TiO}{ }_{2}$ (1 pes\%), es va utilitzar el mateix procediment al descrit per al $\mathrm{Pd} / \mathrm{TiO}_{2}$, emprant una solució aquosa de $53.19 \mathrm{mg}$ de $\mathrm{CuSO}_{4} \cdot 5 \mathrm{H}_{2} \mathrm{O}, \mathrm{AgNO}_{3} \mathrm{i} \mathrm{H}_{2} \mathrm{PtCl}_{6} 6 \mathrm{H}_{2} \mathrm{O}$ (Aldrich) respectivament. 


\section{Microscòpia electrònica de transmissió}

L'anàlisi i indexació dels catalitzadors de nanopartícules metàl-liques dipositades sobre òxid de ceri o òxid de titani, es va dur a terme per microscòpia electrònica d'alta resolució tant en camp clar com en camp fosc en un equip JEOL 2200 HRTEM operant amb un voltatge de $200 \mathrm{kV}$.

Per a la preparació de les mostres es diposita una gota d'una suspensió de catalitzador en diclorometà prèviament sotmès a ultrasons sobre una reixeta de coure recoberta amb un film de carboni.

\section{Difracció de raig $X$}

Aquesta tècnica s'utilitza per a determinar la cristal-linitat dels catalitzadors sintetitzats. Els difractogrames es van registrar amb un difractòmetre PHILIPS X'PERT PW 3719 equipat amb un polaritzador de grafit, escletxes automàtiques amb superfície total de rastreig constant de 14 $\mathrm{mm}$, portamostres giratori i detector proporcional emprant radiació Ka del $\mathrm{Cu}(\alpha=1.54184)$ i una potència d'excitació de $2 \mathrm{~kW}$. La velocitat angular del goniòmetre va ser de $0.02 \mathrm{oxs}^{-1}$, sent l'interval de rastreig d'2 $2=1-10^{\circ}$. 


\section{Anàlisi químic}

El percentatge de metall en els catalitzadors es va determinar per espectrometria atòmica d'absorció en un equip Varian SpectrAA-10 Plus. Per a aquesta mesura els catalitzadors es calcinen a $900-950^{\circ} \mathrm{C}$, es dissolen en una barreja 3:1:1 en pes d' $\mathrm{HCl}, \mathrm{HNO}_{3}$ i HF a $60^{\circ} \mathrm{C}$ durant tota una nit i finalment es dilueixen amb aigua per tal que la dissolució siguia homogènia.

\section{Ressonància magnètica nuclear de líquids (RMN)}

La RMN és una espectroscòpia d'absorció de la radiació electromagnètica en la regió de les radio freqüències per part dels nuclis d'àtoms col-locats en un intens camp magnètic. Les mesures de RMN de líquids s'han realitzat en aquesta tesi utilitzant un espectròmetre Bruker $A V 300$, emprant seqüències de pols simple per a l'adquisició dels espectres de ${ }^{1} \mathrm{H}$ i amb desacoblament de protó per als espectres de ${ }^{13} \mathrm{C}$.

\section{Ressonància magnètica nuclear de sòlids (RMN de sòlids)}

El RMN de sòlids, a diferència dels espectres en dissolució, solen presentar senyals més amples a causa de les interaccións magnètiques entre els espins del nuclis, que estan rígidament enllaçats formant el sòlid. Aquest eixamplament de les senyals poden arribar a l'extrem que, a pesar d'estar presents, siguen indistingibles amb el fons. Als espectres de RMN en dissolució no ocorre tal cosa per l'alta mobilitat tèrmica de les molècules. Les interaccions que produeixen els eixamplaments de la línia de RMN als sòlids son: I'acoblament dipolar, l'asintropia del desplaçament químic i les 92 interaccions cuadrupolars.

\section{Anàlisi elemental}

El contingut en carboni i nitrogen de determinades mostres sòlides es va determinar en un analitzador elemental Euro EA Elemental Analyzer, emprant sulfanilamida com a referència. 


\section{Espectroscòpia Raman}

L'espectroscòpia Raman es fonamenta en la dispersió inelàstica que pateixen els fotons d'una font de radiació monocromàtica, normalment LASER, en interaccionar amb una mostra. Aquesta tècnica permet obtenir informació sobre estats vibracionals i rotacionals dels sòlids analitzats, així com sobre modes de vibració quantitats de xarxes cristal-lines com els fotons.

Els espectres es van adquirir en un equip Renishaw Raman In Via equipat amb un microscopi Leika DM LM i un díode làser $(\lambda=514 \mathrm{~nm}$ ) com a font de radiació. El làser es va enfocar sobre regions de la mostra de 3-5 micres de diàmetre, emprant un objectiu 50X i una longitud òptica de 8 $\mathrm{mm}$. Es van registrar els espectres a la regió de desplaçament Raman de $100-3000 \mathrm{~cm}^{-1}$, amb una resolució $<4 \mathrm{~cm}^{-1}$, acumulant 10 escombrats en un temps total d'acumulació de $100 \mathrm{~s}$. 

En aquest apartat descriurem els reactors y les làmpades que hem emprat per al desenvolupament de la present tesis. S'han utilitzat dos reactors, combinant-los amb 4 làmpades d'emissió a distintes longituds d'ona.

El primer reactor està format per una càmera de $116 \mathrm{ml}$ de capacitat, d'alumini. Aquesta càmera està subjecta a una llum de deuteri mitjançant una finestra $\mathrm{d}^{\prime} \mathrm{MgF}_{2}$. El llum emet principalment a una longitud d'ona de $165 \mathrm{~nm}$. L'espectre d'emissió es pot veure a la Figura 8.1. Aquest llum va ser subministrat per la casa Hammamatsu i té una potència de $30 \mathrm{~W}$. El voltatge és de $1 \mathrm{~V}$ i 1.8A de corrent en estat estacionari. La Figura 8.2 mostra l'esquema del reactor utilitzat. 


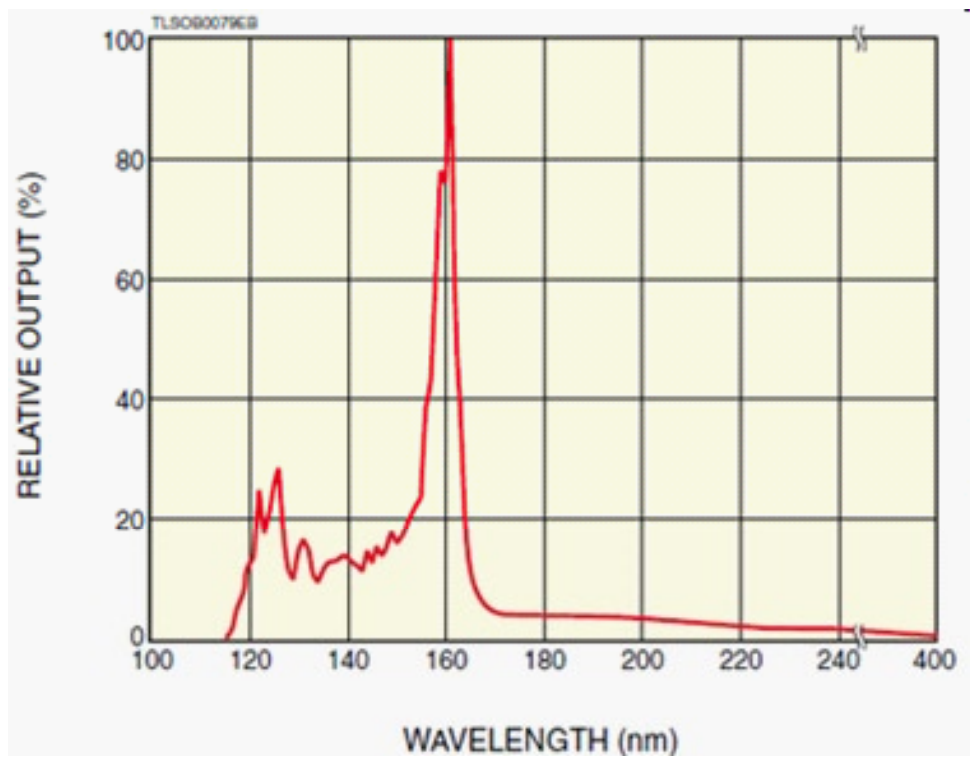

Figura 8.1. Espectre d’emissió de la làmpada de deuteri.

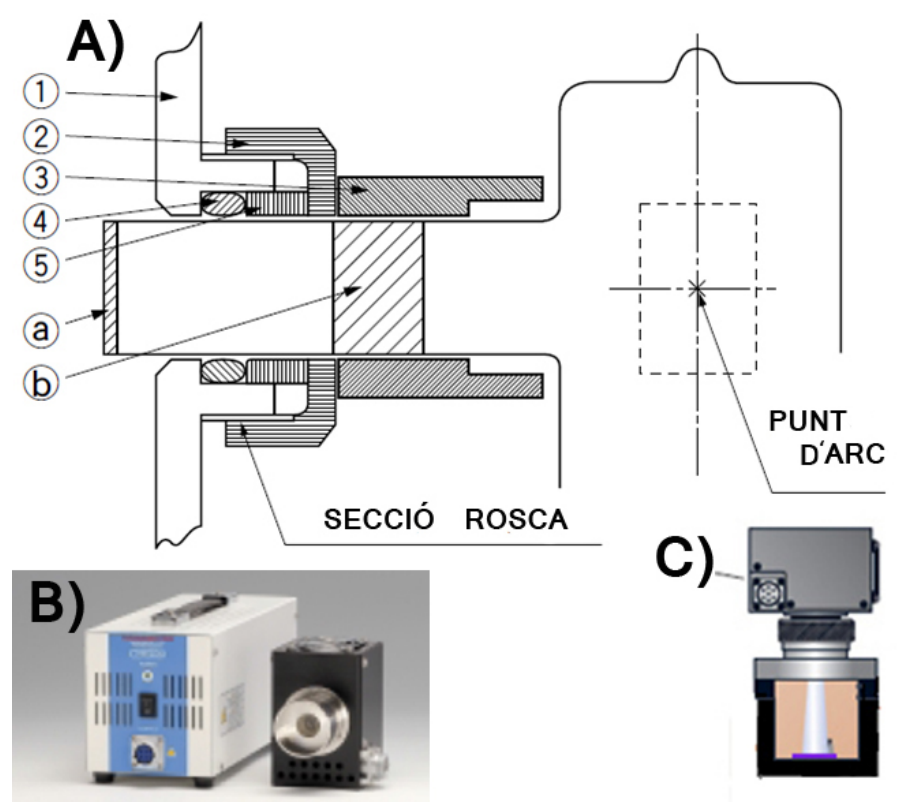

Figura 8.2. A) Detall del tancament entre la làmpada i el reactor on es pot observar la paret del reactor (1), rosca femella d'ajustament (2), tap de topall (3), junta tòrica d'estanqueitat $(15 \times 4 \mathrm{~mm})(4)$, separador (5), finestra de $\mathrm{MgF}_{2}(\mathrm{a})$, segellament (b) B) Foto de la làmpada junt amb la seua reactància ${ }^{2}$ ) Esquema del reactor. 
El segon reactor que s'ha utilitzat està dotat d'un cos cilíndric de quars sintètic (suprasil ${ }^{\circledR}$ ) d'unes dimensions de $15 \times 5 \mathrm{~cm}$ El quars es tanca amb dos cilindres d'alumini que encaixen mitjançant juntes tòriques de cautxú sintètic $\left(V{ }^{\circ}{ }^{\circledR}\right)$ assegurant l'estanquitat del sistema. El reactor forma una càmera de $300 \mathrm{ml}$. Disposa de 3 entrades/sortides amb vàlvules per a la càrrega de gasos i presa de mostra. Les mostres en pols que s'introdueixen han estat pel-letitzades prèviament amb un gra de tamany 46-74 mesh i s'escampen uniformement en una superfície de $4 \times 13 \mathrm{~cm}^{2}$. El reactor està dotat amb un termoparell $i$ un manòmetre digital per al control de la temperatura i pressió, respectivament. El fotorreactor, juntament amb els llums, es tanca mitjançant un cilindre d'alumini exterior, i amb una entrada ràpida es distribueix el $\mathrm{N}_{2}$ a la cambra que queda entre la font d'emissió i la finestra de quars. S'utilitza el $\mathrm{N}_{2}$ per eliminar tant $\mathrm{I}^{\prime} \mathrm{O}_{2}$ com I' $\mathrm{H}_{2} \mathrm{O}$ creant una atmosfera inert i que d'aquesta manera l'emissió VUV (185nm) arribe al nostre reactor. El flux de $\mathrm{N}_{2}$ que s'ha utilitzador per a la purga és de $250 \mathrm{ml} / \mathrm{min}$ durant els 5 minuts previs a encendre el llum i després un flux constant de $20 \mathrm{ml} / \mathrm{min}$ en el transcurs de la reacció. La Figura 8.3 mostra l'esquema i fotografia del reactor utilitzat.
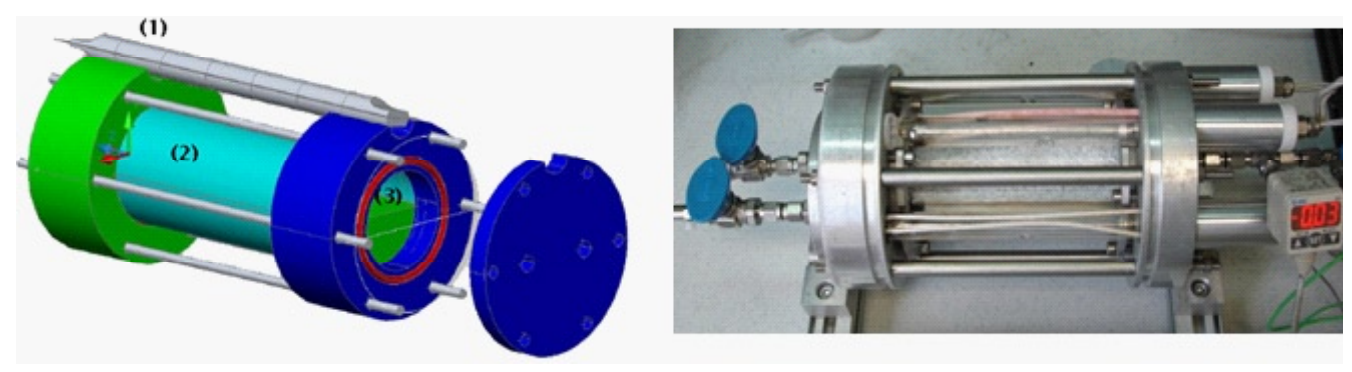

Figura 8.3: Esquerra, fotorreactor juntament amb làmpada de In $\mathrm{Hg}$ (1), finestra de quars sintètic (2), càmera de gasos (3). Dreta, foto del fotorreactor. 


\section{Làmpada d'amalgama In-Hg}

Aquest llum té principalment dues bandes d'emissió a $185 \mathrm{~nm}$ i 250 $\mathrm{nm}$. La potència emesa a $254 \mathrm{~nm}$ és de $10 \mathrm{~W}$ i $4 \mathrm{~W}$ a $185 \mathrm{~nm}$. Aquest llum és de Heraeus i per la irradiació a $185 \mathrm{~nm}$ s'han utilitzat tres llums d'una potència elèctrica de $45 \mathrm{~W}$ cadascuna.En la figura 8.6 es pot veure l'espectre d'emisssió d'aquestes làmpades.

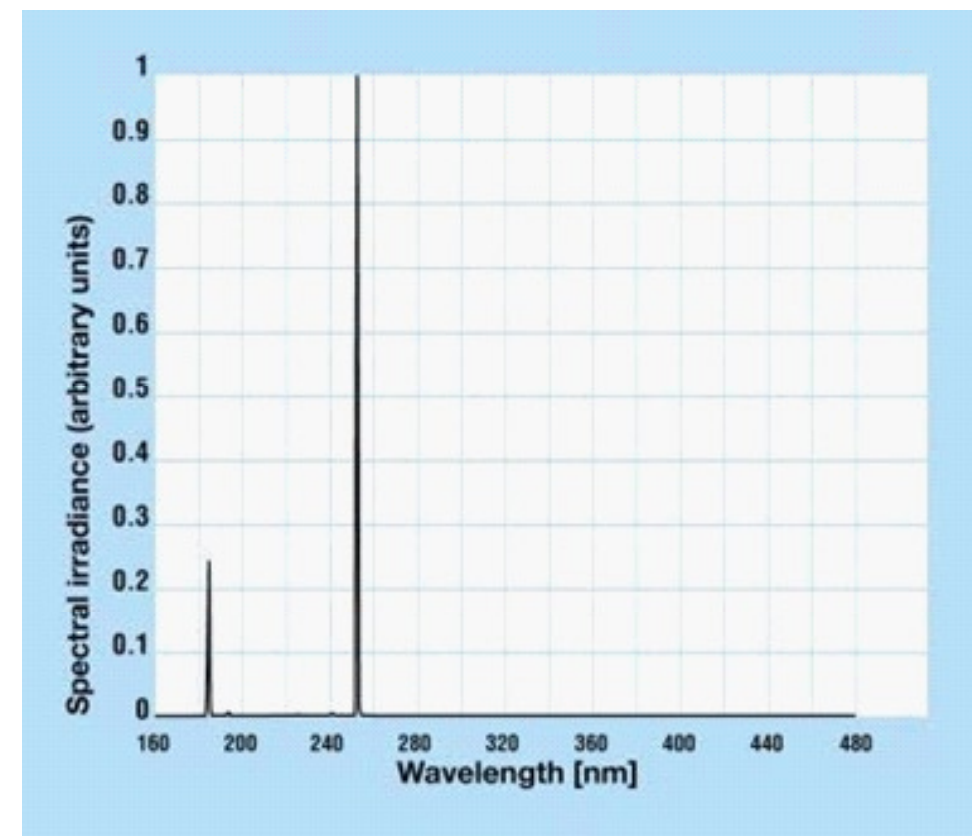

Figura 8.4. Espectre d’emissió de la làmpada d’amalgama In-Hg

\section{Simulador Solar}

El simulador solar utilitzat en la present tesi va ser subministrat per Oriel (Newport 66321). Aquest model té un sistema de reflector darrere i una òptica de condensació. La refrigeració del llum es realitza mitjançant ventilació d'aire forçada. Aquest sistema està dotat amb un llum de $\mathrm{Hg}(\mathrm{Xe})$ $1000 \mathrm{~W}$ de potència. L'esquema de la làmpada i una foto del sistema es mostra a la Figura 8.5. D'altra banda la Figura 8.6 mostra un espectre de la irradiança de la làmpada. En la Figura 8.7 es pot veure l'espectre del filtre que utilitzat per a irradiar amb el simulador solar sols amb llum visible ( $\lambda<400 \mathrm{~nm})$. 


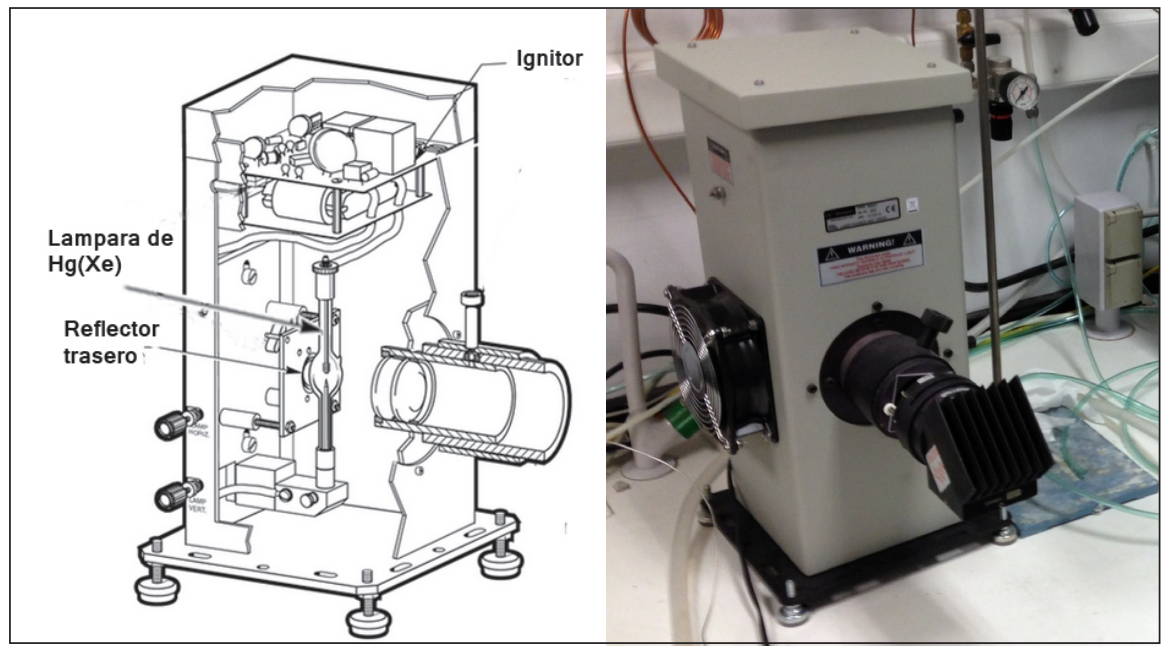

Figura 8.5. Esquerra, esquema del simulador solar Oriel. Dreta, foto del simulador solar.

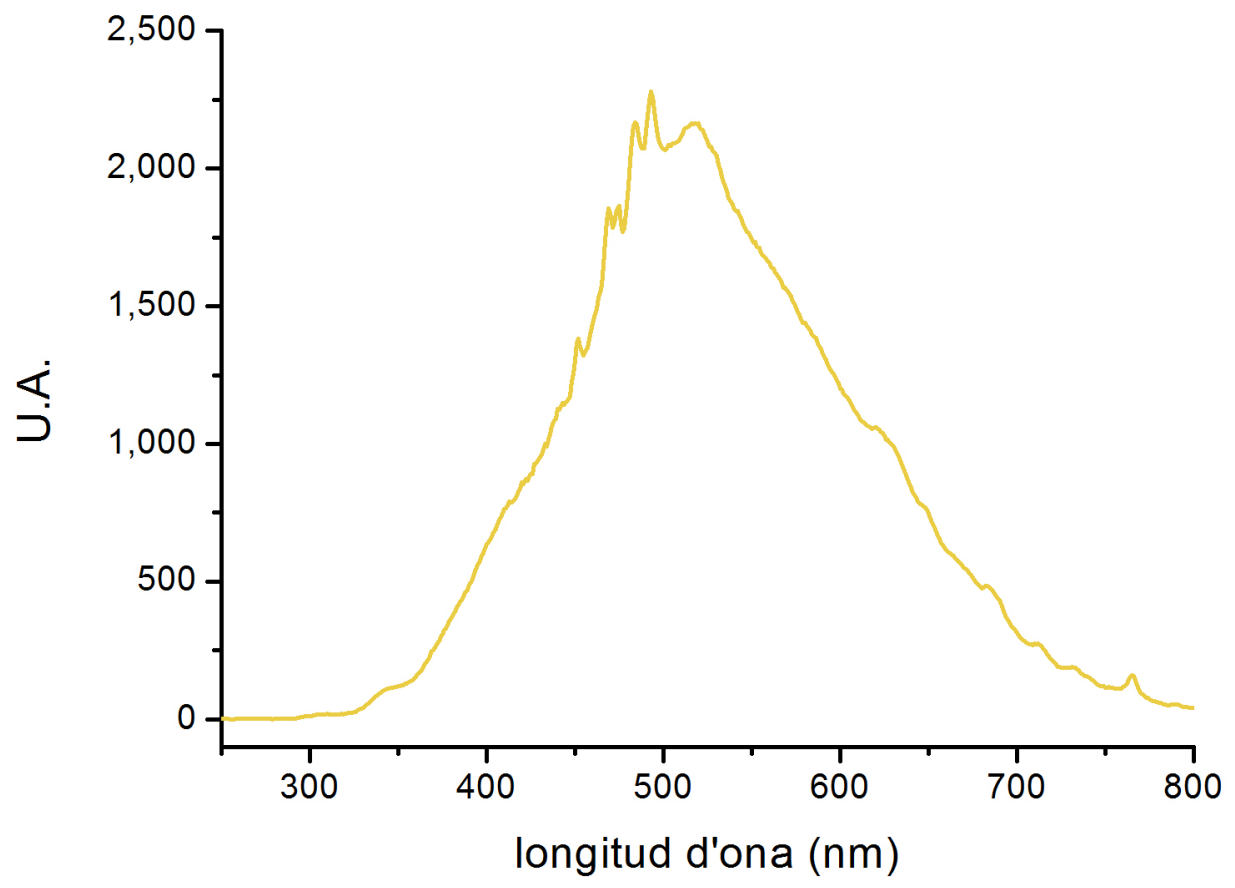

Figura 8.6. Espectre de simulador solar. 


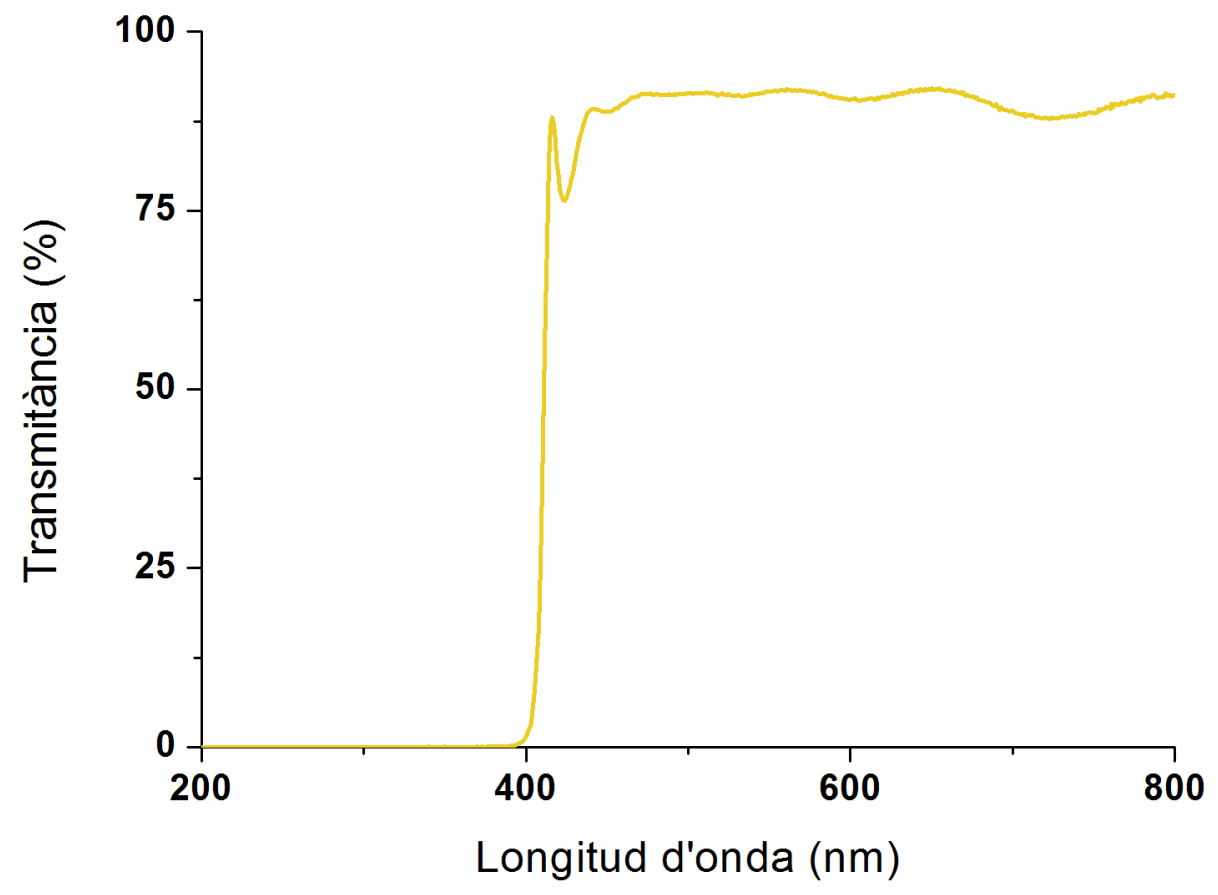

Figura 8.7. Escpectre del filtre de tall del simulador solar ( $\lambda<400 \mathrm{~nm}$ ).

\section{Llum visible LED}

Per a la irradiació amb llum de l'espectre visible s'ha utilitzat un díode d'emissió de llum (LED) que posseeix una banda principal centrada a $450 \mathrm{~nm}$ i una altra més ampla que va des dels 550 als $750 \mathrm{~nm}$. Aquest díode té un flux de $9000 \mathrm{~lm}$, treballant a una potència de $28 \mathrm{~V}$ i 2.1 A d'intensitat. Les Figures 8.8 i 8.9 mostren una fotografia del díode d'emissió de llum i un espectre de la irradiança del llum, respectivament. 


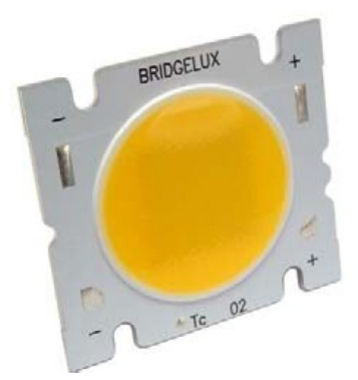

Figura 8.8. Foto del díode d’emissió de llum.

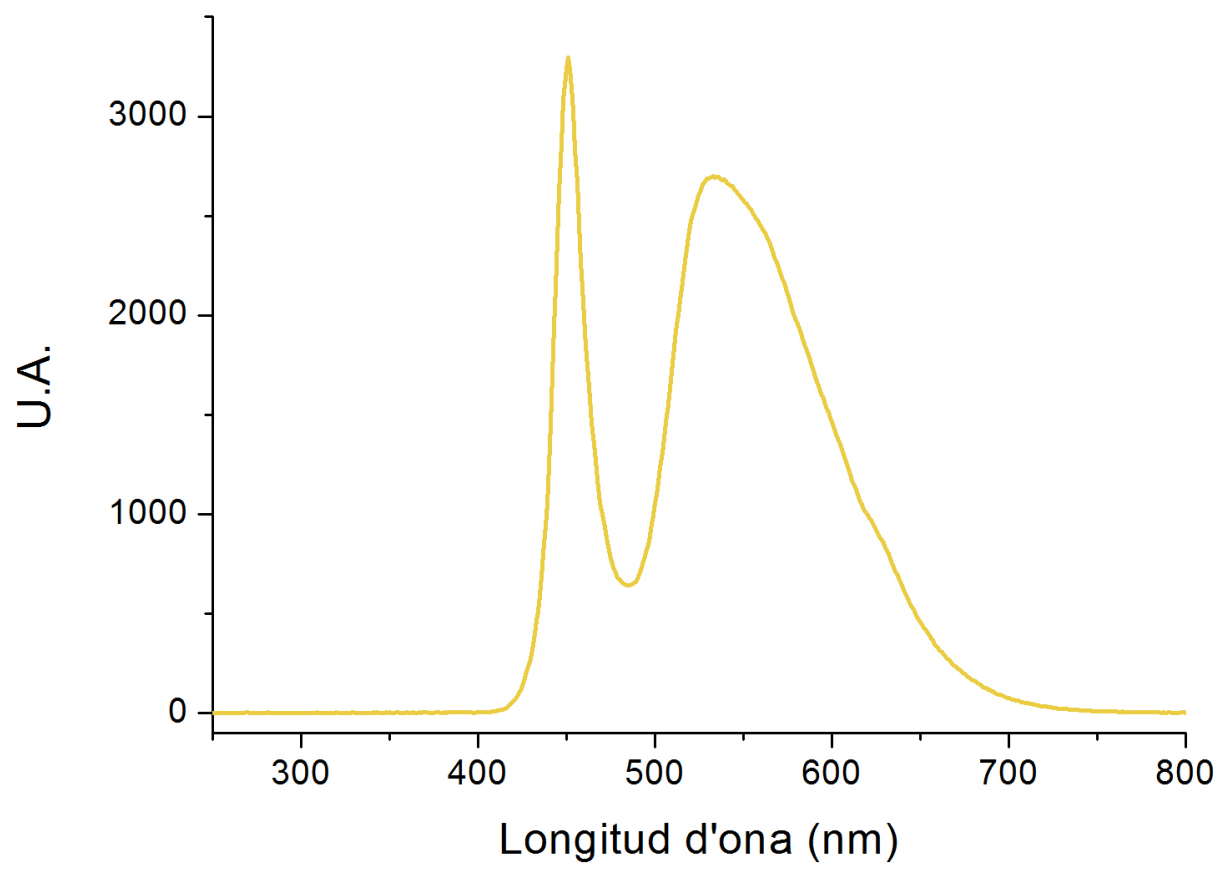

Figura 8.9. Espectre d'irradiança del llum LED. 
Es carrega el catalitzador en el reactor, utilitzant una bomba de buit per evacuar l'atmosfera ambient per baix dels 3 mbar. El temps aproximat de l'evacuació és de 10 minuts. A continuació s'omple el reactor amb el corrent del gas, fins a arribar a 1 bar. Per tal de minimitzar el contingut d'aire que hi ha al reactor, es realitzen tres cicles d'ompliment/evacuació dels gasos.

Els productes gasosos s'han analitzat, utilitzant un Cromatògraf de gasos (GC). El sistema de GC emprat és un analitzador ràpid de gasos de refineria de Bruker dotat amb 3 canals. El primer canal ("Front") analitza l' $\mathrm{H}_{2} \mathrm{i}$ posseeix amb una columna micro packet HayeSep Q i Molsieve 5A, amb l'Argó com a gas portador, i està dotat amb un detector de conductivitat tèrmica (TCD). El segon canal ("Middle") analitza els gasos permanents: $\mathrm{CO}, \mathrm{CO}_{2}, \mathrm{~N}_{2} \mathrm{i}$ $\mathrm{O}_{2}$ mitjançant una combinació d'una columna microempaquetada HaysepQ, HN un altra Molsieve 13x i un detector TCD El gas portador d'aquest segon canal és He. El tercer canal ("Rear") analitza els hidrocarburs des C1 a C6 en una columna plot $\mathrm{Al}_{2} \mathrm{O}_{3} \mathrm{i}$ He com a gas portador. El detector per a aquest tipus de gasos és un detector de ionització de flama (FID). A la figura 8.10 podem feure un esquema de les conexions i tuberies per a cromatògraf de gasos que hem utilitzat. 
Els productes gasosos de la reacció els vam analitzar agafant una mostra de $50 \mathrm{ml}$ de volum del reactor amb una jeringa especial de gasos. La mostra s'injectà al G.C., i passa a través de la linia que conecta els tres "loops" d'injecció, purgant qualsevol resta d'aire u altres mostres anteriors. (Vegeu figura 8.10, linia d'entrada de mostra). Els paràmetres principals del programa emprat per a la separació es resumeixen a la Taula 8.1.

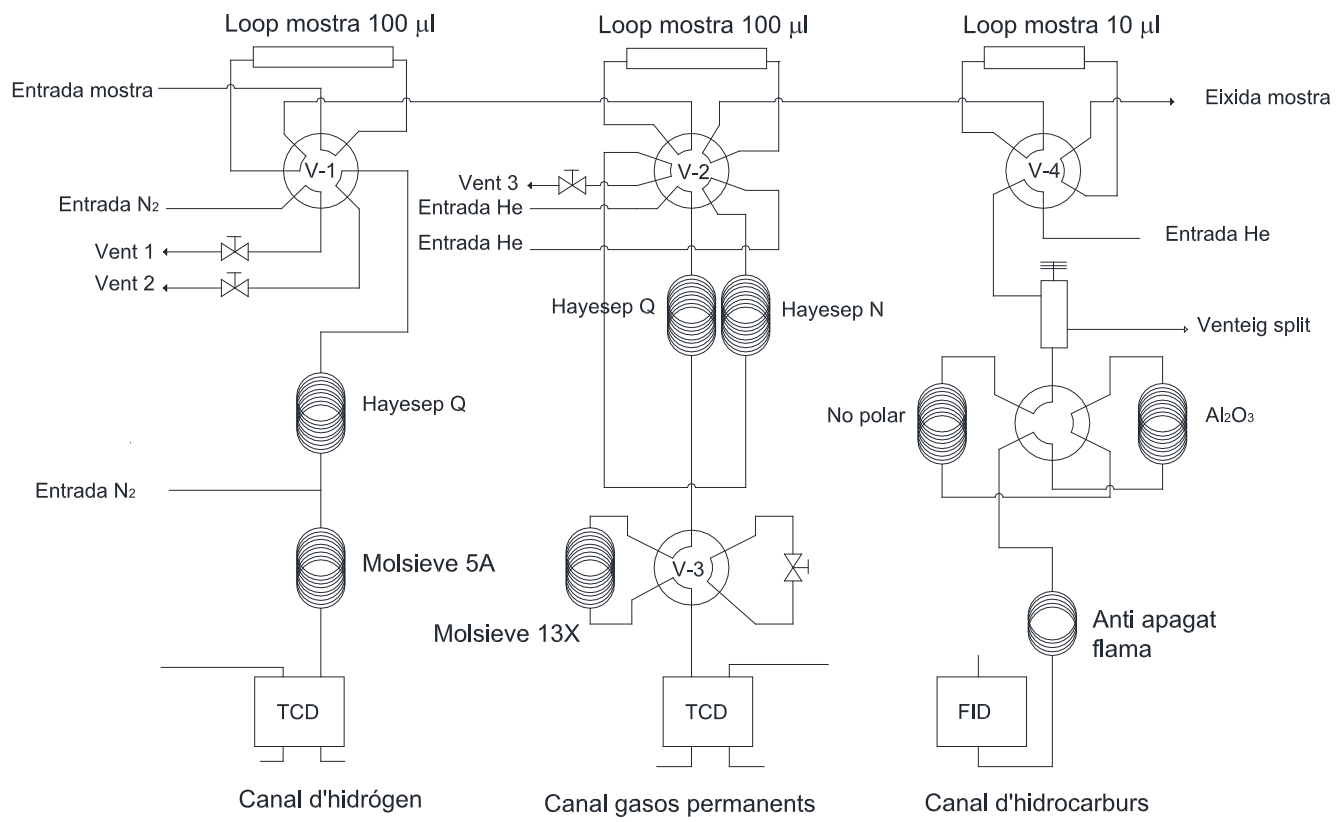

Figura 8.10. Esquema de les conexions i tuberies per al Cromatògraf de gasos.

Conversió Total $_{a}(\mathrm{~T})=\frac{n_{a, t=0}-n_{a, t=f \text { final }}}{n_{a, t=0}} * 100$ 
Taula 8.1. Condicions de programa utilitzat en el GC per l'anàlisi de gasos.

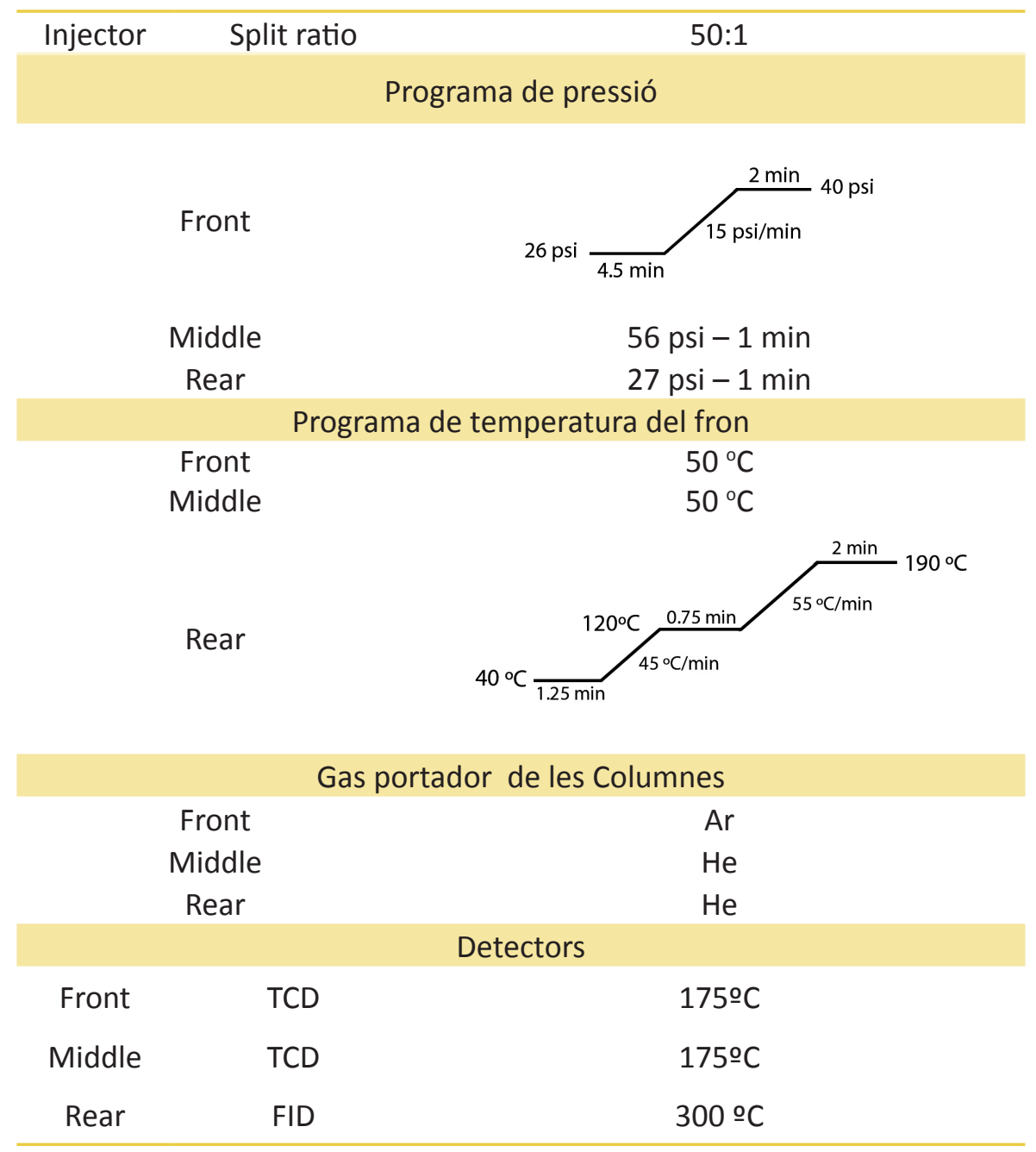


La Figura 8.11 mostra un cromatograma de gasos d'una mostra patró que conté $\mathrm{H}_{2}(8.54 \%), \mathrm{CO}_{2}(1.02 \%), \mathrm{CO}(9.08 \%), \mathrm{N}_{2}(72.41 \%), \operatorname{Ar}(2.04 \%), \mathrm{CH}_{4}$ (1.9\%), $\mathrm{C}_{2} \mathrm{H}_{4}(1.06 \%), \mathrm{C}_{2} \mathrm{H}_{6}(0.99 \%), \mathrm{C}_{3} \mathrm{H}_{8}(1.05 \%), \mathrm{C}_{3} \mathrm{H}_{6}(1.05 \%), \mathrm{C}_{3} \mathrm{H}_{4}(0.9 \%)$.

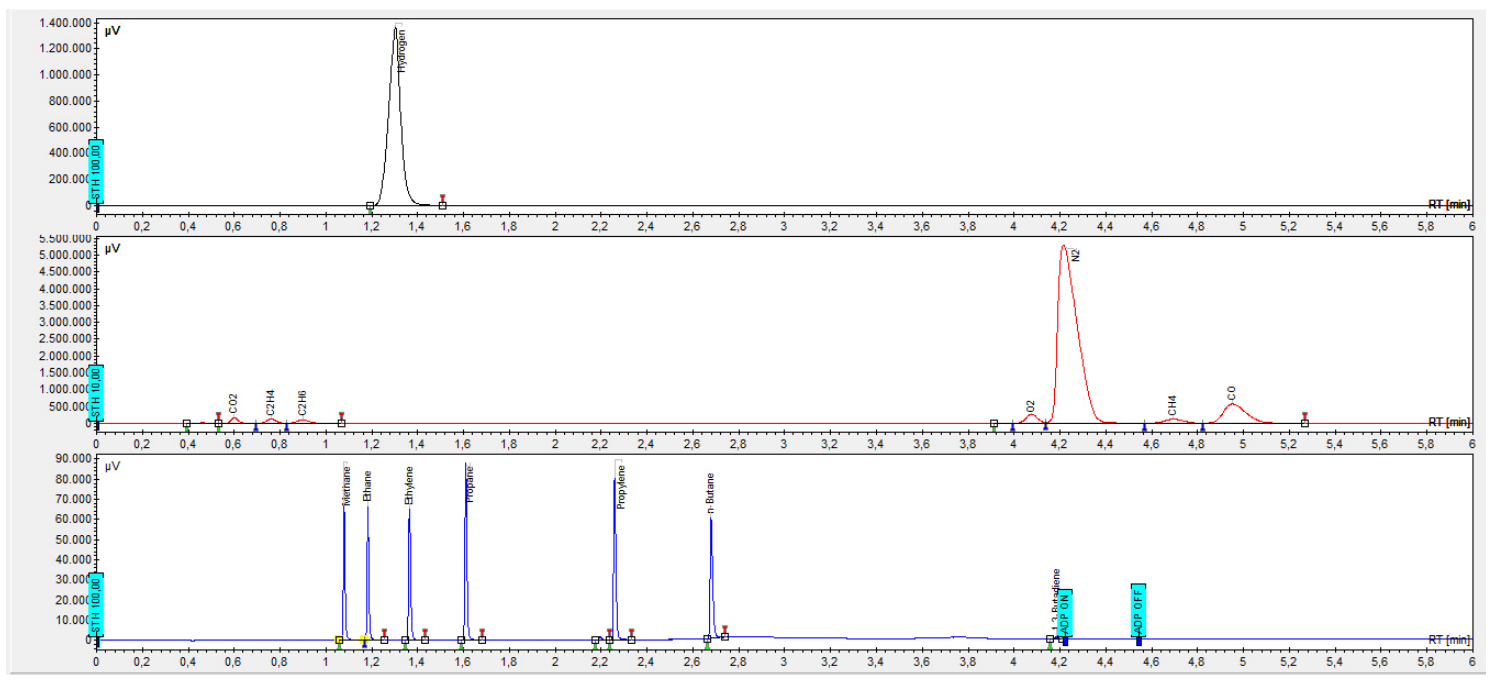

Figura 8.11. Cromatrograma i d'una mostra patró que conté HTCD (a), segon canal dotat amb TCD (b) i el tercer canal dotat amb un FID (c) 
En aquest tipus d'estudis la presència d'una fase gas i d'una fase sòlida obliga a determinar el percentatge de conversió de metà a causa dels productes presentes tant en la fase sòlida com en la fase gasosa. La conversió es determina mitjançant quantificació dels productes presents en cada una de les fases a temps final de reacció. La fase sòlida es quantifica mitjançant anàlisi elemental i amb $\mathrm{RMN}{ }^{13} \mathrm{C}$ del sòlid, i la fase gas per cromatografia, emprant el $\mathrm{N}_{2}$ com a patró intern.

La conversió total, es calcula a partir de les àrees dels reactius en fase gas inicial i final, emprant el $\mathrm{N}_{2}$ com a patró intern. La conversió en la fase gas, la calculem a partir de les àrees dels pics cromatogràfics tant en els dos detectors TCD com en el FID. Els factors de resposta (FR) per als compostos detectats en el FID i en el TCD, els vam obtenir experimentalment injectant mostres gasoses des de mescles certificades en bales pressuritzades subministrades per Aballó-Linde. Tots els factors de resposta emprats els vam calcular en base molar. 
Conversió Total $a(t)=\frac{n_{a, t=0}-n_{a, t=\text { final }}}{n_{a, t=0}} \times 100$

Eq. 8.1.

Conversió $_{\text {Fase gas }}(\mathrm{t})=\frac{n_{a, t=0}-\sum n_{\text {productes gas }, t=\text { final }}}{n_{a, t=0}} \times 100 \quad$ Eq. 8.2.

Conversió $_{\text {Fase sòlida }}(\mathrm{t})=\frac{n_{a, t=0}-\sum n_{\text {productes sòlid }, t=\text { final }}}{n_{a, t=0}} \times 100 \quad$ Eq. 8.3.

$\mathrm{n}_{\mathrm{a}, \mathrm{t}=0}=$ nombre de mols del reactiu a temps inicial

$\mathrm{n}_{\mathrm{a}, \mathrm{t}=\mathrm{final}}=$ nombre de mols del reactiu a temps final

$\mathrm{n}_{\mathrm{p}, \mathrm{t}=\text {-inal }}=$ nombre de mols del producte a temps final

La selectivitat del producte $\mathrm{i}\left(\mathrm{p}_{\mathrm{i}}\right)$, l'hem calculada com:

$$
\begin{aligned}
& \text { Selectivitat }_{p i}(t)=\frac{n_{p i, t=t}}{\left(n_{a, t=0}-n_{p i, t=t}\right)} \times 100 \\
& \mathrm{n}_{\mathrm{pi}, t=\mathrm{t}}=\text { nombre de mols del producte i a un temps de reacció } \\
& \mathrm{n}_{\mathrm{r}, \mathrm{t}=\mathrm{inal}}=\text { nombre de mols del reactiu a temps final } \\
& \mathrm{n}_{\mathrm{r}, \mathrm{t}=0}=\text { nombre de mols del producte a temps inicial }
\end{aligned}
$$

En els experiments que s'arrepleguen productes en la fase sòlida, s'analitzaren per separat, els resultats de l'anàlisi es converteixen en mols de cada producte i amb la massa total de carboni analitzada per anàlisi elemental i el RMN ${ }^{13} \mathrm{C}$ del sòlid. Aquest mols dipositats a la fase sòlida s'incorporen als balanços de carboni per a cada anàlisi, arribant a uns valors quasi sempre superiors al 95\%. En el cas del benzé hi ha balanços que son inferiors, per no haver pogut incorporar als balanços els possibles productes de polimerització que es formen en la reacció i dipositen a les parets del reactor. 
L'activitat catalítica intrínseca expressada com freqüència de renovació del lloc actiu (Turnover frequency, TOF), en base al nombre total de mols d'OH superficials l'hem calculat com es mostra a les equacions 8.4.

$$
\text { TOF }\left(s^{-1}\right)=\frac{\text { Molècules } \mathrm{CH}_{4} \text { convertides }}{\text { Àtoms superficials } \times \text { temps }} \quad \text { Eq. 8.4. }
$$

La identificació dels productes de reacció la vam estudiar per espectrometria de masses. L'espectròmetre de massa emprat va ser un HPAgilent 5973 dotat amb un detector quadrupol d'ionització per impacte electrònic. La columna emprada per a la separació dels productes va ser una HP-5 MS de $30 \mathrm{~m}$ de longitud, $0.25 \mathrm{~mm}$ de diàmetre intern i $0.25 \mu \mathrm{m}$ d'espessor. 
1. Camblor, M.A., A. Corma, and S. Valencia."Synthesis in fluoride media and characterisation of aluminosilicate zeolite beta", Journal of Materials Chemistry, 1998. 8: p. 2137-2145.

2. Corma, A., M.T. Navarro, F. Rey, and S. Valencia."Synthesis of pure polymorph C of Beta zeolite in a fluoride-free system", Chemical Communications, 2001: p. 1486-1487.

3. Corma, A., V. Fornes, J.M. Guil, et al."Preparation, characterisation and catalytic activity of ITQ-2, a delaminated zeolite", Microporous and Mesoporous Materials, 2000. 38: p. 301-309.

4. Corma, A., U. Diaz, M.E. Domine, and V. Fornes."New aluminosilicate and titanosilicate delaminated materials active for acid catalysis, and oxidation reactions using $\mathrm{H}_{2} \mathrm{O}_{2}$ ", Journal of the American Chemical Society, 2000. 122: p. 2804-2809.

5. Corma, A., F. V., M.T. Navarro, and J. Pérez-Pariente."Acidity and Stability of MCM-41 Crystalline Aluminosilicates", J. Catal., 1994. 148: p. 569-574. 



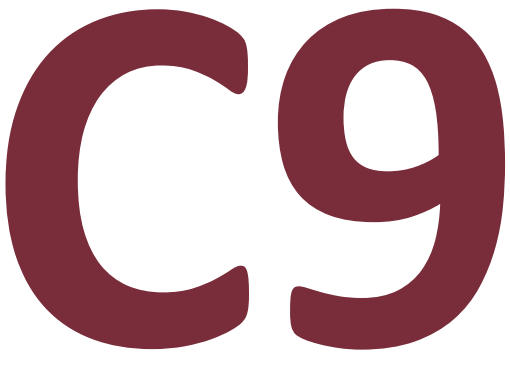

Conclusions

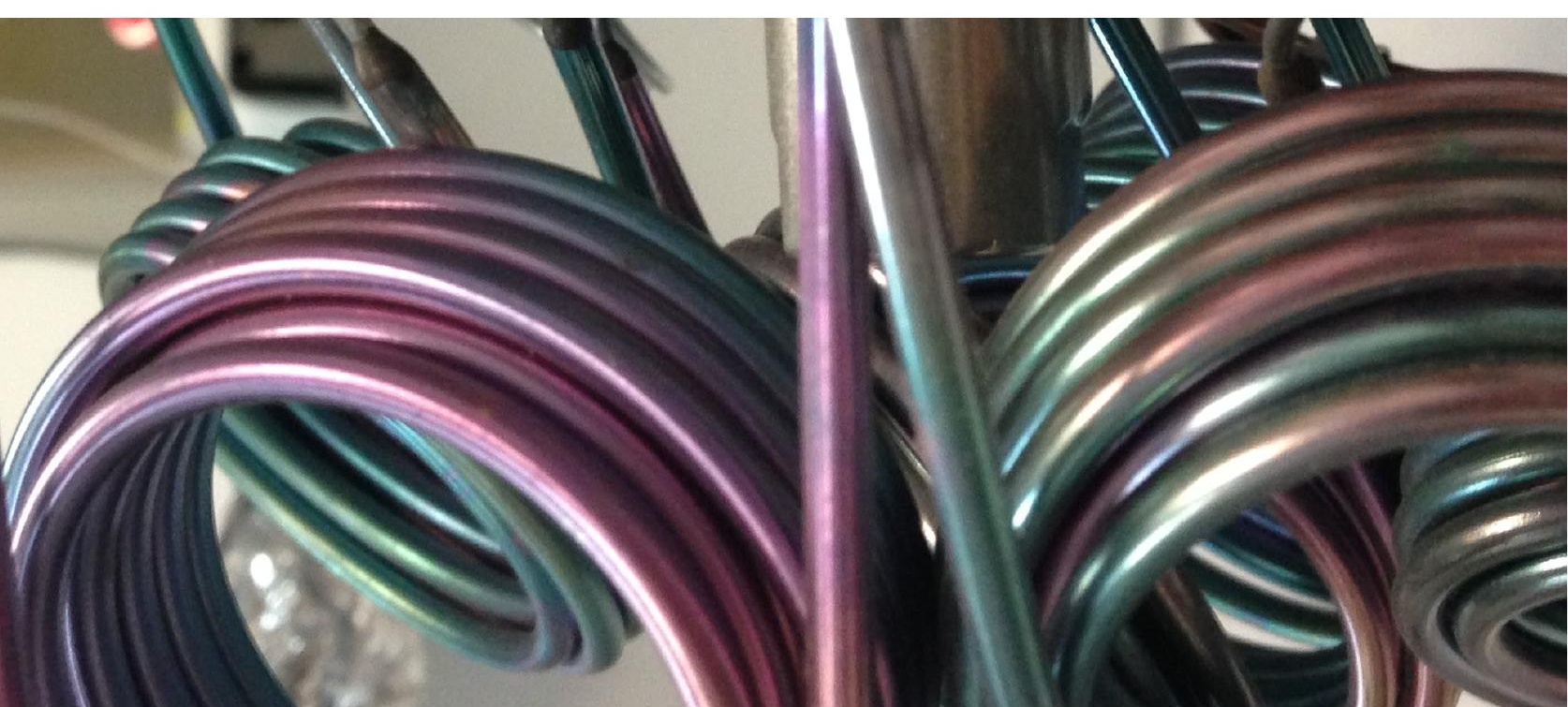



D'acord amb els objectius proposats en la present memòria, hem proporcionat dades que demostren l'aplicabilitat de la radiació UV en la zona llunyana per activar superfícies sòlides amb una elevada densitat de grups hidroxil i de manera indirecta produir la transformació de metà, età, benzé $\mathrm{CO}_{2}$ i CO. Els resultats que hem obtingut són d'una gran novetat i podrien conduir a estratègies que pogueren ser aplicables com a alternatives als processos industrials duts a terme actualment per a l'activació d'aquestes molècules.

En particular les conclusions que es poden extraure de cada un dels capítols que conformen la present tesi doctoral són els següents:

- La irradiació de superfícies d'aluminosilicats i silicats amb una elevada densitat de grups hidroxil amb llum UV Ilunyana genera radicals sililoxil i àtoms d' $\mathrm{H}_{2}$. Els radicals sililoxil són capaços d'iniciar processos radicalaris amb el metà, els quals es troben altament influenciables per la presència d' $\mathrm{O}_{2}$ en el medi. En el cas més favorable s'ha aconseguit la transformació del $17 \%$ de $\mathrm{CH}_{4}$ mitjançant la irradiació de zeolita Beta en presència $d^{\prime} \mathrm{O}_{2}$ amb una selectivitat cap als productes oxigenats d'un àtom de $\mathrm{C}$ superior al $90 \%$. Aquest procés té un consum d'energia estimat de $7.16 \mathrm{Gcal}^{*} \mathrm{~mol}^{-1} \mathrm{CH}_{4}$ convertit. Es considera que la tècnica 
d'irradiació amb llum UV llunyana podria ser competitiva front al procés industrial del reformat al vapor, el qual requereix una major inversió tant en infraestructura com en equipament.

- La irradiació de zeolita Beta amb llum UV Ilunyana en presència d'una atmosfera d'età contenint $\mathrm{O}_{2}$ produeix la conversió d'aquest hidrocarbur en una mescla de compostos oxigenats d'un i dos carbonis, amb un consum d'energia estimat 7 vegades inferior al procés anàleg emprant $\mathrm{CH}_{4}$

- La irradiació de zeolita ZSM-5 amb llum UV llunyana en presència de benzé condueix a la formació de fenol amb una selectivitat del $10 \%$ i una conversió del $89 \%$. Si el procés es porta a terme en un sistema amb $\mathrm{NH}_{3}$ en excés, s'obté la formació d'Anilina amb selectivitats al voltant del $6 \%$. Els balanços de matèria, però, indiquen la formació de quantitats elevades d'oligòmers que s'assumeix que provenen de l'oligo/polimerització d'aquests benzens substituïts.

- La irradiació de $\mathrm{CO}_{2}$ amb llum UV a la zona llunyana permet fins a una conversió del $40 \%$ de $\mathrm{CO}_{2}$ a una barreja de $\mathrm{CH}_{4}$ i CO. La presència de la LDH augmenta la conversió de $\mathrm{CO}_{2}$ respecte a processos anàlegs en els quals el sòlid es troba absent i la irradiació es porta a terme en fase gas. Mentre que la irradiació amb barreges $d^{\prime} \mathrm{H}_{2}$ no es veu molt influïda per la presència de sòlid, s'ha observat un clar augment de la conversió per a la transformació de $\mathrm{CO}_{2}$ amb vapor d' $\mathrm{H}_{2} \mathrm{O}$ en presència de sòlids bàsics. Aquests solids augmentaen més de tres vegades la conversió del $\mathrm{CO}_{2}$.

- S'ha desenvolupat un procés d'activació del $\mathrm{CO}_{2}$ en dues etapes, la primera de les quals es duu a terme en fase gas irradiant $\mathrm{CO}_{2}$ anhidre amb llum UV Ilunyana per generar $\mathrm{CO}$ amb selectivitat total. La segona etapa consisteix en la reacció de $\mathrm{CO}$ amb $\mathrm{H}_{2}$ o vapor d' $\mathrm{H}_{2} \mathrm{O}$ sobre un 
fotocatalitzador i emprant llum solar. Aquesta segona reacció transcorre amb conversions pràcticament totals utilitzant un catalitzador tipus $p$ com el $\mathrm{NiO}$ i atmosfera d' $\mathrm{H}_{2}$. La selectivitat cap al $\mathrm{CH}_{4}$ és del $90 \%$.

En conjunt, els treballs d'aquesta tesi doctoral demostren l'interès que les irradiacions amb llum UV Ilunyana poden tindre per a l'activació de molècules poc reactives com ara hidrocarburs lleugers i $\mathrm{CO}_{2}$. Els nostres estudis han demostrat igualment que la presència d'una superfície sòlida pot augmentar l'eficiència i variar la distribució de productes en aquests processos. Atès l'interès que les irradiacions basades en llum solar tenen actualment com a font d'energia renovable, cal destacar el procés de reducció del CO que es pot dur a terme mitjançant llum solar i l'ocupació de fotocatalitzadors convencionals com òxids metàl-lics. 



\section{0

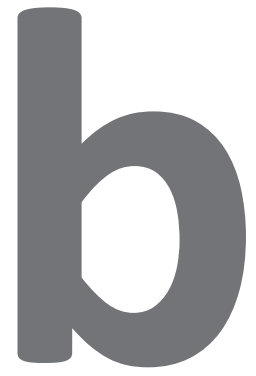 \\ publicacions}

1. Sastre, F., V. Fornés, A. Corma, and H. García."Selective, RoomTemperature Transformation of Methane to C1 Oxygenates by Deep UV Photolysis over Zeolites", Journal of the American Chemical Society, 2011. 133: p. 17257-17261.

2. Sastre, F., V. Fornés, A. Corma, and H. García."Conversion of Methane into C1 Oxygenates by Deep-UV Photolysis on Solid Surfaces: Influence of the Nature of the Solid and Optimization of Photolysis Conditions", Chemistry - A European Journal, 2012. 18: p. 1820-1825.

3. Sastre, F., A. Corma, and H. García."Deep UV photocatalytic activation of ethane on silica surfaces", Applied Catalysis B: Environmental, 2012. 128: p. 84-90.

4. Sastre, F., A. Corma, and H. García." $185 \mathrm{~nm}$ Photoreduction of $\mathrm{CO}_{2}$ to Methane by Water. Influence of the Presence of a Basic Catalyst", Journal of the American Chemical Society, 2012. 134: p. 14137-14141

5. Sastre, F., M. Oteri, A. Corma, and H. García."Photocatalytic Water Gas Shift using visible or simulated solar light for the efficient, roomtemperature hydrogen generation", Energy \& Environmental Science, 2013.

6. Sastre, F., A. Corma, and H. García."Visible or Solar light photocatalytic $\mathrm{CH}_{4}$ generation from $\mathrm{CO}^{\prime \prime}$ 



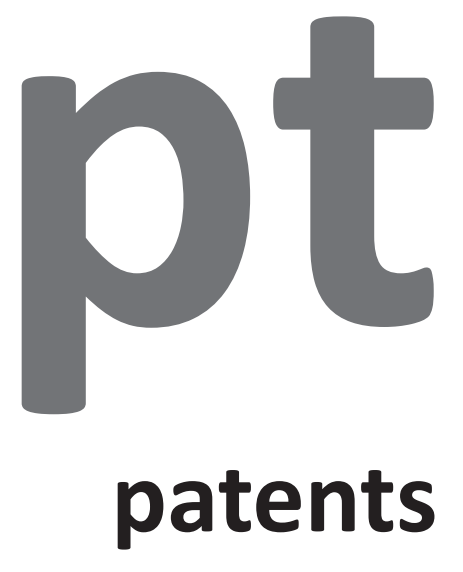

1. Sastre, F., A. Corma, and H. García."Procedimiento de transformación de metano a derivados oxigenados de un átomo de carbono", Consejo Superior de Investigaciones Científicas (CSIC),Universitat Politècnica De València. PCT/ES2012/070008, 2012

2. Sastre, F., A. Corma, and H. García."Reducción fotoquímica de dióxido de carbono a compuestos con aplicación como combustibles.", Consejo Superior de Investigaciones Científicas (CSIC), Universitat Politècnica De València. 2013 



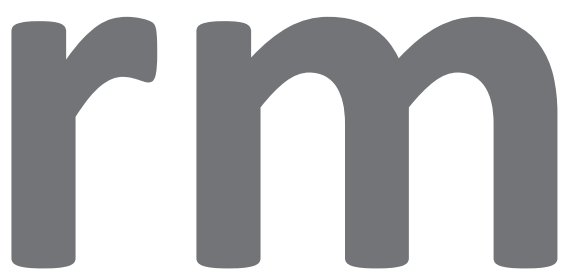

\section{resum}

En la present tesi doctoral s'ha estudiat l'aplicació de llum UV Ilunyana per a l'activació d'hidrocarburs, $\mathrm{CO}_{2}$ i CO. S'ha demostrat l'aplicabilitat de la radiació UV Ilunyana per activar superfícies sòlides amb una elevada densitat de grups hidroxils i produir la transformació de metà, età, benzé, $\mathrm{CO}_{2}$ i $\mathrm{CO}$.

Fotòlisi amb Ilum UV Ilunyana (165 o $185 \mathrm{~nm}$ ) dels grups hidroxil de la superfície dels sòlids condueix a la ruptura d'enllaços homolítics $\mathrm{O}-\mathrm{H}$ generant radicals sililoxil que poden iniciar l'activació de metà o età a temperatura ambient. La distribució dels productes d'irradiació amb aquest procediment de radicals depèn de l'absència o presència d'oxigen i pot conduir a la formació de productes oxigenats d'un o dos carbonis juntament amb alcans lleugers. Hem estudiat el comportament de la irradiació zeolita ZSM-5 amb llum UV Ilunyana amb la presència de benzè y atmosferes de $\mathrm{NH}_{3} \circ \mathrm{H}_{2} \mathrm{O}$ 
La irradiació de $\mathrm{CO}_{2}$ amb llum UV a la zona llunyana, permet la conversió del $\mathrm{CO}_{2}$ a una barreja de $\mathrm{CH}_{4}$ i $\mathrm{CO}$. La presència de sòlids augmenta la conversió de $\mathrm{CO}_{2}$ respecte a processos anàlegs en els quals el sòlid es troba absent i la irradiació es porta a terme en fase gas.

S'ha desenvolupat un procés d'activació del $\mathrm{CO}_{2}$ en dues etapes, les primeres de les quals, es duu a terme en fase gas irradiant $\mathrm{CO}_{2}$ anhidre amb Ilum UV Ilunyana per generar CO. La segona etapa consisteix en la reacció de $\mathrm{CO}$ amb $\mathrm{H}_{2}$ o vapor d' $\mathrm{H}_{2} \mathrm{O}$ sobre un fotocatalitzador i emprant llum solar.

S'ha demostrat el gran interès que irradiacions amb llum UV llunyana poden tenir per a l'activació de molècules poc reactives com ara hidrocarburs lleugers i $\mathrm{CO}_{2}$. 


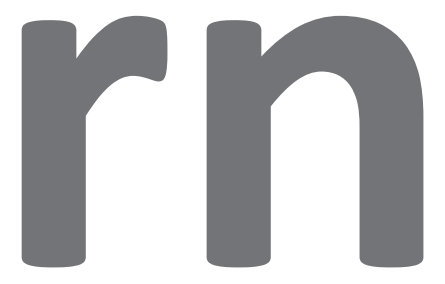

\section{resumen}

En la presente tesis doctoral se ha estudiado la aplicación de luz UV en la zona profunda para la activación de hidrocarburos, $\mathrm{CO}_{2}$ y $\mathrm{CO}$. Se ha demostrado la aplicabilidad de la radiación UV lejana para activar superficies sólidas con una elevada densidad de grupos hidroxilos y producir la transformación de metano, etano, benceno, $\mathrm{CO}_{2}$ y $\mathrm{CO}$.

La fotólisis con luz UV lejana (165 o $185 \mathrm{~nm}$ ) de los grupos hidroxilo de la superficie de los sólidos conducen a la ruptura de enlaces homolíticos $\mathrm{O}-\mathrm{H}$ generando radicales sililoxil que pueden iniciar la activación de metano o etano a temperatura ambiente. La distribución de los productos de irradiación con este procedimiento de radicales depende de la ausencia o presencia de oxígeno y puede conducir a la formación de productos oxigenados de uno o dos carbonos junto con alcanos ligeros. Hemos estudiado el comportamiento de la irradiación zeolita ZSM- 5 con luz UV lejana con la presencia de benceno en atmósferas de $\mathrm{NH}_{3} \circ \mathrm{H}_{2} \mathrm{O}$ 
La irradiación de $\mathrm{CO}_{2}$ con luz UV en la zona lejana, permite la conversión del $\mathrm{CO}_{2}$ a una mezcla de $\mathrm{CH}_{4}$ y $\mathrm{CO}$. La presencia de sólidos tales como las HT aumenta la conversión de $\mathrm{CO}_{2}$ con respecto a procesos análogos en los que el sólido se encuentra ausente y la irradiación se lleva a cabo en fase gas.

Se ha desarrollado un proceso de activación del $\mathrm{CO}_{2}$ en dos etapas, las primeras de las cuales, se lleva a cabo en fase gas irradiando $\mathrm{CO}_{2}$ anhidro con luz UV lejana para generar $\mathrm{CO}$. La segunda etapa consiste en la reacción de $\mathrm{CO}$ con $\mathrm{H}_{2}$ o vapor de $\mathrm{H}_{2} \mathrm{O}$ sobre un fotocatalizador y empleando luz solar.

Se ha demostrado el gran interés que irradiaciones con luz UV lejano pueden tener para la activación de moléculas poco reactivas tales como hidrocarburos ligeros y $\mathrm{CO}_{2}$. 


\section{0 \\ abstract}

In this doctoral thesis we have studied the irradiation in the deep UV region for the activation of hydrocarbons, $\mathrm{CO}_{2}$ and $\mathrm{CO}$. We have demonstrated the applicability of the deep UV irradiation for activating surfaces with a high density of hydroxyl groups and we have achieved the conversion of methane, ethane, benzene, $\mathrm{CO}$ and $\mathrm{CO}_{2}$.

Deep UV photolysis (165 or $185 \mathrm{~nm}$ ) of surface silanol groups leads the homolytic $\mathrm{O}-\mathrm{H}$ bond breaking, generating silyloxyl radicals and hydrogen atoms. Silyloxyl radicals are able to activate methane and ethane through hydrogen abstraction, whereby methyl or ethyl radicals are formed. The product distribution of this radical process depends on the absence or presence of oxygen and may lead to the formation of C1 or C2 oxygenates together with light alkanes. We have studied the behavior of ZSM-5 zeolite irradiated with deep UV light in the presence of benzene or $\mathrm{NH}_{3} \mathrm{H}_{2} \mathrm{O}$ atmospheres. 
Photolysis of $\mathrm{CO}_{2}$ irradiation in the deep UV zone in the presence of $\mathrm{H}_{2}$ or $\mathrm{H}_{2} \mathrm{O}$, gives $\mathrm{CH}_{4}$. The presence of solids such as $\mathrm{LDH}$ increases the conversion of $\mathrm{CO}_{2}$ compared with similar processes where there is no solid and irradiation is carried out in gas phase. We have developed a $\mathrm{CO}_{2}$ activation process in two stages; the first one is conducted under anhydrous $\mathrm{CO}_{2}$ gas with deep UV irradiation to generate $\mathrm{CO}$. The second stage involves the reaction of $\mathrm{CO}$ with $\mathrm{H}_{2}$ or $\mathrm{H}_{2} \mathrm{O}$ in gas phase or on a photocatalyst and using sunlight.

It has shown the great interest deep UV region may have to activate unreactive molecules such as light hydrocarbons and $\mathrm{CO}_{2}$. 



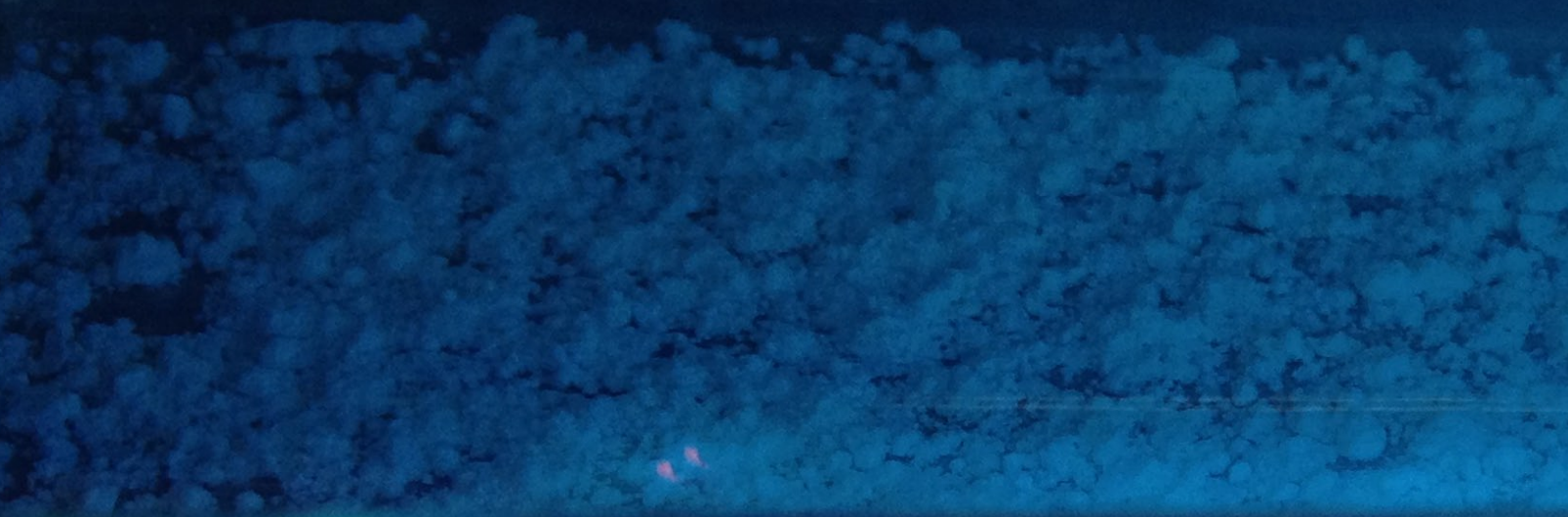

(3) 